\title{
APT Blanket System Loss-of-Flow Accident (LOFA) Analysis Based on Initial Conceptual Design - Case 1: with Beam Shutdown and Active RHR
}

by

L. L. Hamm

Westinghouse Savannah River Company

Savannah River Site

Aiken, South Carolina 29808

S. Y. Lee

M. A. Shadday

F. G. Smith III

A document prepared for SENDING TO LANL at , , from - .

DOE Contract No. DE-AC09-96SR18500

This paper was prepared in connection with work done under the above contract number with the U.S.

Department of Energy. By acceptance of this paper, the publisher and/or recipient acknowledges the U. S. Government's right to retain a nonexclusive, royalty-free license in and to any copyright covering this paper, along with the right to reproduce and to authorize others to reproduce all or part of the copyrighted paper. 
WSRC-TR-98-0058

\section{APT BLANKET SYSTEM LOSS-OF-FLOW ACCIDENT (LOFA) ANALYSIS BASED ON INITIAL CONCEPTUAL DESIGN :}

\section{Case 1: with Beam Shutdown and Active RHR}

\section{Larry Hamm \\ Si Young Lee \\ M. Andy Shadday}

Frank G. Smith, III

Westinghouse Savannah River Company Savannah River Site Aiken, SC 29808

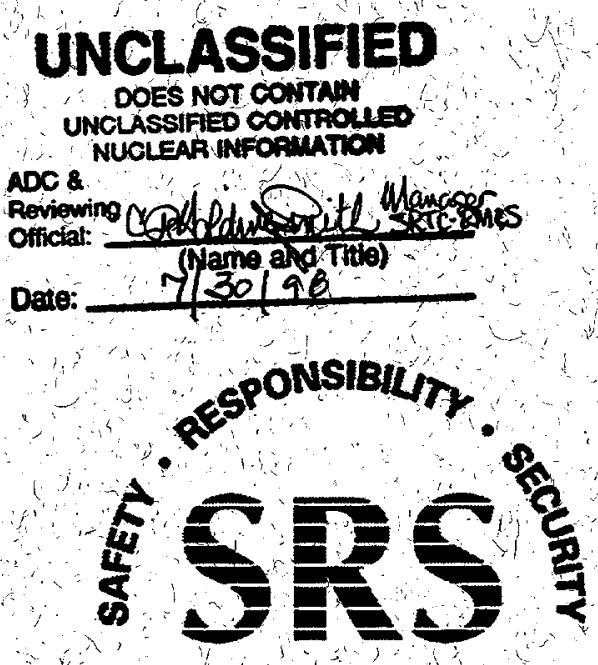




\section{DISCLAIMER}

This report was prepared as an account of work sponsored by an agency of the United States Government. Neither the United States Government nor any agency thereof, nor any of their employees, makes any warranty, express or implied, or assumes any legal liability or responsibility for the accuracy, completeness, or usefulness of any information, apparatus, product, or process disclosed, or represents that its use would not infringe privately owned rights. Reference herein to any specific commercial product, process, or service by trade name, trademark, manufacturer, or otherwise does not necessarily constitute or imply its endorsement, recommendation, or favoring by the United States Government or any agency thereof. The views and opinions of authors expressed herein do not necessarily state or reflect those of the United States Government or any agency thereof.

This report has been reproduced directly from the best available copy.

Available to DOE and DOE contractors from the Office of Scientific and Technical Information, P.O. Box 62, Oak Ridge, TN 37831; prices available from (615) 576-8401.

Available to the public from the National Technical Information Service, U.S. Department of Commerce; 5285 Port Royal Road, Springfield, VA 22161. 


\section{DISCLAIMER}

Portions of this document may be illegible in electronic image products. Images are produced from the best available original document. 
WSRC-TR-98-0058

KEYWORDS:

Accelerator Production of Tritium

Blanket System

Conceptual Design

TRAC Code

FLOWTRAN-TF Code

System Model

Detailed Bin Model

Safety Analysis

RETENTION - Permanent

\section{APT BLANKET SYSTEM LOSS-OF-FLOW ACCIDENT (LOFA) ANALYSIS BASED ON INITIAL CONCEPTUAL DESIGN -}

\section{Case 1: with Beam Shutdown and Active RHR}

SAVANNAH RIVER TECHNOLOGY CENTER

L. Larry Hamm

Si Young Lee

$M$. Andy Shadday

Frank G. Smith, III

Publication Date: March, 1998

Westinghouse Savannah River Company

Savannah River Site

Aiken, SC 29808

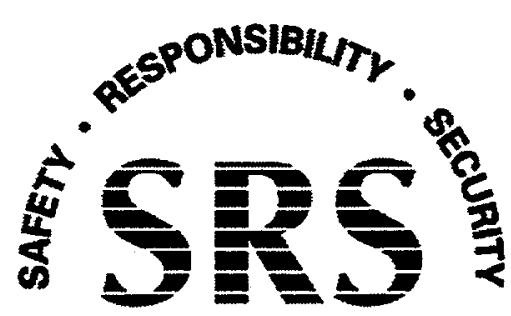

Prepared for the U.S. Department of Energy under Contract No. DE-AC09-96SR18500 
DOCUMENT: WSRC-TR-98-0058

TITLE: $\quad$ APT BLANKET SYSTEM LOSS-OF-FLOW ACCIDENT (LOFA) ANALYSES BASED ON INITIAL CONCEPTUAL

DESIGN - Case 1: with Beam Shutdown and Active RHR

\section{APPROVALS}

L. Larry Hamm, Task Leader (EM\&S Group/SRTC)

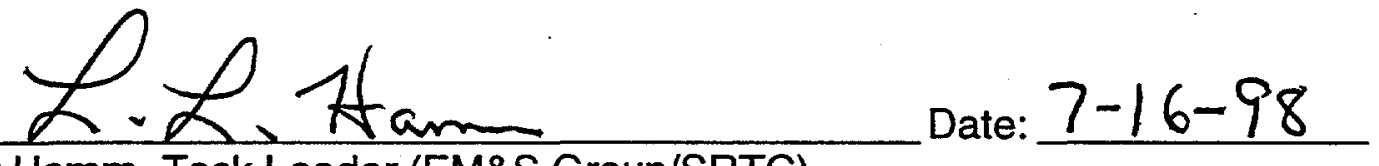

\section{Hotpong Kele}

Date: $7-20-98$

Si Young Lee, Co-author (EM\&S Group/SRTC)
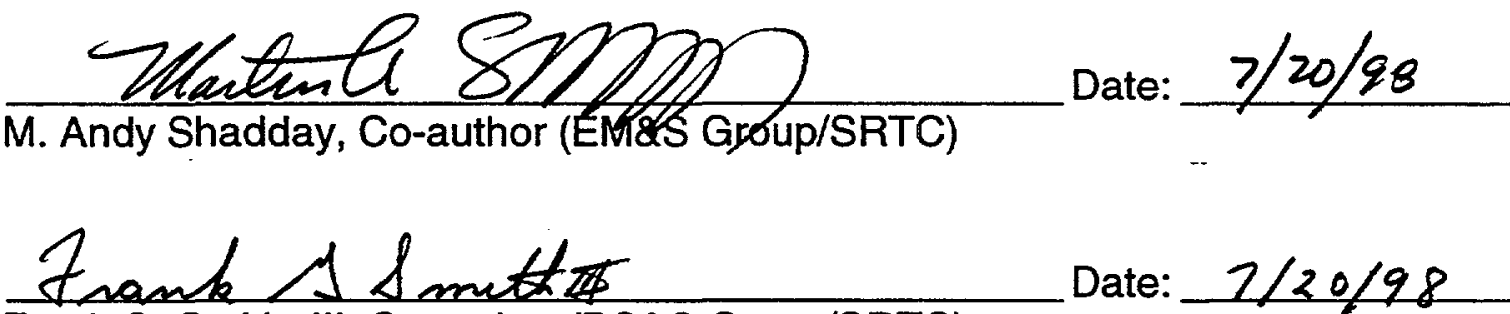

Date:

Frank G. Smith, III, Co-author (PC\&C Group/SRTC)

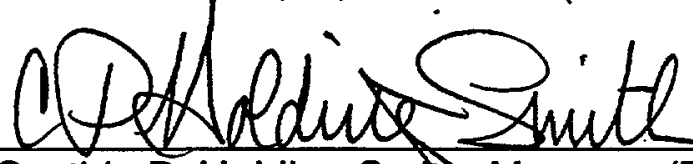

Cynthia P. Holding-Smit Manager (EM\&S Group/SRTC)

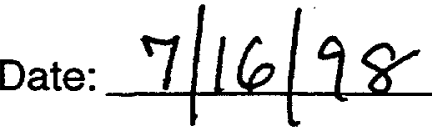

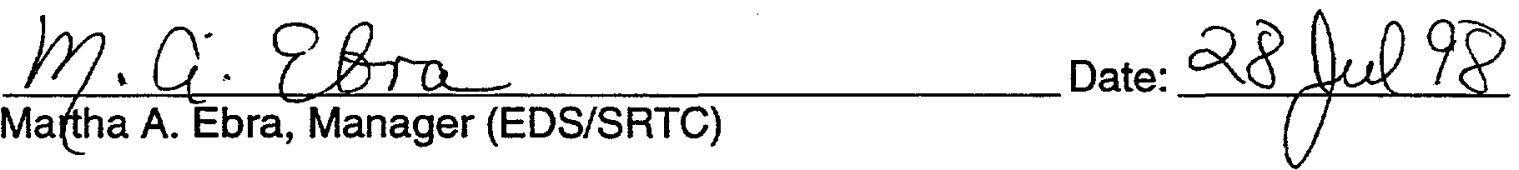

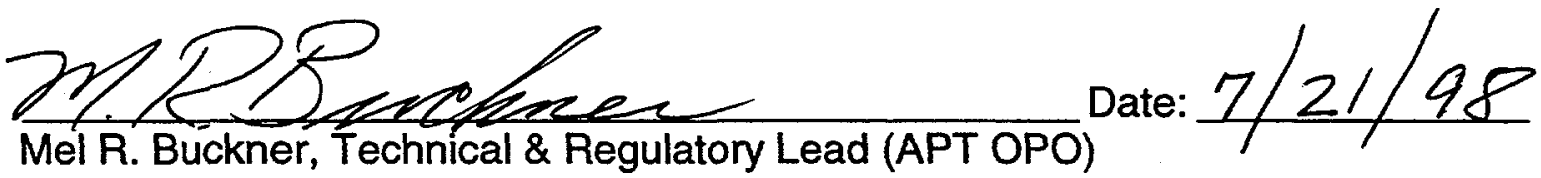

The internal technical review function is being performed at the APT project level and is coordinated through LANL. 


\section{Table of Contents}

1 Introduction 1

2 TRAC 1-D System Model 2

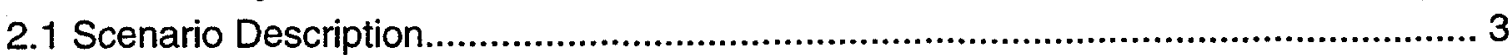

2.2 Model Upgrades ...................................................................................... 3

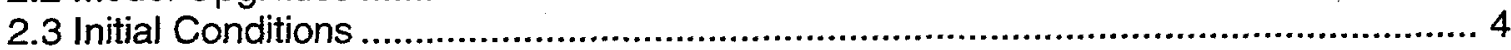

2.4 Transient Boundary Conditions........................................................................... 4

2.5 Trips and Controls ......................................................................................... 4

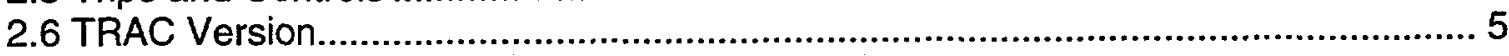

3 TRAC System Model Results $\quad$. $\quad 8$

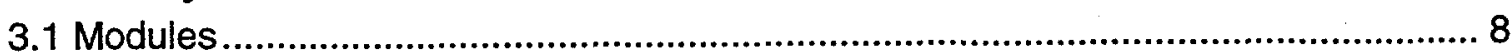

3.2 HR Loop and Pressurizer ...................................................................... 9

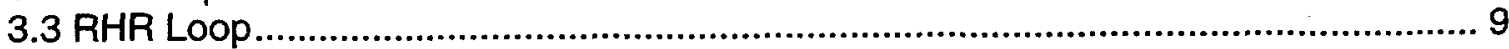

3.4 Cavity Vessel and Flood System .................................................................10

4 FLOWTRAN-TF Detailed Bin Model $\quad 10$

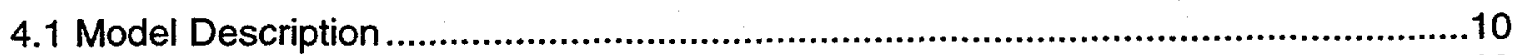

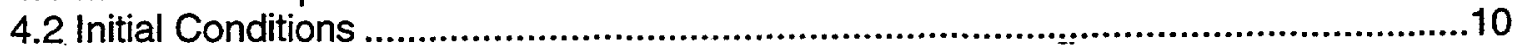

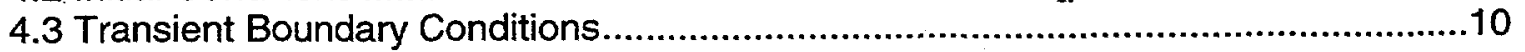

5 FLOWTRAN-TF Bin Model Results $\quad 15$

6 Conclusions $\quad 18$

6.1 Comparison to Thermal/Hydraulic Design Criteria .............................................18

6.2 Design Issues ..........................................................................................19

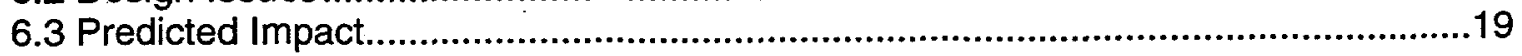

7 References $\quad 19$

Appendix A: TRAC Model Component Nomenclature

Appendix B: LOFA (Case 1) TRAC Results

Appendix C: TRAC Standard Input File for LOFA Case 1 (with Beam Shutdown and Active RHR)

Appendix D: TRAC Graphics Input File for LOFA Case 1 (with Beam Shutdown and Active RHR)

Appendix E: FLOWTRAN-TF Input File for LOFA Case 1 (with Beam Shutdown and Active RHR) 


\section{List of Figures}

Figure 1-1 Decay heat power fractions of full power for various types of blanket modules. .2

Figure 2-1 Top cross-sectional face map of 6 lumped blanket system modules .7

Figure 4-1 Finite element mesh of APT reference 1 blanket plate.

Pump coast down transients from TRAC system analysis.

Pressure and flow transients with $10 \%$ pre-incident flow at 60 sec.

Pressure and flow transients with $5 \%$ pre-incident flow at $60 \mathrm{sec}$.

Pressure and flow transients with $2 \%$ pre-incident flow at $60 \mathrm{sec}$.

Pressure and flow transients with $1 \%$ pre-incident flow at $60 \mathrm{sec}$.

\section{List of Tables}

Table 2-1 . 6 lumped blanket module system model used for the present PSAR analysis. 5

Table 2.5-1 Trip signals used in the LOFA simulation. 6

Table 4.2-1

Table 4.3-1 Initial conditions for FLOWTRAN-TF LOFA analysis. 


\section{Introduction}

This report is one of a series of reports that document normal operation and accident simulations for the Accelerator Production of Tritium (APT) blanket heat removal system, [1-7]. These simulations were performed for the Preliminary Safety Analysis Report. The results of simulations of a Loss-Of-Flow-Accident (LOFA) where power is lost to all of the pumps that circulate water in the blanket region are documented in this report. The accident simulations were performed, using TRAC to model transient behavior of the heat removal system, and FLOWTRAN-TF, a computer code developed at the Savannah River Technology Center, to model detailed transient behavior in a blanket module.

For the loss-of-flow accident analyses, parametric studies were performed varying the time for beam shutdown, the rate of primary pump coast-down, and the flowrate of coolant during post-incident residual heat removal. After the APT beam system shutdown, decay power drops rapidly. Figure 1-1 shows transient decay power after shutdown as a fraction of steady-state power for the $1700 \mathrm{MeV}$ APT design with 13 tungsten ladders [8]. Results from a single TRAC system calculation were used to generate boundary conditions for the loss-of-flow accident analyses. The system calculation provided a transient for total coolant flow having approximately $5 \%$ of the pre-incident flow 60 seconds after initiation of the loss-of-flow-accident. As shown below, the results from that system calculation were then used to generate four additional sets of transient boundary conditions having exactly $1 \%, 2 \%, 5 \%$ and $10 \%$ of the pre-incident coolant flow 60 seconds into the transient. The flows, pressures and temperatures from these transients provided boundary conditions for a series of FLOWTRAN-TF calculations that produced the final results of the LOFA analyses.

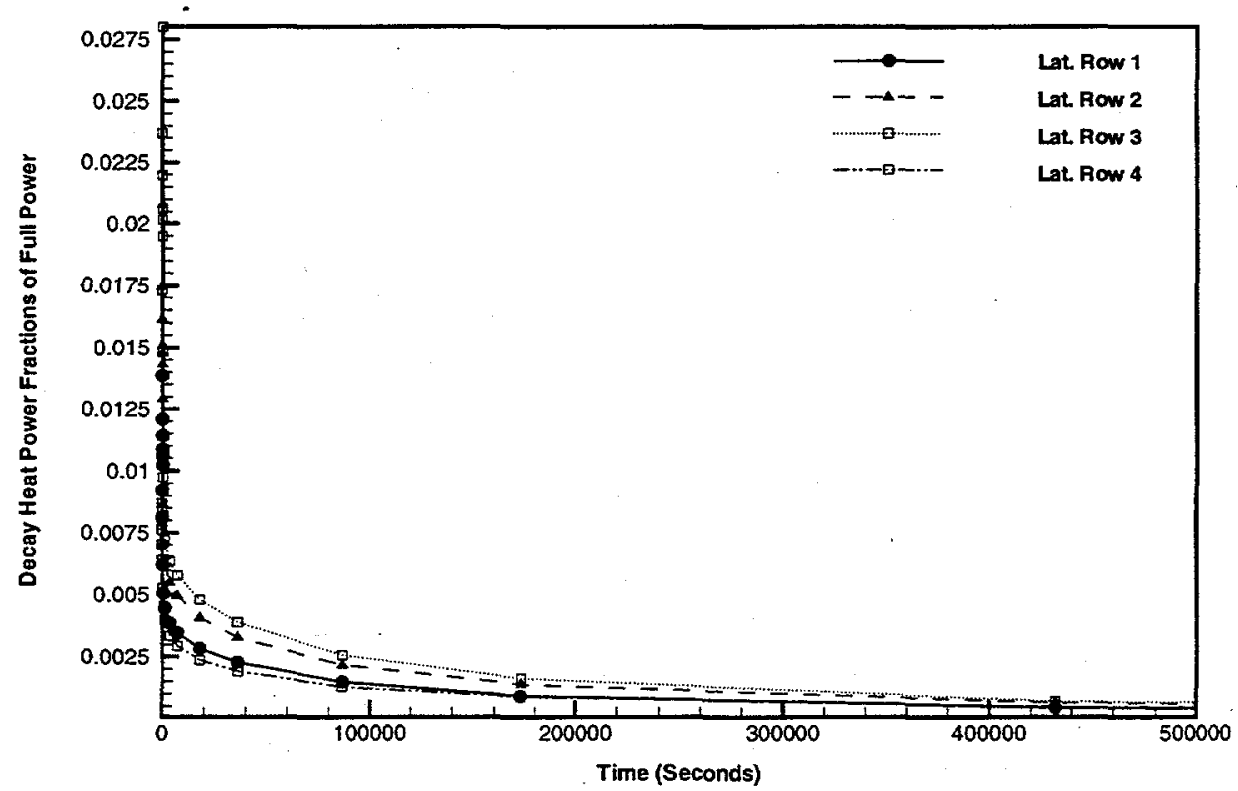

Figure 1-1 Decay heat power fractions of full power for various types of blanket modules. 


\section{TRAC 1-D System Model}

Current blanket system consists of 16 unique blanket modules based on the existing cruciform-type design components (the necessary design specifications required to develop a plate-type set of modules is currently not available but will be used in future revisions to these calculations). Each module is separately connected to the two fixed coolant headers. A lumping strategy was developed based on module similarity, deposited power levels, and locations that resulted in a total of six separate lumped modules and reduced computational effort requirements. The six lumped modules are, respectively: the first-row lateral modules; the second-row lateral modules; the decoupler / Row 1 downstream module; the Row 1 / Row 2 downstream module; the Row 2 / Row 2 downstream module; and the remaining low-power modules, which consist of the upstream module, the four bottom modules, and the two top modules. Figure 2-1 shows cross-sectional face map for the 6 module blanket system. Table 2-1 summarizes module description, thermal deposited power, and connection pipe size of each of the 6 blanket modules as modeled in the one-dimensional lumped approach. Figure A-1 shows the locations of all the six modules and the internal piping connections as included in the one-dimensional TRAC system model. The TRAC components and piping connections for the heat removal (HR), pressurizer, residual heat removal (RHR) blanket coolant systems, and cavity vessel flood system are also shown in Figs. A-2 to A-6. Table A-1 lists all the blanket system components, number of cells for the components, and the component descriptions for the present one-dimensional lumped blanket system model. The present 6 lumped module TRAC blanket system model includes 170 components and 152 junctions with 10 trip control signals using for the transient loss-of flow accident (LOFA) simulation. Detailed TRAC system model descriptions are provided in Refs. [9, 10].

\subsection{Scenario Description}

Current blanket coolant system has one primary heat removal (HR), one secondary HR, two $100 \%$ primary residual heat removal (RHR), and two $100 \%$ secondary RHR. Both the HR and. RHR loops are connected to the large fixed headers (20.5 inch diameter) internal to the target/blanket cavity vessel. Under steady-state normal operation condition the blanket module system is connected to a single main primary loop, with three $50 \%$ pumps in parallel. Two pumps are normally operating and the remaining pump is available for immediate startup in the event of failure of a running pump. The coolant loop has two $50 \%$ heat exchangers in parallel. The two RHR primary loops are both sized to accommodate $100 \%$ of the decay heat removal requirements. Currently, the RHR components are sized for approximately $4 \%$ of the full power flow, 1569 $\mathrm{kg} / \mathrm{sec}$, under any design basis accident conditions. Each of the RHR primary loops has one heat exchanger and one pump. The current baseline design has the RHR systems shutdown in standby mode during normal operation to enhance the system's response to some design basis accident scenarios such as loss-of-flow accident (LOFA) and lossof-coolant accident (LOCA). Under the accident condition only one RHR system is activated to circulate the coolant water to the internal blanket modules. Normal operation conditions for the key blanket system parameters are shown in Appendix A.

As one of design basis accidents, the loss of pumping flow accident due to the loss of power in the primary and secondary HR pumps was simulated by restarting steady-state 
normal operation results performed by the one-dimensional 6 integrated module blanket system model in a transient mode. For the initiation of the LOFA simulation, two primary and secondary HR pumps are tripped off without time delay at the time 0 second. As soon as the accident occurs, the primary and secondary RHR pumps are initiated and are running continuously since the primary and secondary RHR pumps are supplied with on-site backup diesel power as well as a dc backup power supply. After the LOFA is initiated, system pressure is depressurized immediately and then the RHR pump reaches full speed in about 15 seconds after the accident starts. Detailed control signals for the key component operations are provided in Section 2.6.

\subsection{Model Upgrades}

Component action tables for the break component and check valves were updated to activate the action signals of the hardware components such as check valves, pumps, heat structures of the six blanket modules, and fill boundaries to simulate the LOFA scenario. Component action tables for the RHR pump and the HR/RHR check valves are based on the S-shaped forcing function values. Normal steady-state operation conditions can be obtained by using either transient mode or constrained steady-state with definition of the monitoring parameters of specific components. For the present accident analyses the constrained steady-state (CSS) capabilities are added to the TRAC normal operation system model. Signal variables and trip signals of the system model are also updated by using the control procedure for the LOFA scenario as described in Ref. [9].

\subsection{Initial Conditions}

Before simulating the accident condition, steady-state results under normal operation (NO) conditions are required to provide the restart input to the transient simulation model of the LOFA. The steady-state NO conditions of the APT blanket system were obtained by specifying maximum pump rotational speeds of the two HR pumps with desired total liquid flowrate using as a monitoring parameter under the constrained steady-state (CSS) controller option. Initial temperatures for the pressurizer and the RHR system components were $40 \mathrm{C}$. Steady-state values under normal operating conditions for the key system parameters of the APT blanket system are listed in Appendix A with additional details provided in Ref. [1].

\subsection{Transient Boundary Conditions}

The TRAC system model for the steady state NO calculations is documented in Refs. [9, 10]. The steady-state NO TRAC run was restarted in a transient mode to initiate the LOFA simulation. To establish an appropriate fly-wheel inertia for the primary heat removal pumps a parametric study was performed (i.e., varying the TRAC pump parameters) using the TRAC system model with the integrated six modules under the LOFA conditions. The inertia terms were set such that a $5 \%$ of pre-incident flowrate is achieved at $60 \mathrm{sec}$ after pump deactivation occurs. System operation conditions of the secondary systems were simulated by using fill boundary condition with transient mass flowrate table at the inlet of the secondary sides of the two HR heat exchanger components. 


\subsection{Trips and Controls}

Power to the two primary and secondary HR.pumps was tripped off immediately to initiate the LOFA scenario, and the beam power was tripped off with 1.0 seconds time delay after the pressure difference between the suction side and the discharge side of each primary HR pump was reduced to $0.70788 \mathrm{MPa}$ (102.7 psia) corresponding to $95 \%$ of the total pressure difference across the HR pump. The RHR pump was actuated without time delay after the pressure difference between the suction and discharge sides of each primary HR pump was reduced to $0.70788 \mathrm{MPa}$ (102.7 psia). The beam trip was simulated by changing the steady-state NO power in the heat structure of each blanket module to the time dependent decay power curve. Figure 1-1 shows transient decay power curves for the blanket heat structures. The beam power trips actually occurred about 1.21 seconds after the initiation of the transient accident so that the time to reduce $5 \%$ of the pressure difference across the HR pump is about 0.21 second. The RHR pumping power signal was set to actuate without delay after $5 \%$ reduction of the pressure difference across the primary HR pump, and then the RHR pump speed was attained to the full speed $(94.35 \mathrm{rad} / \mathrm{sec})$ in 15 seconds after the accident initiation by using the component action table with S-shaped forcing function values [9]. Check valves on the discharge sides of the HR and RHR pumps were actuated to avoid flow reversal immediately after the initiation of the LOFA accident. If flow reversal occurs during the accident condition, the HR and RHR check valves were set to be closed immediately. Table 2.5-1 lists all the trip signals and component controls used for the LOFA simulation.

\subsection{TRAC Version}

This transient model was run using TRAC-PF1/MOD2 version 5.4.28a [18]. A modified version of TRAC to generate graphics files was employed [10]. 
Table 2-1 6 lumped blanket module system model used for the present PSAR analysis.

\begin{tabular}{|c|c|c|c|}
\hline $\begin{array}{l}6 \\
\text { Lumped } \\
\text { Modules }\end{array}$ & $\begin{array}{l}\text { Prototypic } 16 \text { Full Blanket } \\
\text { Modules }\end{array}$ & $\begin{array}{l}\text { Thermal Deposited } \\
\text { Power } \\
\text { Downilow } 1 \text { Upilow } \\
\text { Total Power }\end{array}$ & $\begin{array}{l}\text { Pipe } \\
\text { Size } \\
\text { (inch) }\end{array}$ \\
\hline Module 1 & $\begin{array}{l}\text { Front } 1^{\text {st }} \text { Lateral Dec. / Row } 1 \\
\text { Module } \\
\text { Back } 1^{\text {st }} \text { Lateral Dec. / Row } 1 \\
\text { Module }\end{array}$ & $\begin{array}{l}8.222 \mathrm{MW} / \\
15.768 \mathrm{MW} / \\
23.990 \mathrm{MW}\end{array}$ & 7.500 \\
\hline Module 2 & $\begin{array}{l}\text { Front } 2^{\text {nd }} \text { Lateral Row } 2 / \text { Row } 3 \\
\text { Modules } \\
\text { Back } 2^{\text {nd }} \text { Lateral Row } 2 / \text { Row } 3 \\
\text { Modules }\end{array}$ & $\begin{array}{l}3.060 \mathrm{MW} / \\
7.660 \mathrm{MW} / \\
10.720 \mathrm{MW}\end{array}$ & 4.750 \\
\hline Module 3 & $\begin{array}{l}1^{\text {st }} \text { Downstream Dec. / Row } 1 \\
\text { Module }\end{array}$ & $\begin{array}{c}0.744 \mathrm{MW} / 2.812 \mathrm{MW} / \\
3.556 \mathrm{MW}\end{array}$ & 3.750 \\
\hline Module 4 & $\begin{array}{l}2^{\text {nd }} \text { Downstream Row } 1 / \text { Row } 2 \\
\text { Module }\end{array}$ & $\begin{array}{c}3.924 \mathrm{MW} / 5.412 \mathrm{MW} / \\
9.336 \mathrm{MW}\end{array}$ & 5.375 \\
\hline Module 5 & $\begin{array}{c}3^{\text {rd }} \text { Downstream Row } 2 / \text { Row } 2 \\
\text { Module }\end{array}$ & $\begin{array}{c}1.355 \mathrm{MW} / 1.811 \mathrm{MW} / \\
3.167 \mathrm{MW}\end{array}$ & 6.000 \\
\hline Module 6 & $\begin{array}{c}\text { Low Power Modules } \\
\text { Blanket Upstream Dec. / Row } 2 \\
\text { Module } \\
\text { Lower Front Dec. / Row } 2 \text { Module } \\
\text { Lower Front Row } 2 \text { / Row } 2 \\
\text { Module } \\
\text { Lower Back Dec. / Row } 2 \text { Module } \\
\text { Lower Back Row } 2 \text { / Row } 2 \\
\text { Module } \\
\text { Upper Front Row } 2 \text { / Row } 2 \\
\text { Module } \\
\text { Upper Back Row } 2 \text { / Row } 2 \\
\text { Module }\end{array}$ & $\begin{array}{c}\text { (Horizontal Flow) } \\
0 \mathrm{MW} / \\
5.712 \mathrm{MW} / \\
5.712 \mathrm{MW}\end{array}$ & 3.875 \\
\hline $\begin{array}{l}\text { Total } \\
\text { Deposited } \\
\text { Power }\end{array}$ & & $\begin{array}{c}17.305 \mathrm{MW} / 39.175 \\
\mathrm{MW} / 56.480 \mathrm{MW}\end{array}$ & \\
\hline
\end{tabular}


Table 2.5-1 Trip signals used in the LOFA simulation.

\begin{tabular}{|c|c|c|c|}
\hline $\begin{array}{l}\text { Trip } \\
\text { Signal } \\
\text { ID }\end{array}$ & $\begin{array}{l}\text { Control } \\
\text { Component }\end{array}$ & $\begin{array}{l}\text { Signal Variables } \\
\text { ID Number } \\
\text { (Control Variable) }\end{array}$ & Signal Values \\
\hline 101 & $\begin{array}{l}\text { Fill boundary for } \\
\text { secondary heat } \\
\text { exchanger side }\end{array}$ & 1 (time) & $1.0 \mathrm{e}-06 \mathrm{sec}$ \\
\hline 102 & $\begin{array}{l}\text { Cavity flood system } \\
\text { valve }\end{array}$ & $\begin{array}{c}10 \text { (cavity vessel } \\
\text { pressure) }\end{array}$ & valve closed \\
\hline 103 & RHR check valve & $\begin{array}{c}1 \text { (time) and action } \\
\text { table (S-shaped forcing } \\
\text { function) }\end{array}$ & $1.0 \mathrm{e}-06 \mathrm{sec}$ \\
\hline 104 & Heat structure & $\begin{array}{l}4 \text { (the pressure } \\
\text { difference between the } \\
\text { suction and discharge } \\
\text { sides of the primary HR } \\
\text { pump) and time delay }\end{array}$ & $\begin{array}{l}1.0 \text { sec time delay after } 5 \% \\
\text { reduction of the pressure } \\
\text { difference across the } \\
\text { primary HR pump }\end{array}$ \\
\hline 105 & RHR pump & $\begin{array}{l}4 \text { (the pressure } \\
\text { difference between the } \\
\text { suction and discharge } \\
\text { sides of the primary HR } \\
\text { pump), no time delay, } \\
\text { and action table (S- } \\
\text { shaped forcing } \\
\text { function) }\end{array}$ & $\begin{array}{l}\text { full speed-in } 15 \text { sec. after } \\
5 \% \text { reduction of the } \\
\text { pressure difference across } \\
\text { the primary HR pump }\end{array}$ \\
\hline 106 & Primary HR pump & no time delay & $1.0 \mathrm{e}-06 \mathrm{sec}$ \\
\hline 107 & $\begin{array}{l}\text { Primary HR check } \\
\text { valve }\end{array}$ & $\begin{array}{c}1 \text { (time) and action table } \\
\text { (S-shaped forcing } \\
\text { function) }\end{array}$ & $1.0 \mathrm{e}-06 \mathrm{sec}$ \\
\hline 108 & $\begin{array}{l}\text { Cavity vessel check } \\
\text { valve }\end{array}$ & 1 (time) & valve closed \\
\hline 109 & $\begin{array}{c}\text { Cavity vessel check } \\
\text { valve on the HR } \\
\text { side }\end{array}$ & 1 (time) & valve closed \\
\hline 110 & $\begin{array}{l}\text { Cavity vessel vent } \\
\text { valve }\end{array}$ & 7 (pressurizer pressure) & valve closed \\
\hline
\end{tabular}




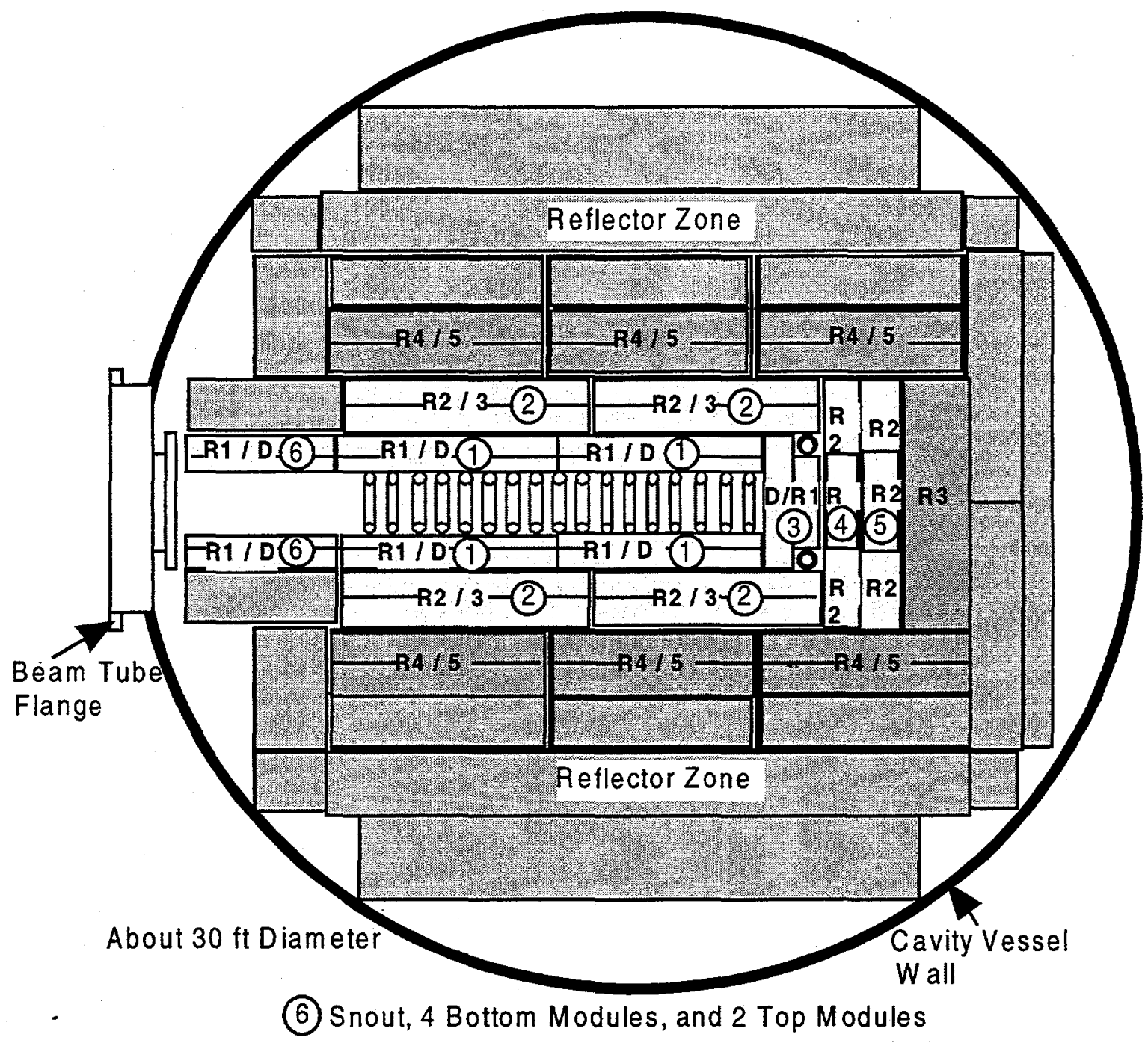

Figure 2-1 Top cross-sectional face map of 6 lumped blanket system modules 


\section{$3 \quad$ TRAC System Model Results}

The LOFA model to simulate the loss of power for the primary and secondary HR pumps was run for 600 seconds after the initiation of the accident. The simulation results show that the pressurizer and a single RHR system can mitigate this design basis accident without any damage to the blanket module system and structure. During the accident the liquid in the pressurizer was not drained completely so that gas inside the pressurizer is not entrained into the heat removal system loops such as the HR and RHR ssystems. The temperature of the coolant water surrounding the blanket modules does not reach saturation temperature leading to the phase change inside the blanket system under any of the LOFA transient times. The next subsections provide descriptions of the transient phenomena for the key blanket component systems observed in the accident simulation in more detail.

\subsection{Modules}

Figure B1-1 shows the component layout of the internal blanket module system used in the TRAC system model. All the modules are connected to the fixed headers. Primary coolant water is supplied to the hot blanket modules through the inlet fixed header and returned to the outlet fixed header. These two fixed headers are located inside the cavity vessel. Figures $\mathrm{B} 2-2 \mathrm{a}$ to $\mathrm{B} 2-7 \mathrm{~d}$ show the transient results for pressures, fluid temperatures, liquid subcoolings, and void fractions for the three plenums (inlet, middle, and exit plenums) of each blanket module. The results show that upflow region of each blanket module has near-stagnant liquid flow at about 60 seconds after the initiation of the LOFA at which primary HR flowrate was already reduced to below $5 \%$ of the full power flowrate $(1569 \mathrm{~kg} / \mathrm{sec})$. None of the module channels have voidage within the liquid coolant through the transient accident period. The graphical results show that rapid transient behaviors for the flow channels of all the six blanket modules continue up to about 100 seconds after the initiation of the LOFA accident. RHR pump was actuated after the accident, and RHR coolant water with initial $40 \mathrm{C}$ temperature came into the internal hot.blanket module system. As a result, fluid temperatures of the six blanket modules dropped more quickly for about 20 seconds. Finally, the six blanket modules were established with small RHR liquid flowrates controlled by the gravitational hydraulic head.

Figs. B3-26 through B3-43 show detailed graphical results for the solid structures of the six blanket modules. Maximum lead temperature was $152 \mathrm{C}$ during normal operation condition near the mid-plane of the first lateral module. Generally, solid temperatures were decreased quickly up to 50 seconds since the initiation of the loss of power, and then after rising up about 2 to $3 \mathrm{C}$ for about 50 seconds the solid temperatures slowly approached steady-state equilibrium values following the trend of the decay heat curve shown in Fig. 1-1. Maximum aluminum cladding surface temperature was $93.5 \mathrm{C}$ during normal operation condition at the mid-plane of the blanket module 1 and then it dropped to the minimum value (about $47 \mathrm{C}$ ) near the exit of the module 1 channel at the transient time of 50 seconds. After about 200 seconds, the aluminum surface temperatures started to approach stabilized cooling condition slowly. 


\subsection{HR Loop and Pressurizer}

Figure B1-2 shows the HR system component layout used for the one-dimensional TRAC system model. Transient behaviors for key thermal-hydraulic parameters of the two internal fixed headers are graphically shown in Figs. B1-1a to B1-1d. As the primary $H R$ liquid flowrate decreased quickly for the loss of pumping power, hot leg pressure increased radidly to 107 psia at about 60 seconds after the loss of power, and finally the hot-leg fixed header pressure is slightly higher than the cold-leg fixed header pressure by the elevation height difference. Cold-leg fixed header temperature was decreased by $2.5 \mathrm{C}$ during first 35 seconds after the accident due to the incoming RHR cold water (40 C) and rapid decay of primary coolant water flowrate. Both of the fixed headers had zero voidage during the entire transient simulation period. Transient behaviors for important thermal-hydraulic parameters of most external balance of plant (BOP) components are shown in Figs. B2-8a to B2-25e. The results show that liquid flowrates for the two primary HR pumps have reduced to about $5 \%$ of the normal full flowrates through the primary HR loop at about 60 seconds after the loss of pumping power. Fluid temperature at the pump suction side was decreased rapidly and established as constant temperature of about $51.5 \mathrm{C}$ at about 100 seconds as shown in Fig. B2-b8. At this time coolant liquid flowrate of the primary $\mathrm{HR}$ system was about zero. Figs. B2-9a to B2-10e show the transient behaviors of the two primary HR pumps during the LOFA simulation time. The two HR pumps show near-symmetric behaviors with no cavitation during the accident.

Figure B1-3 shows the component layout for the pressurizer system connected to the inlet fixed header external to the cavity vessel. Initial fluid temperature of the pressurizer was assumed to $40 \mathrm{C}$. Figs. B2-15a to B2-15e show transient behaviors of the key thermal-hydraulic parameters for the pressurizer and surge line during the loss of the pumping power accident. From the results, the liquid in the pressurizer was not drained completely during the accident so that gas inside the pressurizer is not entrained into the heat removal system loop. Void fraction in the surge line of the pressurizer was zero during the transient accident to satisfy the design requirement for the pressurizer component. No void was entrained into the primary HR loop through the surge line of the pressurizer during the entire transient time of the LOFA accident.

\subsection{RHR Loop}

Figure B1-4 shows layout for the RHR system. The initial temperature for the RHR system was $40 \mathrm{C}$. Maximum RHR flowrate was about $4 \%$ of total full power liquid flowrate. The RHR system has check valve on the RHR pump discharge side to prevent flow reversal during the LOFA scenario. The transient responses of the RHR system to the LOFA scenario are shown in Figs. B2-16a to B2-16e and B2-17a to B217e. Figure B2-16a shows pressures for the RHR pump suction and discharge sides. No void at the RHR pump suction and discharge sides was initiated during the accident as shown in Fig. B2-16e. During the initial phase of the accident RHR check valve was activated to avoid backflow in the RHR system, and then RHR flowrate was near zero for the RHR check valve closing. At about 60 seconds after the accident, liquid flowrate in the RHR system was established to the full capacity. 
Figure B2-17b shows the RHR primary heat exchanger inlet and outlet temperatures. The current CDR has the two 100\% RHR systems shutdown in standby mode during normal operation, but from the current baseline design only one RHR system is operated during the accident. Initial inlet temperature was the same as steady-state stagnant RHR temperature $40 \mathrm{C}$, and then RHR water temperature quickly increased as soon as the RHR pump circulates the water through the blanket modules internal to the cavity vessel.

\subsection{Cavity Vessel and Flood System}

Figure B1-5 shows the TRAC component layout that shows the heat transfer connections between the blanket module heat structures and the cavity vessel. Figure B1-6 shows the TRAC component layout for the cavity vessel and flood system. During the LOFA accident, the cavity flood system pool is stagnant with an ambient temperature of $40 \mathrm{C}$. The cavity vessel has no liquid phase with ambient temperature saturated at about 5 psia during the LOFA due to the loss of power.

\section{FLOWTRAN-TF Detailed Bin Model}

\subsection{Model Description}

The basic FLOWTRAN-TF model is described in Refs. $[11,12]$ and was used in this version for the LOFA analyses. The FLOWTRAN-TF model was developed to simulate the thermal-hydraulic conditions in a lateral row 1 blanket module using the reference 1 plate-type design [13]. The areal mesh of the bin model is shown in Figure 4-1 along with the location and indexing used for the 12 discrete flow channels.

\subsection{Initial Conditions}

Initial conditions for all of the flow transients are normal operating conditions as reported in Ref. [1]. The TRAC supplied initial conditions used in the FLOWTRAN-TF calculations are listed in Table 4.2-1.

In addition, based on information supplied by Los Alamos National Laboratory [14], we assume an initial pre-incident coolant flow of $1.488 \mathrm{~kg} / \mathrm{s}$ to the 12 half flow channels that surround a single blanket plate-type module and a nominal pre-incident deposited power for a single plate of $61.5 \mathrm{~kW}$.

\subsection{Transient Boundary Conditions}

Transient profiles of plate boundary condition variables generated by the TRAC system model and normalized to their respective pre-incident conditions are shown in Fig. 4.3-1. Conditions for the TRAC calculation were adjusted so that the coolant flow reached approximately $10 \%$ of the pre-incident flow 60 seconds into the accident. There was no void formation within the coolant loops for this accident scenario. From Fig. 4.3-1, we see that the flow decreases in an approximately exponential manner while the inlet temperature remains nearly constant. The inlet and exit pressures follow the flow transient and approach hydrostatic limits that depend on the system configuration. In 
fact, as shown in Fig. 4.3-2, the TRAC results can be closely approximated by the equations:

$$
\begin{gathered}
\frac{Q}{Q_{0}}=\frac{Q_{\infty}}{Q_{0}}+\left[1-\frac{Q_{\infty}}{Q_{0}}\right] \exp \left(\frac{t}{\tau}\right) \\
\frac{P_{i n}}{P_{i n}^{0}}=\frac{P_{i n}^{\infty}-K_{i n} Q^{2}}{P_{i n}^{\infty}-K_{\text {in }} Q_{0}^{2}} \\
\frac{P_{\text {exis }}}{P_{\text {exit }}^{0}}=\frac{P_{\text {exit }}^{\infty}-K_{\text {exit }} Q^{2}}{P_{\text {exit }}^{\infty}-K_{\text {exit }} Q_{0}^{2}}
\end{gathered}
$$

where:

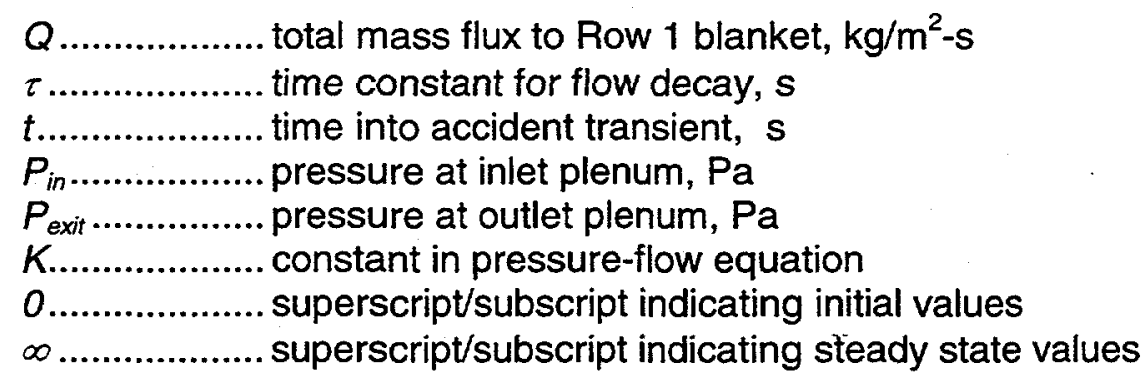

The parameters used in Eqs. (4.3-1) through (4.3-3) were obtained from the TRAC system calculations and from least squares fitting of the TRAC transients. Values of the fitted parameters are given in Table 4.3-1.

The $\mathrm{K}$ coefficients in Eqs. (4.3-2) and (4.3-3) were derived using mass flux at the inlet to the blanket modules in the correlations in place of volumetric flow rate. Neglecting density changes, the mass flux is directly proportional to volumetric flow and can be taken directly from the TRAC system calculations. Beyond 15 seconds, the fitted flow transient falls below the system calculation providing a conservative approximation to the flow. Prior to 15 seconds the two curves are very close to each other although the fitted curve is slightly non-conservative. There are slight offsets in the steady-state pressure transients that originate from the fact that the initial system pressure is not exactly reproduced. That is, at the inlet for example,

$$
P_{i n}^{0} \neq P_{\text {in }}^{\infty}-K_{\text {in }} Q_{0}^{2}
$$

The slight difference of about $1 \%$ in pressure between these values is indicated by the offset in the normalized pressure transients.

Using the parameters in Table 4.3-1, transients were created such that the coolant flow reached exactly $1 \%, 2 \%, 5 \%$ and $10 \%$ of the pre-incident value 60 seconds after initiation of the loss of flow accident. These transient pressure and flow profiles are shown in Figs. 4.3-3 through 4.3-6 for the $10 \%, 5 \%, 2 \%$ and $1 \%$ flow cases, respectively. 
Table 4.2-1 Initial conditions for FLOWTRAN-TF LOFA analysis.

\begin{tabular}{|c|ccc|}
\hline & Pressure (MPa) & Temperature (C) & Void \\
\hline Channel Inlet & 0.686 & 53.04 & 0 \\
Channel Outlet & 0.584 & & \\
\hline
\end{tabular}

Table 4.3-1 Transient Curve Fitting Parameters.

\begin{tabular}{|cc|}
\hline $\begin{array}{c}\text { Equation Parameters } \\
\text { From Datariting }\end{array}$ & Value \\
\hline$\tau$ & $14.025 \mathrm{sec}$ \\
$P_{i n}^{\infty}$ & $819285 \mathrm{~Pa}$ \\
$K_{i n}$ & 0.4204 \\
$P_{\text {exit }}^{\infty}$ & $791098 \mathrm{~Pa}$ \\
$K_{\text {exit }}$ & 0.7163 \\
\hline
\end{tabular}

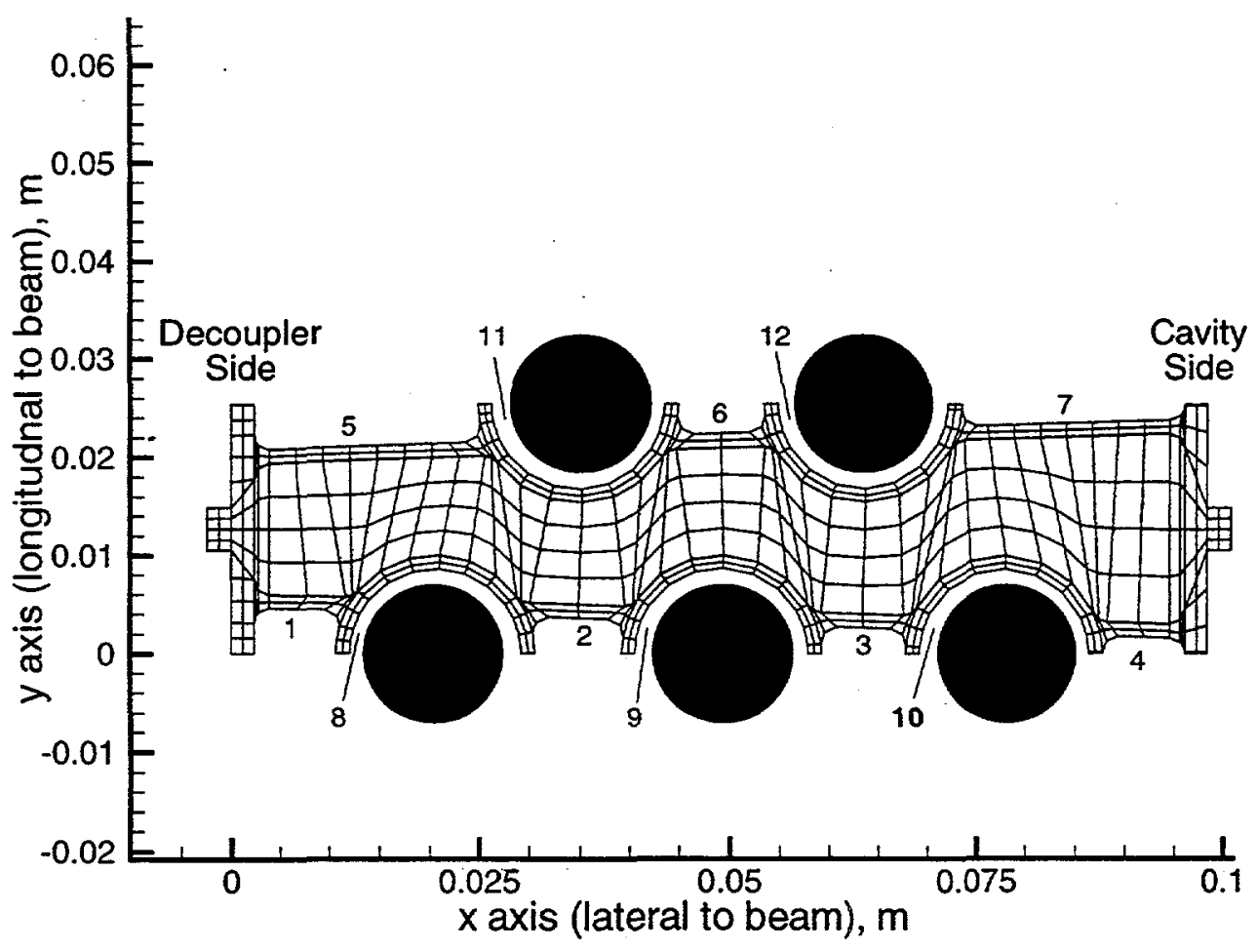

Figure 4-1 Finite element mesh of APT reference 1 blanket plate. 


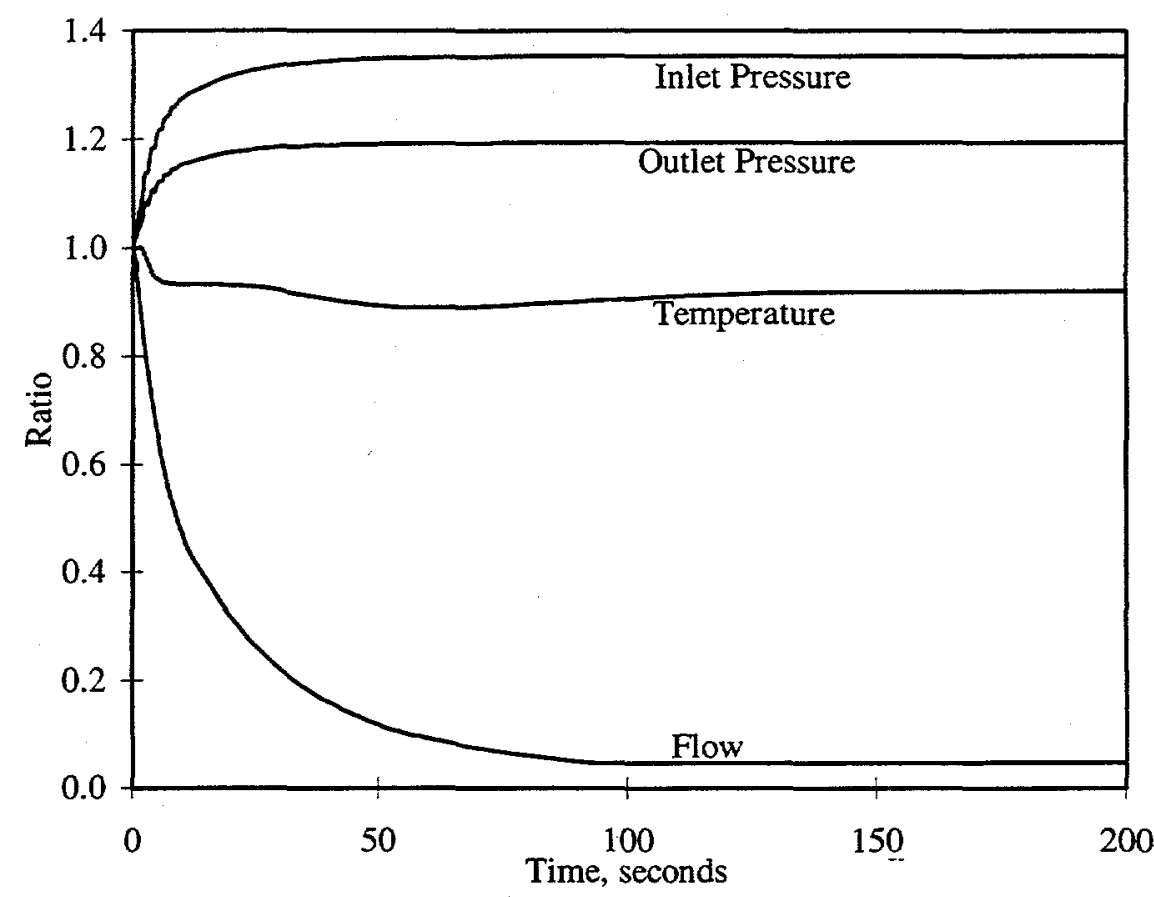

Figure 4.3-1 Pump coast down transients from TRAC system analysis.

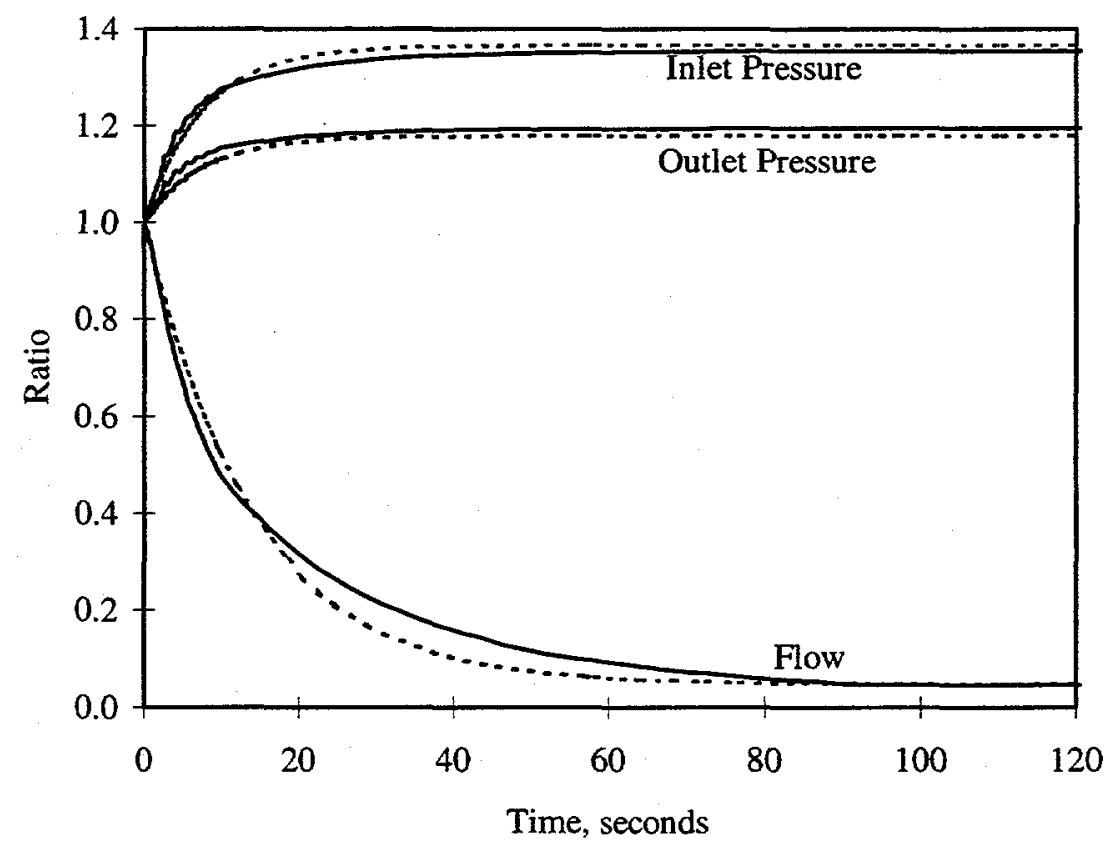

Figure 4.3-2 Curve fits (dashed lines) to TRAC transients (solid lines). 


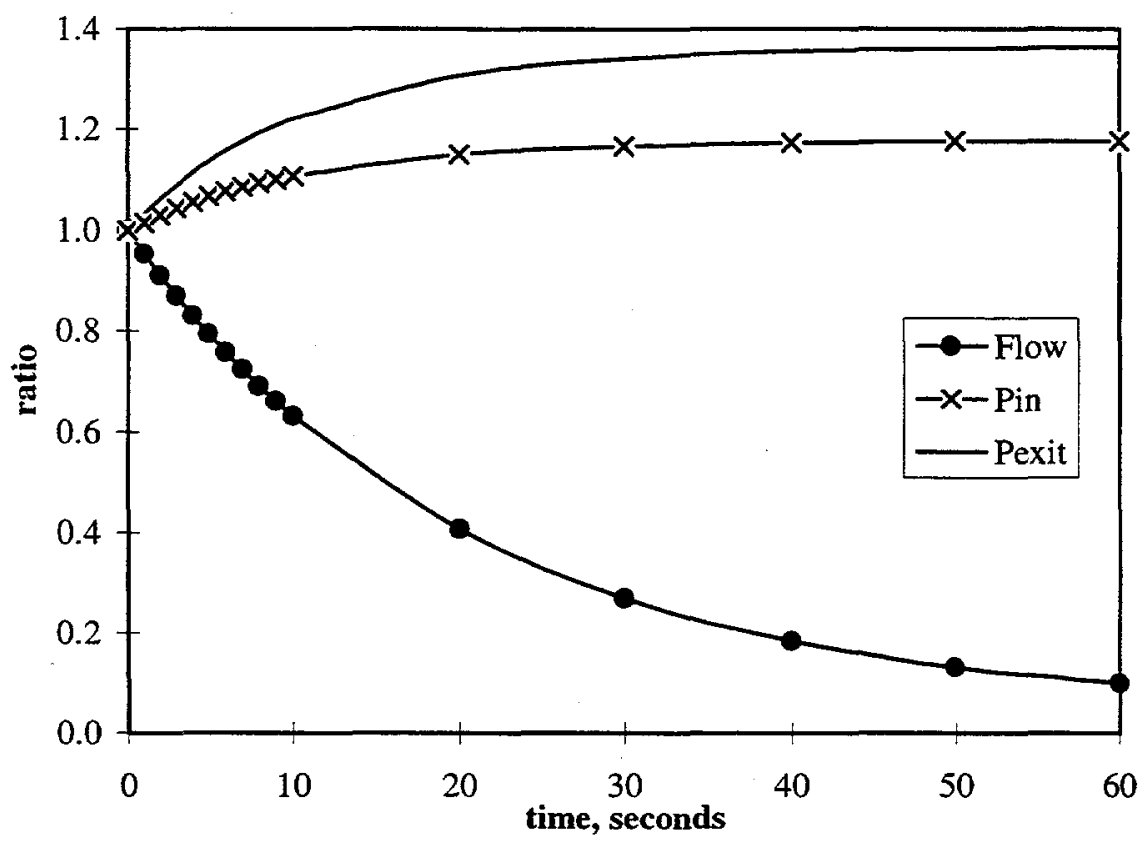

Figure 4.3-3 Pressure and flow transients with $10 \%$ pre-incident flow at 60 sec.

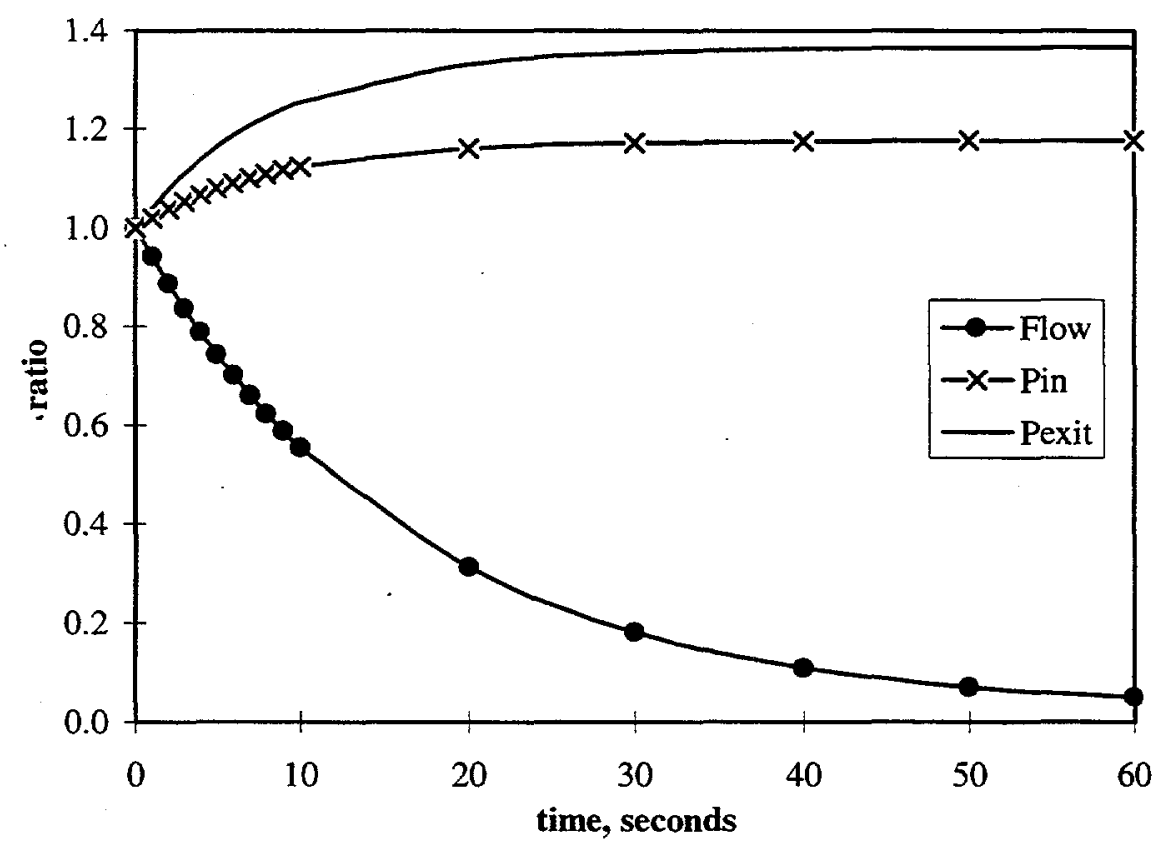

Figure 4.3-4 Pressure and flow transients with 5\% pre-incident flow at 60 sec. 


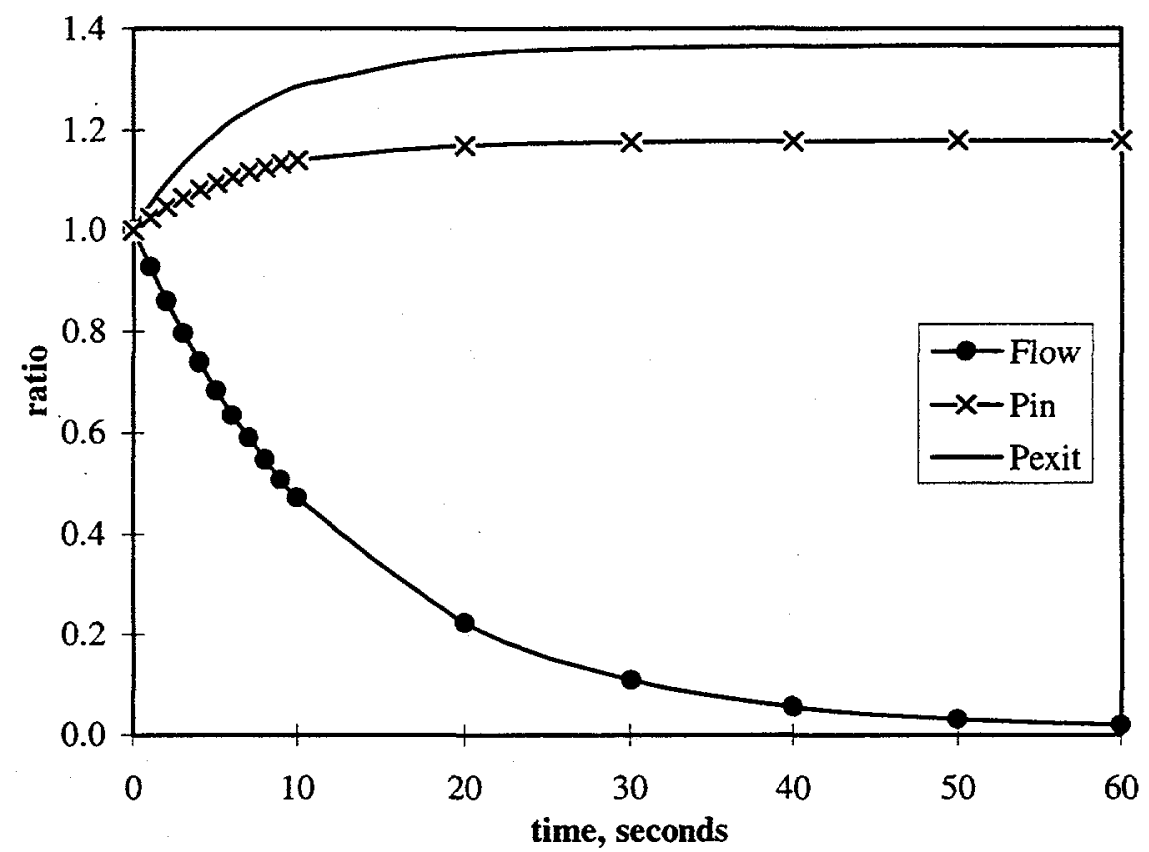

Figure 4.3-5 Pressure and flow transients with $2 \%$ pre-incident flow at 60 sec.

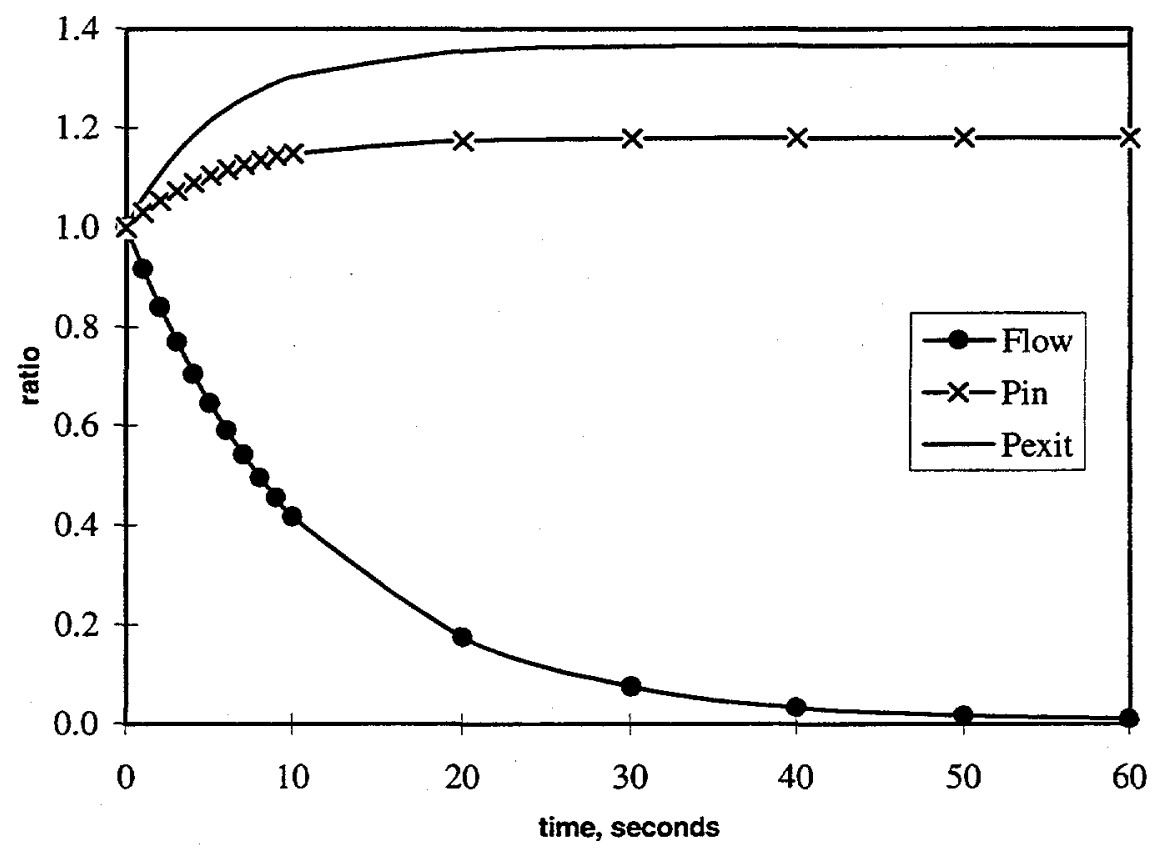

Figure 4.3-6 Pressure and flow transients with $1 \%$ pre-incident flow at 60 sec.

\section{FLOWTRAN-TF Bin Model Results}

The four sets of transient flow and pressure boundary conditions shown in Figs. 4.3-3 through 4.3-6 were run with the FLOWTRAN-TF model of a single reference 1 lateral 
row 1 blanket plate module to assess safety margins during a loss of flow accident. Since the inlet temperature does not change significantly during the first 60 seconds, the TRAC calculated inlet temperature transient shown in Fig. 4.3-1 was used for each of the calculations. The two safety criteria appropriate for LOFA accident scenarios are:

1. Keeping the aluminum metal temperature below the limit of $115 \mathrm{C}$ imposed to maintain structural integrity. Material limits for the platetype structures have been tentatively set to: (1) $115 \mathrm{C}$ for steady-state normal operation or indefinite times of exposure; and (2) $150 \mathrm{C}$ for exposures less than 10,000 hours.

2. Keeping the aluminum surface temperature below the local saturation temperature to prevent steam formation and possible flow blockage in the flow channels.

The analysis procedure was to run each of the above four transients while varying the time delay for beam trip. Nominally, a beam trip is expected to occur one second after the initiating event for the loss of flow accident. Determining the time delay that could be tolerated in these scenarios gives an indication of the safety margin inherent in the blanket module design. Table 5-1 summarizes results of these calculations. As a conservative measure, the delay time that keeps the aluminum temperature below the $115 \mathrm{C}$ limit was found.

Table 5-1 Summary of LOFA Transient Results

\begin{tabular}{|c|c|c|}
\hline Transient & $\begin{array}{c}\text { Beam Trip Delay } \\
T_{A}=115 \mathrm{C}\end{array}$ & $\begin{array}{c}\text { Beam Trip Delay } \\
T_{\text {wall }}=T_{\text {sat }}\end{array}$ \\
\hline $\begin{array}{l}10 \% \text { Flow } \\
5 \% \text { Flow } \\
2 \% \text { Flow } \\
1 \% \text { Flow }\end{array}$ & $\begin{array}{c}22.5 \mathrm{sec} \\
18 \mathrm{sec} \\
15 \mathrm{sec} \\
13 \mathrm{sec}\end{array}$ & $\begin{array}{l}57 \mathrm{sec} \\
45 \mathrm{sec} \\
36 \mathrm{sec} \\
32 \mathrm{sec}\end{array}$ \\
\hline
\end{tabular}

Adding an additional $20 \%$ margin to the deposited power (i.e. using a pre-incident power of $73.8 \mathrm{~kW}$ ), the $5 \%$ flow transient trims the $T_{\text {wall }}=T_{\text {sat }}$ criteria at 39 seconds. Maximum aluminum surface temperatures during the transients where the $T_{\text {wall }}=T_{\text {sat }}$ criteria are trimmed are plotted in Fig. 5-1. Maximum aluminum metal temperatures during the transients where the $T_{A l}=115 \mathrm{C}$ criteria are trimmed are plotted in Fig. 5-2.

In Fig. 5-1 we see that, for all of the scenarios, the saturation temperature has reached a steady-state value of around $165 \mathrm{C}$ by the time the surface temperature limits are reached. Local saturation temperature rises during the transients because the pressure is increasing. The conservative aluminum temperature limit of $115 \mathrm{C}$ is exceeded at the surface for from 25 to 35 seconds during these transients. For all four cases, the wall temperature first exceeds saturation in flow channel number eight about mid way up the channel. After the beam power is tripped, at the time when the criterion is trimmed, the metal temperatures rapidly decrease.

From Fig. 5-2 we see that the maximum pre-incident aluminum temperature is about $100 \mathrm{C}$. Following the loss of coolant flow, the maximum aluminum temperature 
increases to the limit of $115 \mathrm{C}$ in from 13 to 23 seconds depending on the flow transient. At this point, when the beam power is shut off, the metal temperatures rapidly decrease.

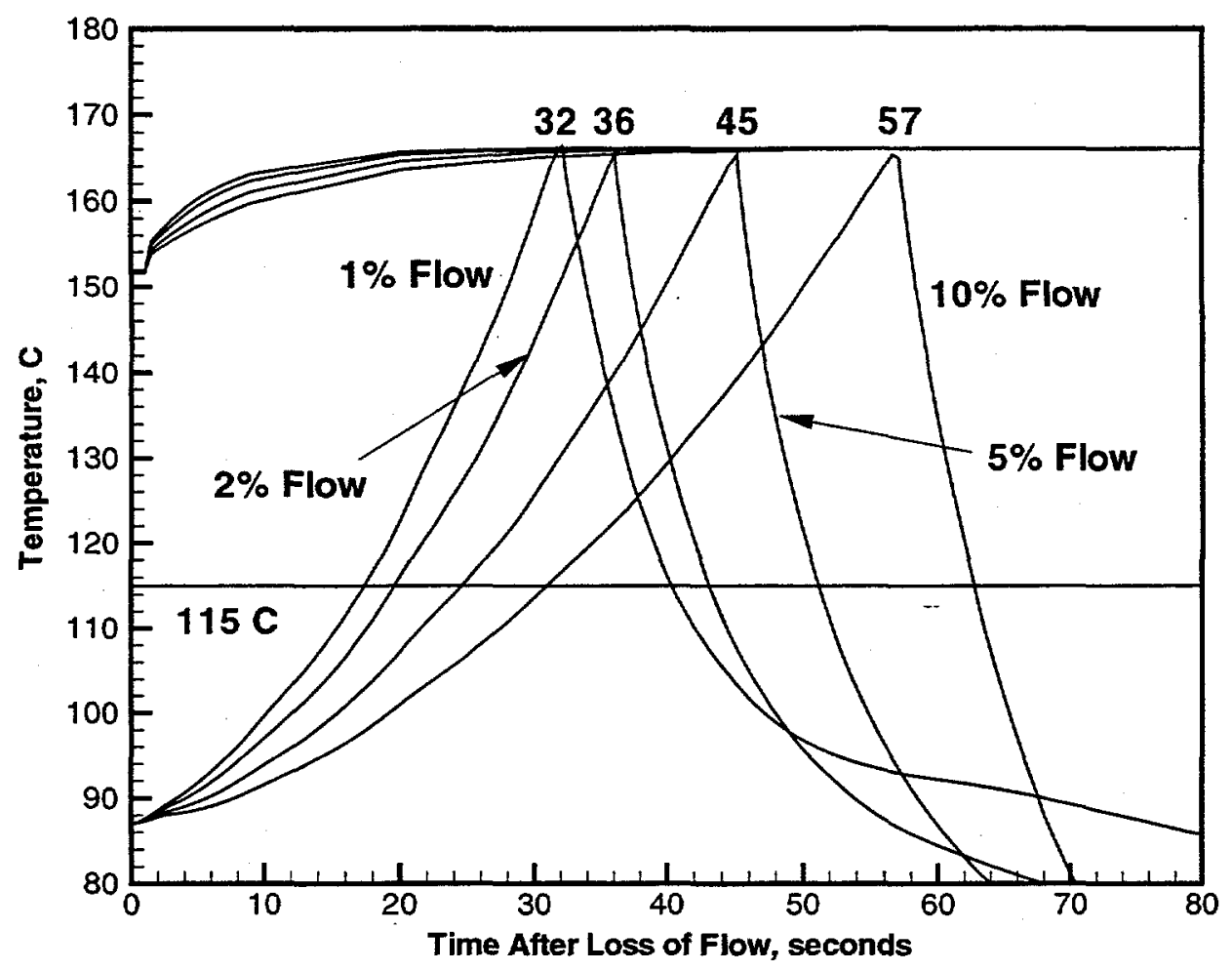

Figure 5-1 Aluminum surface temperature transients for $T_{\text {wall }}=T_{\text {sat }}$ criteria. 


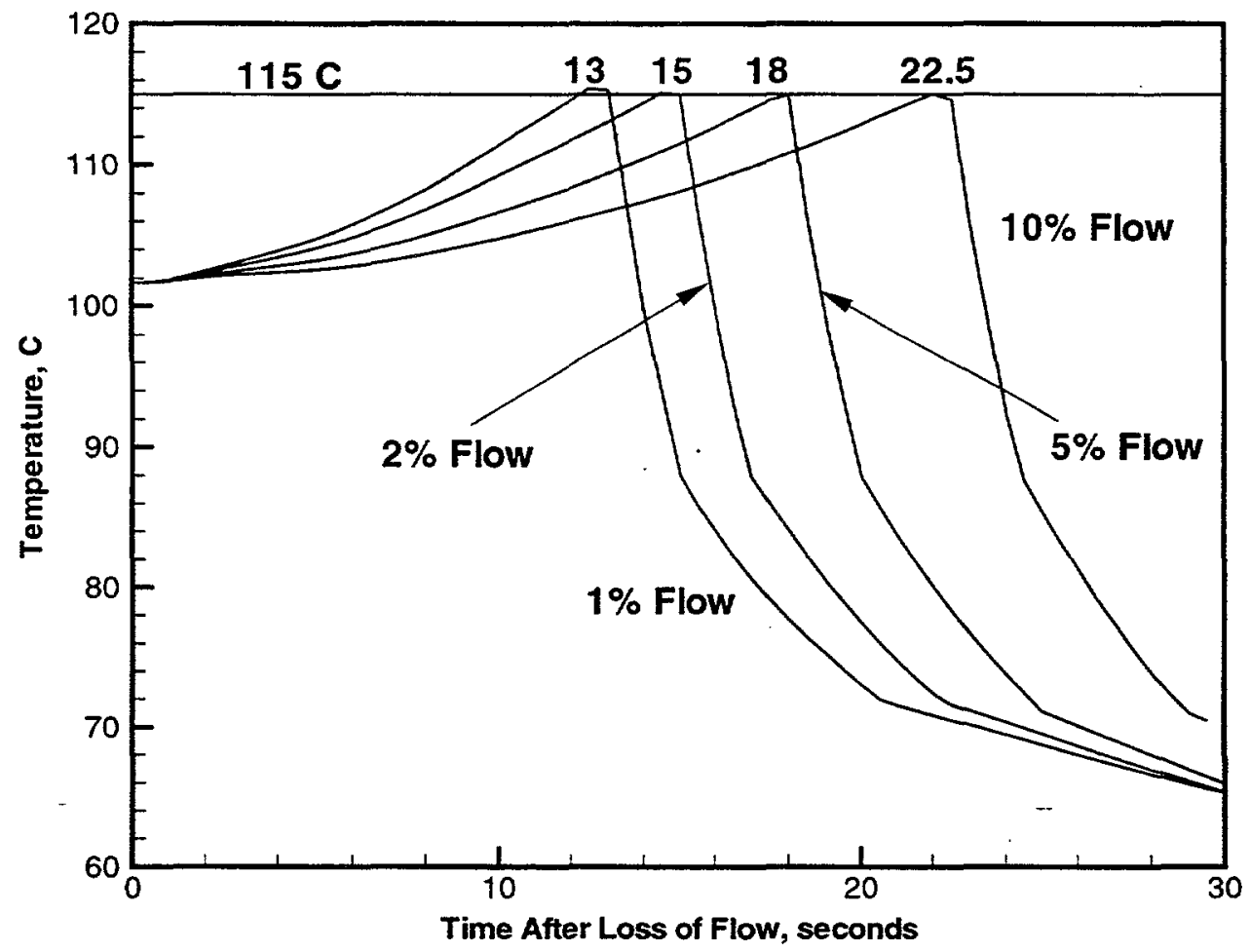

Figure 5-2 Maximum aluminum temperature transients for $T_{A l}=115 \mathrm{C}$ criteria.

\section{Conclusions}

\subsection{Comparison to Thermal/Hydraulic Design Criteria}

Simulations performed using the TRAC system model and the FLOWTRAN-TF detailed bin model show that the APT blanket modules maintain a coolable geometry during the LOFA scenario. The thermal/hydraulic $(T / H)$ design criteria, along with the basis for their development, is discussed in Refs. [15-16]. For LOFA the T/H onset criteria are based on meeting very strict phenomenological limits with a high degree of confidence, as follows:

- for local heated surfaces within the module components, the onset-of-significantvoids [OSV]) at a three sigma confidence level; and

- for the remaining unheated piping sections of the blanket system, the onset-of-bulkboiling $[\mathrm{OBB}]$ ) at a three sigma confidence level.

Additional (steady-state derived) material design criteria are imposed on the maximum lead and aluminum (Series 6061 - Type T6) metal temperatures acceptable for the module components. The limiting values for these parameters are $327.5 \mathrm{C}$ and $115 \mathrm{C}$ 
for lead and aluminum, respectively. These material design criteria ensure that a coolable geometry can be maintained throughout the expected lifetime of each module unit.

Confidence bounds are required to establish the acceptable level of probability of exceeding these criteria. The results presented in this report represent primarily best estimate values (however, some parameters were set to their estimated upper bounds, such as power density). Quantification of overall uncertainties and then their corresponding confidence levels (i.e., operating and modeling uncertainties) have not yet been performed. Future efforts to perform a response surface analysis are planned. At that time quantification of safety margins will be determined.

\subsection{Design Issues}

Adequate safety margin is provided by the reference 1 plate-type design to allow the APT blanket section to withstand the LOFA scenarios analyzed. In particular, the maximum aluminum temperature remained below $115 \mathrm{C}$ with beam trips delayed by from 10 to 20 seconds. The maximum aluminum temperature exceeded $165 \mathrm{C}$ if the beam trips were delayed by from 30 to 60 seconds. However, following beam trip, aluminum temperatures rapidly declined and the exposure limit was never approached. The design basis LOFA assumes beam trip within one second of the accident initiation. With the plate-type blanked design, this criteria provides a large safety margin.

The TRAC system model predicts a peak lead temperature in module \#1 of $152 \mathrm{C}$ and the detailed FLOWTRAN-TF bin model predicts a peak lead temperature of $112.8 \mathrm{C}$. The cruciform design was used in the TRAC system model, and the plate design was used in the FLOWTRAN-TF model. This points out the need for consistency between the two models. The TRAC model will be upgraded in order to provide this consistency.

\subsection{Predicted Impact}

Blanket conditions during LOFA fall within all specified thermal/hydraulic design criteria. No on-site or off-site impact to people or the environment would occur from conditions within the blanket region of the APT as a result of LOFA.

\section{References}

1. L. L. Hamm, S. Y. Lee, M. A. Shadday, and F. G. Smith, III, "Normal Operation (NO) of APT Blanket System and its Components, Based on Initial Conceptual Design," Westinghouse Savannah River Company, WSRC-TR-98-0057 (July 1998).

2. L. L. Hamm, S. Y. Lee, M. A. Shadday, and F. G. Smith, III, "APT Blanket System Loss-of-Coolant Accident (LOCA) Analysis Based on Initial Conceptual Design Case 1: External HR Break Near Inlet Header," Westinghouse Savannah River Company, WSRC-TR-98-0059 (July 1998).

3. L. L. Hamm, S. Y. Lee, M. A. Shadday, and F. G. Smith, III, "APT Blanket System Loss-of-Coolant Accident (LOCA) Analysis Based on Initial Conceptual Design Case 2: External HR Break at Pump Outlet with Pump Trip," Westinghouse Savannah River Company, WSRC-TR-98-0060 (July 1998). 
4. L. L. Hamm, S. Y. Lee, M. A. Shadday, and F. G. Smith, III, "APT Blanket System Loss-of-Coolant Accident (LOCA) Analysis Based on Initial Conceptual Design Case 3: External HR Break at Pump Outlet without Pump Trip," Westinghouse Savannah River Company, WSRC-TR-98-0061 (July 1998).

5. L. L. Hamm, S. Y. Lee, M. A. Shadday, and F. G. Smith, III, "APT Blanket System Loss-of-Coolant Accident (LOCA) Analysis Based on Initial Conceptual Design Case 4: External Pressurizer Surge Line Break Near Inlet Header," Westinghouse Savannah River Company, WSRC-TR-98-0062 (July 1998).

6. L. L. Hamm, S. Y. Lee, M. A. Shadday, and F. G. Smith, III, "APT Blanket System Loss-of-Coolant Accident (LOCA) Analyses Based on Initial Conceptual Design Case 5: External RHR Break Near Inlet Header," Westinghouse Savannah River Company, WSRC-TR-98-0063 (July 1998).

7. L. L. Hamm, S. Y. Lee, M. A. Shadday, and F. G. Smith, III, "APT Blanket System Internally Dry Flooded Cavity Accident (IDFCA) Based on Initial Plate-Type Design - Demonstration of Bin Heat Conduction Capability," Westinghouse Savannah River Company, WSRC-TR-98-0064 (July 1998).

8. G. Willcutt, "Decay Power Fractions for $1700 \mathrm{MeV}$ Design," e-mail memo from Los Alamos National Laboratory, March 20, 1997.

9. L. L. Hamm, S. Y. Lee, M. A. Shadday, and F. G. Smith, III, "APT Blanket System Model Based On Initial Conceptual Design - Integrated 1D TRAC System Model," Westinghouse Savannah River Company, WSRC-TR-98-0053 (July 1998).

10. L. L. Hamm, S. Y. Lee, M. A. Shadday, and F. G. Smith; III, "TRAC Code Modifications made for APT Blanket Safety Analyses," Westinghouse Savannah River Company, WSRC-TR-98-0054 (July 1998).

11. L. L. Hamm, S. Y. Lee, M. A. Shadday, and F. G. Smith, III, "APT Blanket Detailed Bin Model Based on Initial Plate-Type Design - 3D FLOWTRAN-TF Model," Westinghouse Savannah River Company, WSRC-TR-98-0055 (July 1998).

12. L. L. Hamm, S. Y. Lee, M. A. Shadday, and F. G. Smith, III, "FLOWTRAN-TF Code Modifications made for. APT Blanket Safety Analyses," Westinghouse Savannah River Company, WSRC-TR-98-0056 (July 1998).

14. R. Kapernick, "Preliminary Blanket Safety Calculations", e-mail memo from Los Alamos National Laboratory, December 11, 1997.

15. R. Kapernick, "Blanket Reference 1 Plate-Type Design for Lateral Row 1 Module", e-mail memo from Los Alamos National Laboratory, Oct. 11, 1997.

16. L. L. Hamm, S. Y. Lee, M. A. Shadday, and F. G. Smith, III, "APT Blanket System Safety Analysis Methodology," Westinghouse Savannah River Company WSRCTR-98-0052 (May 1998).

17. "APT Conceptual Design Report," Los Alamos National Laboratory report, LA-UR97-1329 (April 1997).

18. Safety Code Development Group, "TRAC-PF1/MOD2: An Advanced Best Estimate Computer Program for Pressurized Water Reactor Thermal-Hydraulic Analysis," Los Alamos National Laboratory report LA-12031-M, Vol. 1 (NUREG/CR-5673), (July 21, 1993). 


\section{Appendix A: TRAC Model Component Nomenclature}

Table A-1 Blanket System Component Descriptions in TRAC Model.

\begin{tabular}{|c|c|c|c|c|}
\hline System & Component Type & Comp & $\begin{array}{l}\text { No of } \\
\text { Cells }\end{array}$ & Descriptions \\
\hline \multirow[t]{25}{*}{$\mathrm{HR}$} & Fixed Header $(\mathrm{FH})$ & 380 & 1 & coolant Supply FH \\
\hline & & 340 & 1 & coolant Return FH \\
\hline & Pressurizer (Pzr) & 760 & 1 & Pzr surge line 1 connected to Supply FH 380 \\
\hline & & 761 & 2 & Pzr surge line 2 \\
\hline & & 762 & 1 & Pzr surge line 3 \\
\hline & & 763 & 1 & Pzr surge line 4 \\
\hline & & 764 & 1 & Pzr surge line 5 \\
\hline & & 765 & 13 & Pzr surge line 6 \\
\hline & & 766 & 9 & primary $\mathrm{Pzr}$ \\
\hline & Hot Leg Loop & 20 & 1 & pipe connected to Return $\mathrm{FH} 340$ \\
\hline & & 21 & 1 & plenum for potential break loc. \\
\hline & & 22 & 7 & pipe connection to external loop \\
\hline & & 23 & 1 & pipe connect. for potential break \\
\hline & & 24 & 13 & connection pipe \\
\hline & & 25 & 1 & connection pipe \\
\hline & & 26 & 2 & pipe connected to two pumps \\
\hline & & 27 & 1 & plenum for two pump connection \\
\hline & & 28 & 2 & pump\#1 suction pipe \\
\hline & & 29 & 7 & pump\#2 suction pipe \\
\hline & & 30 & 2 & pump located at cell face 2 \\
\hline & & 31 & 2 & pump located at cell face 2 \\
\hline & & 32 & 3 & check valve located at pump\#1 discharge \\
\hline & & 33 & 3 & check valve located at pump\#2 discharge \\
\hline & & 34 & 1 & pump outlet plenum \\
\hline & & 36 & 1 & connect. pipe between pump and pipe \\
\hline \multirow[t]{17}{*}{ - } & & 37 & 1 & $\mathrm{HX}$ connect. pipe for potential break \\
\hline & & 38 & 1 & pipe connect. to two HX's inlet plenum \\
\hline & & 40 & 1 & plenum \\
\hline & $\mathrm{HX}$ & 48 & 3 & $\mathrm{HX} \# 1$ inlet pipe \\
\hline & & 50 & 4 & 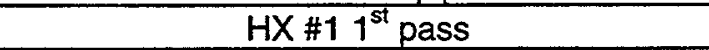 \\
\hline & & 52 & 3 & HX\#1 middle header \\
\hline & & 54 & 4 & $H X \# 12^{\text {nd }}$ pass \\
\hline & & 49 & 3 & $\mathrm{HX \# 2}$ inlet pipe \\
\hline & & 51 & 4 & $H X \# 21^{\text {st }}$ pass \\
\hline & & 53 & 3 & HX \#2 middle header \\
\hline & & 55 & 4 & $\mathrm{HX} \# 22^{\text {nd }}$ pass \\
\hline & & 710 & 1 & HX\#1 secondary side fill \\
\hline & & 711 & 4 & $H X \# 12^{\text {nd }}$ pass secondary side \\
\hline & & 712 & 3 & HX \#1 middle header secondary side \\
\hline & & 713 & 4 & $\mathrm{HX} \# 11^{\text {st }}$ pass secondary side \\
\hline & & 714 & 1 & HX \#1 secondary side break BC \\
\hline & & 730 & 1 & HX \#2 secondary side fill BC \\
\hline
\end{tabular}


WESTINGHOUSE SAVANNAH RIVER COMPANY

BLANKET SAFETY ANALYSIS FOR LOFA

(CASE 1: WITH BEAM SHUTDOWN AND ACTIVE RHR)
Report:

Section:

Date:

Page:
WSRC-TR-98-0058

Appendix A

$07 / 13 / 98$

2 of 12

Table A-1 Blanket System Component Descriptions in TRAC Model (continued).

\begin{tabular}{|c|c|c|c|c|}
\hline System & Component Type & Comp & $\begin{array}{l}\text { No } \\
\text { of } \\
\text { Cells }\end{array}$ & Descriptions \\
\hline & & 731 & 4 & $H X \# 22^{\text {nd }}$ pass secondary side \\
\hline & & 732 & 3 & $\mathrm{HX} \# 2$ middle header secondary side \\
\hline & & 733 & 4 & $\mathrm{HX} \# 21^{\text {st }}$ pass secondary side \\
\hline & & 734 & 1 & HX \#2 secondary side break BC \\
\hline \multirow[t]{12}{*}{ HR } & Cold Leg Loop & 56 & 3 & HX \#1 outlet pipe \\
\hline & & 57 & 6 & HX \#2 outlet pipe \\
\hline & & 60 & 3 & $\mathrm{HX}$ outlet plenum merged after two HX's \\
\hline & & 62 & 1 & $\begin{array}{l}\text { cold leg pipe } \\
\end{array}$ \\
\hline & & 63 & 1 & cold leg pipe \\
\hline & & 64 & 13 & cold leg pipe located outside cavity wall \\
\hline & & 65 & 1 & pipe for cold leg pipe break \\
\hline & & 66 & 1 & horizontal cold leg pipe penetration \\
\hline & & 67 & 1 & plenum for internal break on HR loop \\
\hline & & 854 & 2 & HR isolation valve for internal break \\
\hline & & 69 & 1 & plenum for internal LOCA simulation \\
\hline & & 68 & 5 & pipe connect. to $\mathrm{FH} 340$ inside cavity \\
\hline \multirow[t]{9}{*}{$\begin{array}{l}\text { Cavity } \\
\text { Vessel } \\
\end{array}$} & Cold Leg Loop & 850 & 2 & valve located bet. cavity vessel and HR \\
\hline & & 852 & 2 & valve located bet. cavity vessel and $\mathrm{HR}$ \\
\hline & & & 1 & plenum for cavity vessel connection \\
\hline & & 828 & 3 & cavity vent valve \\
\hline & & 802 & 1 & break component for cavity vent pressure BC \\
\hline & & 823 & 11 & pipe for cavity lower section simulation \\
\hline & & 824 & 1 & plenum for cavity connection \\
\hline & & 840 & 2 & valve to connect cavity line to Module 1 \\
\hline & & 825 & 4 & pipe for cavity middle section simulation \\
\hline \multirow[t]{8}{*}{$\begin{array}{l}\text { Cavity } \\
\text { Pool }\end{array}$} & Cavity Flood Line & 820 & 13 & $\begin{array}{l}\text { pipe for cavity pool connection to cavity } \\
\text { vessel }\end{array}$ \\
\hline & & 821 & 2 & cavity flood line valve \\
\hline & & 822 & 1 & flood line pipe inside cavity vessel \\
\hline & Cavity Flood Pool & 801 & 1 & break component for cavity pool BC \\
\hline & & 810 & 10 & pipe for top cavity pool section \\
\hline & & 811 & 1 & plenum for middle cavity pool section \\
\hline & & 812 & 7 & pipe for lower cavity pool section \\
\hline & & 813 & 1 & plenum for cavity pool bottom \\
\hline \multirow[t]{10}{*}{ RHR } & RHR Loop & 621 & 1 & pipe located to return $\mathrm{FH}$ \\
\hline & & 623 & 10 & pipe located inside the cavity vessel \\
\hline & & 624 & 1 & pipe located outside the cavity vessel \\
\hline & & 625 & 18 & pipe bet. RHR pump and pipe comp. \#624 \\
\hline & & 630 & 2 & RHR pump located at face 2 \\
\hline & & 640 & 3 & check valve located at pump discharge \\
\hline & & 652 & 4 & HX tubes \\
\hline & & 660 & 16 & pipe at the cold leg side \\
\hline & & 661 & 1 & pipe located before cavity vessel \\
\hline & & 662 & 8 & cold leg pipe inside cavity vessel \\
\hline
\end{tabular}


Table A-1 Blanket System Component Descriptions in TRAC Model (continued).

\begin{tabular}{|c|c|c|c|c|}
\hline System & Component Type & Comp & $\begin{array}{l}\text { No } \\
\text { of } \\
\text { Cells }\end{array}$ & Descriptions \\
\hline & & 663 & 1 & cold leg pipe connected to supply FH \\
\hline & & 672 & 1 & fill for $\mathrm{HX}$ secondary side $\mathrm{BC}$ \\
\hline & & 671 & 4 & HX secondary shell side \\
\hline & & 673 & 1 & break comp. for $\mathrm{HX}$ secondary side $\mathrm{BC}$ \\
\hline \multirow[t]{32}{*}{ Module } & Module 1 Flow & 454 & 7 & pipe connected to supply FH \\
\hline & & 80 & 1 & $\begin{array}{l}\text { plenum for potential internal break simulation } \\
\text { at Module } 1\end{array}$ \\
\hline & & 375 & 5 & $\begin{array}{l}\text { pipe connection bet. Suuply FH and Module } \\
1 \text { upper plenum }\end{array}$ \\
\hline & & 370 & 1 & upper plenum for Module 1 downcomer \\
\hline & & 360 & 5 & Module 1 downflow region \\
\hline & & 350 & 1 & $\begin{array}{c}\text { middle plenum bet. Module } 1 \text { downflow and } \\
\text { upflow regions }\end{array}$ \\
\hline & & 300 & 5 & Module 1 upflow region \\
\hline & & 330 & 1 & upper plenum for module 1 upflow region \\
\hline & & 335 & 5 & $\begin{array}{l}\text { connection pipe after Module } 1 \text { upper } \\
\text { plenum }\end{array}$ \\
\hline & & 429 & 4 & pipe connected to return FH \\
\hline & Module 2 Flow & 173 & 7 & pipe coonected to supply FH \\
\hline & & 81 & 1 & $\begin{array}{l}\text { plenum for potential internal break simulation } \\
\text { at Module } 2\end{array}$ \\
\hline & & 82 & 3 & pipe connection \\
\hline & & 172 & 1 & upper plenum for Module 2 downcomer \\
\hline & & 158 & 6 & Module 2 downflow region \\
\hline & & 147 & 1 & $\begin{array}{l}\text { middle plenum bet. Module } 2 \text { downflow and } \\
\text { upflow regions }\end{array}$ \\
\hline & & 102 & 6 & Module 2 upflow region \\
\hline & & 133 & 1 & upper plenum for module 2 upflow region \\
\hline & & 136 & 7 & pipe connected to return FH \\
\hline & Module 3 Flow & 415 & 7 & pipe connected to supply FH \\
\hline & & 85 & 1 & $\begin{array}{l}\text { plenum for potential internal break simulation } \\
\text { at Module } 3\end{array}$ \\
\hline & & 86 & 3 & pipe connection \\
\hline & & 479 & 1 & upper plenum for Module 3 downcomer \\
\hline & & 478 & 5 & Module 3 downflow region \\
\hline & & 418 & 1 & $\begin{array}{l}\text { middle plenum bet. Module } 3 \text { downflow and } \\
\text { upflow regions }\end{array}$ \\
\hline & & 409 & 5 & Module 3 upflow region \\
\hline & & 423 & 1 & upper plenum for module 3 upflow region \\
\hline & & 417 & 7 & pipe connected to return FH \\
\hline & Module 4 Flow & 485 & 7 & pipe connected to supply FH \\
\hline & & 87 & 1 & $\begin{array}{l}\text { plenum for potential internal break simulation } \\
\text { at Module } 4\end{array}$ \\
\hline & & 88 & 3 & pipe connection \\
\hline & & 489 & 1 & upper plenum for Module 4 downcomer \\
\hline
\end{tabular}


Table A-1 Blanket System Component Descriptions in TRAC Model (continued).

\begin{tabular}{|c|c|c|c|c|}
\hline System & Component Type & Comp & $\begin{array}{l}\text { No or } \\
\text { Cells. }\end{array}$ & Descriptions \\
\hline & & 480 & 6 & Module 4 downflow region \\
\hline & & 419 & 1 & $\begin{array}{c}\text { middle plenum bet. Module } 4 \text { downflow and } \\
\text { upflow regions }\end{array}$ \\
\hline & & 412 & 6 & Module 4 upflow region \\
\hline & & 483 & 1 & upper plenum for module 4 upflow region \\
\hline & & 484 & 7 & pipe connected to return FH \\
\hline Module & Module 5 Flow & 513 & 7 & pipe connected to supply $\mathrm{FH}$ \\
\hline & & 89 & 1 & $\begin{array}{l}\text { plenum for potential internal break } \\
\text { simulation at Module } 5\end{array}$ \\
\hline & & 90 & 3 & pipe connection \\
\hline & & 510 & 1 & upper plenum for Module 5 downcomer \\
\hline & & 507 & 6 & Module 5 downflow region \\
\hline & & 503 & 1 & $\begin{array}{c}\text { middle plenum bet. Module } 4 \text { downflow and } \\
\text { upflow regions }\end{array}$ \\
\hline & & 500 & 6 & Module 5 upflow region \\
\hline & & 508 & 1 & upper plenum for Module 5 upflow region \\
\hline & & 511 & 7 & pipe connected to return FH \\
\hline & Module 6 Flow & 541 & 7 & pipe connected to supply FH \\
\hline & & 83 & 1 & $\begin{array}{l}\text { plenum for potential internal break } \\
\text { simulation at Module } 6\end{array}$ \\
\hline & & 84 & 1 & pipe connection \\
\hline & & 538 & 1 & upper plenum for Module 6 decoupler \\
\hline & & 535 & 5 & Module 6 downcomer region \\
\hline & & 531 & 1 & $\begin{array}{l}\text { middle plenum bet. Module } 6 \text { decoupler and } \\
\text { main heated regions }\end{array}$ \\
\hline & & 528 & 5 & Module 6 main heated region \\
\hline & & 536 & 1 & $\begin{array}{l}\text { upper plenum for module } 6 \text { main heated } \\
\text { region }\end{array}$ \\
\hline & & 539 & 12 & pipe connected to return FH \\
\hline & $\begin{array}{l}\text { Module } 1 \text { Heater } \\
\text { Structure }\end{array}$ & 901 & 5 & Al tube structure in Row 1 \\
\hline & & 951 & 5 & Lead zone with Al cladding in Row 1 \\
\hline & & 984 & 5 & Al tube structure in decoupler \\
\hline & $\begin{array}{l}\text { Module } 2 \text { Heater } \\
\text { Structure }\end{array}$ & 905 & 6 & Al tube structure in Row 2 \\
\hline & & 955 & 6 & Lead zone with Al cladding in Row 2 \\
\hline & & 916 & 6 & Al tube structure in Row 3 \\
\hline & & 966 & 6 & Lead zone with Al cladding in Row 3 \\
\hline & $\begin{array}{l}\text { Module } 3 \text { Heater } \\
\text { Structure }\end{array}$ & 911 & 5 & Al tube structure in Row 1 \\
\hline & & 961 & 5 & Lead zone with Al cladding in Row 1 \\
\hline & & 988 & 5 & Al tube structure in decoupler \\
\hline & $\begin{array}{l}\text { Module } 4 \text { Heater } \\
\text { Structure }\end{array}$ & 912 & 6 & Al tube structure in Row 1 \\
\hline & & 962 & 6 & Lead zone with Al cladding in Row 1 \\
\hline & & 931 & 6 & Al tube structure in Row 2 \\
\hline
\end{tabular}


Table A-1 Blanket System Component Descriptions in TRAC Model (continued).

\begin{tabular}{|c|c|c|c|c|}
\hline System & Component Type & $\begin{array}{c}\text { Comp } \\
\#\end{array}$ & $\begin{array}{c}\text { No } \\
\text { of } \\
\text { Cells }\end{array}$ & \\
\hline & $\begin{array}{c}\text { Module 5 Heater } \\
\text { Structure }\end{array}$ & 978 & 6 & Lead zone with Al cladding in Row 2 \\
\hline & & 963 & 6 & Al tube structure in Row 2 \\
\hline & & 932 & 6 & Lead zone with Al cladding in Row 2 \\
\hline & $\begin{array}{c}\text { Module 6 Heater } \\
\text { Structure }\end{array}$ & 915 & 5 & Al tube structure in Row 2 \\
\hline & & 965 & 5 & Lead zone with Al cladding in Row 2 \\
\hline
\end{tabular}

Table A-2 Steady State Conditions.

\begin{tabular}{|c|c|c|}
\hline Parameter & Units & $\begin{array}{c}\text { Calculated } \\
\text { Values }\end{array}$ \\
\hline Total power deposited in blanket modules & $\mathrm{MW}$ & 56.5 \\
\hline Total flow rate & $\mathrm{kg} / \mathrm{sec}$ & 1569 \\
& $\mathrm{gpm}$ & 25252 \\
\hline Pressure in cold-leg fixed header & $\mathrm{MPa}$ & 0.7325 \\
& $\mathrm{psia}$ & 106.24 \\
\hline Pressure in hot-leg fixed header & $\mathrm{MPa}$ & 0.4563 \\
& $\mathrm{psia}$ & 66.180 \\
\hline Pressurizer (cell \#1) pressure & $\mathrm{MPa}$ & 0.7311 \\
& $\mathrm{psia}$ & 106.03 \\
\hline Pump \#1 suction pressure & $\mathrm{MPa}$ & 0.2751 \\
& $\mathrm{psia}$ & 39.90 \\
\hline Pump \#1 discharge pressure & $\mathrm{MPa}$ & 1.0356 \\
& $\mathrm{psia}$ & 150.20 \\
\hline Pump \#2 suction pressure & $\mathrm{MPa}$ & 0.2958 \\
& $\mathrm{psia}$ & 42.91 \\
\hline Pump \#2 discharge pressure & $\mathrm{MPa}$ & 1.0409 \\
& $\mathrm{psia}$ & 150.97 \\
\hline Temperature in cold-leg fixed header & $\mathrm{C}$ & 49.43 \\
& $\mathrm{~F}$ & 121.0 \\
\hline Temperature in hot-leg fixed header & $\mathrm{C}$ & 58.03 \\
& $\mathrm{~F}$ & 136.5 \\
\hline Max. fluid temperature of the hottest & $\mathrm{C}$ & 71.95 \\
module & $\mathrm{F}$ & 161.5 \\
\hline
\end{tabular}




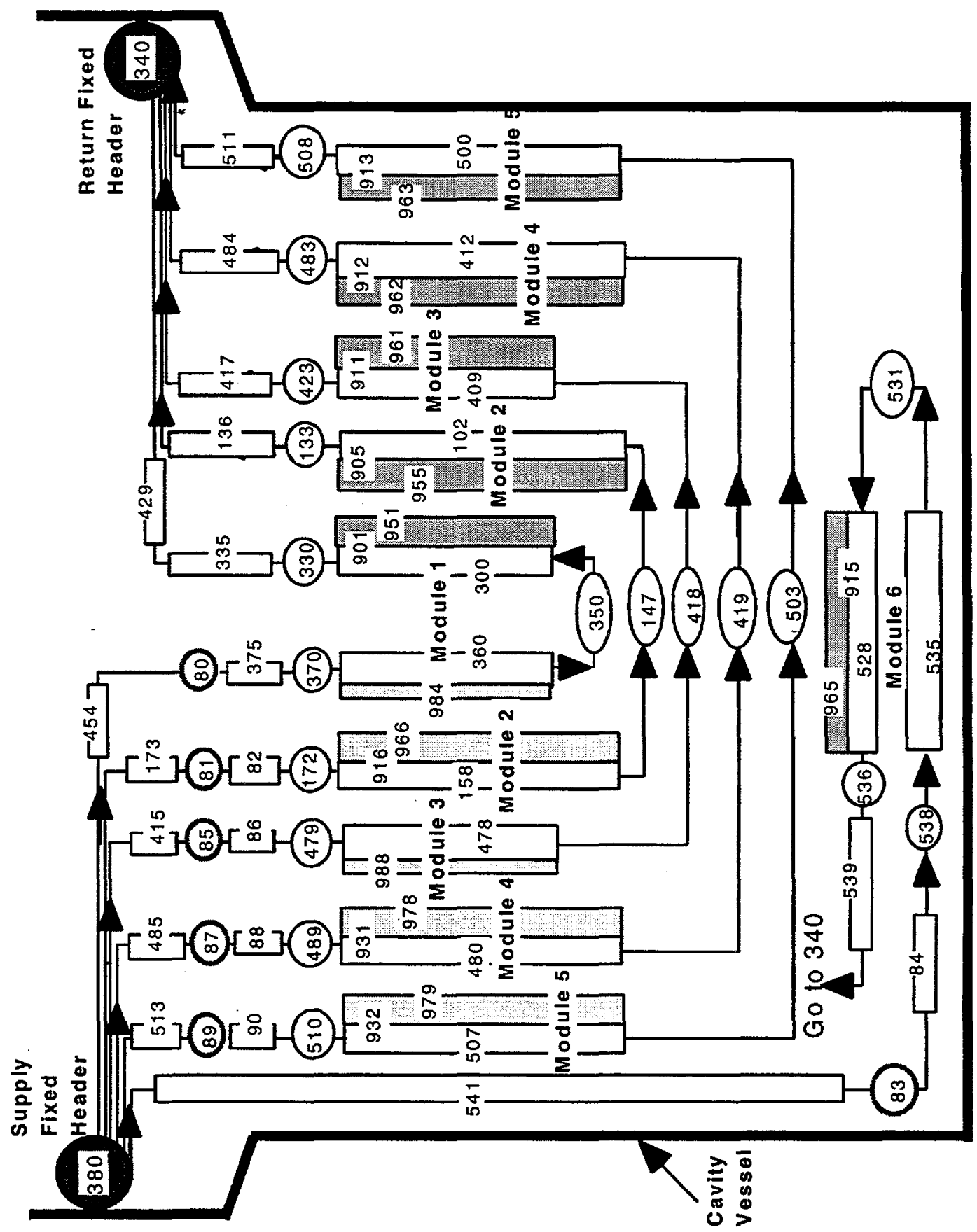

Figure A-1 6 blanket module layout for safety analysis. 


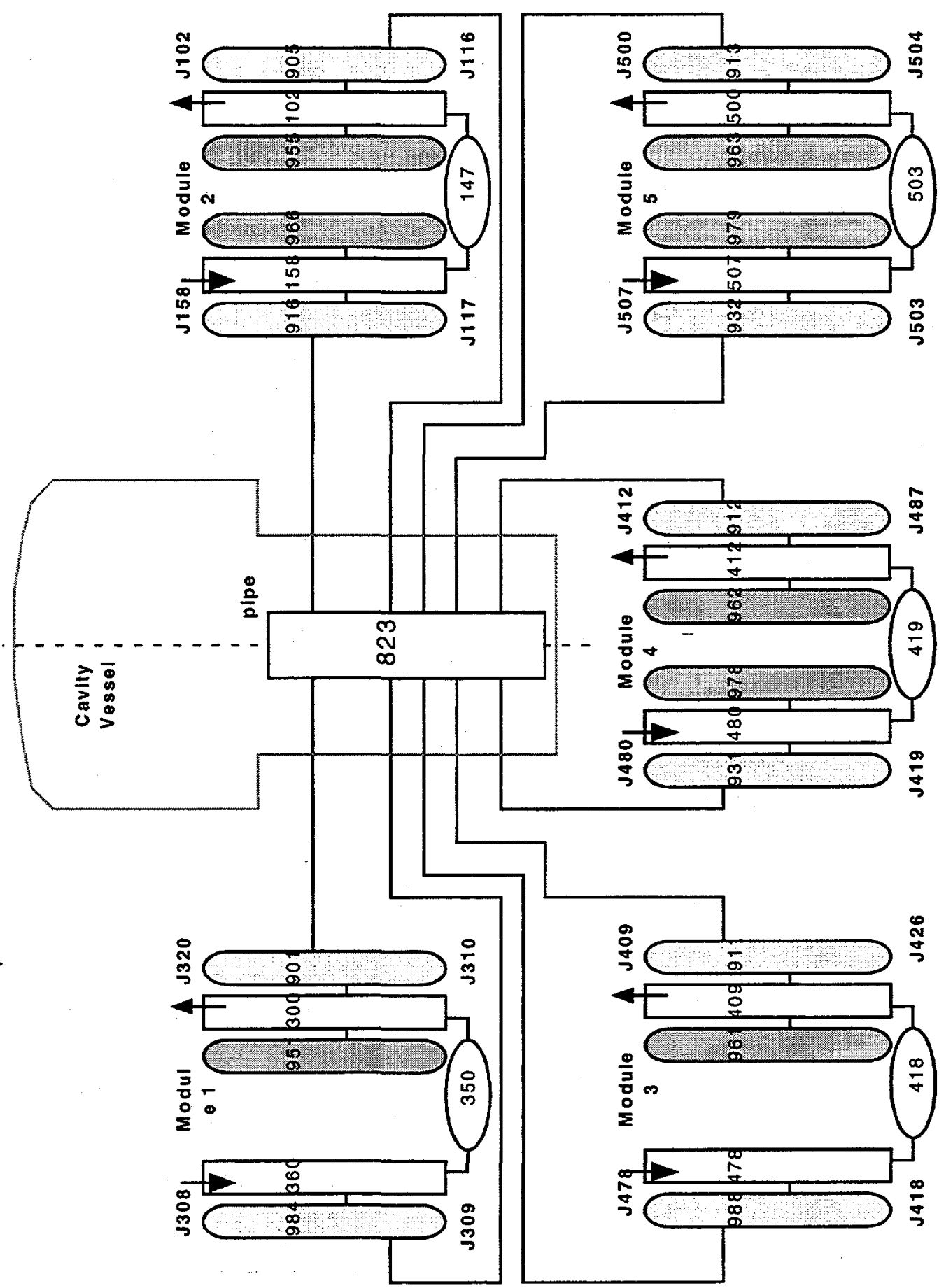

Figure A-2 TRAC component layout for the cavity vessel and blanket module heat structures. 


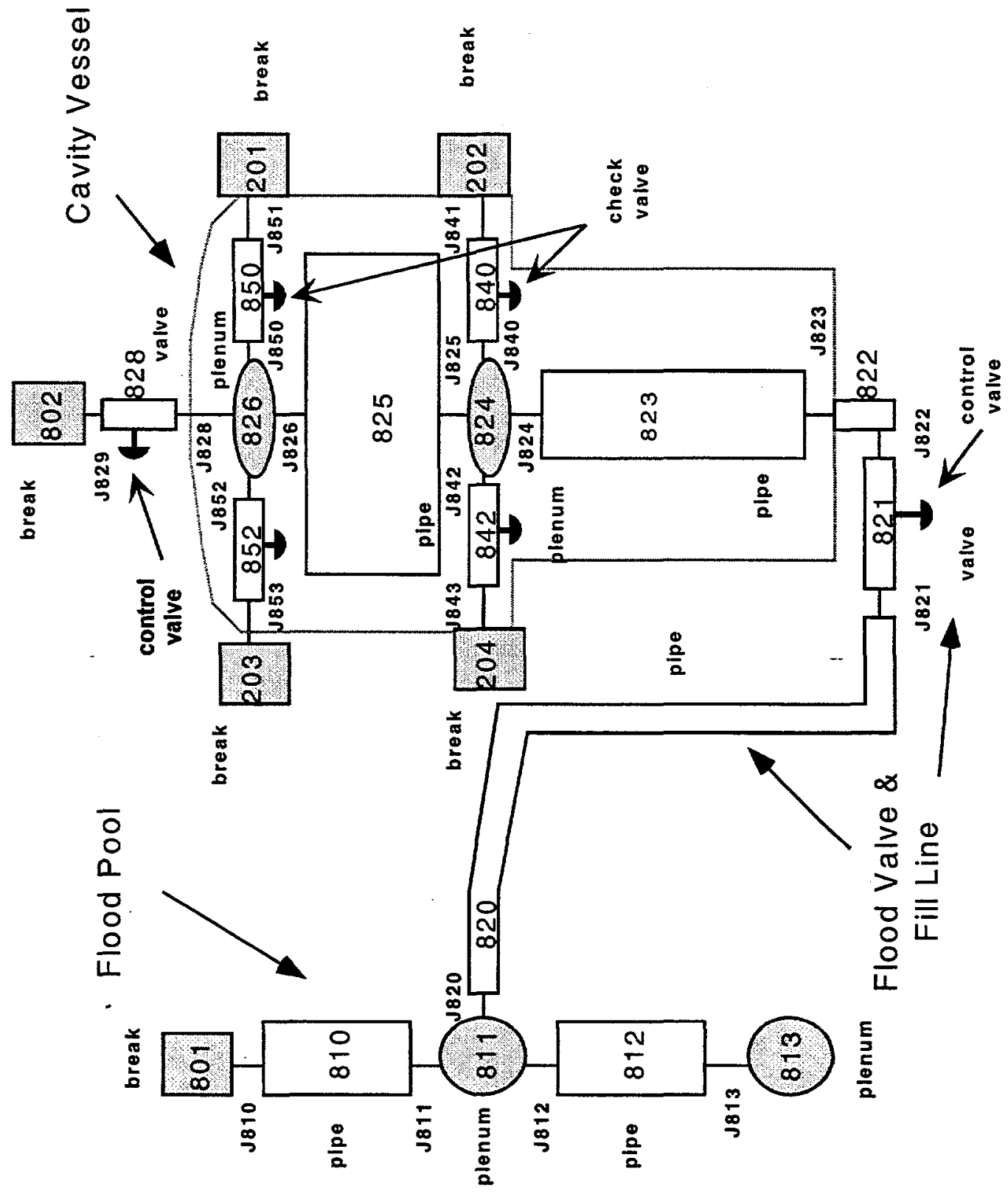

Figure A-3 TRAC component layout for the cavity vessel and cavity flood system. 


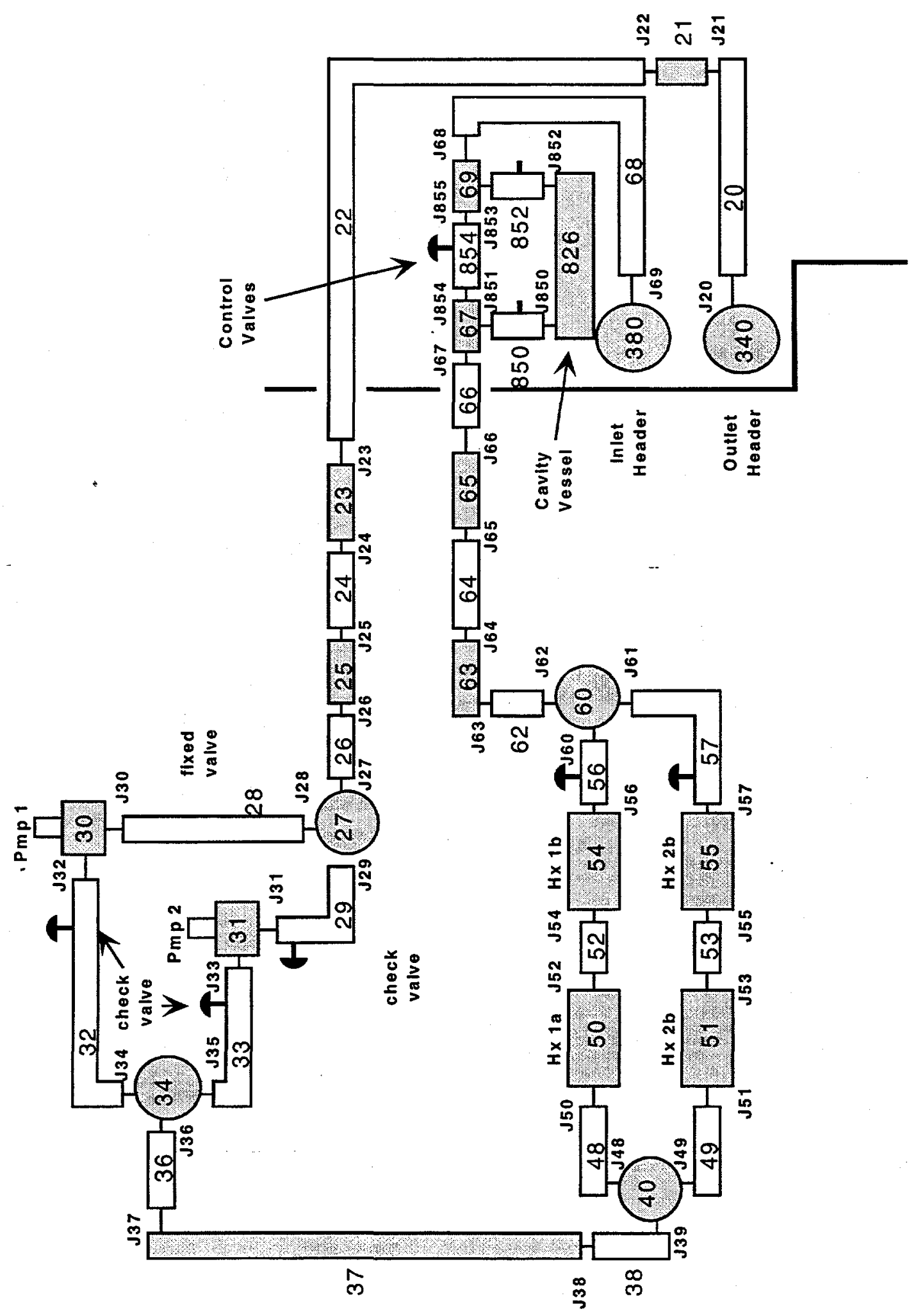

Figure A-4 TRAC component layout for blanket primary HR coolant loop. 
Report:

Section:

Date:

Page:

$\begin{array}{r}\text { WSRC-TR-98-0058 } \\ \text { Appendix A } \\ 07 / 13 / 98 \\ 10 \text { of } 12 \\ \hline\end{array}$

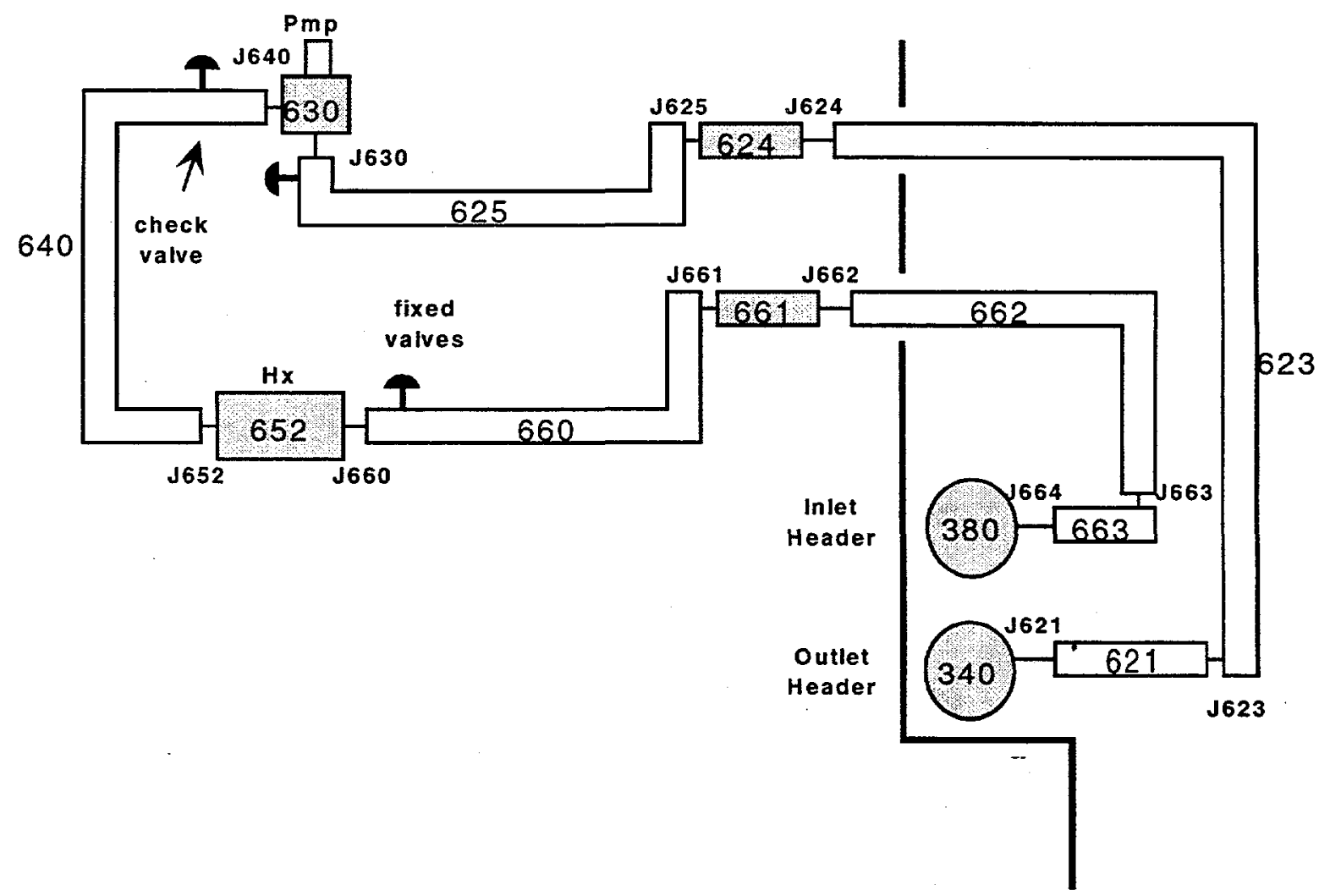

Figure A-5 TRAC component layout for blanket primary RHR coolant loop. 


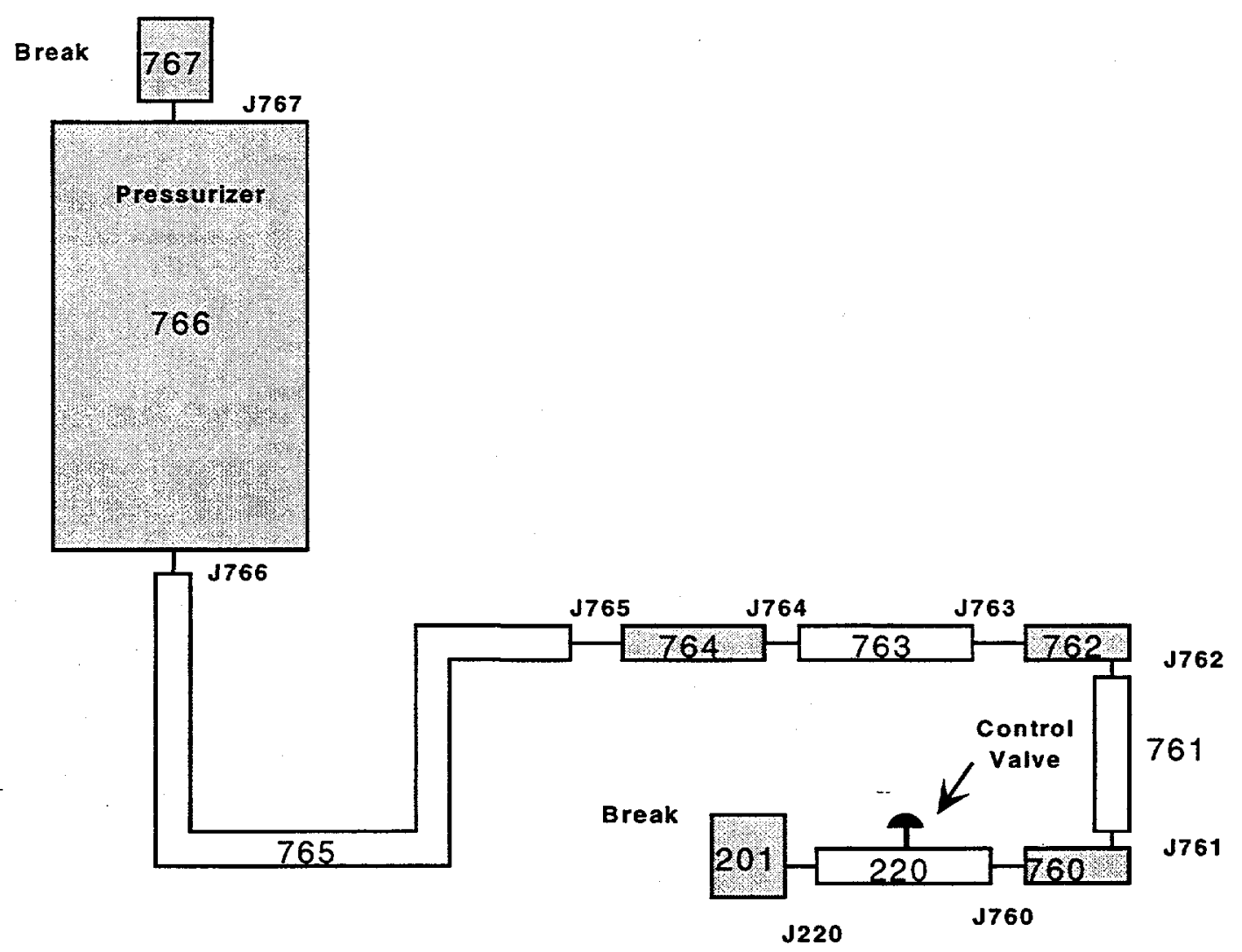

Figure A-6 TRAC component layout for blanket primary pressurizer and surge line. 


\section{Appendix B: LOFA (Case 1) TRAC Results}

\section{Appendix B1 LOFA (Case 1) TRAC Plenum Component Figures}

The following figures are from a TRAC simulation for Case 1 of a LOFA (with beam shutdown and active RHR):

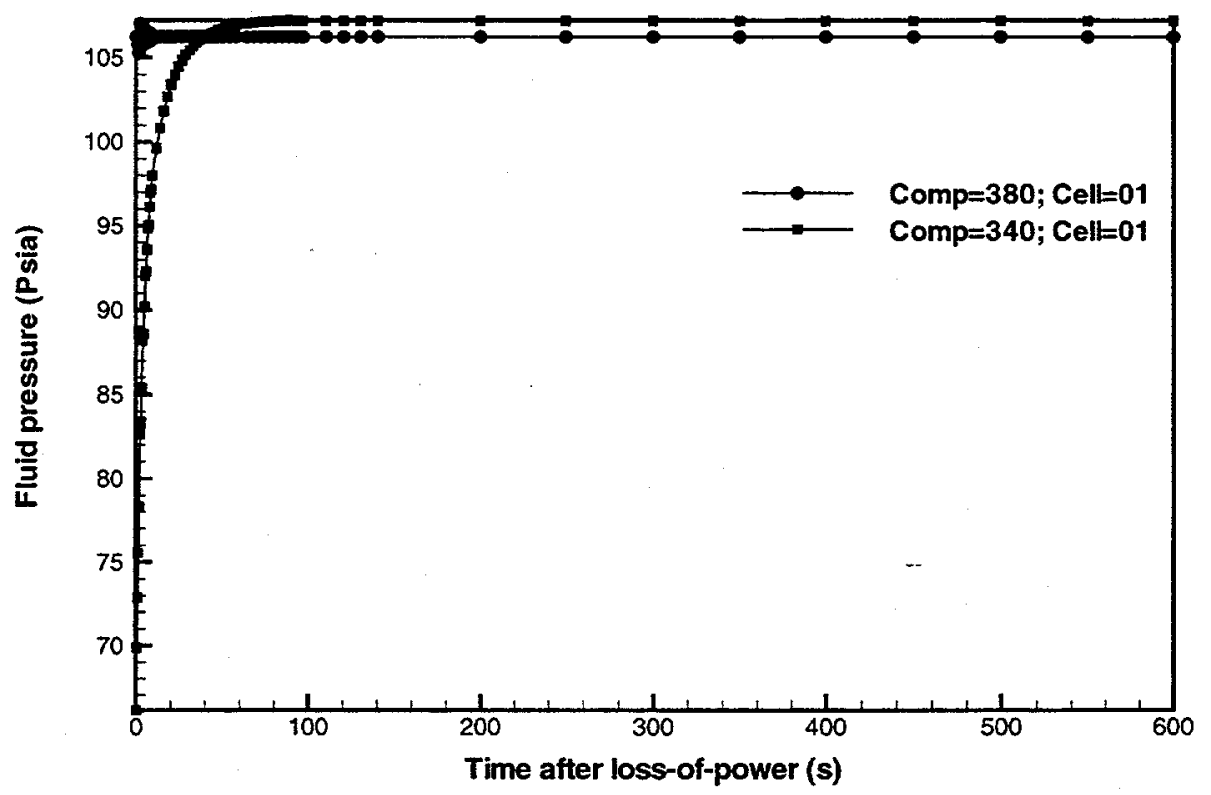

Figure B-1a Fixed header fluid pressures for a LOFA (Case 1: with beam shutdown and active RHR). 


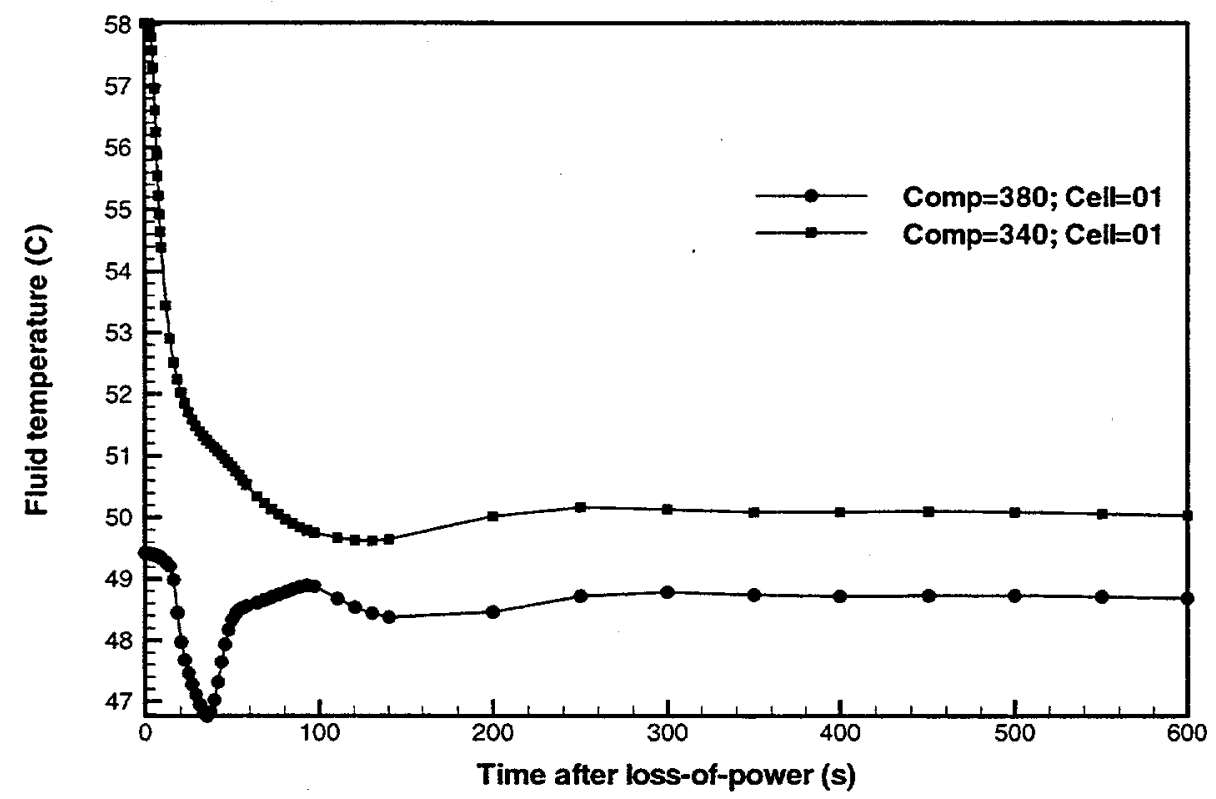

Figure B-1b Fixed header fluid temperatures for a LOFA (Case 1: with beam shutdown and active RHR).

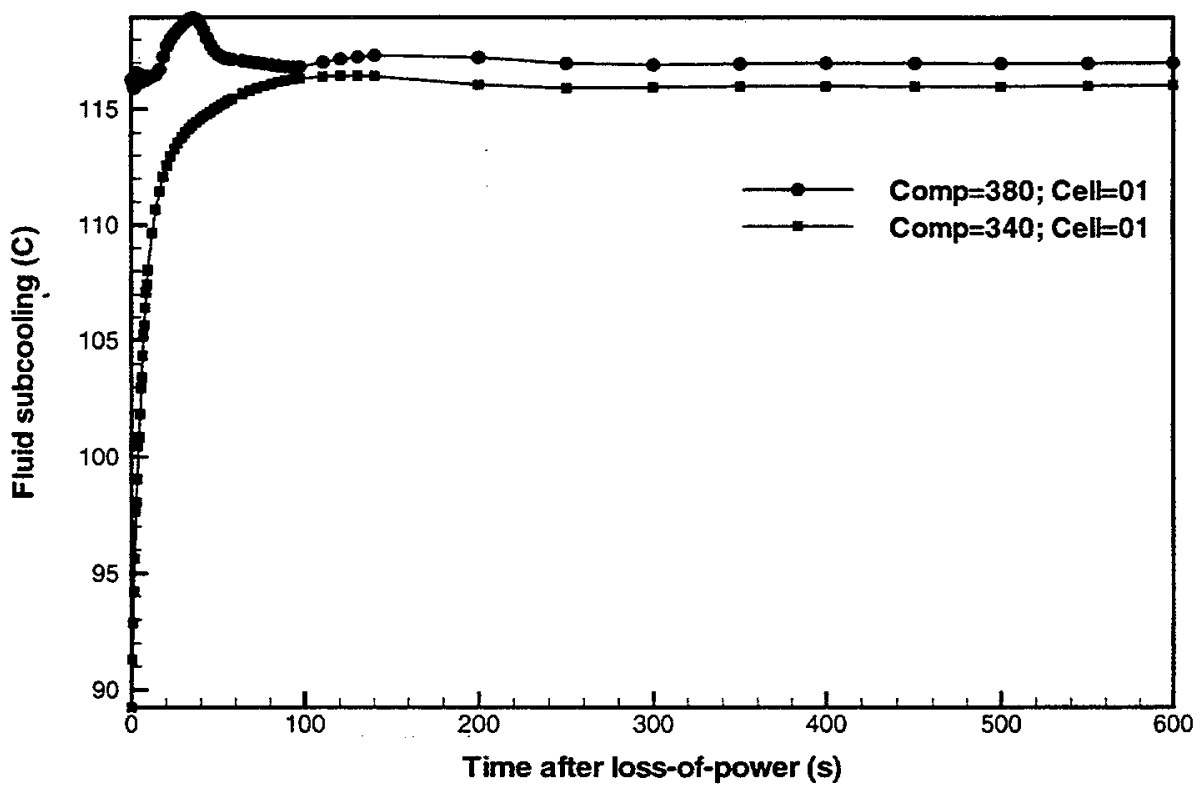

Figure B-1c Fixed header fluid subcoolings for a LOFA (Case 1: with beam shutdown and active $R H R$ ). 


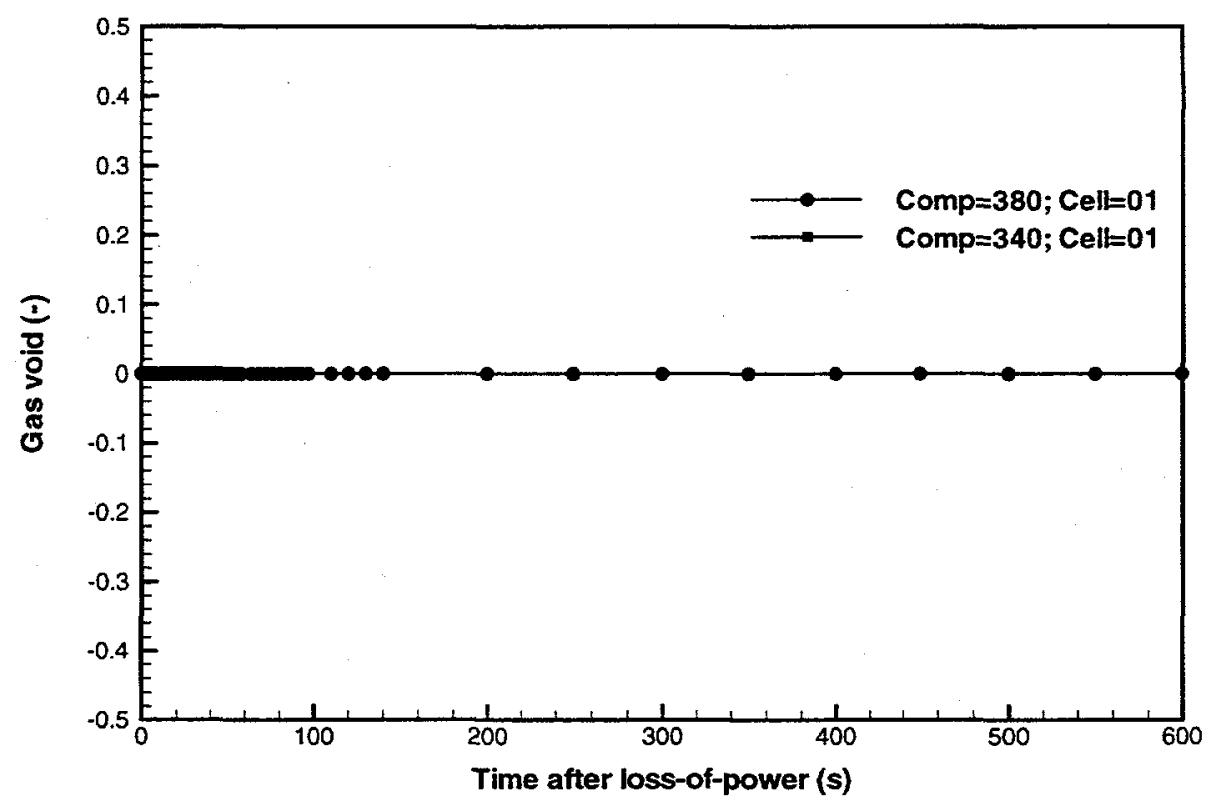

Figure B-1d Fixed header void fractions for a LOFA (Case 1:-" with beam shutdown and active RHR).

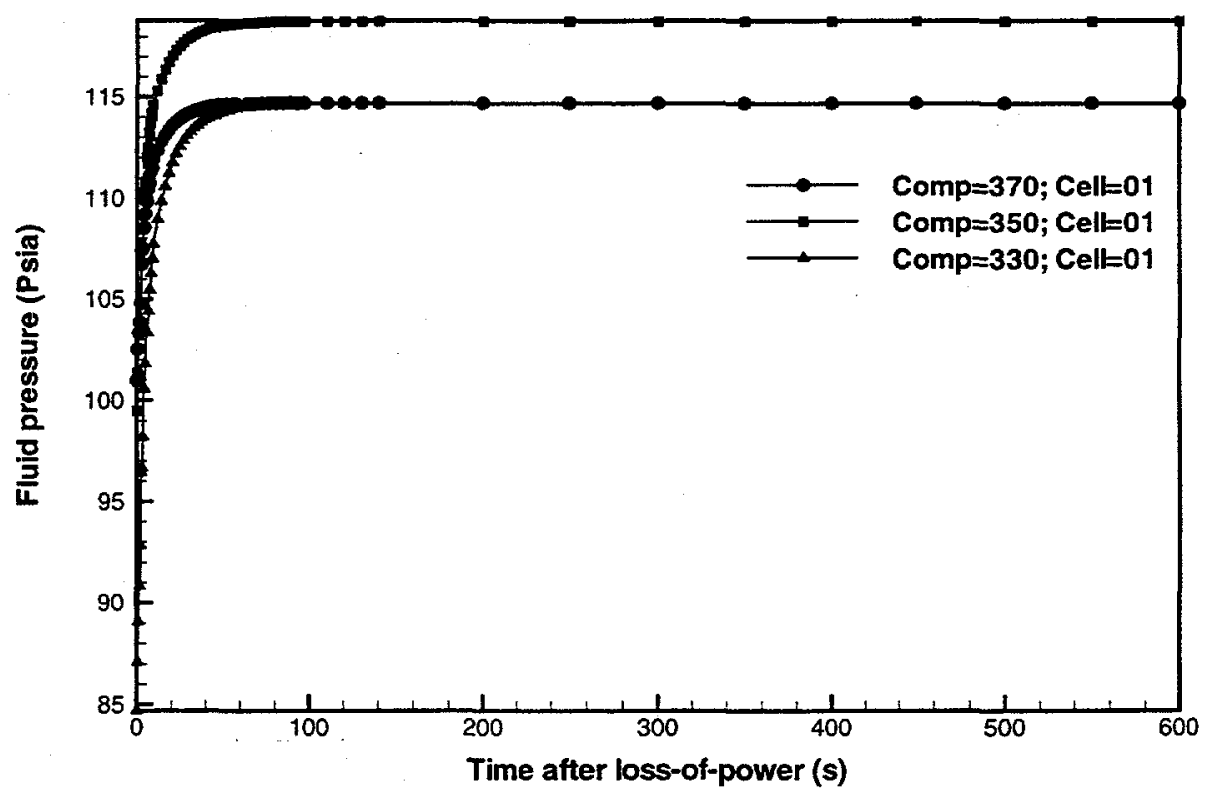

Figure B-2a Module 1 plenum fluid pressures for a LOFA (Case 1: with beam shutdown and active RHR). 


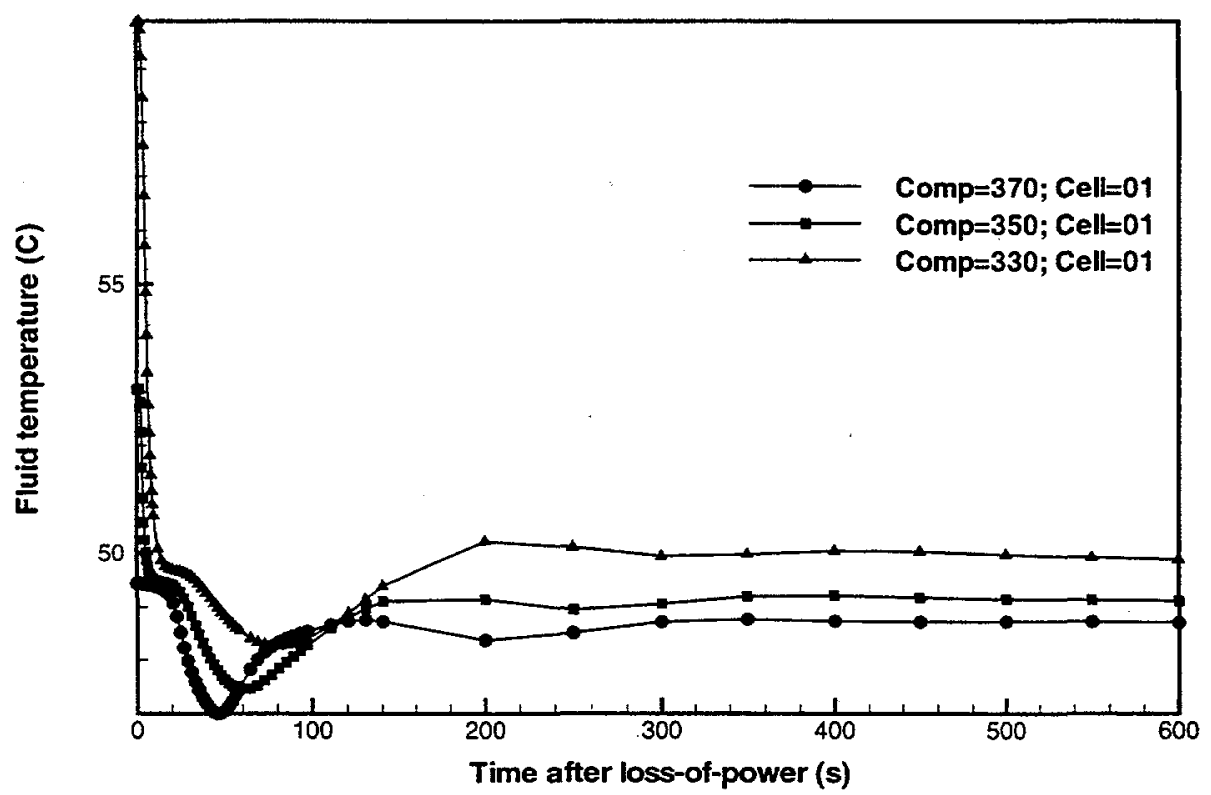

Figure $\mathrm{B}-2 \mathrm{~b}$ Module 1 plenum fluid temperatures for a LOFA (Case 1: with beam shutdown and active RHR).

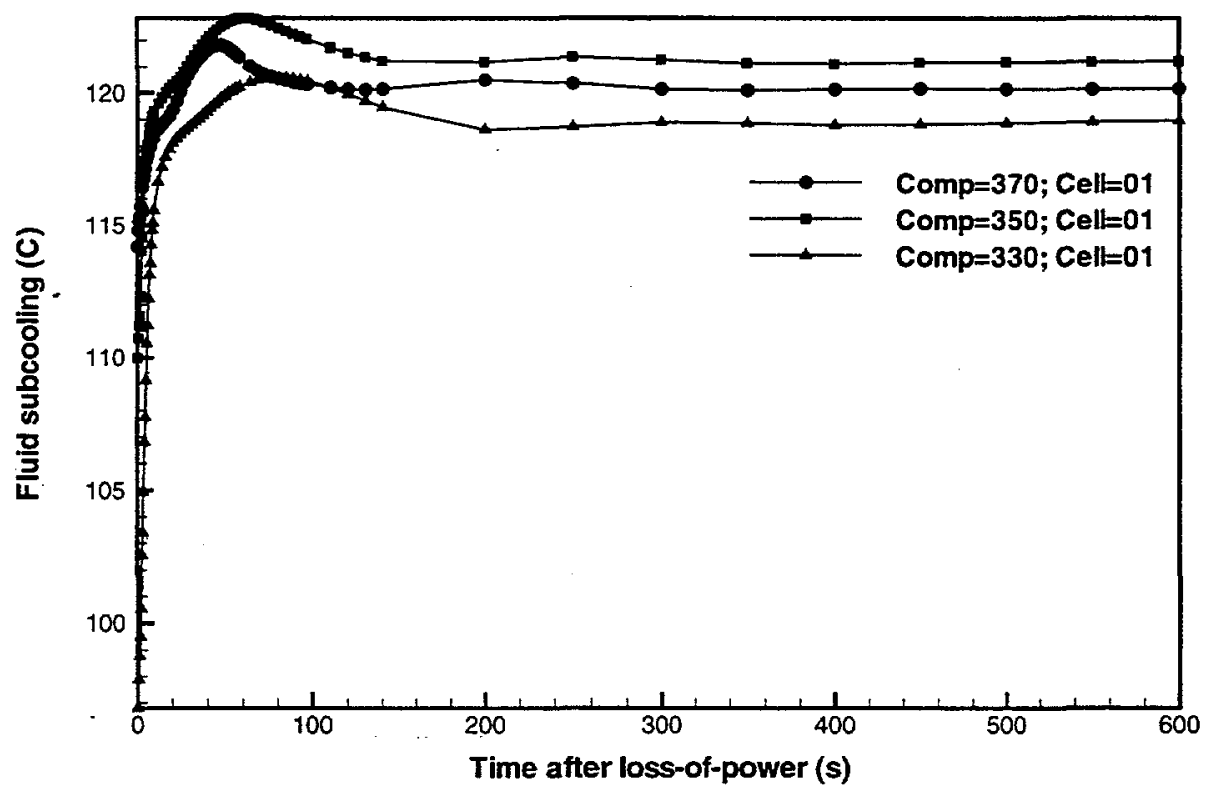

Figure B-2c Module 1 plenum fluid subcoolings for a LOFA (Case 1: with beam shutdown and active RHR). 


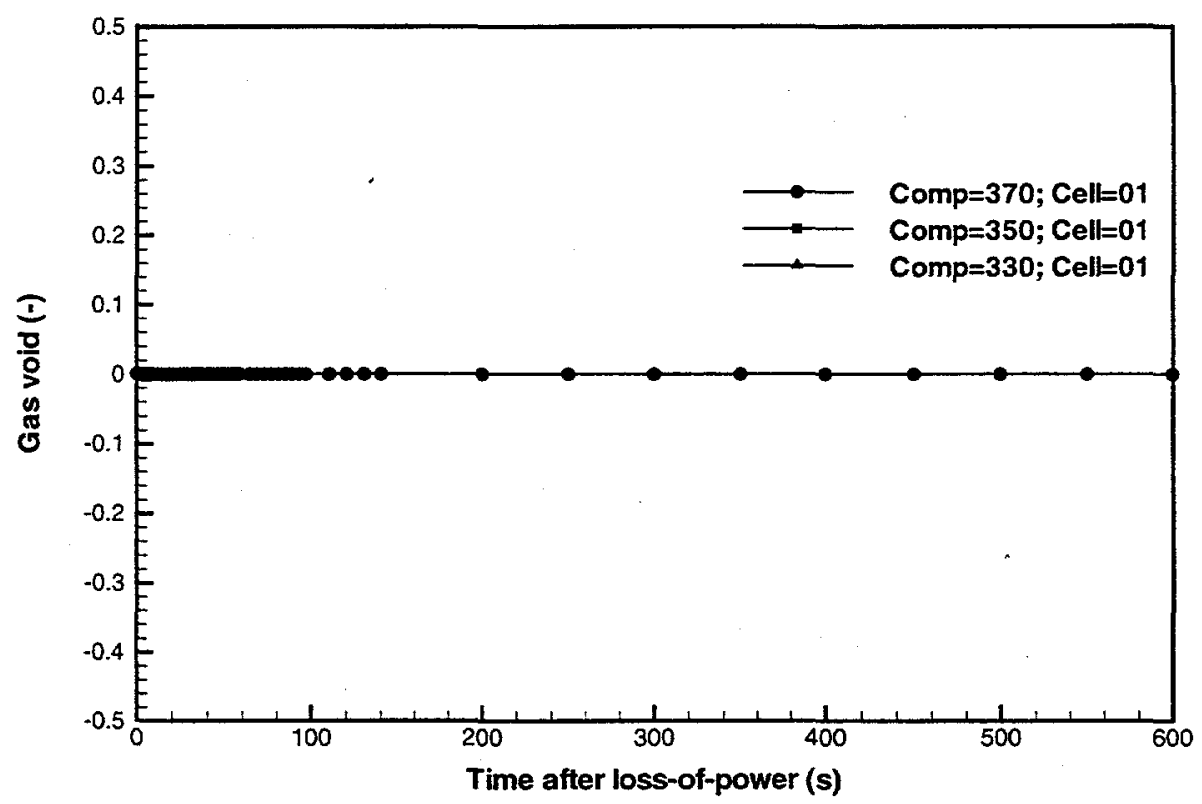

Figure B-2d Module 2 plenum void fractions for a LOFA (Case 1: with beam shutdown and active RHR).

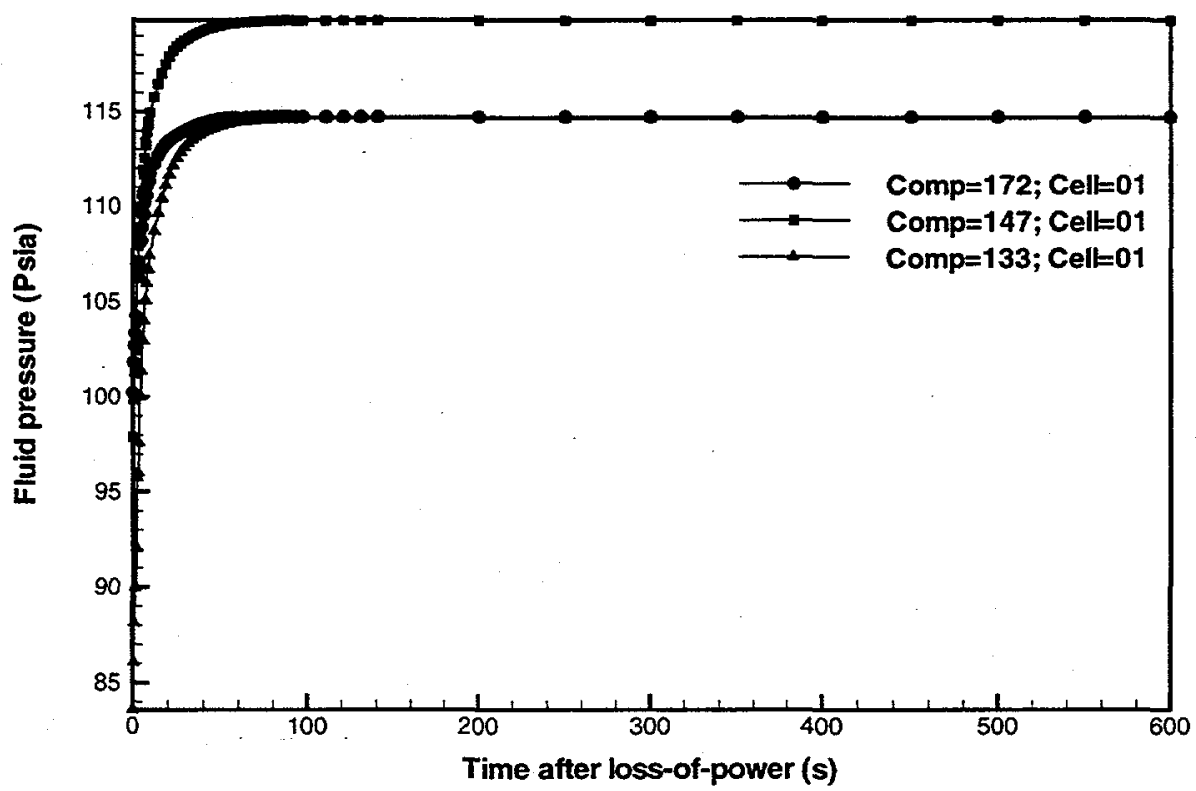

Figure B-3a Module 2 plenum fluid pressures for a LOFA (Case 1: with beam shutdown and active RHR). 


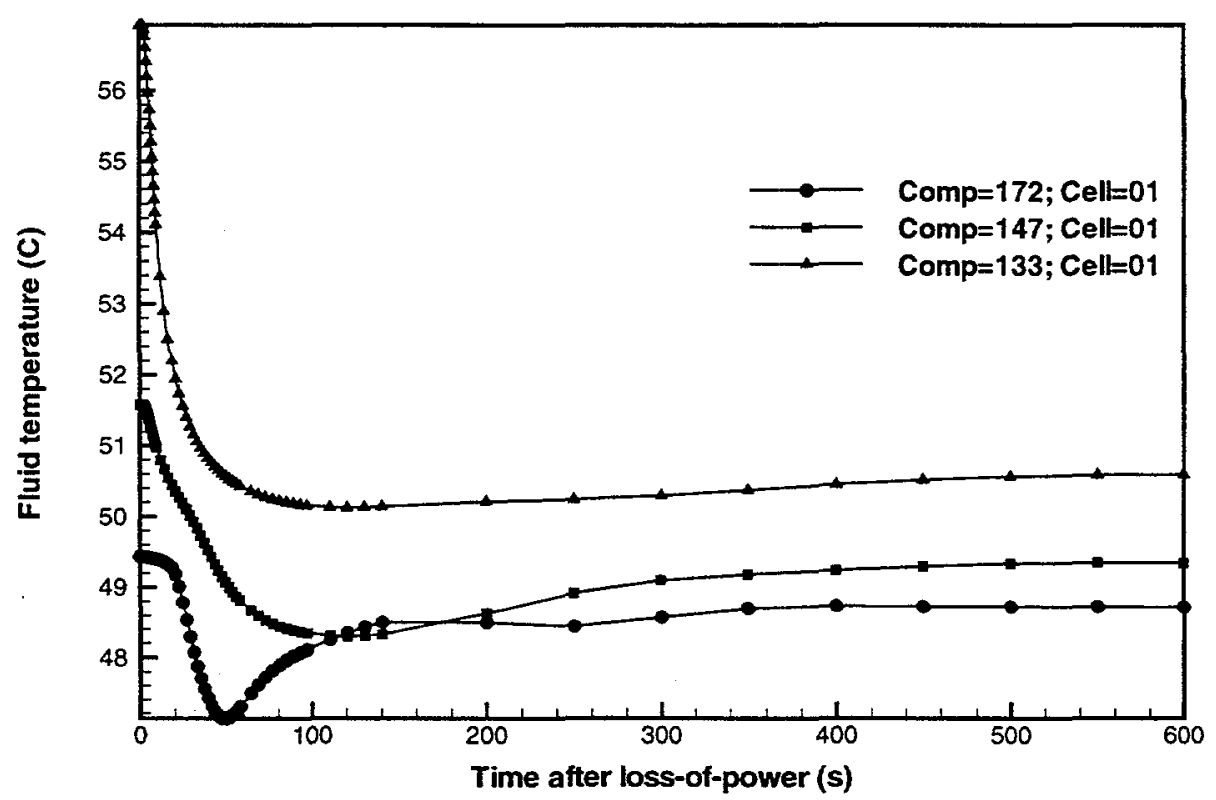

Figure B-3b Module 2 plenum fluid temperatures for a LOFA (Case 1: with beam shutdown and active RHR).

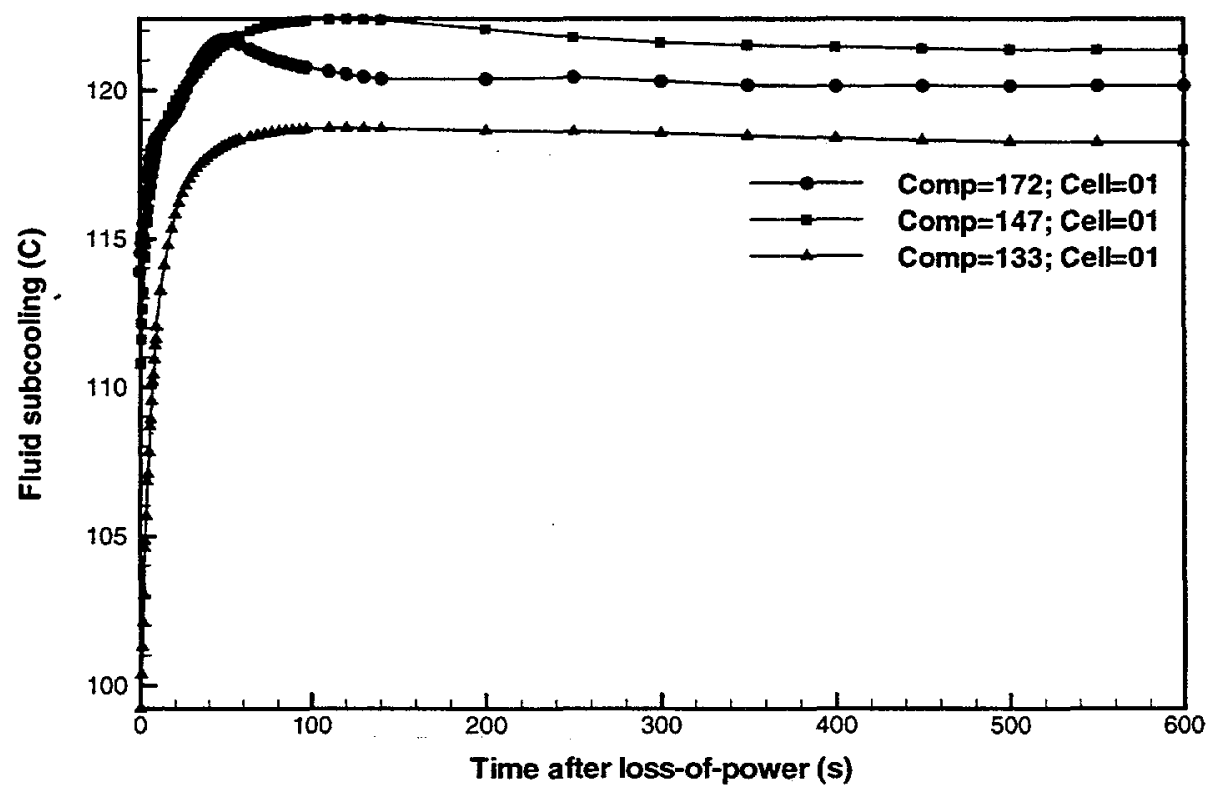

Figure B-3c Module 2 plenum fluid subcoolings for a LOFA (Case 1: with beam shutdown and active RHR). 


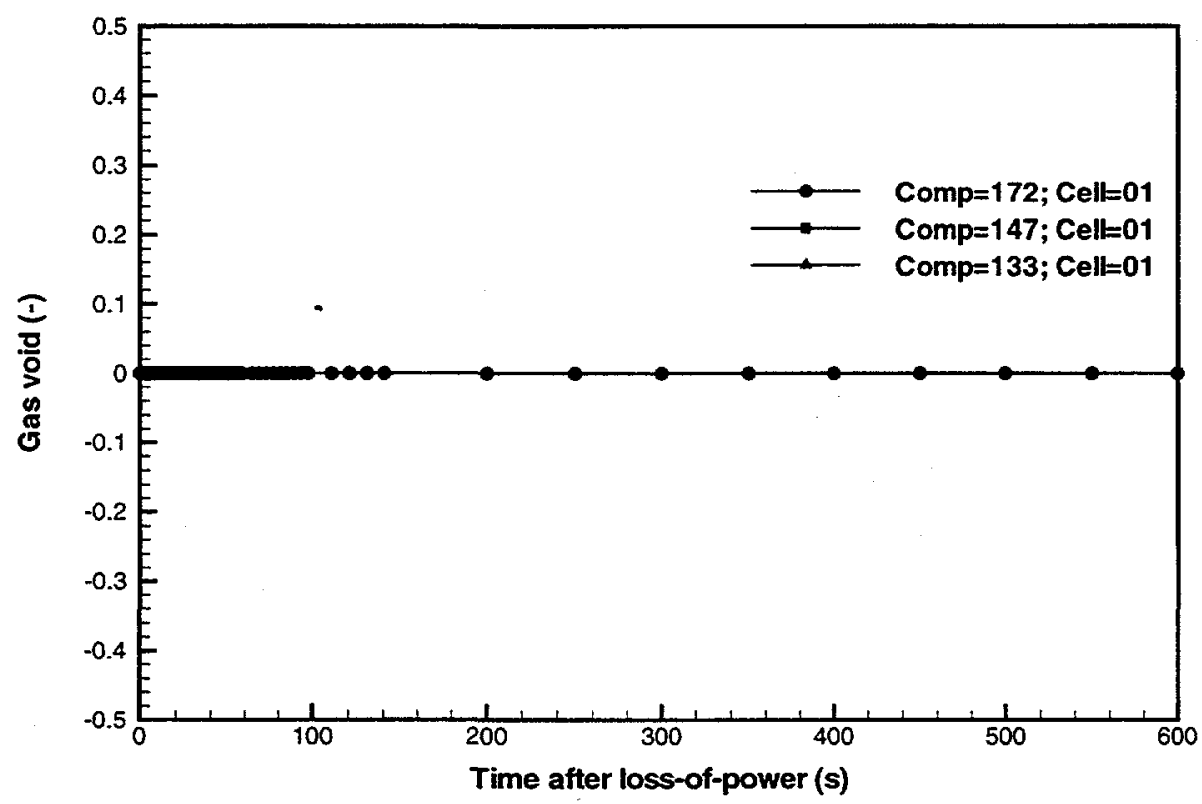

Figure B-3d Module 2 plenum void fractions for a LOFA (Case 1: with beam shutdown and active RHR).

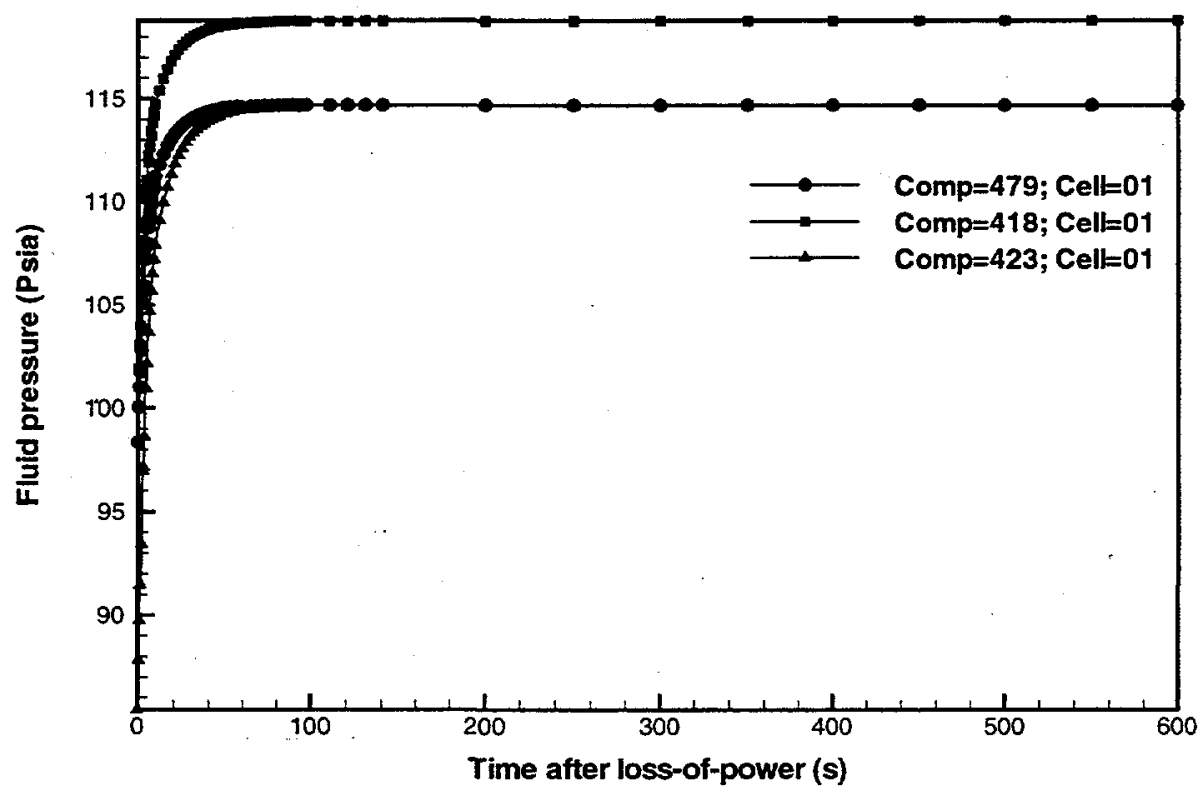

Figure B-4a Module 3 plenum fluid pressures for a LOFA (Case 1: with beam shutdown and active RHR). 


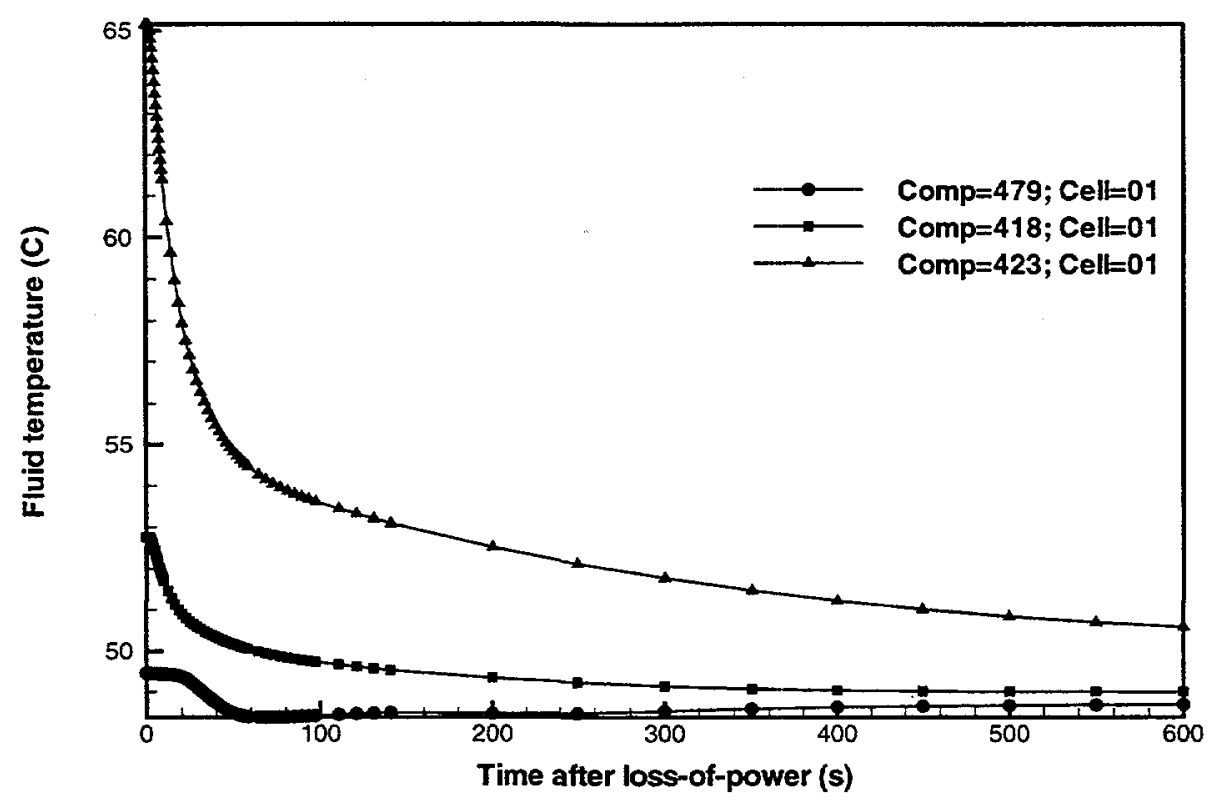

Figure B-4b Module 3 plenum fluid temperatures for a LOFA (Case 1: with beam shutdown and active RHR).

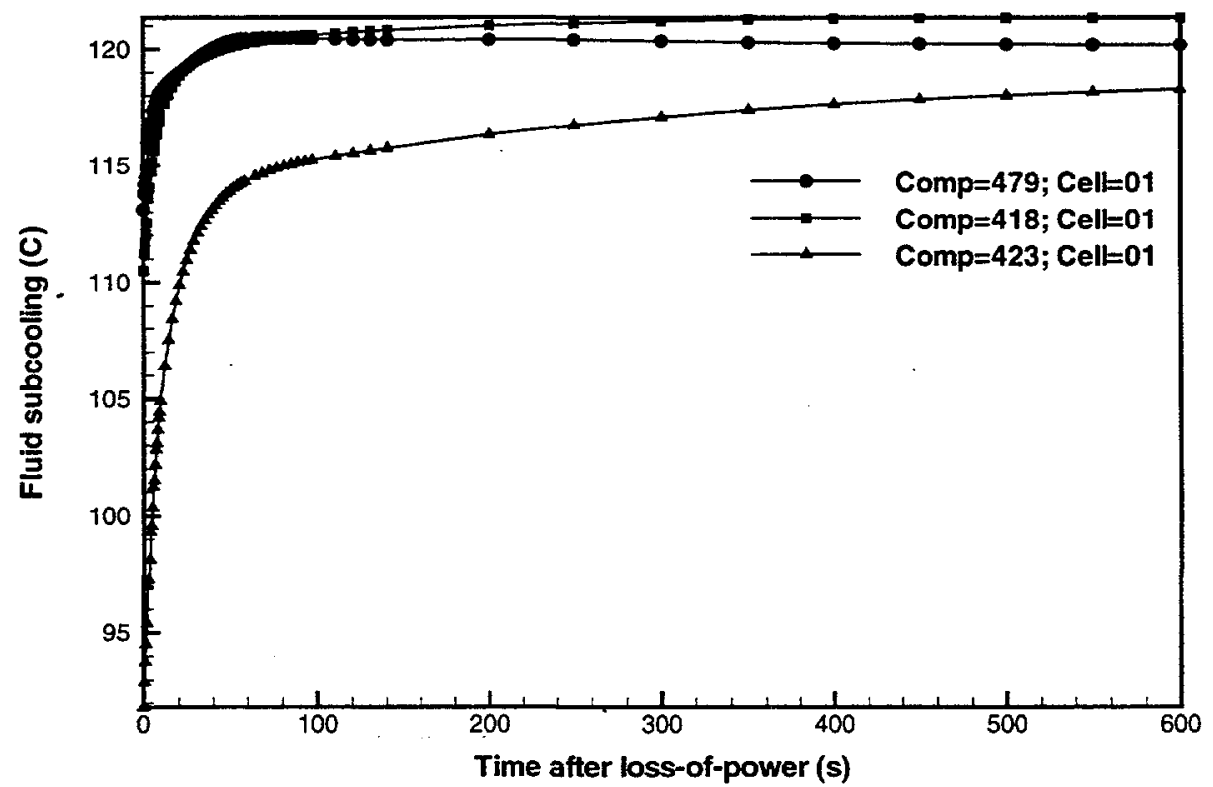

Figure B-4c Module 3 plenum fluid subcoolings for a LOFA (Case 1: with beam shutdown and active RHR). 


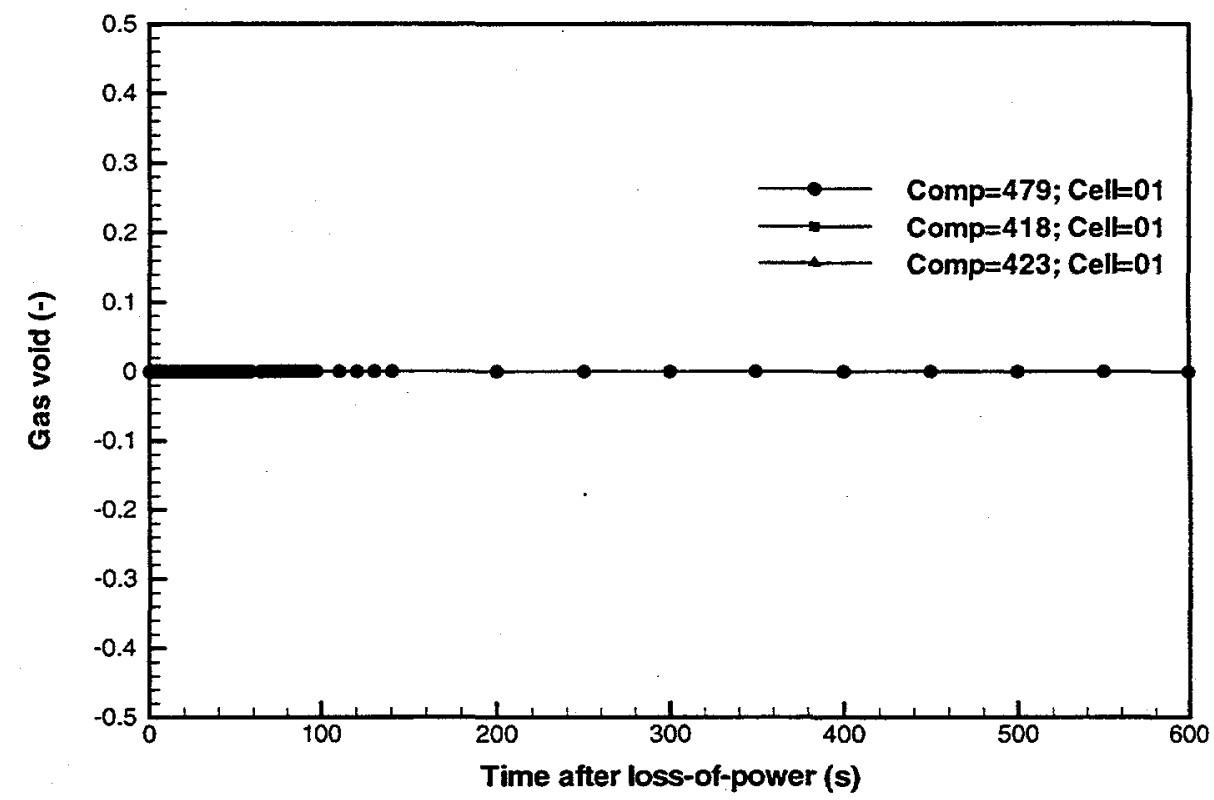

Figure B-4d Module 3 plenum void fractions for a LOFA (Casē 1: with beam shutdown and active RHR).

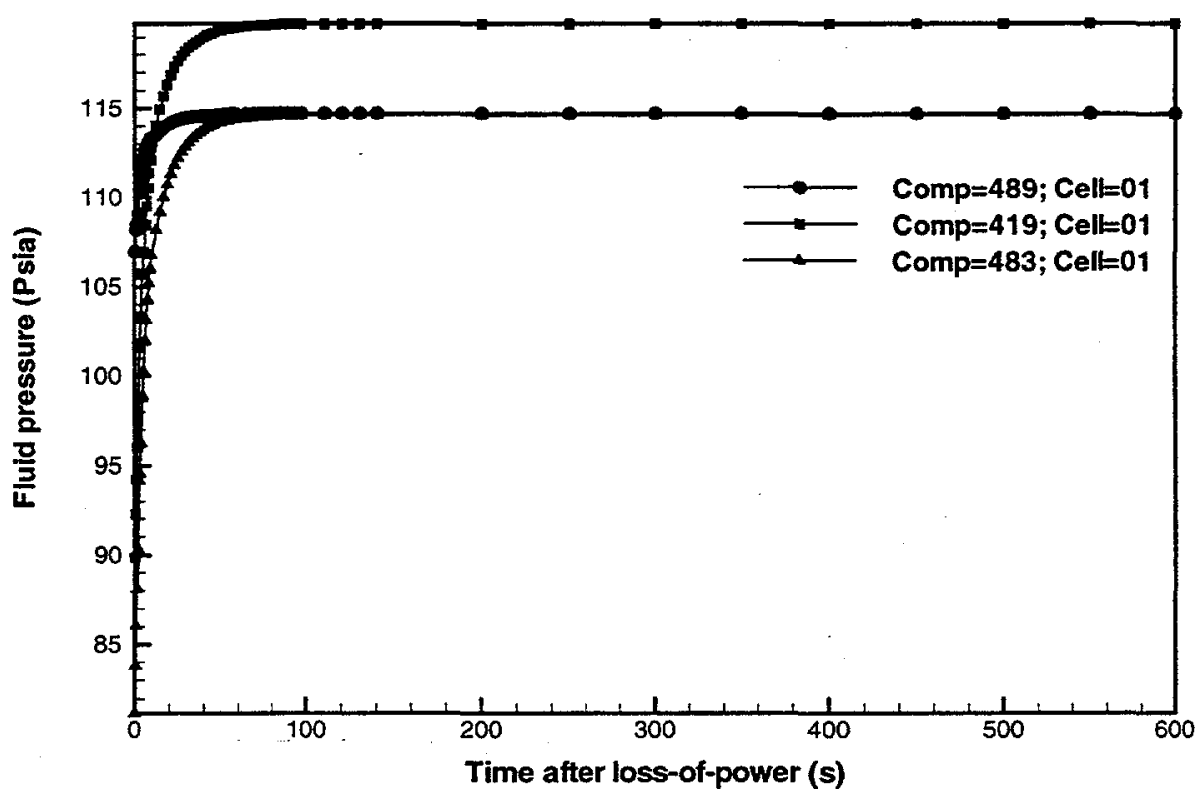

Figure B-5a Module 4 plenum fluid pressures for a LOFA (Case 1: with beam shutdown and active RHR). 


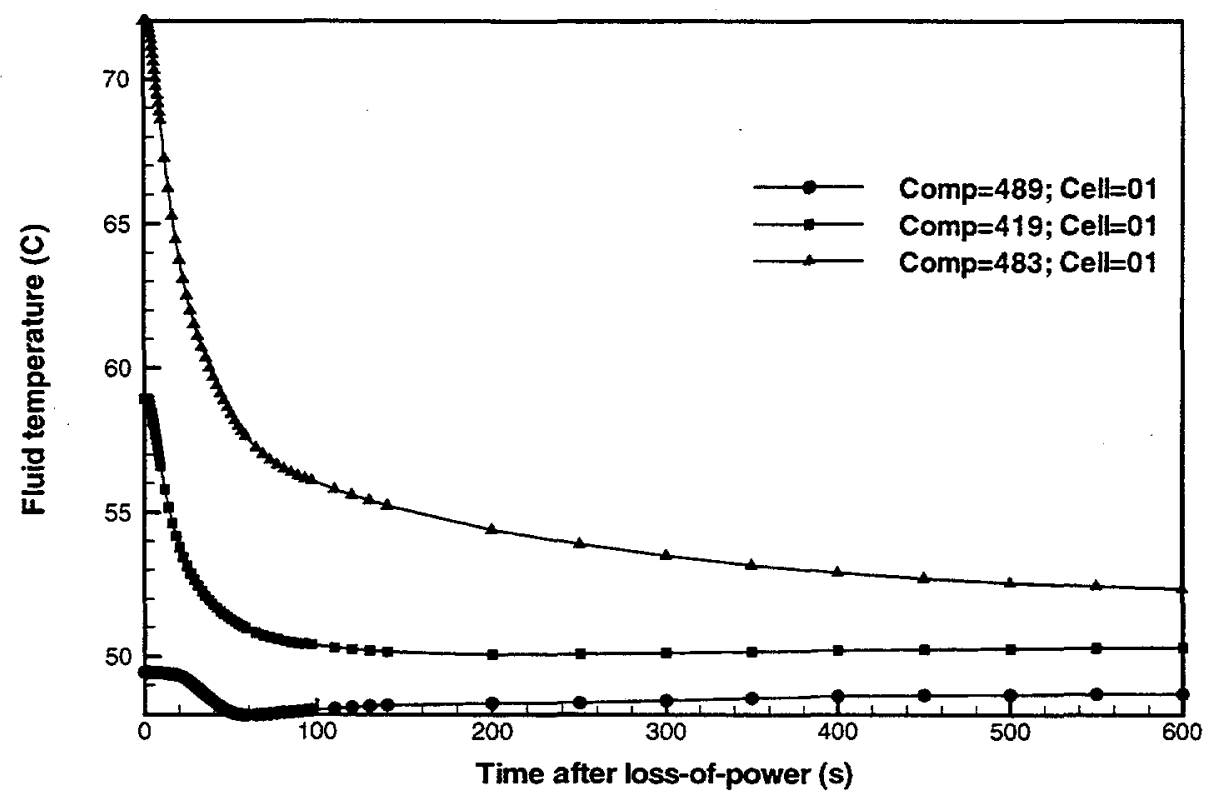

Figure B-5b Module 4 plenum fluid temperatures for a LOFA (Case 1: with beam shutdown and active RHR).

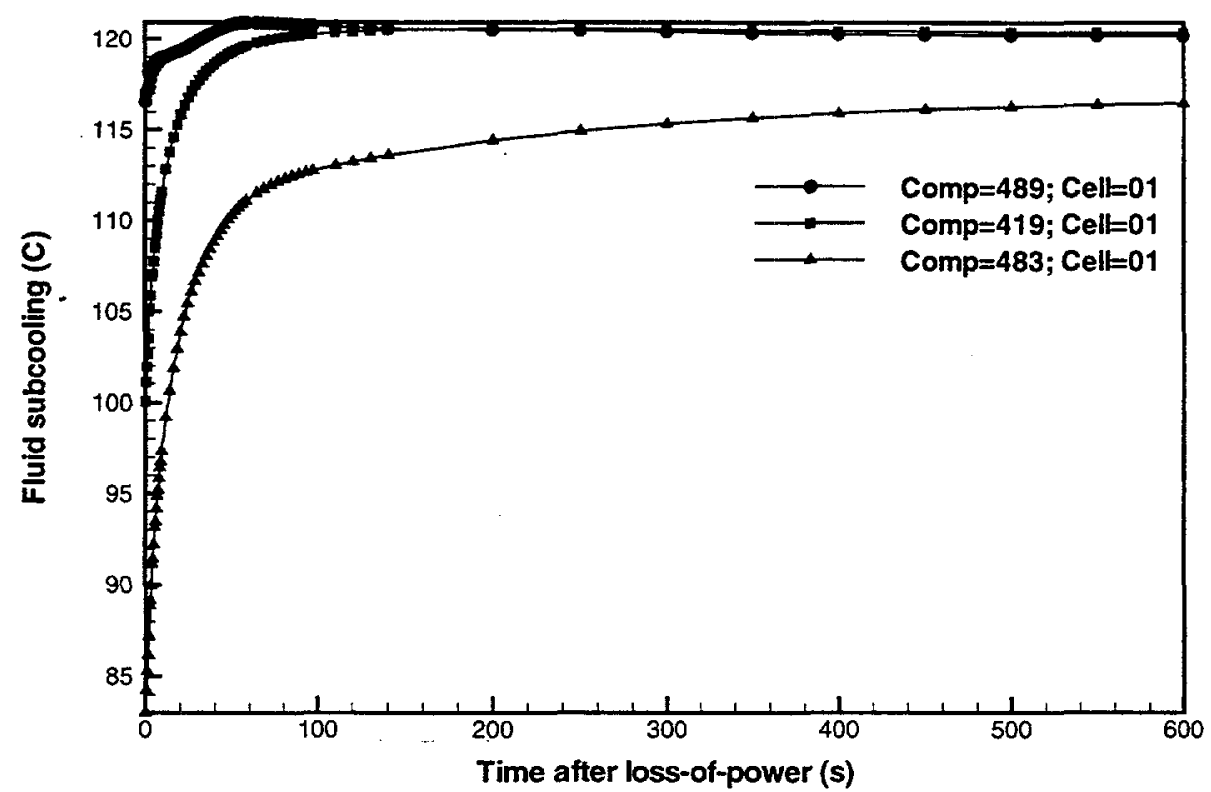

Figure B-5c Module 4 plenum fluid subcoolings for a LOFA (Case 1: with beam shutdown and active RHR). 


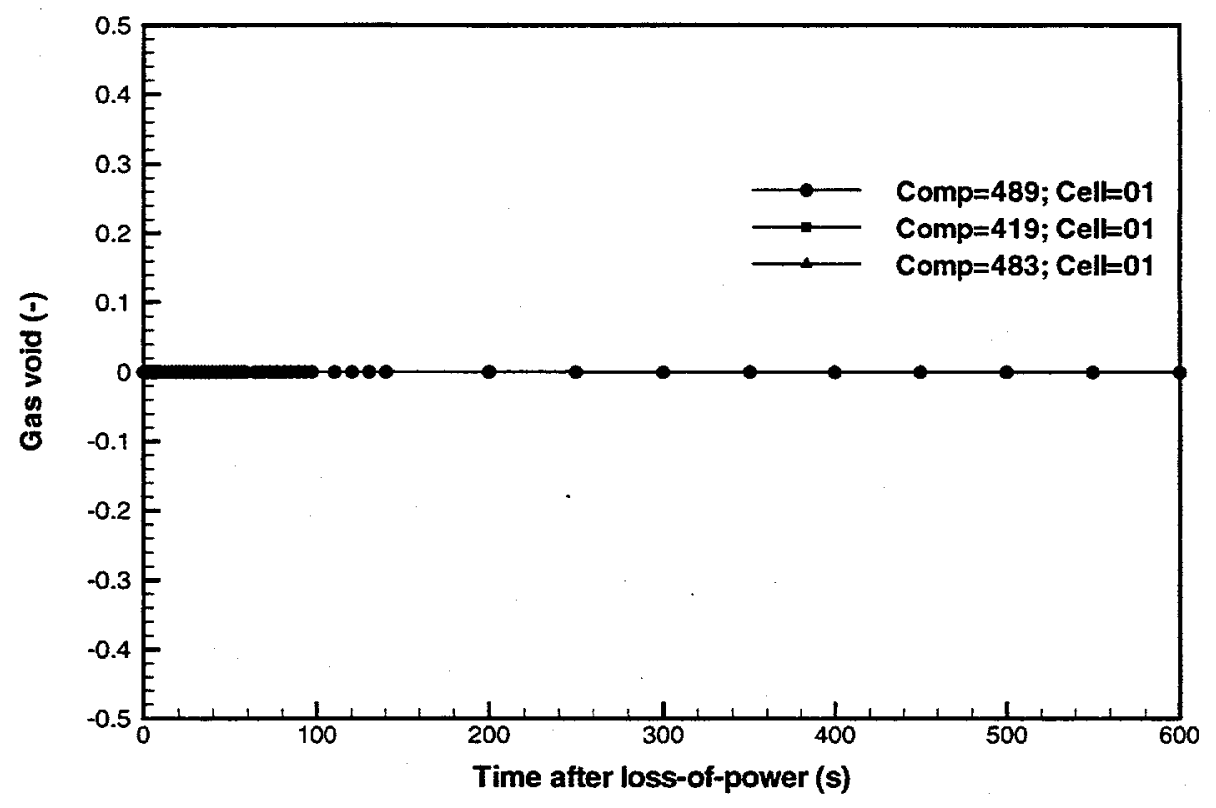

Figure B-5d Module 4 plenum void fractions for a LOFA (Casë 1: with beam shutdown and active RHR).

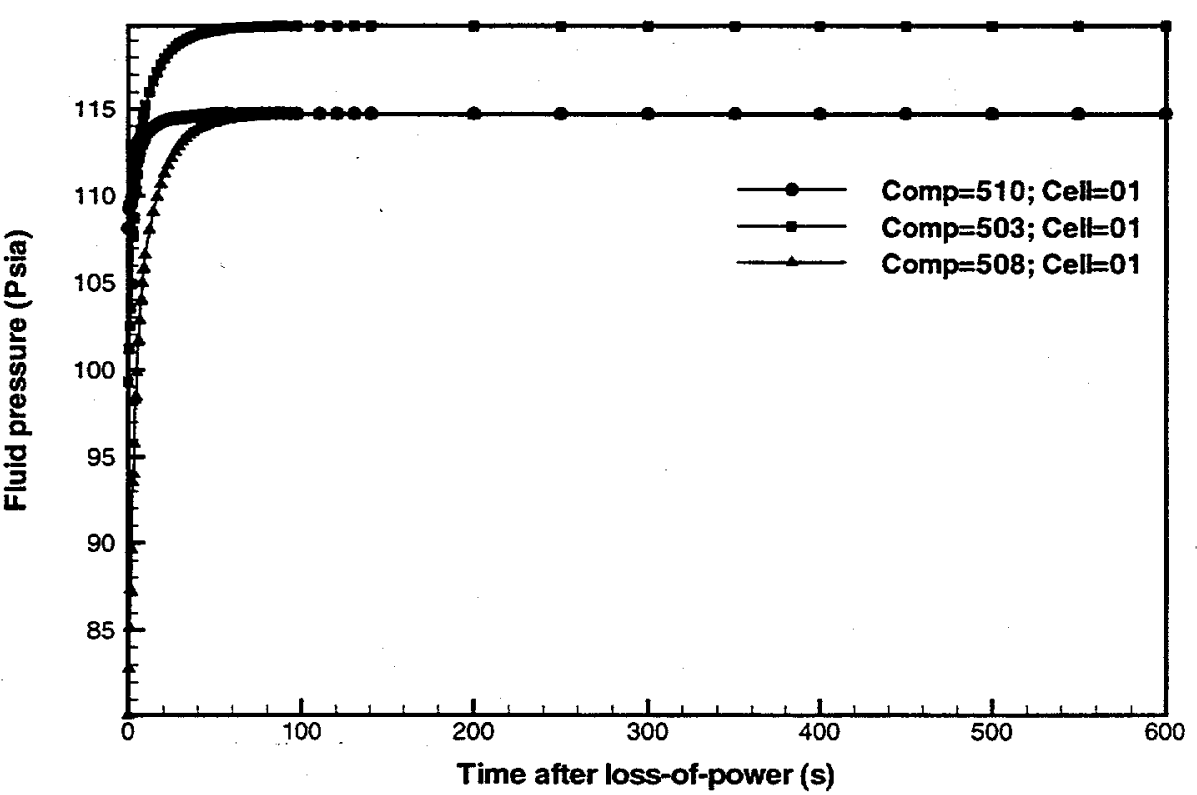

Figure B-6a Module 5 plenum fluid pressures for a LOFA (Case 1: with beam shutdown and active RHR). 


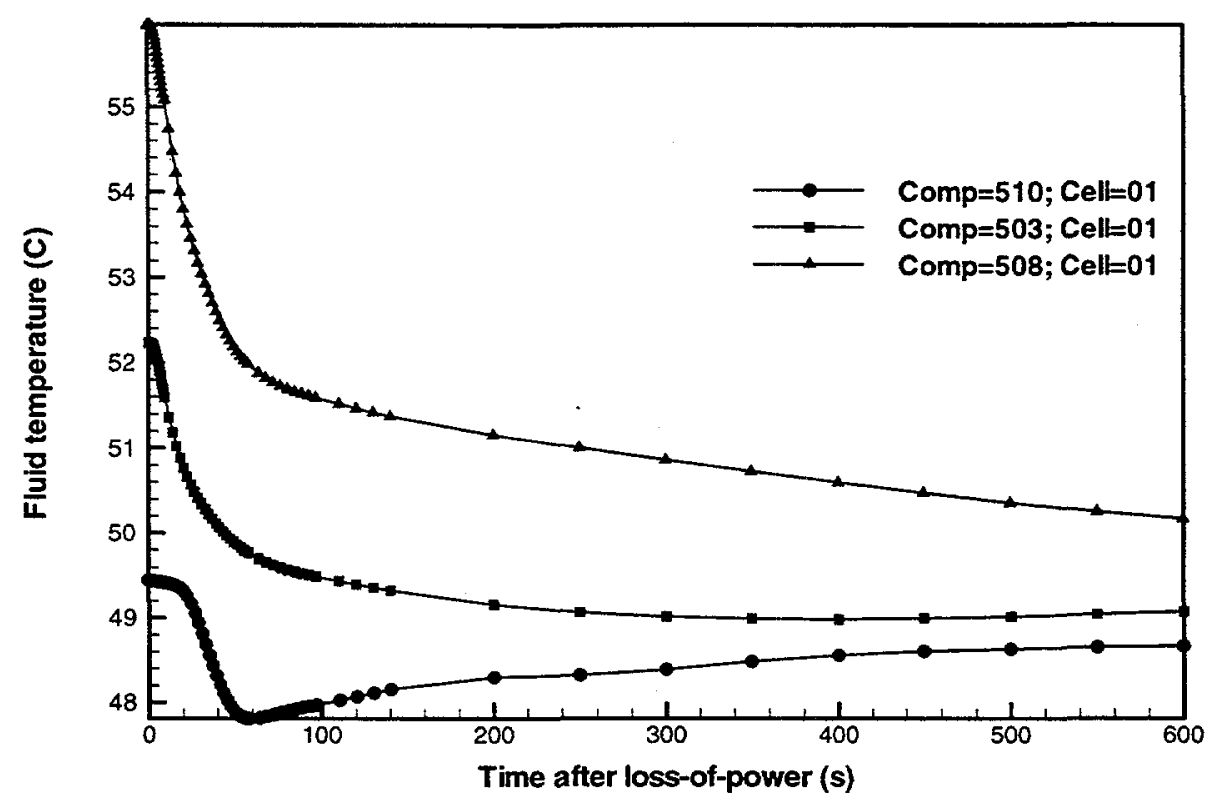

Figure B-6b Module 5 plenum fluid temperatures for a LOFA (Case 1: with beam shutdown and active RHR).

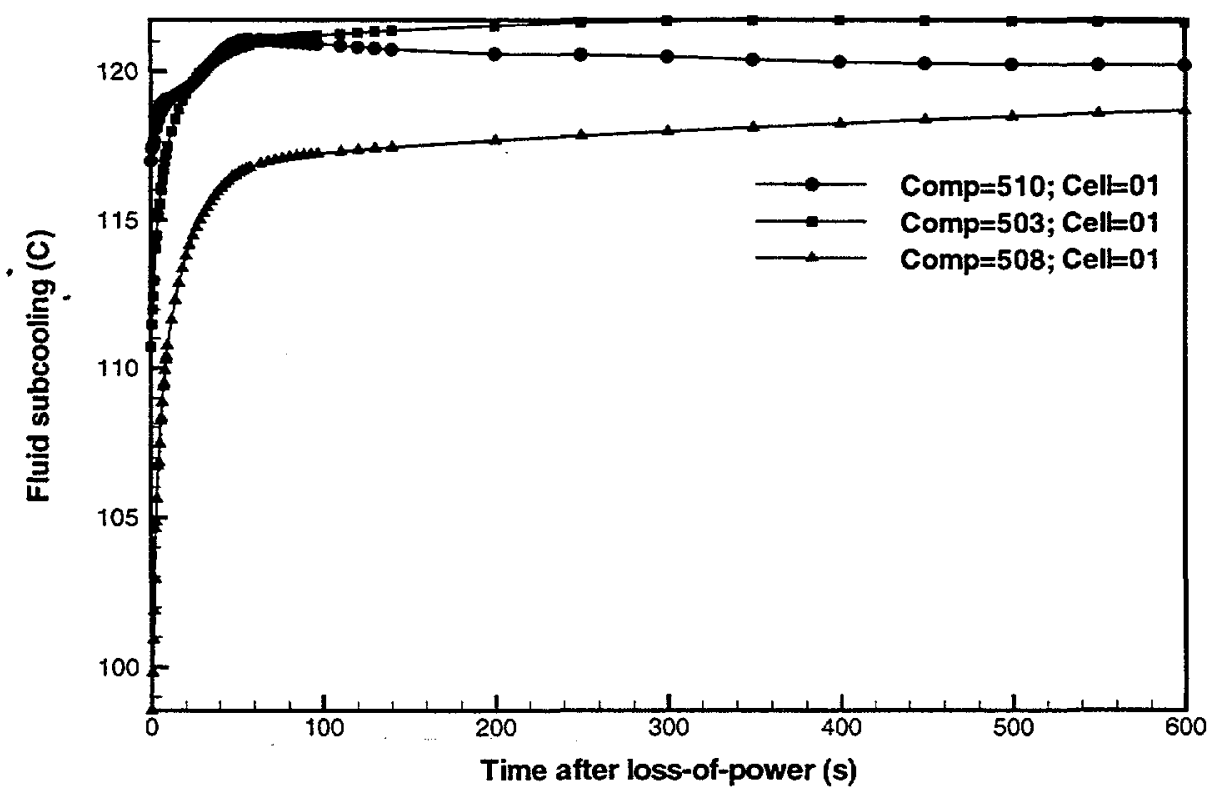

Figure B-6c Module 5 plenum fluid subcoolings for a LOFA (Case 1: with beam shutdown and active RHR). 


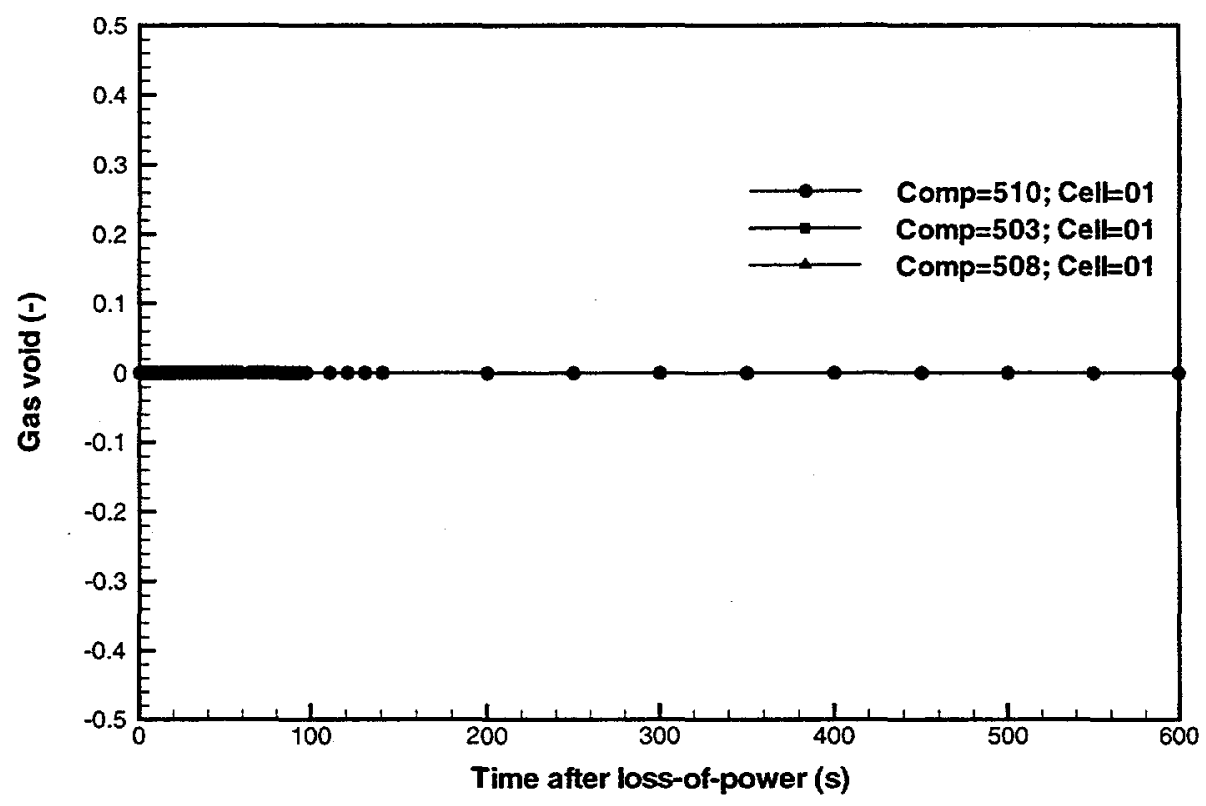

Figure B-6d Module 5 plenum void fractions for a LOFA (Case 1: with beam shutdown and active RHR).

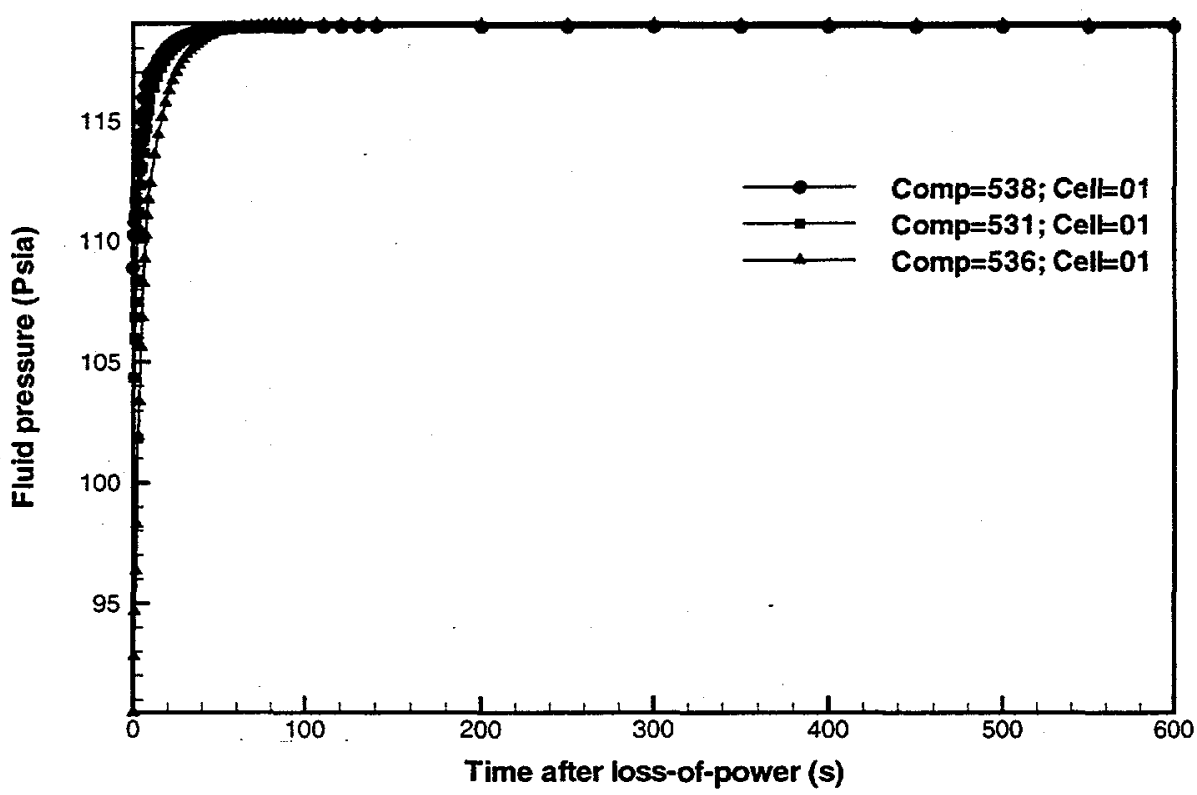

Figure B-7a Module 6 plenum fluid pressures for a LOFA (Case 1: with beam shutdown and active RHR). 


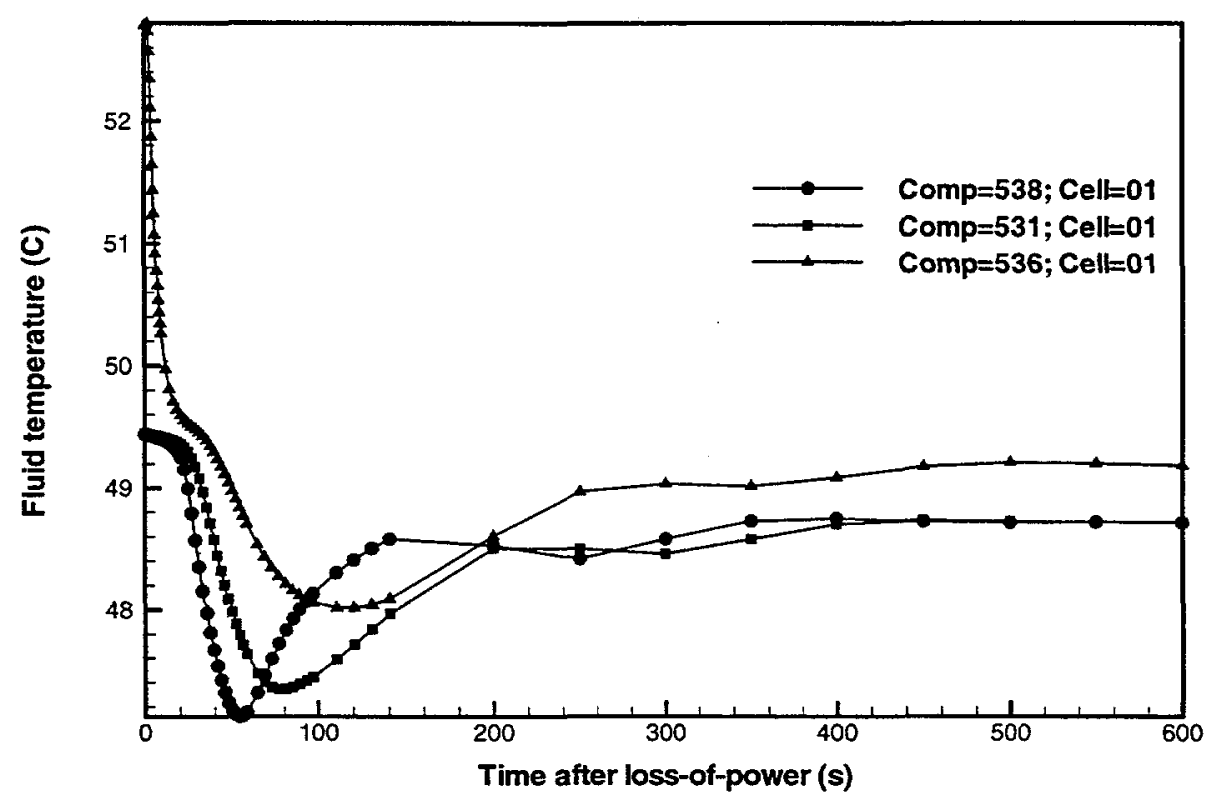

Figure B-7b Module 6 plenum fluid temperatures for a LOFA (Case 1: with beam shutdown and active RHR).

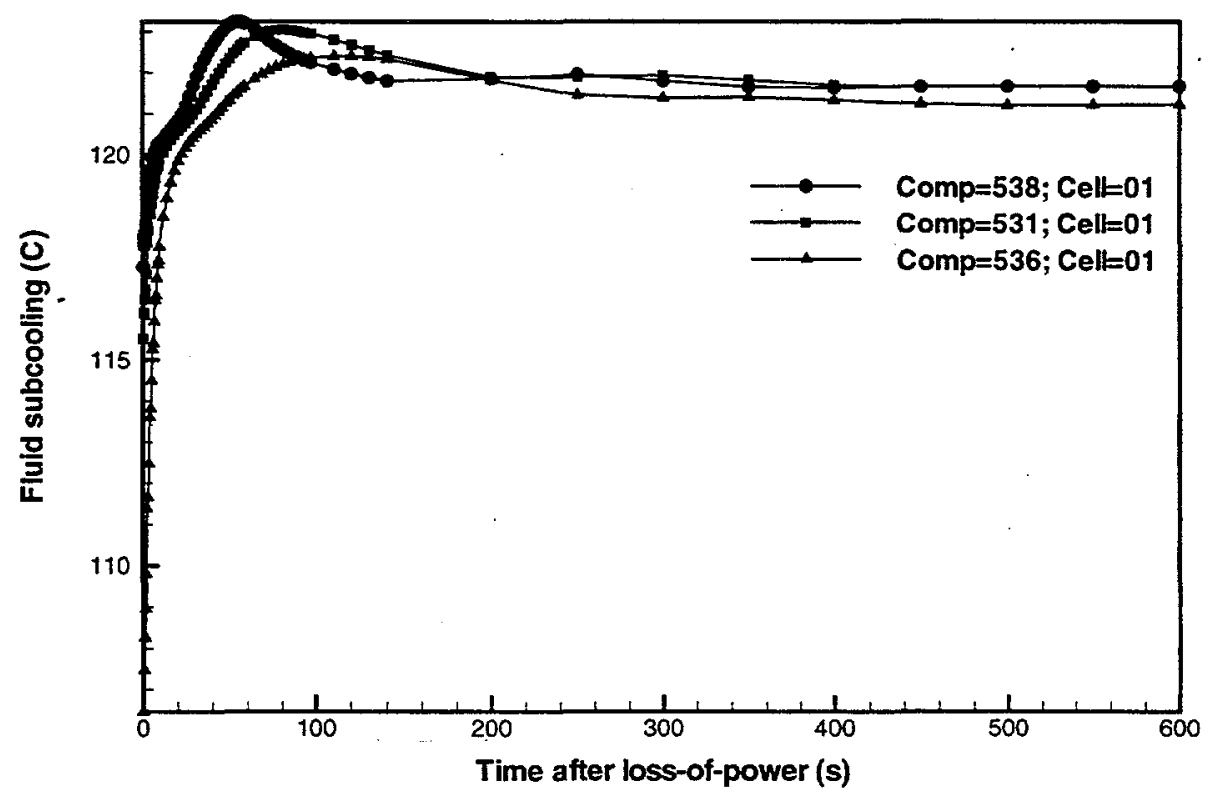

Figure B-7c Module 6 plenum fluid subcoolings for a LOFA (Case 1: with beam shutdown and active RHR). 


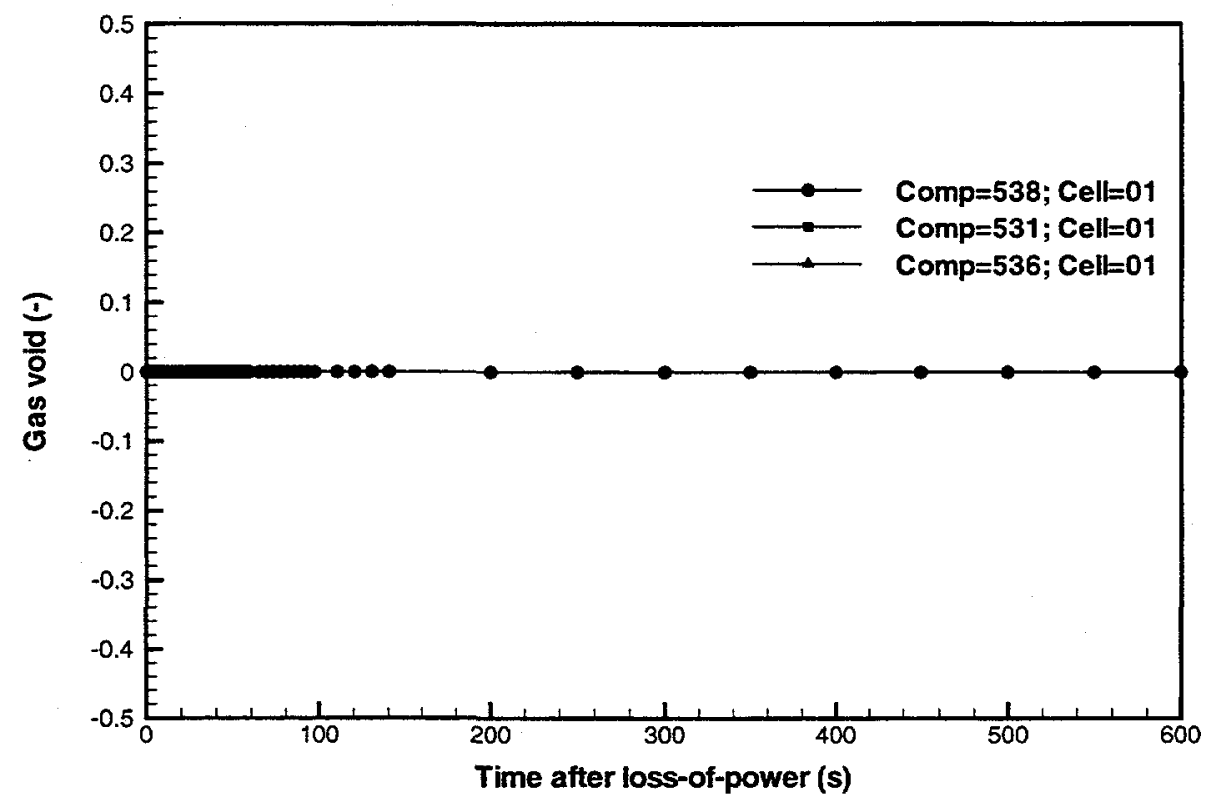

Figure B-7d Module 6 plenum void fractions for a LOFA (Case 1: with beam shutdown and active RHR). 


\section{Appendix B2 LOFA (Case 1) TRAC Pipe, Pump, and Valve Component} Figures

The following figures are from a TRAC simulation for Case 1 of a LOFA (with beam shutdown and active RHR):

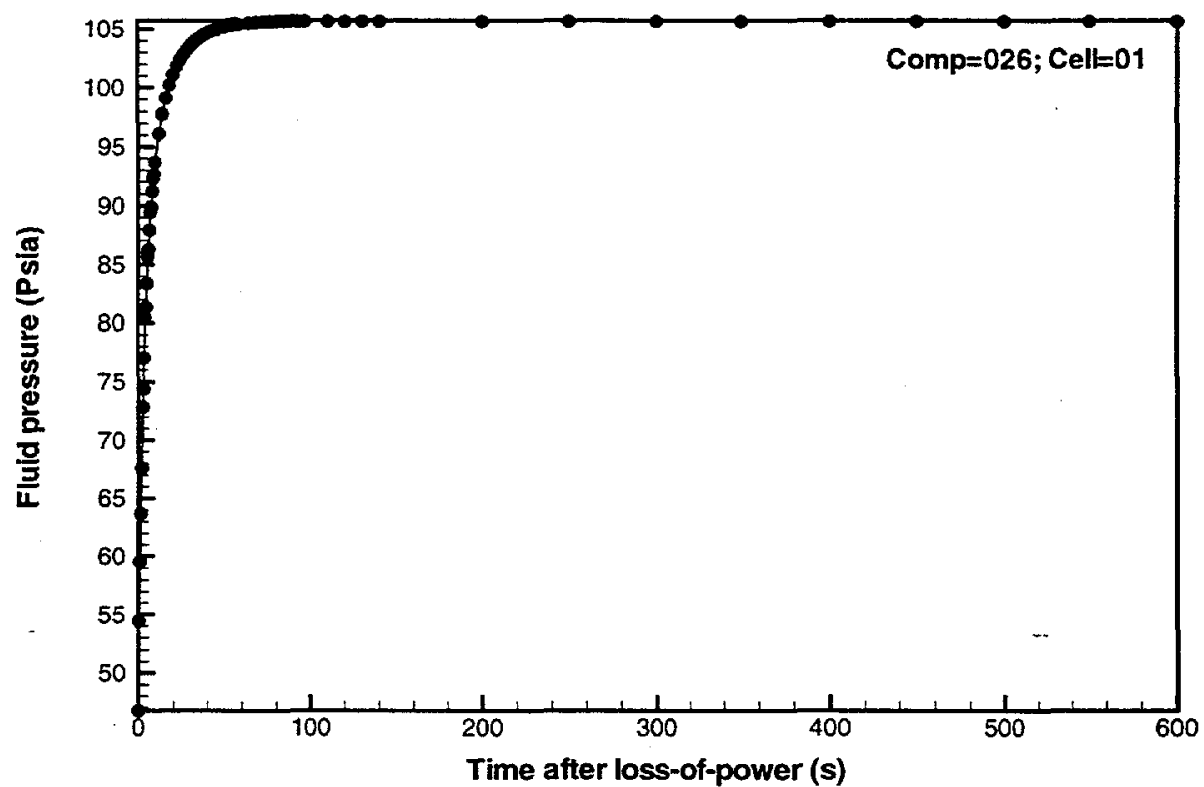

Figure B-8a Primary HR hot-leg piping fluid pressures for a LOFA (Case 1: with beam shutdown and active RHR). 


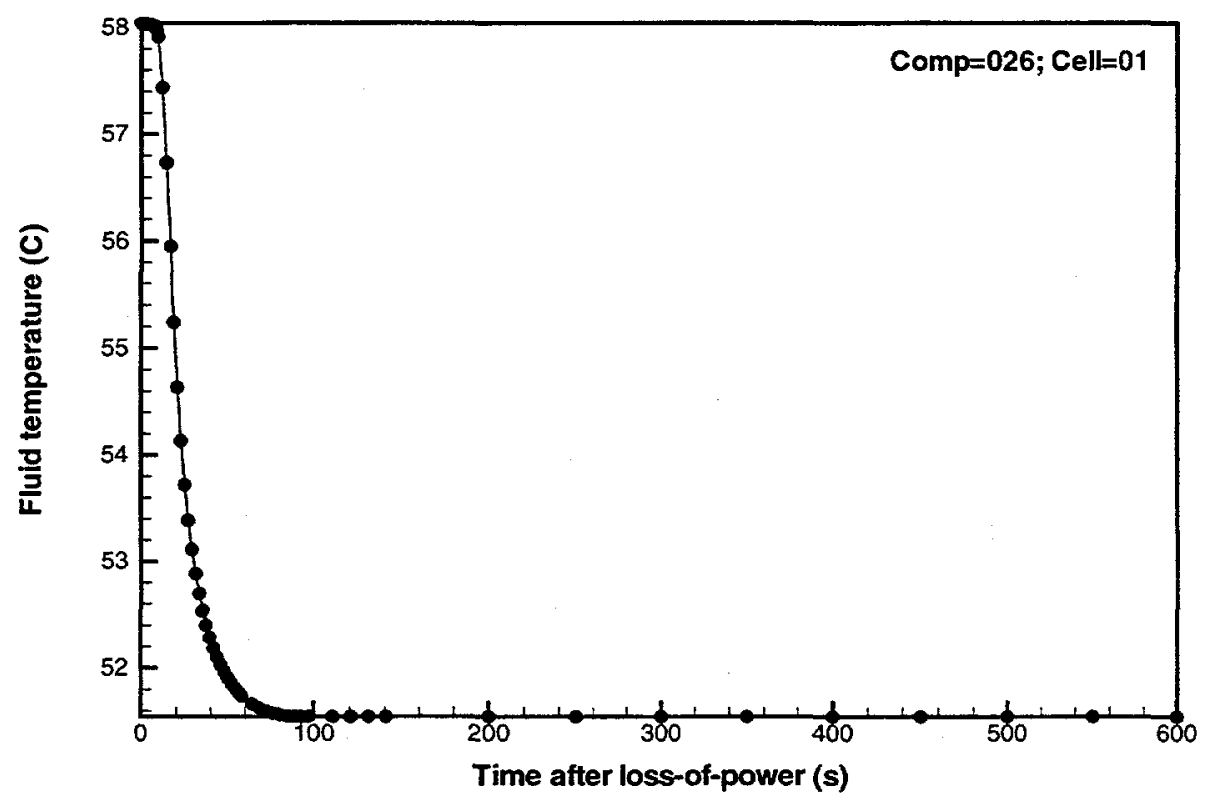

Figure B-8b Primary HR hot-leg piping fluid temperatures for a LOFA (Case 1: with beam shutdown and active RHR).

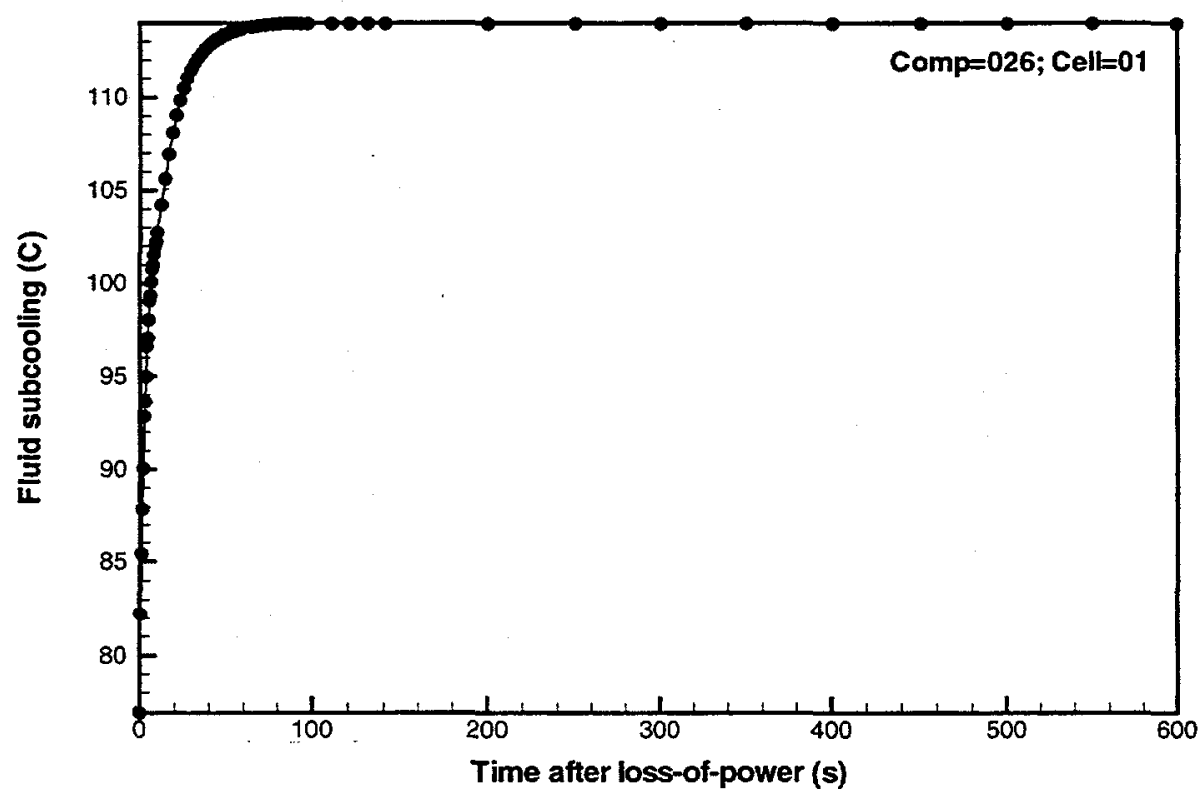

Figure B-8c Primary HR hot-leg piping fluid subcoolings for a LOFA (Case 1: with beam shutdown and active RHR). 


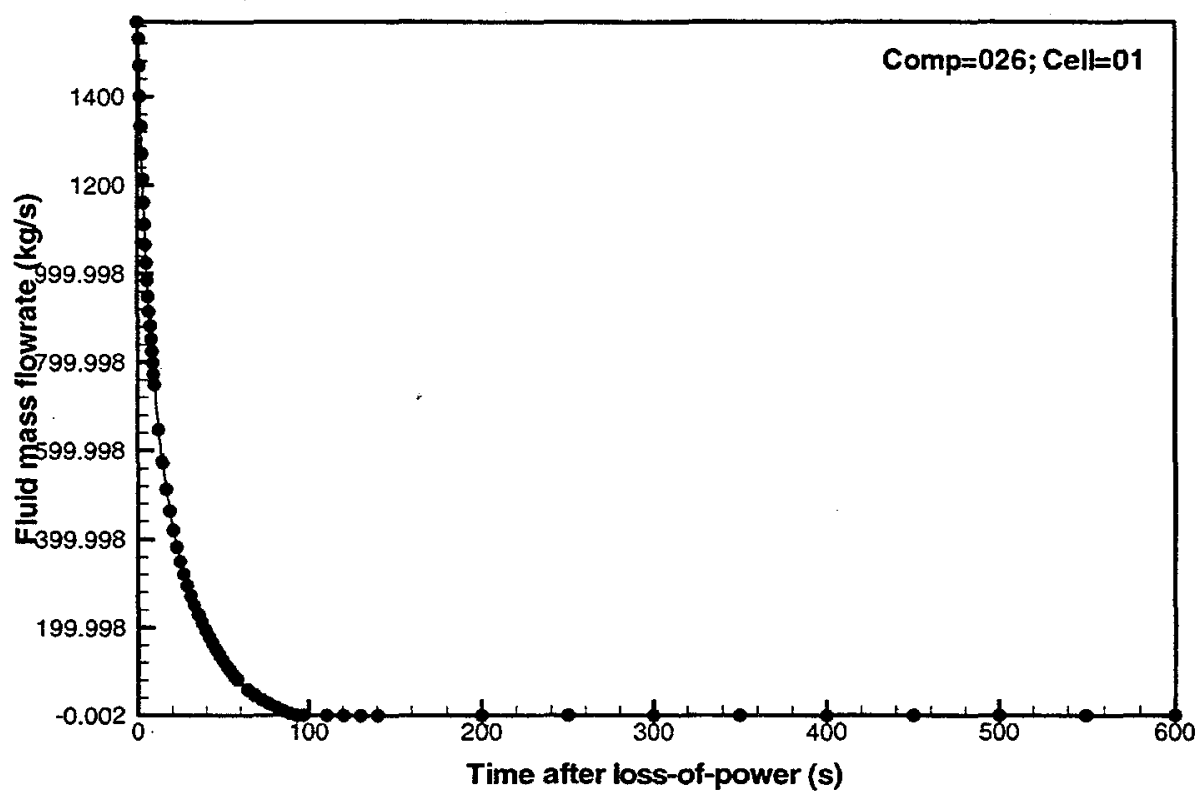

Figure B-8d Primary HR hot-leg piping liquid mass flowrates for a LOFA (Case 1: with beam shutdown and active RHR).

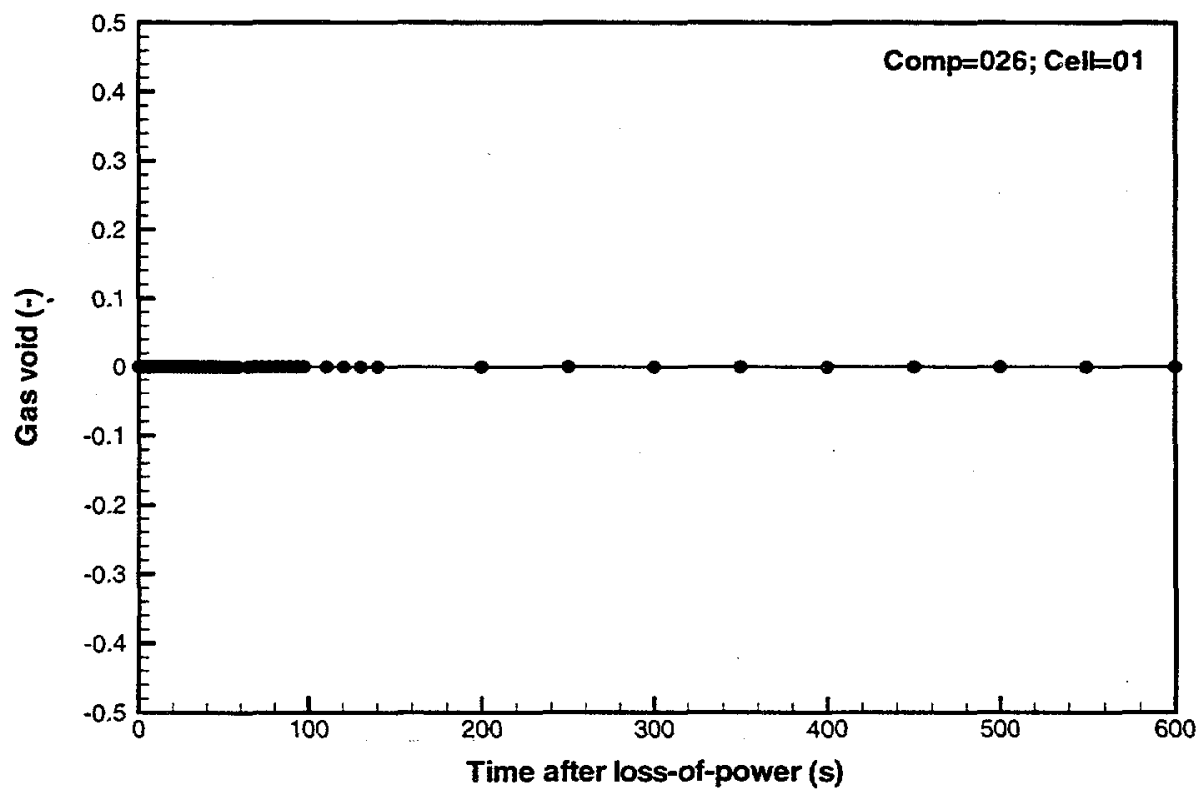

Figure B-8e Primary HR hot-leg piping void fractions for a LOFA (Case 1: with beam shutdown and active RHR). 


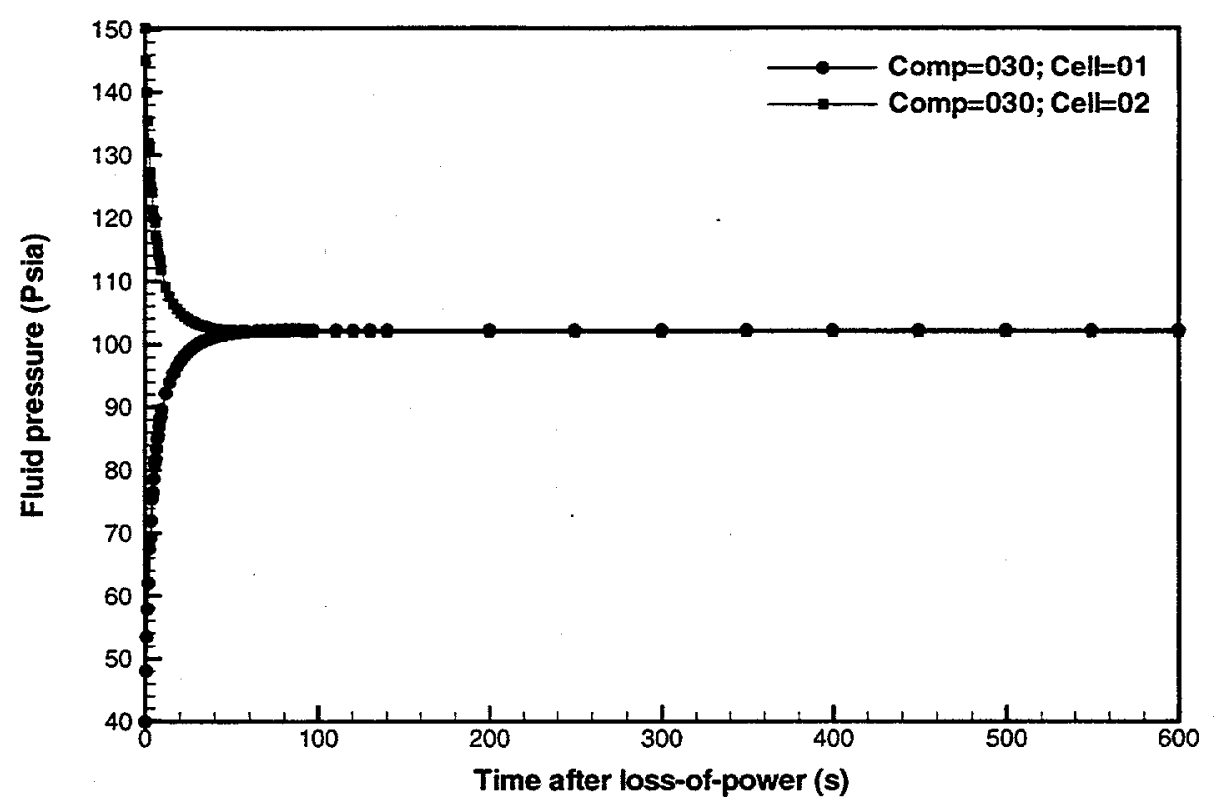

Figure B-9a Primary HR pump 1 fluid pressures for a LOFA (Case 1: with beam shutdown and active RHR).

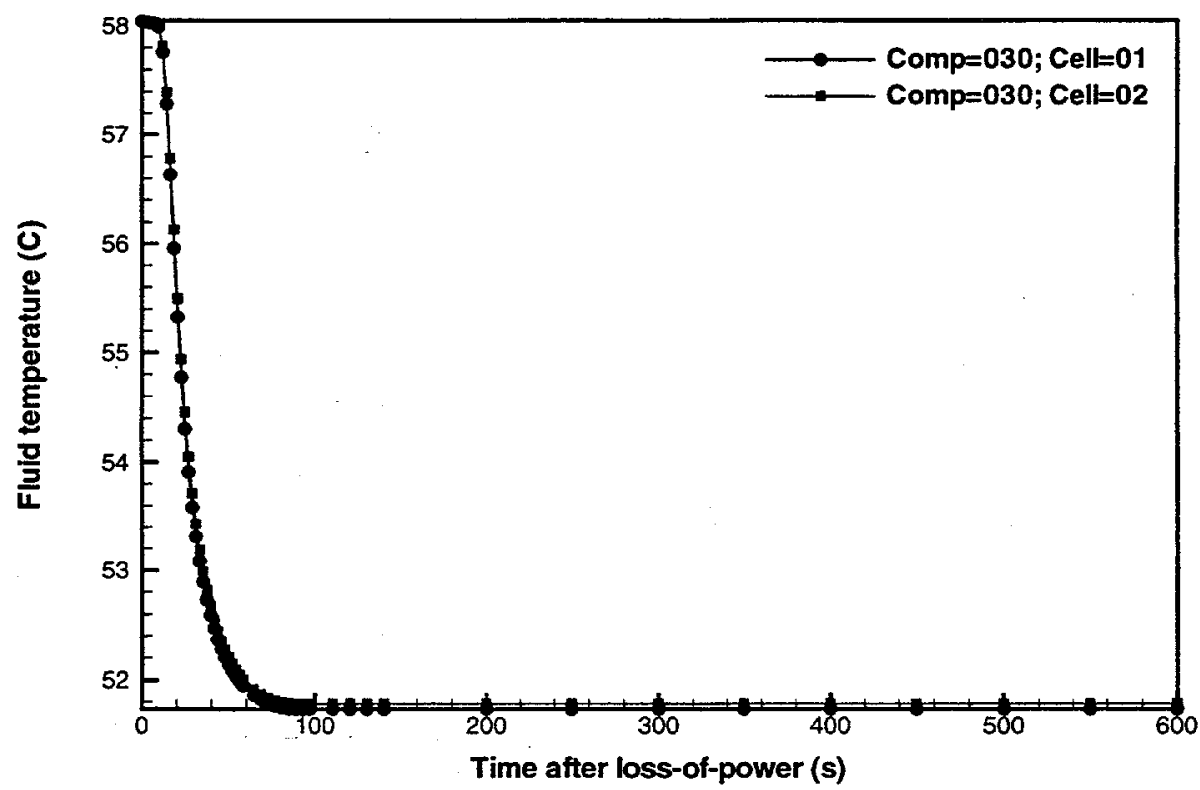

Figure B-9b Primary HR pump 1 fluid temperatures for a LOFA (Case 1: with beam shutdown and active RHR). 


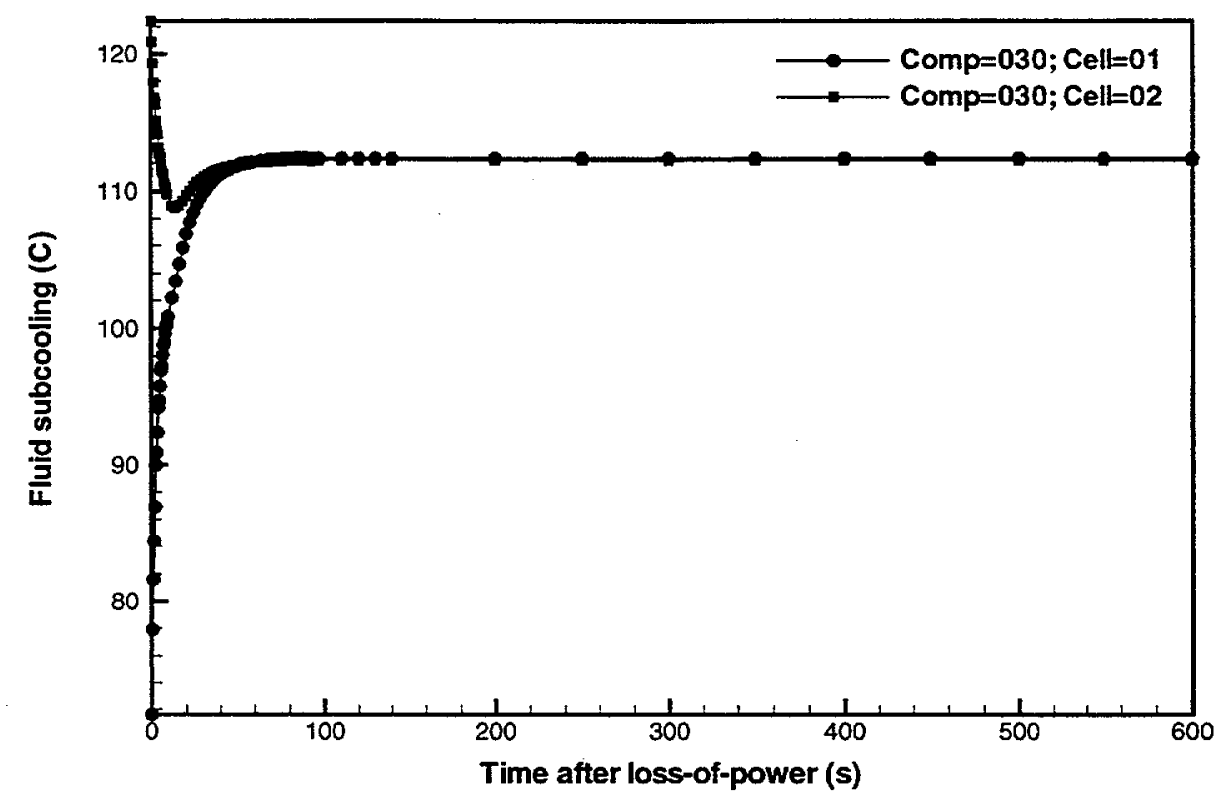

Figure B-9c Primary HR pump 1 fluid subcoolings for a LOFA (Case 1: with beam shutdown and active RHR).

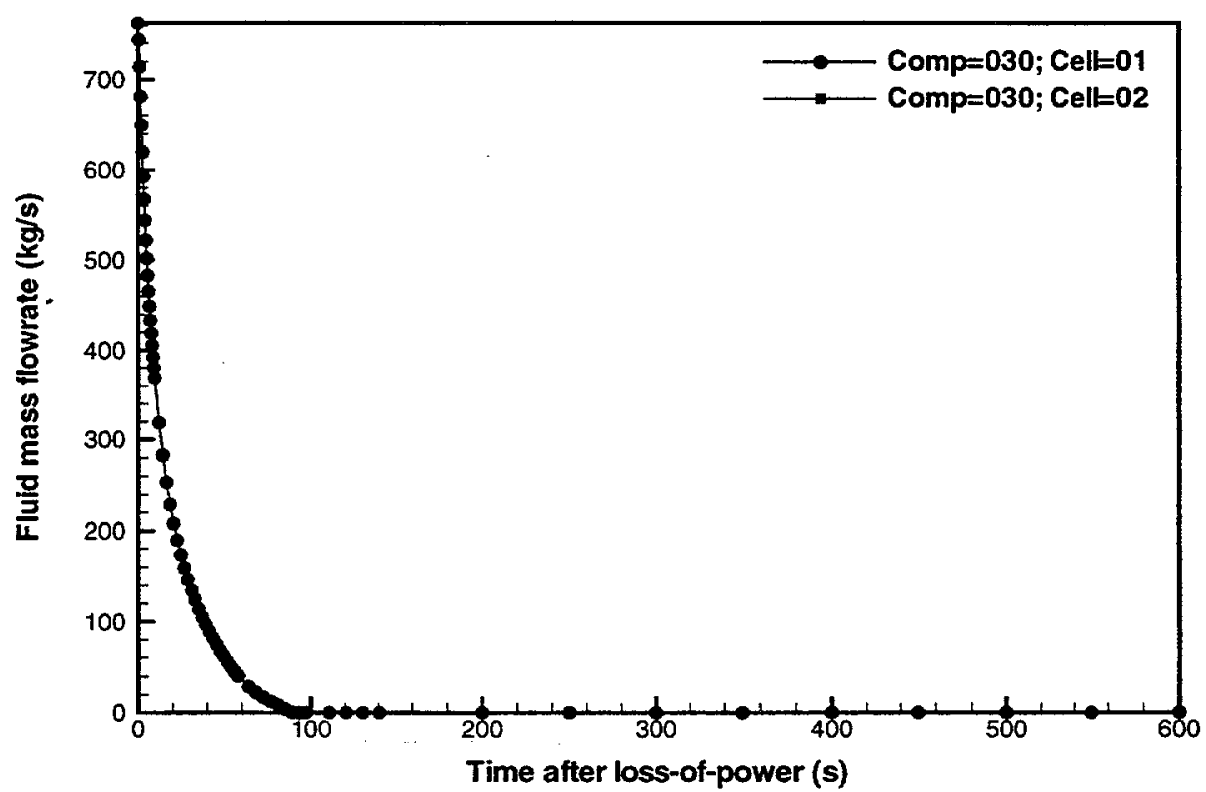

Figure B-9d Primary HR pump 1 liquid mass flowrates for a LOFA (Case 1: with beam shutdown and active RHR). 


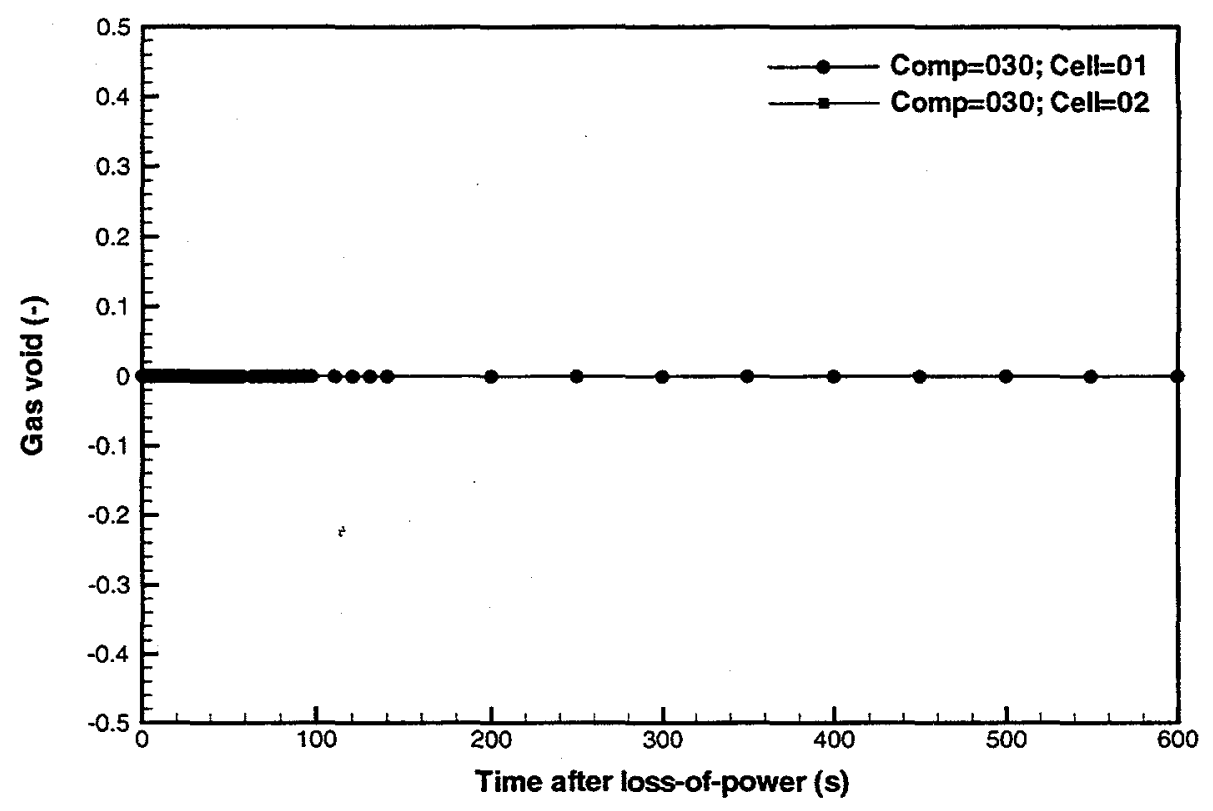

Figure B-9e Primary HR pump 1 void fractions for a LOFA (Case 1: with beam shutdown and active RHR).

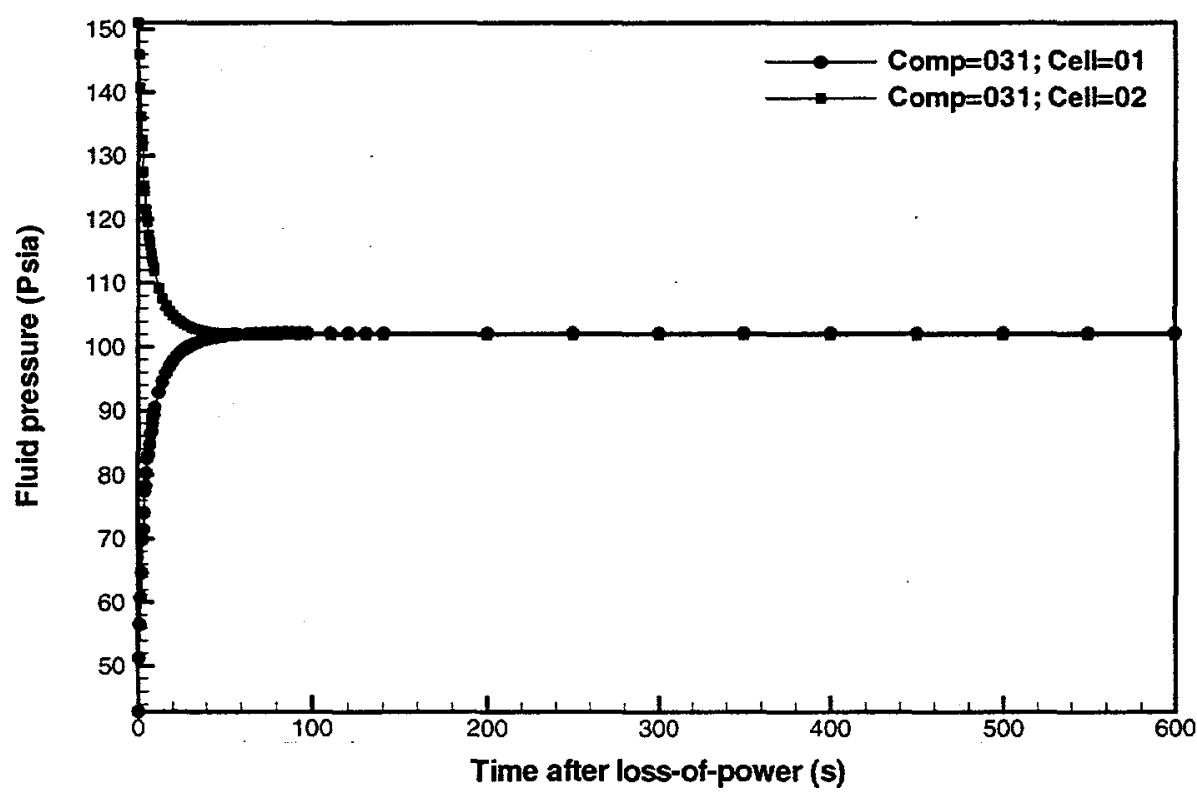

Figure B-10a Primary HR pump 2 fluid pressures for a LOFA (Case 1: with beam shutdown and active RHR). 


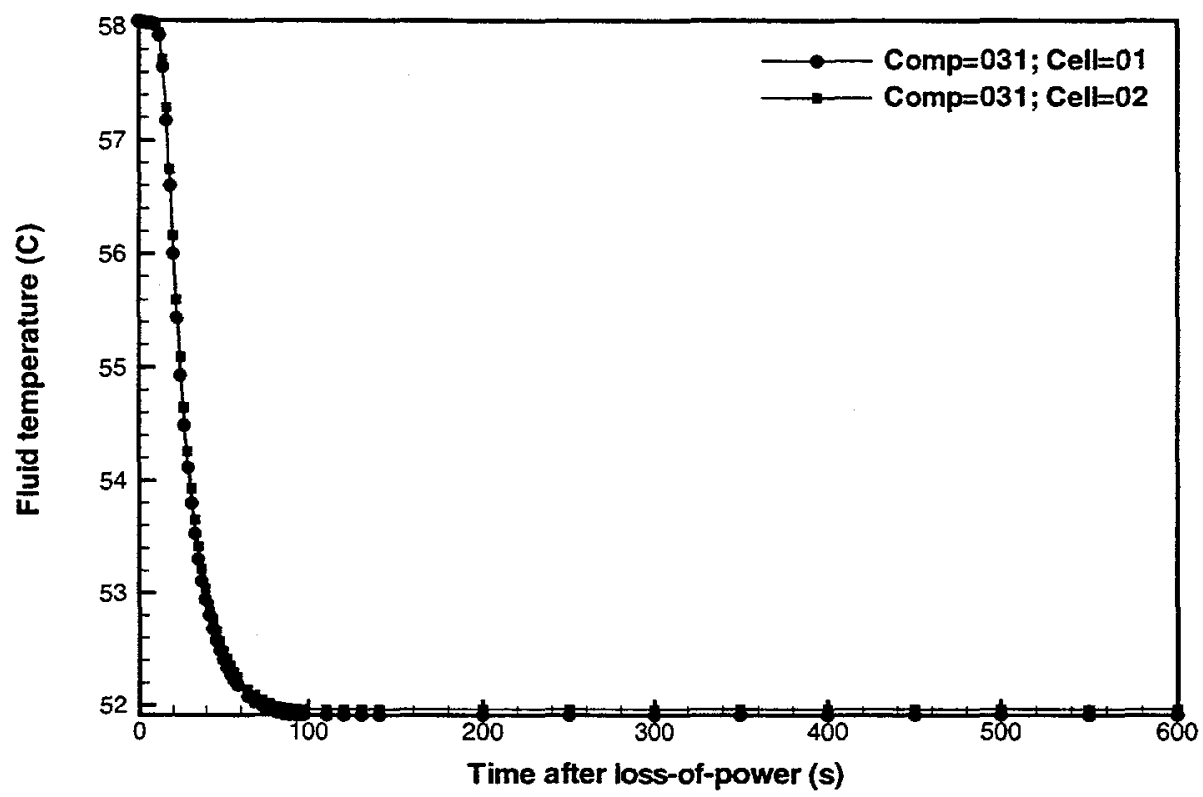

Figure B-10b Primary HR pump 2 fluid temperatures for a LOFA (Case 1: with beam shutdown and active RHR).

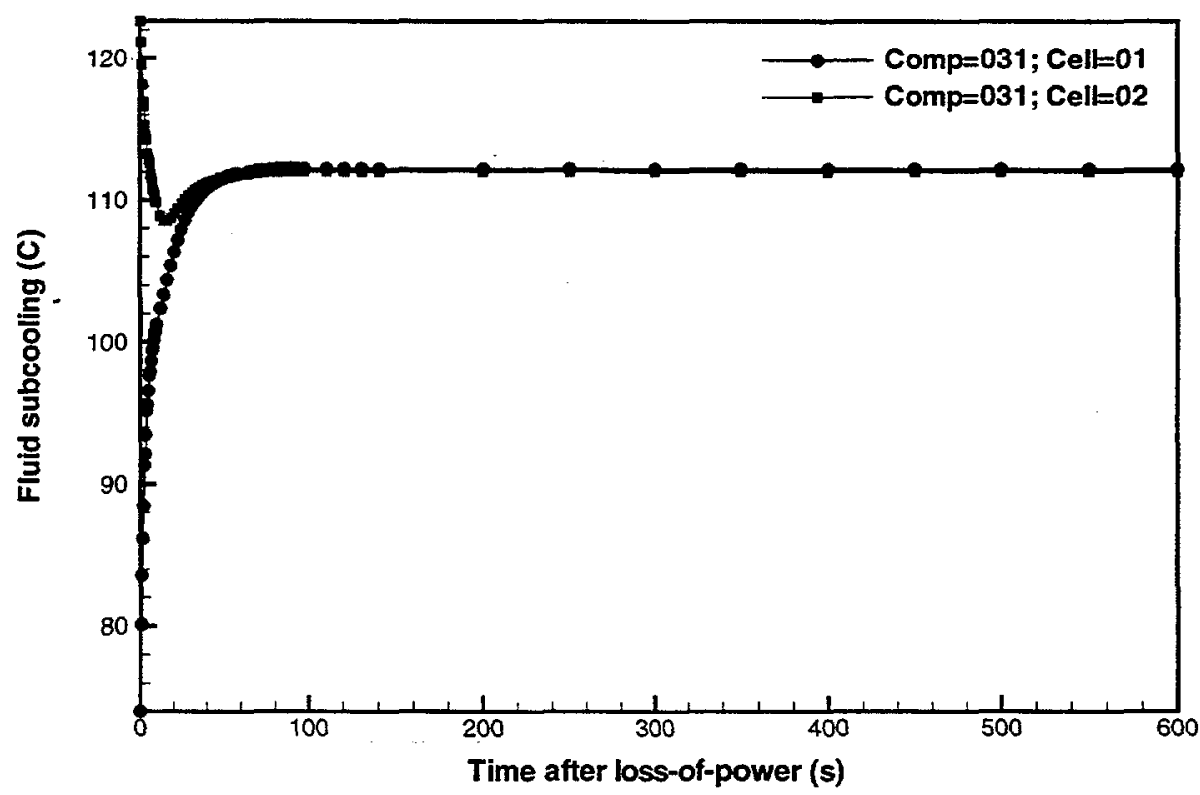

Figure B-10c Primary HR pump 2 fluid subcoolings for a LOFA (Case 1: with beam shutdown and active RHR). 


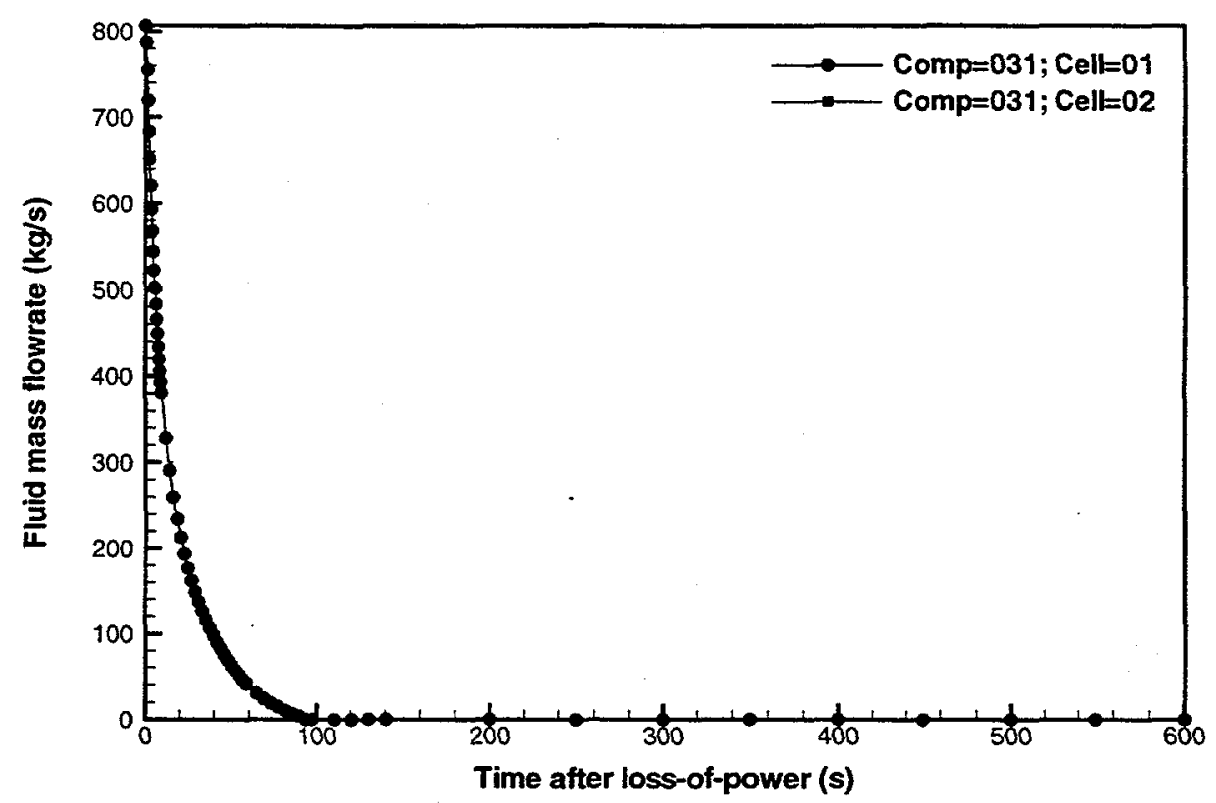

Figure B-10d Primary HR pump 2 liquid mass flowrates for a LOFA (Case 1: with beam shutdown and active RHR).

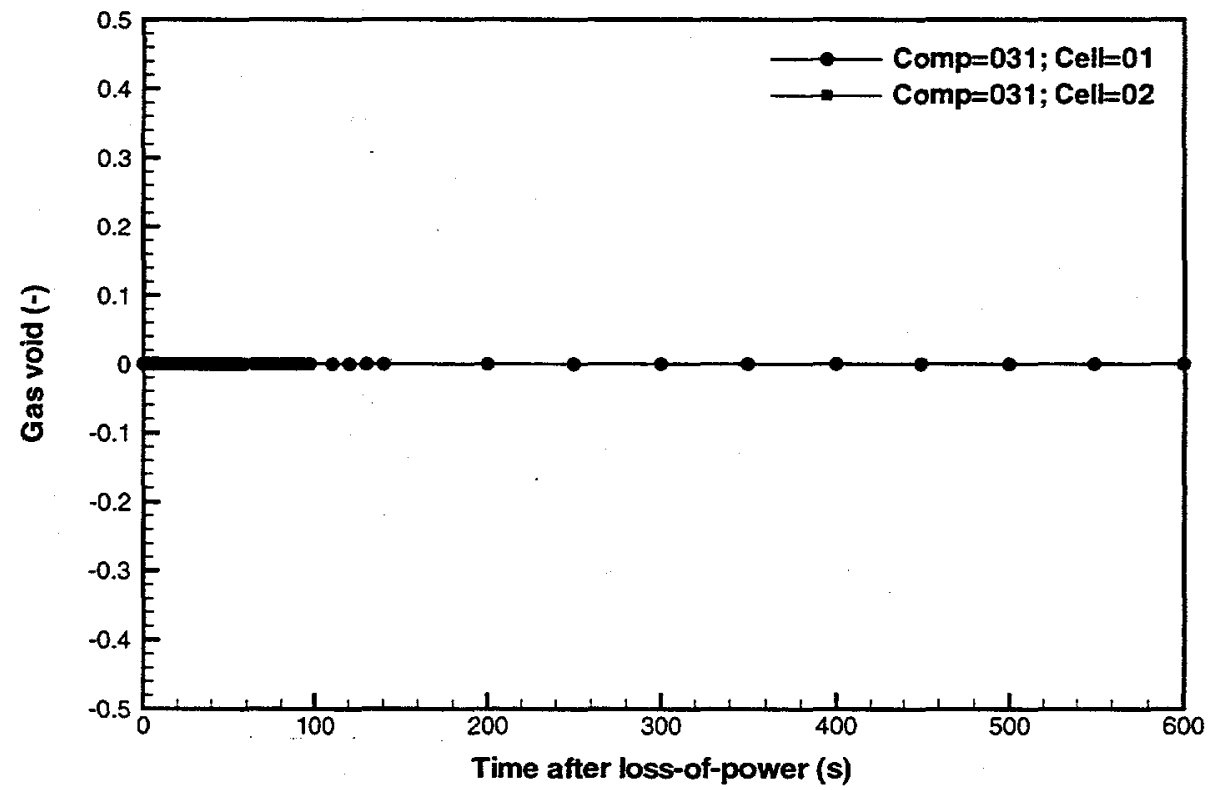

Figure B-10e Primary HR pump 2 void fractions for a LOFA (Case 1: with beam shutdown and active RHR). 


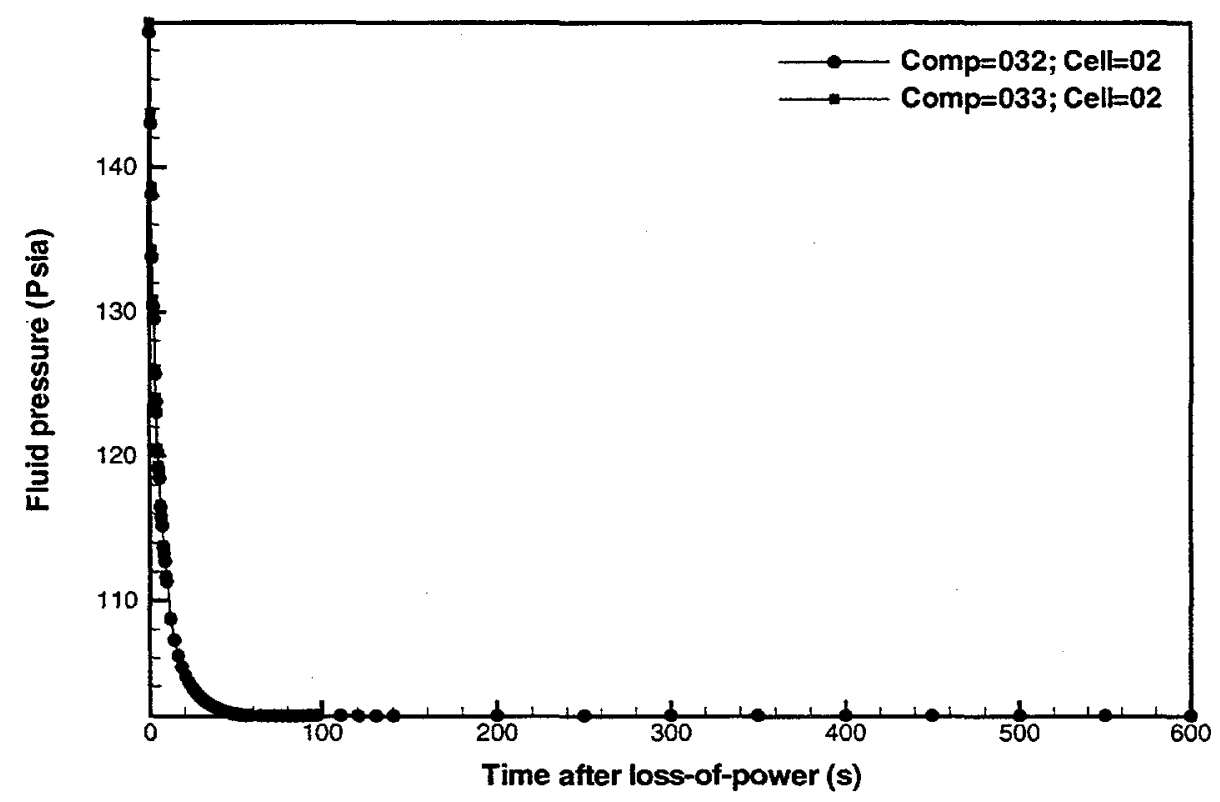

Figure B-11a Primary HR pump discharge piping fluid pressures for a LOFA (Case 1: with beam shutdown and active RHR).

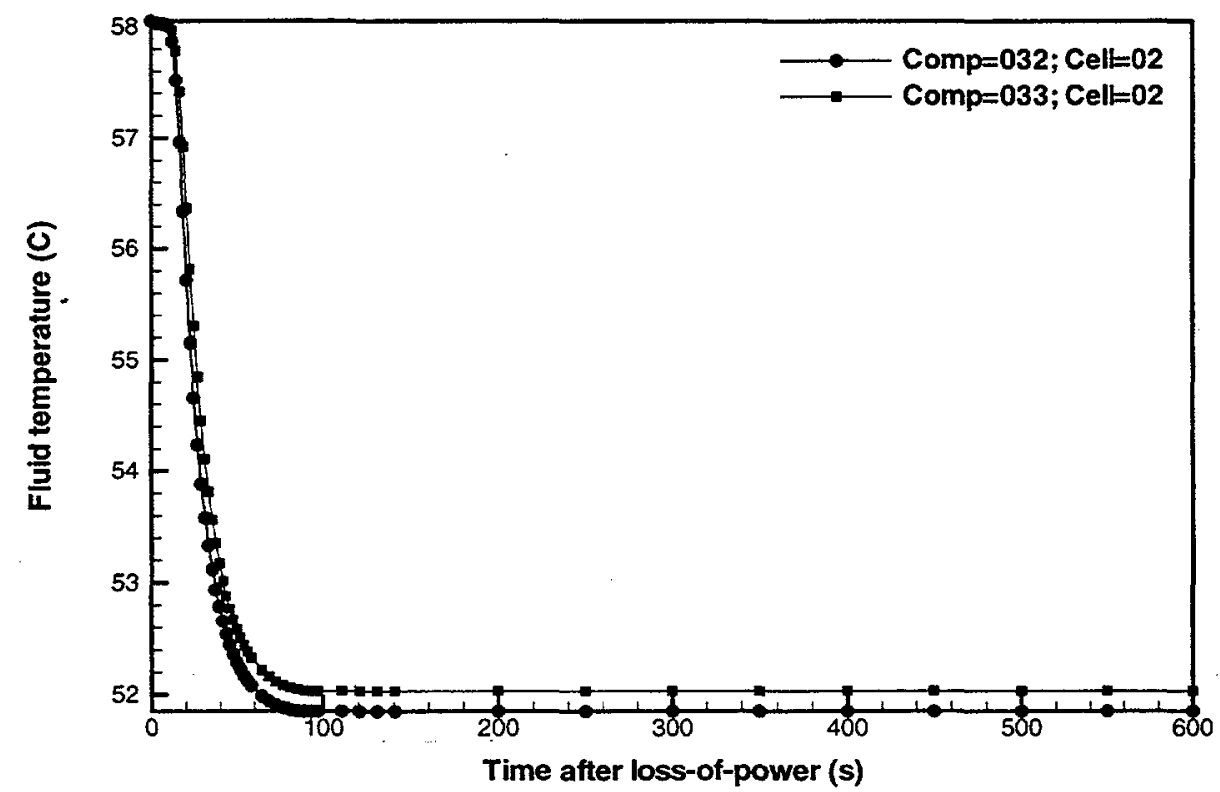

Figure B-11b Primary HR pump discharge piping fluid temperatures for a LOFA (Case 1: with beam shutdown and active RHR). 


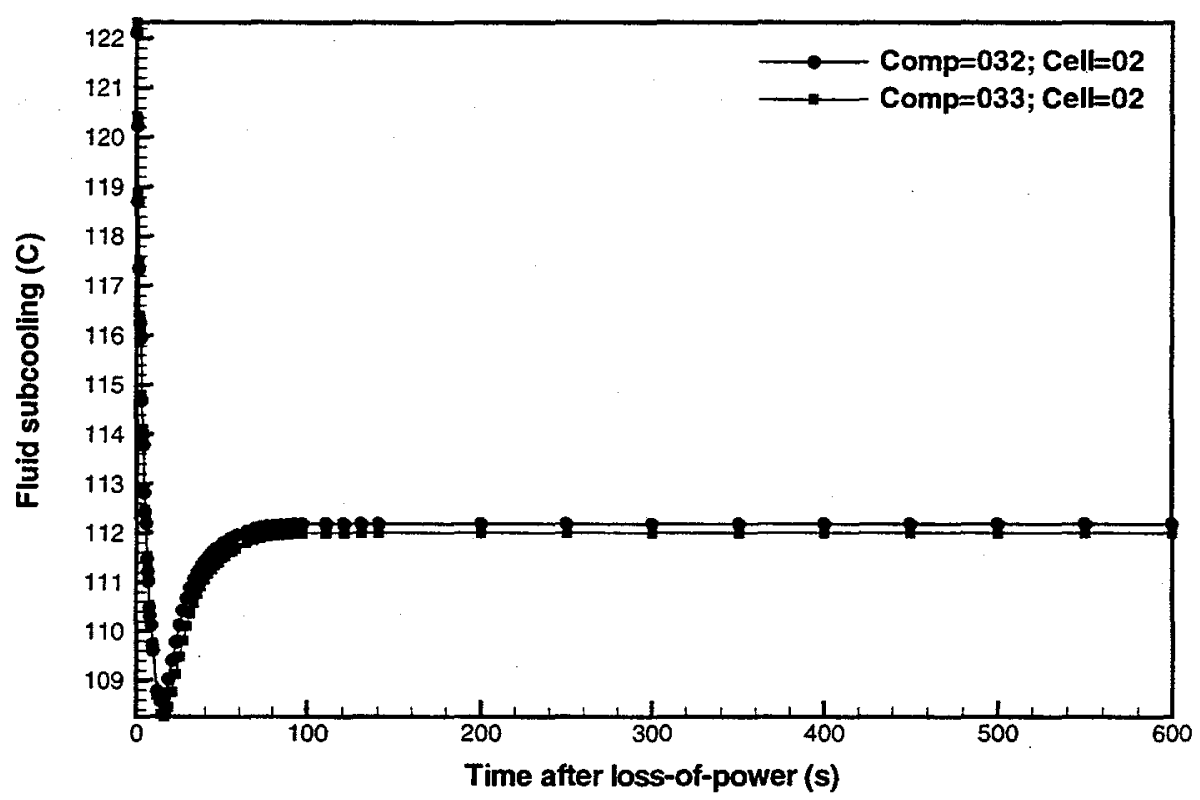

Figure B-11C Primary HR pump discharge piping fluid subcoolings for a LOFA (Case 1: with beam shutdown and active RHR).

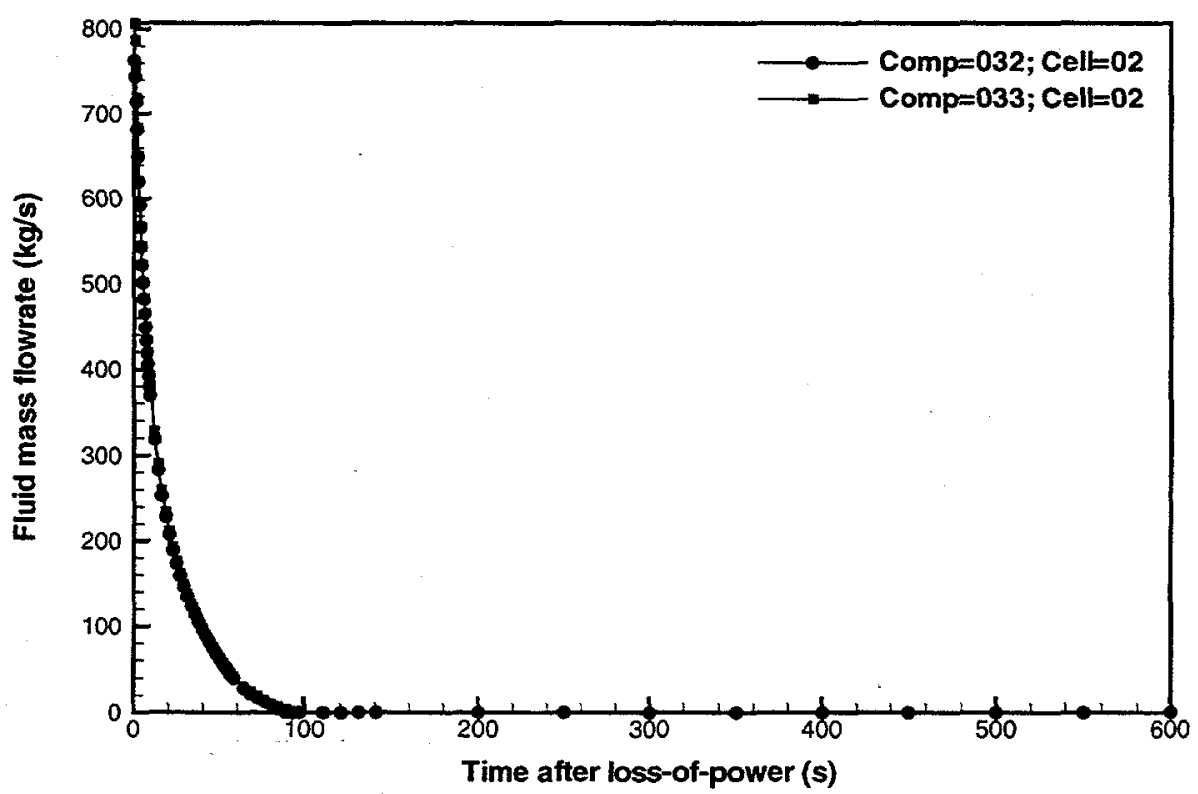

Figure B-11d Primary HR pump discharge piping liquid mass flowrates for a LOFA (Case 1: with beam shutdown and active RHR). 


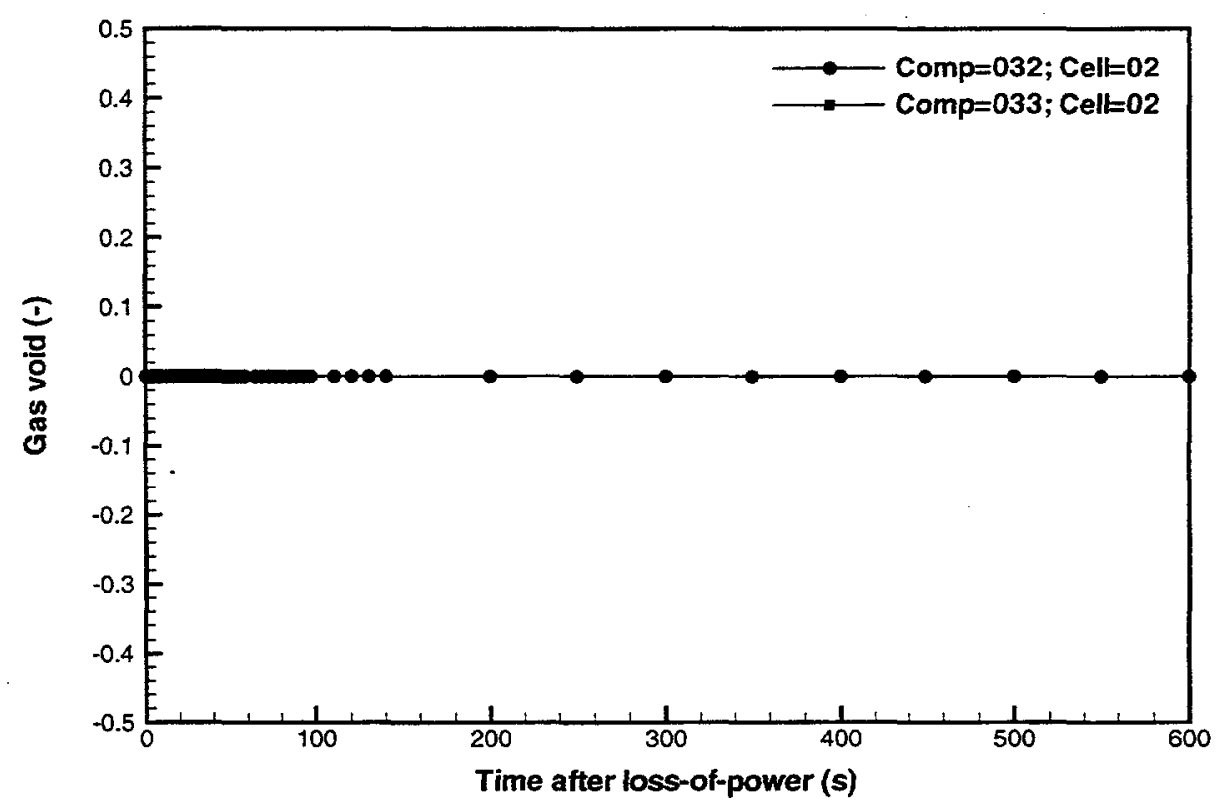

Figure B-11e Primary HR pump discharge piping void fractions for ä LOFA (Case 1: with beam shutdown and active RHR).

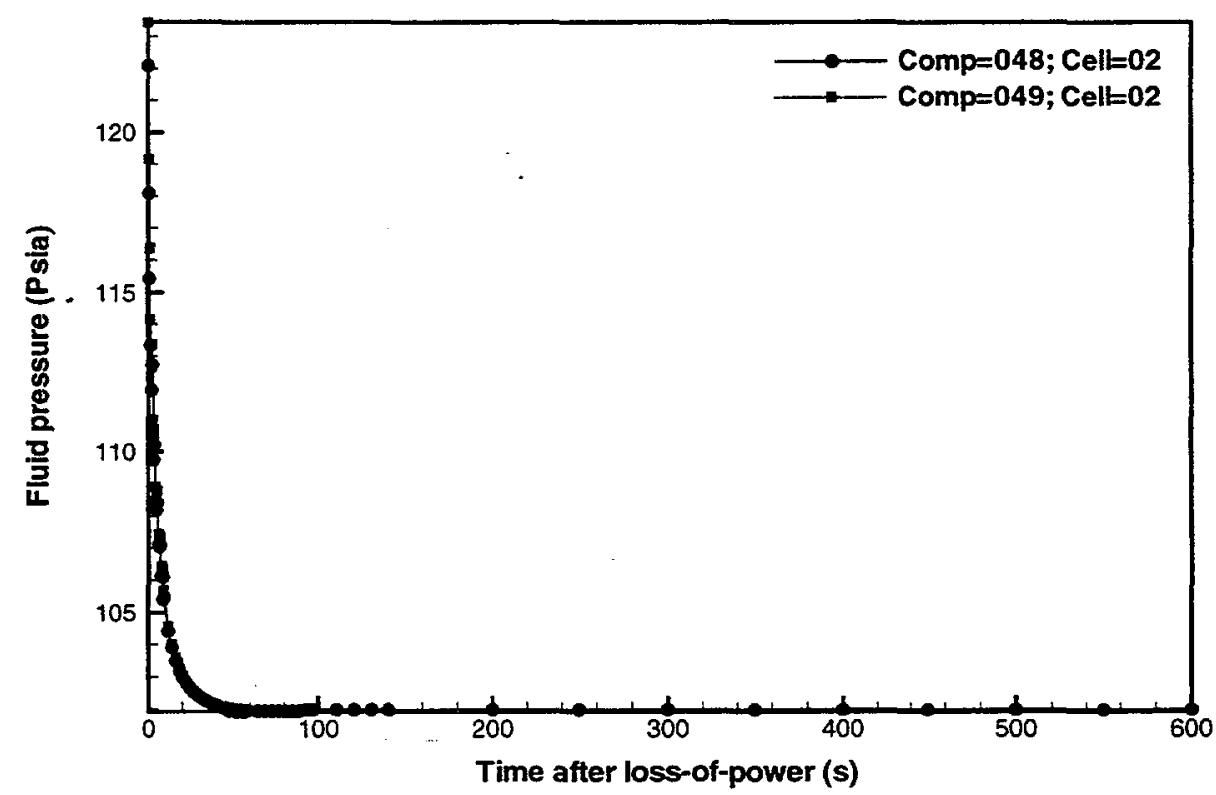

Figure B-12a Primary HR heat exchanger inlet piping fluid pressures for a LOFA (Case 1: with beam shutdown and active RHR). 


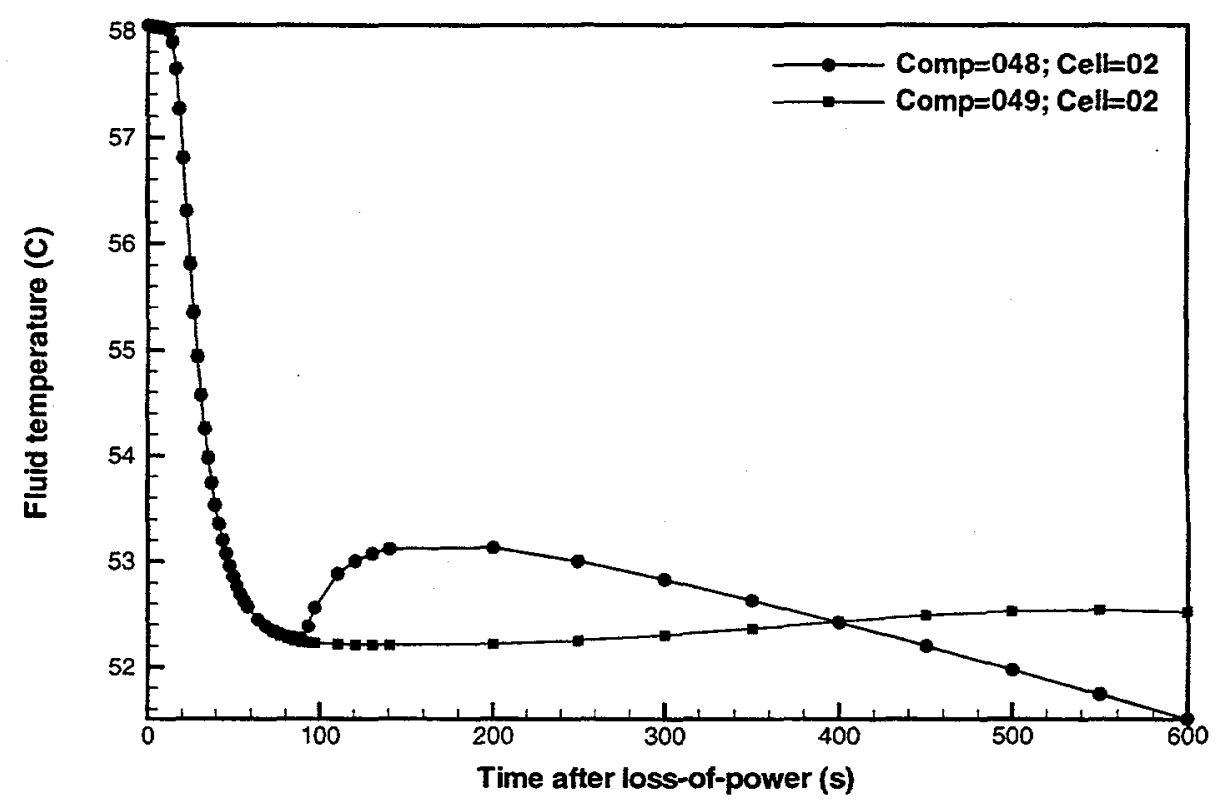

Figure B-12b Primary HR heat exchanger inlet piping fluid tëmperatures for a LOFA

(Case 1: with beam shutdown and active RHR).

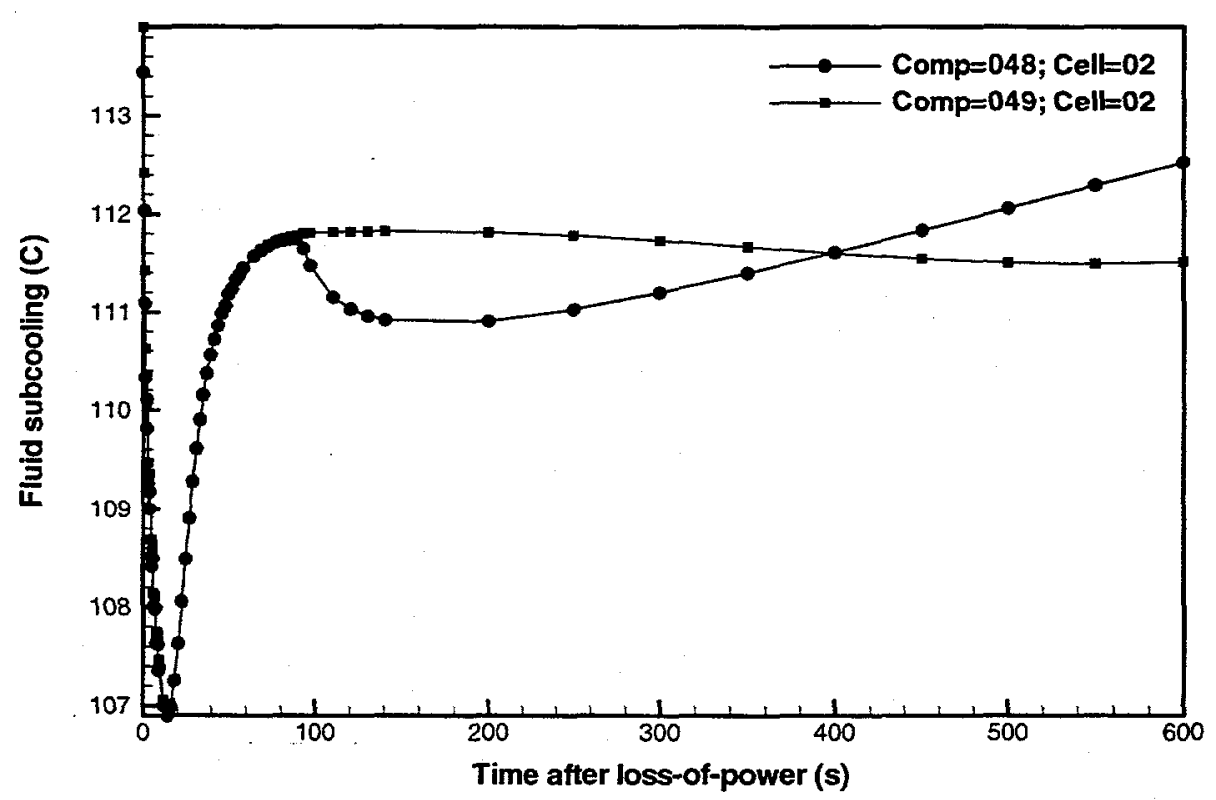

Figure B-12c Primary HR heat exchanger inlet piping fluid subcoolings for a LOFA (Case 1: with beam shutdown and active RHR). 


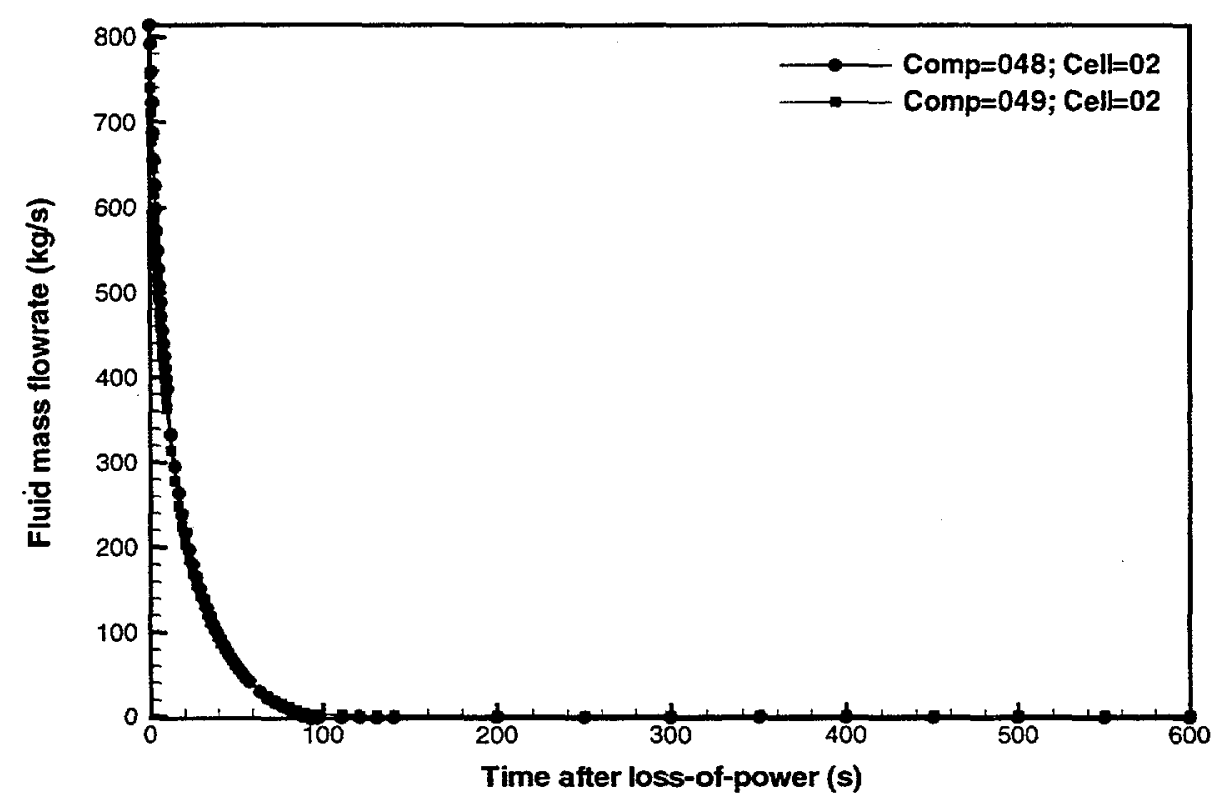

Figure B-12d Primary HR heat exchanger inlet piping liquid mass flowrates for a LOFA (Case 1: with beam shutdown and active RHR).

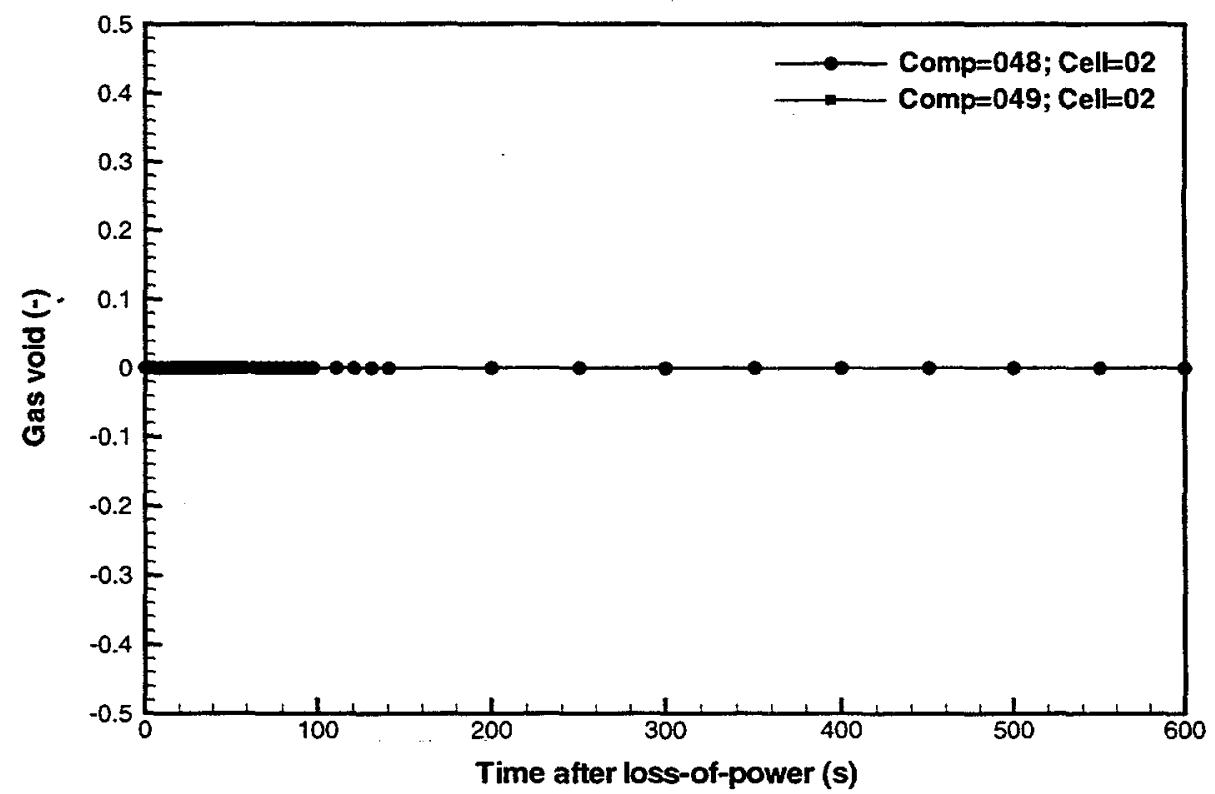

Figure B-12e Primary HR heat exchanger inlet piping void fractions for a LOFA (Case 1: with beam shutdown and active RHR). 


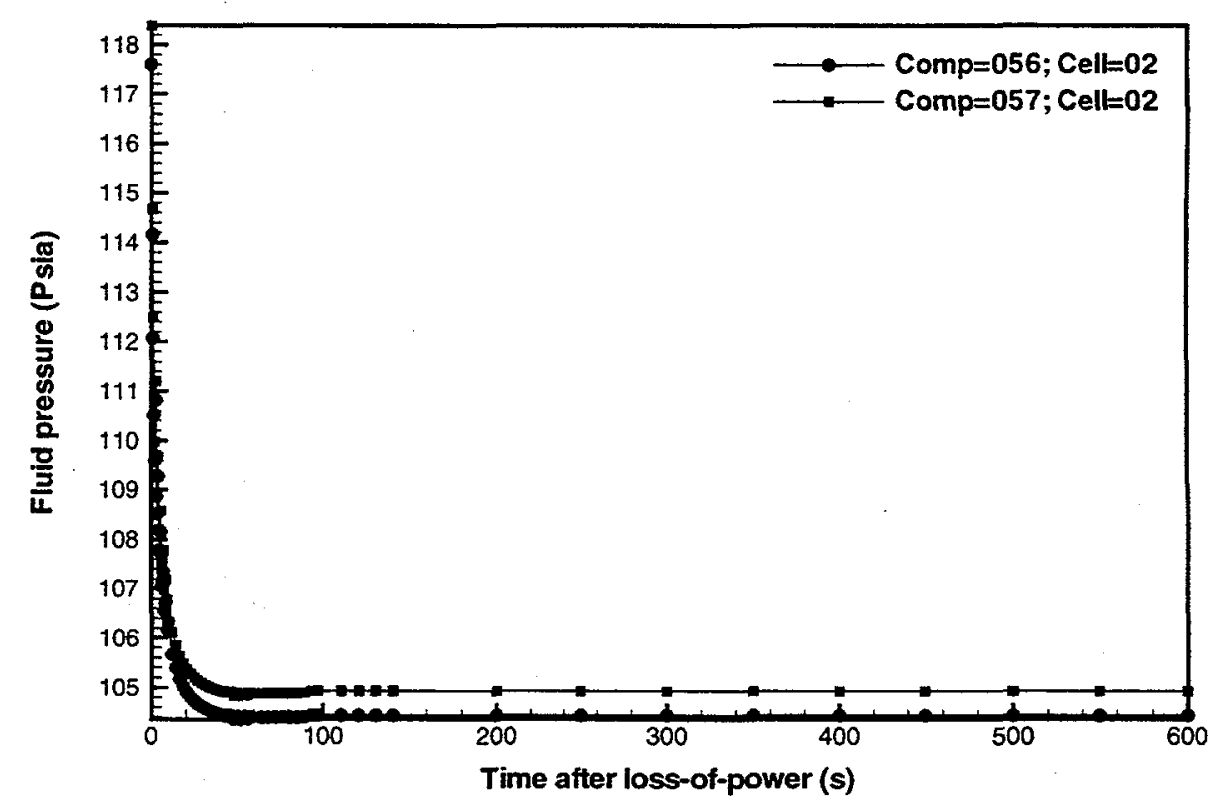

Figure B-13a Primary HR heat exchanger outlet piping fluid pressures for a LOFA (Case 1: with beam shutdown and active RHR).

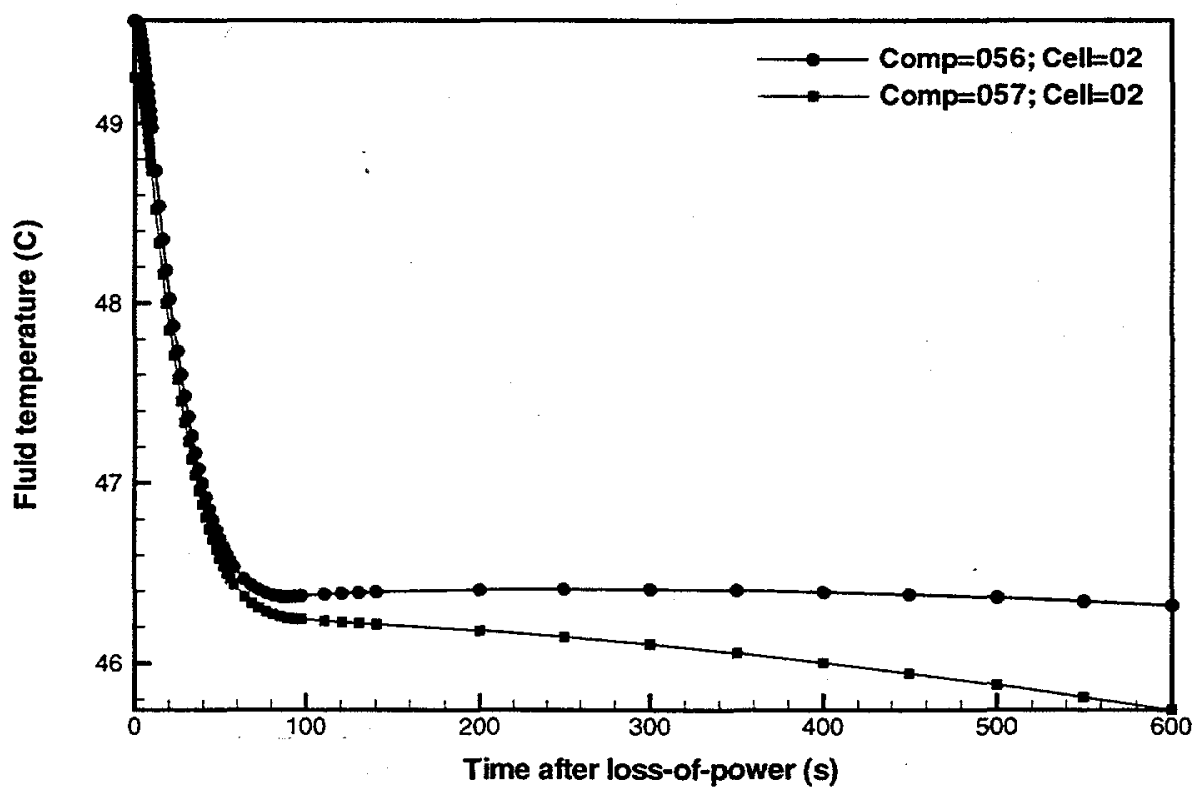

Figure B-13b Primary HR heat exchanger outlet piping fluid temperatures for a LOFA (Case 1: with beam shutdown and active RHR). 


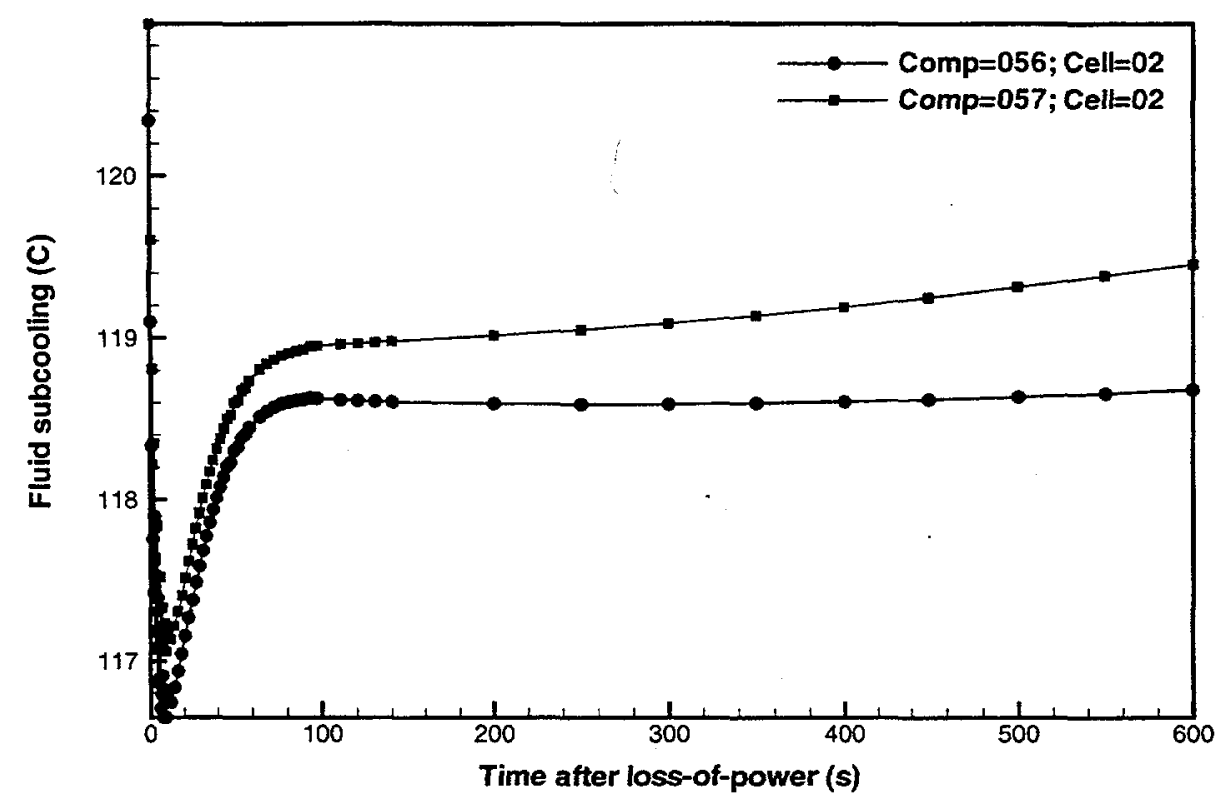

Figure B-13c Primary HR heat exchanger outlet piping fluid subcootings for a LOFA (Case 1: with beam shutdown and active RHR).

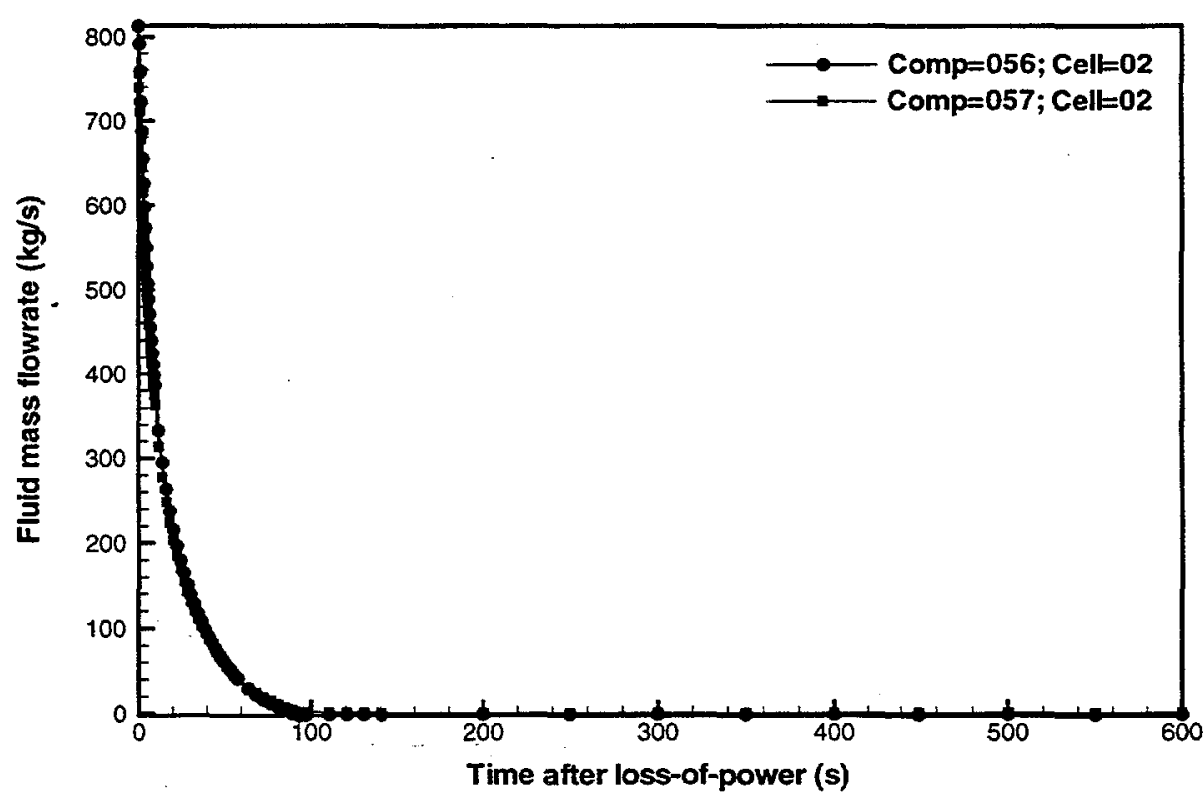

Figure B-13d Primary HR heat exchanger outlet piping liquid mass flowrates for a LOFA (Case 1: with beam shutdown and active RHR). 


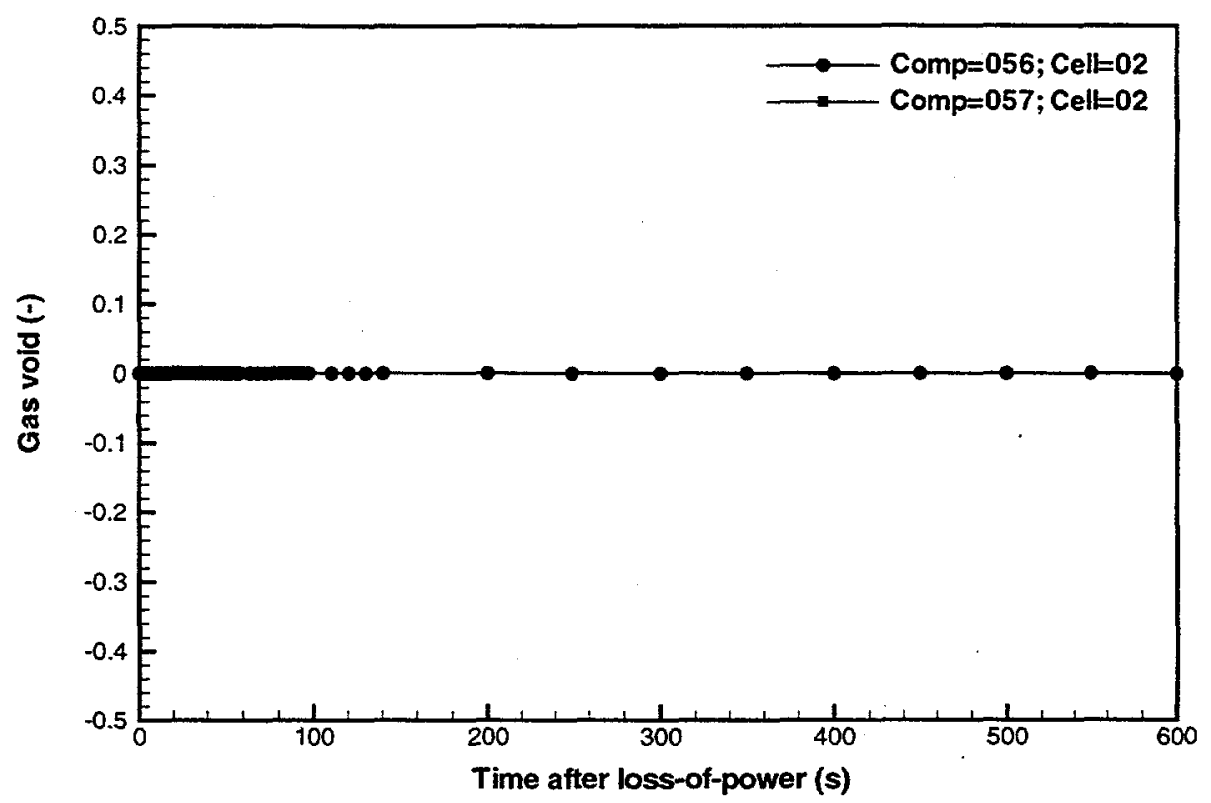

Figure B-13e Primary HR heat exchanger outlet piping void fractions for a LOFA (Case 1: with beam shutdown and active RHR).

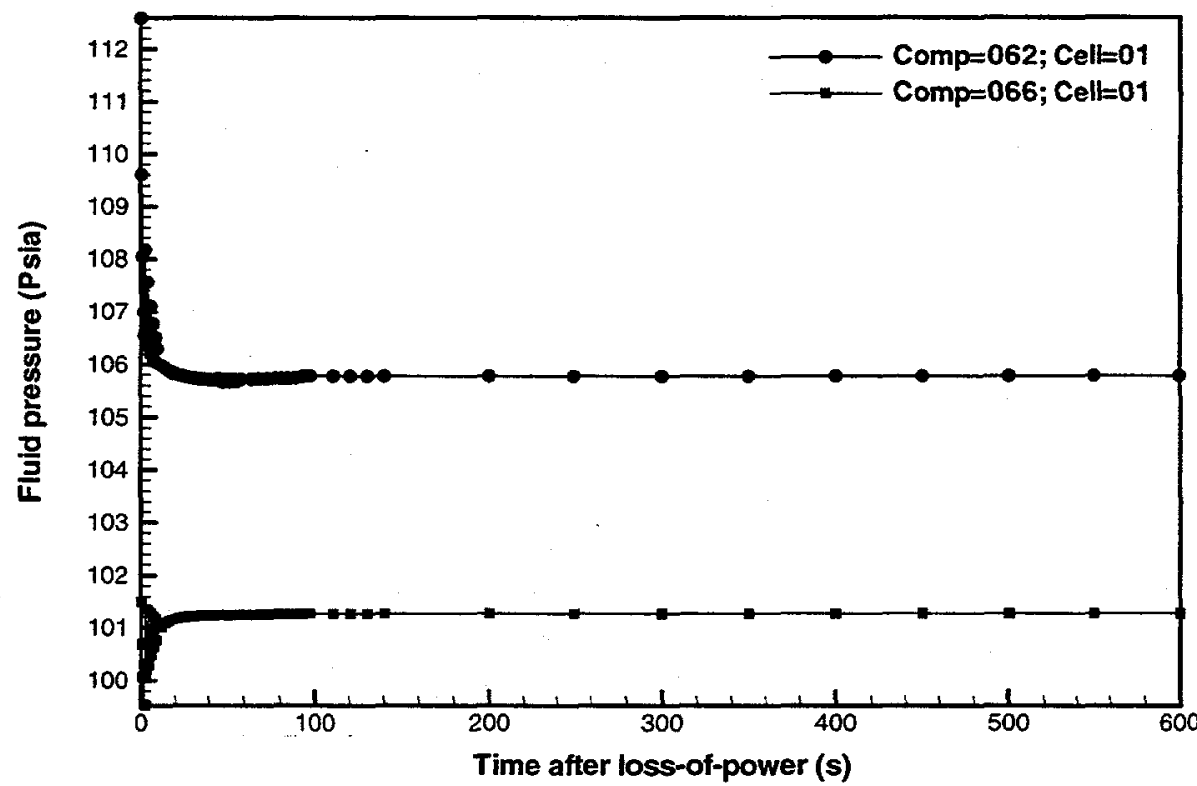

Figure B-14a Primary HR cold-leg piping fluid pressures for a LOFA (Case 1: with beam shutdown and active RHR). 


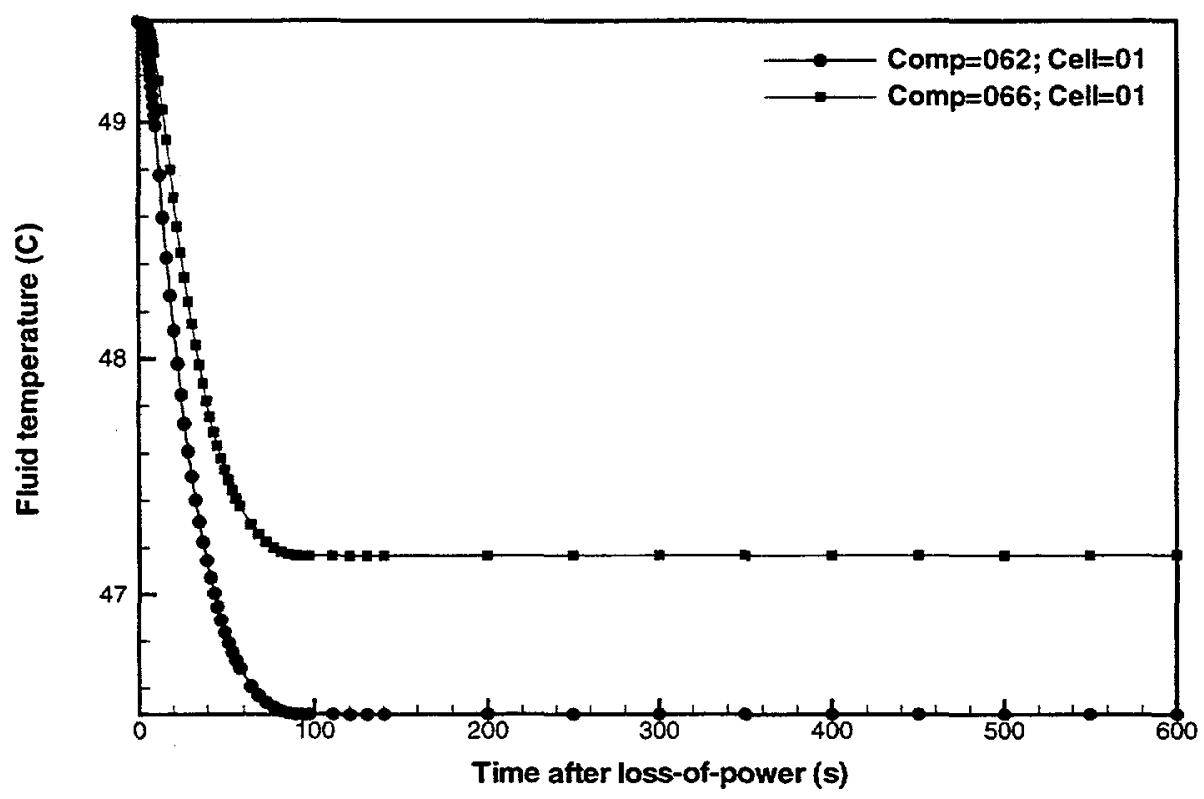

Figure B-14b Primary HR cold-leg piping fluid temperatures for a LOFA (Case 1: with beam shutdown and active RHR).

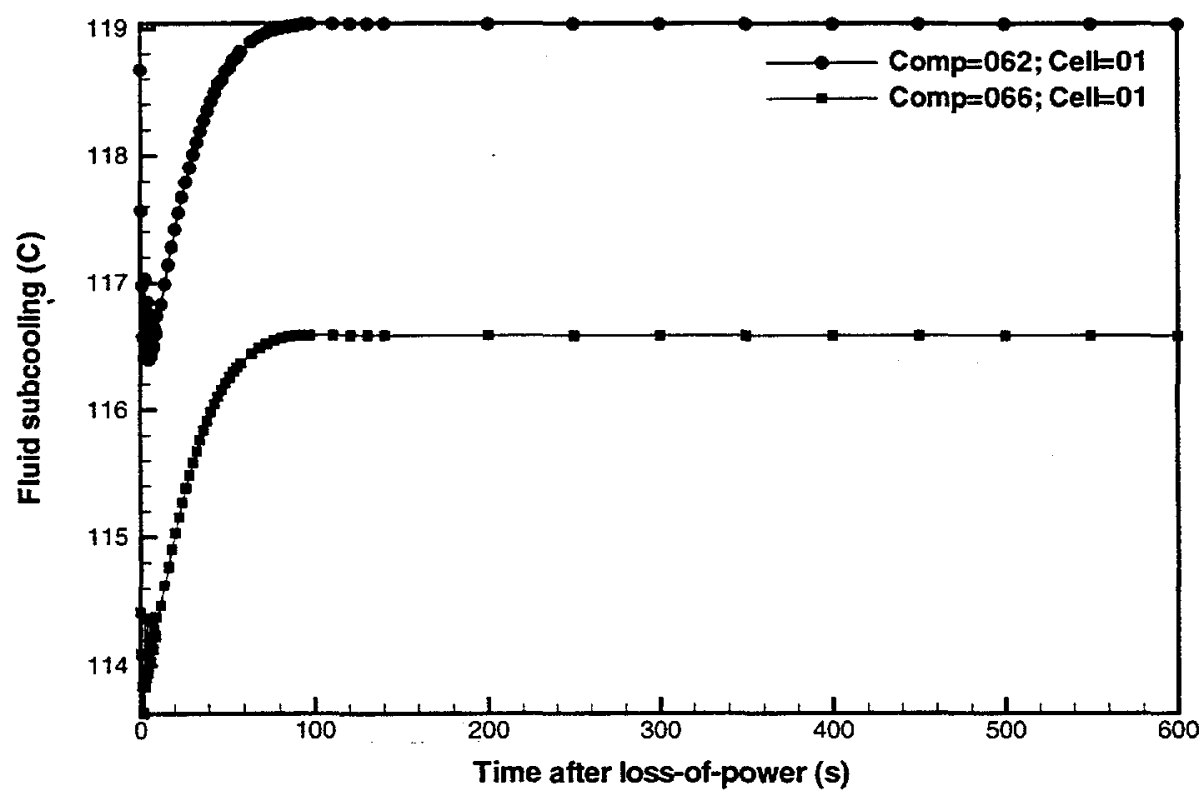

Figure B-14c Primary HR cold-leg piping fluid subcoolings for a LOFA (Case 1: with beam shutdown and active RHR). 


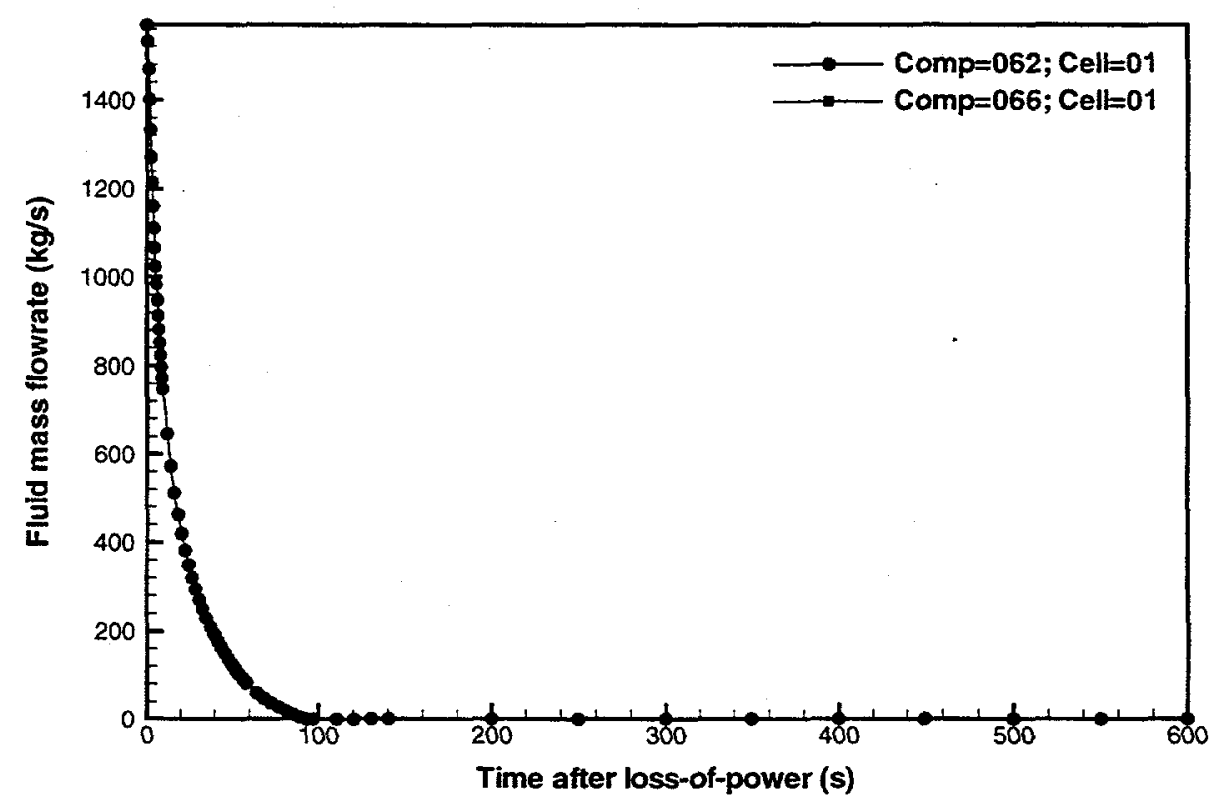

Figure B-14d Primary HR cold-leg piping liquid mass flowrätes for a LOFA (Case 1: with beam shutdown and active RHR).

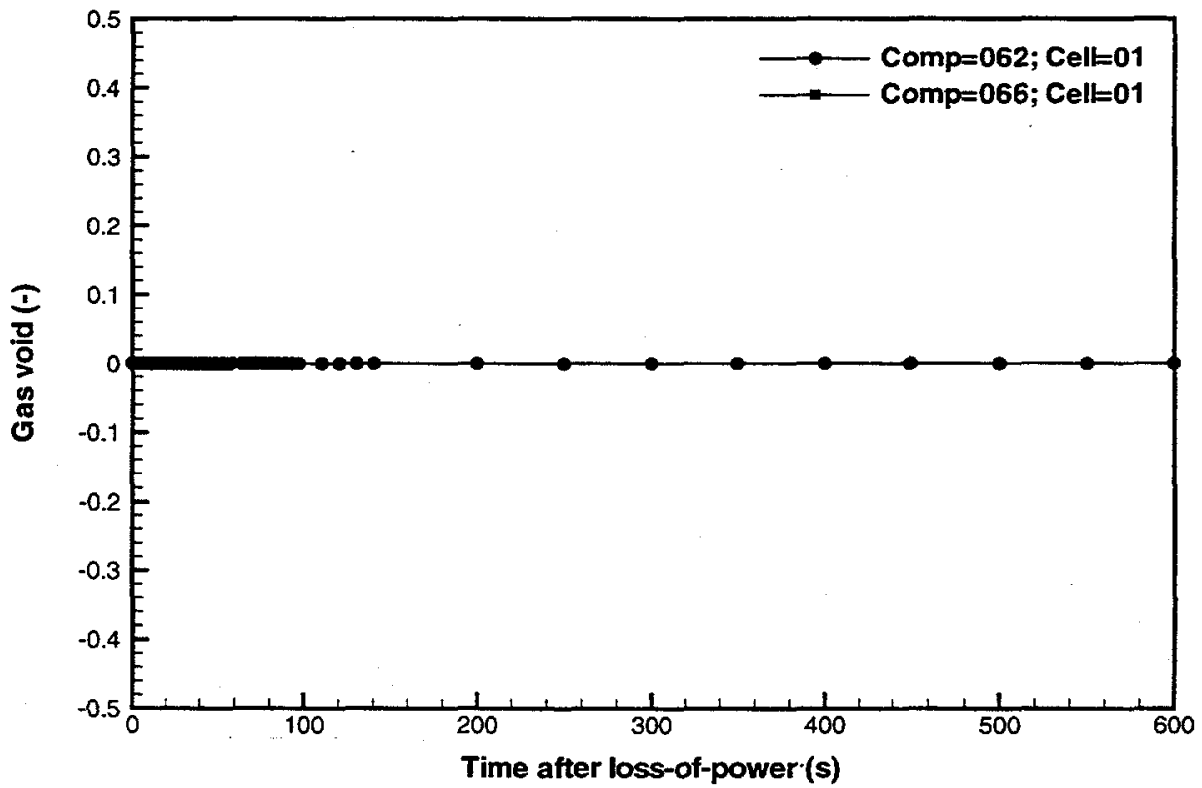

Figure B-14e Primary HR cold-leg piping void fractions for a LOFA (Case 1: with beam shutdown and active RHR). 


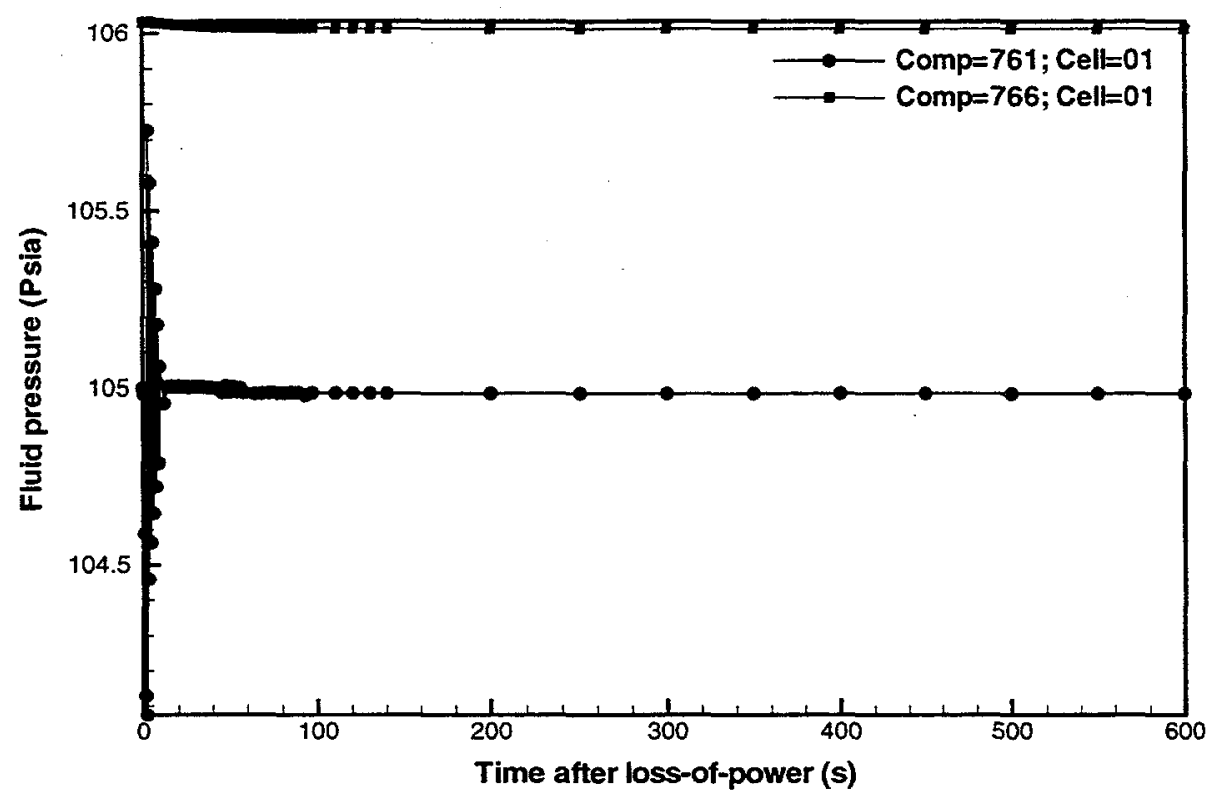

Figure B-15a Primary HR pressurizer and surge line fluid pressures for a LOFA (Case 1: with beam shutdown and active RHR).

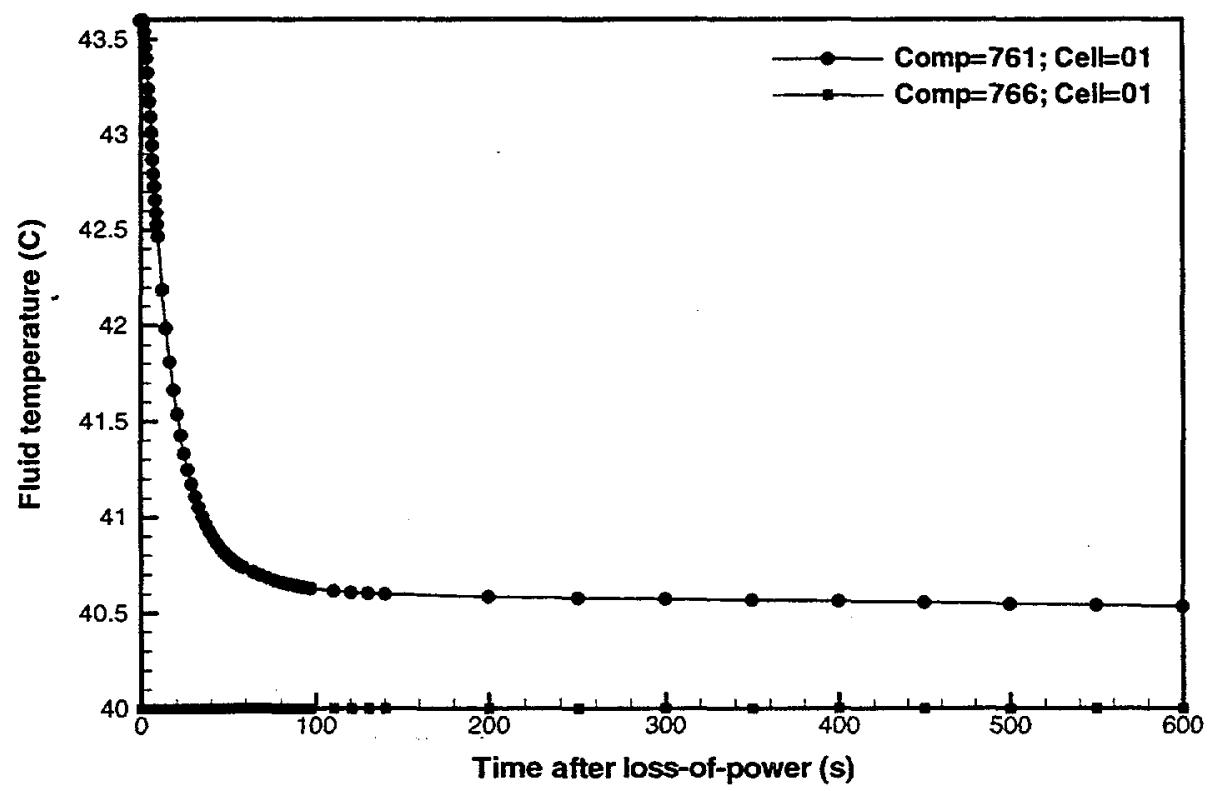

Figure B-15b Primary HR pressurizer and surge line fluid temperatures for a LOFA (Case 1: with beam shutdown and active RHR). 


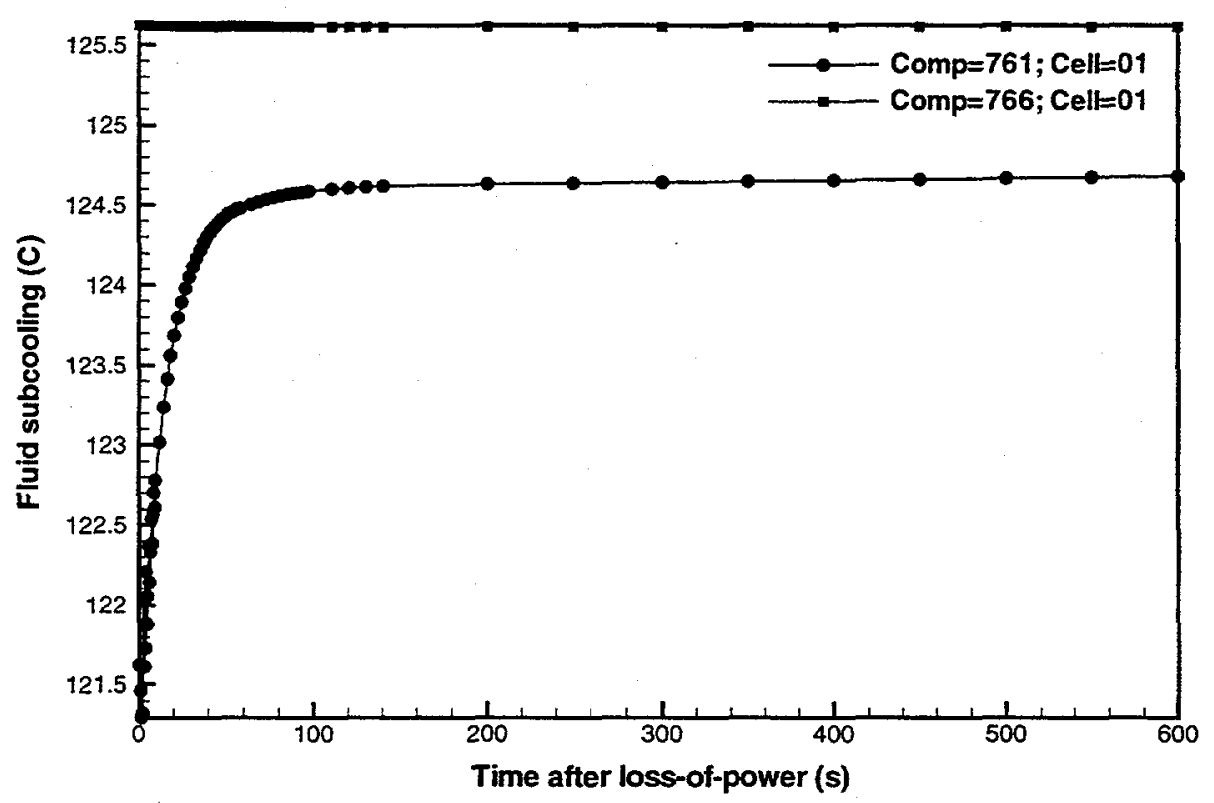

Figure B-15c Primary HR pressurizer and surge line fluid subcoolings for a LOFA (Case 1: with beam shutdown and active RHR).

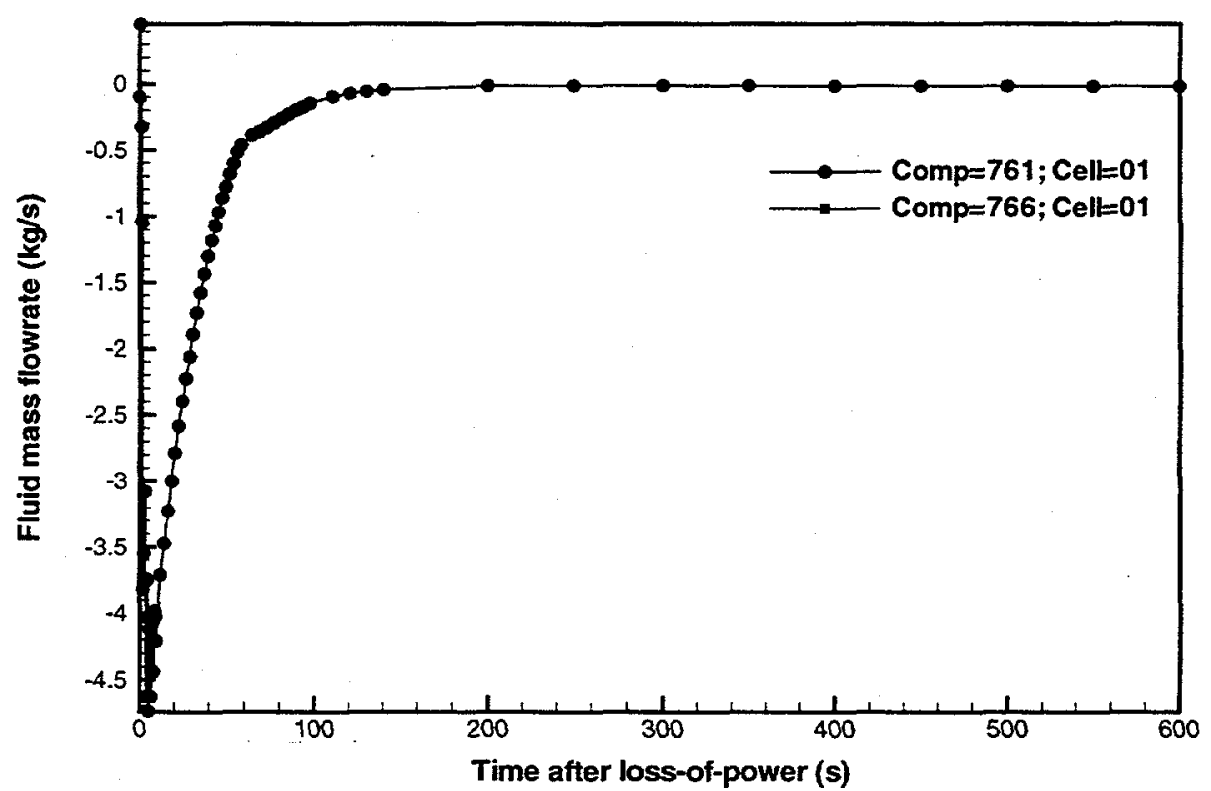

Figure B-15d Primary HR pressurizer and surge line liquid mass flowrates for a LOFA (Case 1: with beam shutdown and active RHR). 


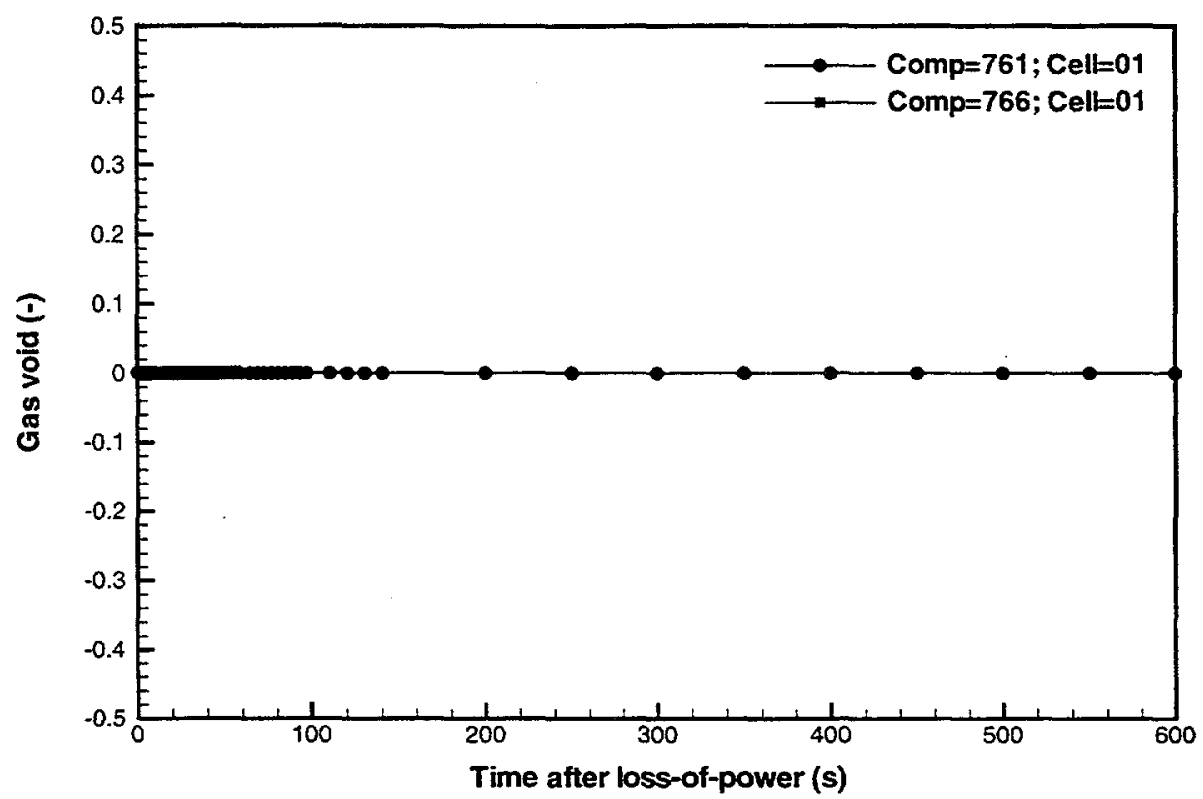

Figure B-15e Primary HR pressurizer and surge line void fractions for a LOFA (Case 1: with beam shutdown and active RHR).

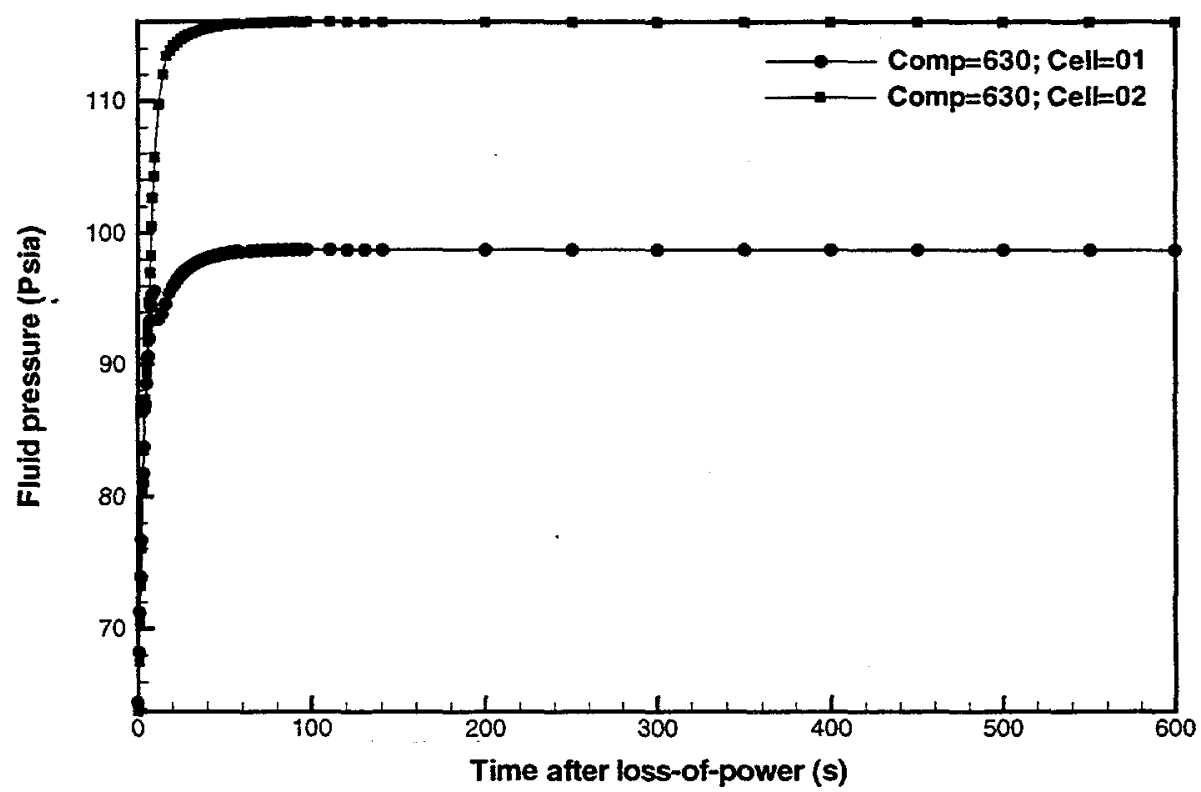

Figure B-16a Primary RHR pump fluid pressures for a LOFA (Case 1: with beam shutdown and active RHR). 


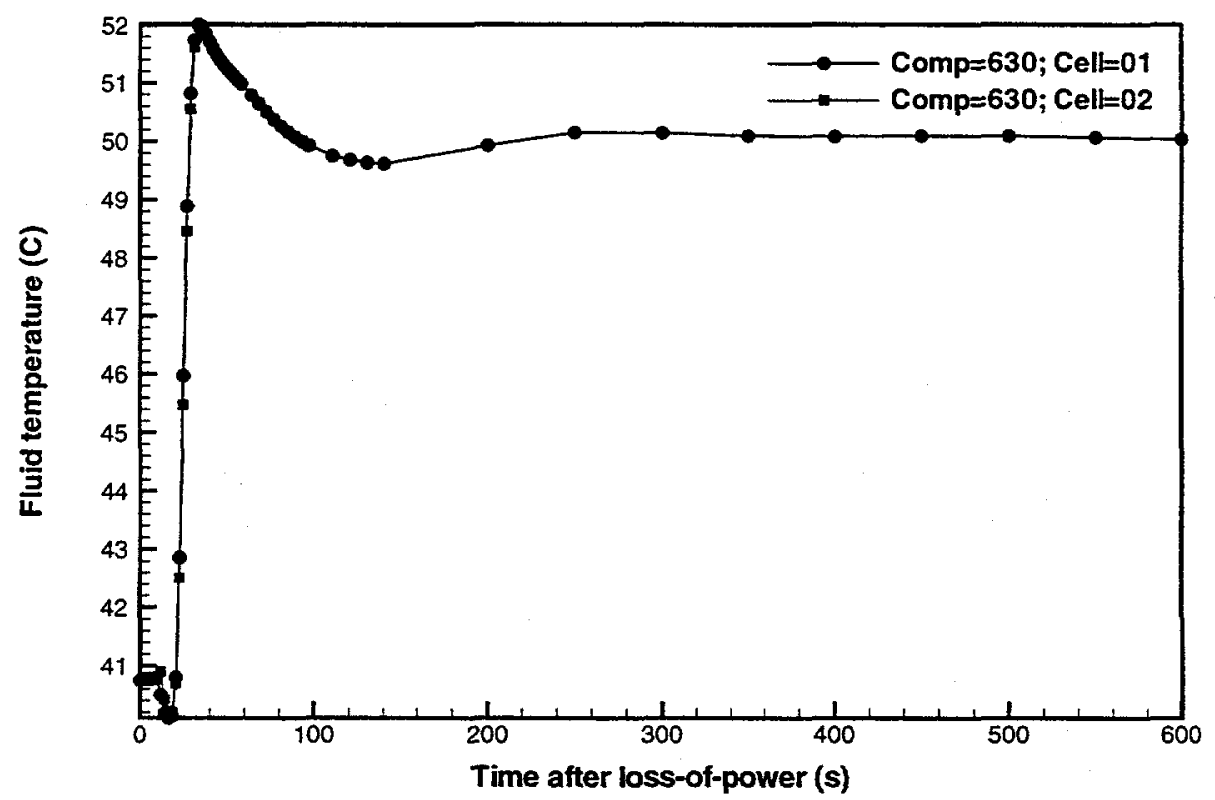

Figure B-16b Primary RHR pump fluid temperatures for a LOFA (Case 1: with beam shutdown and active RHR).

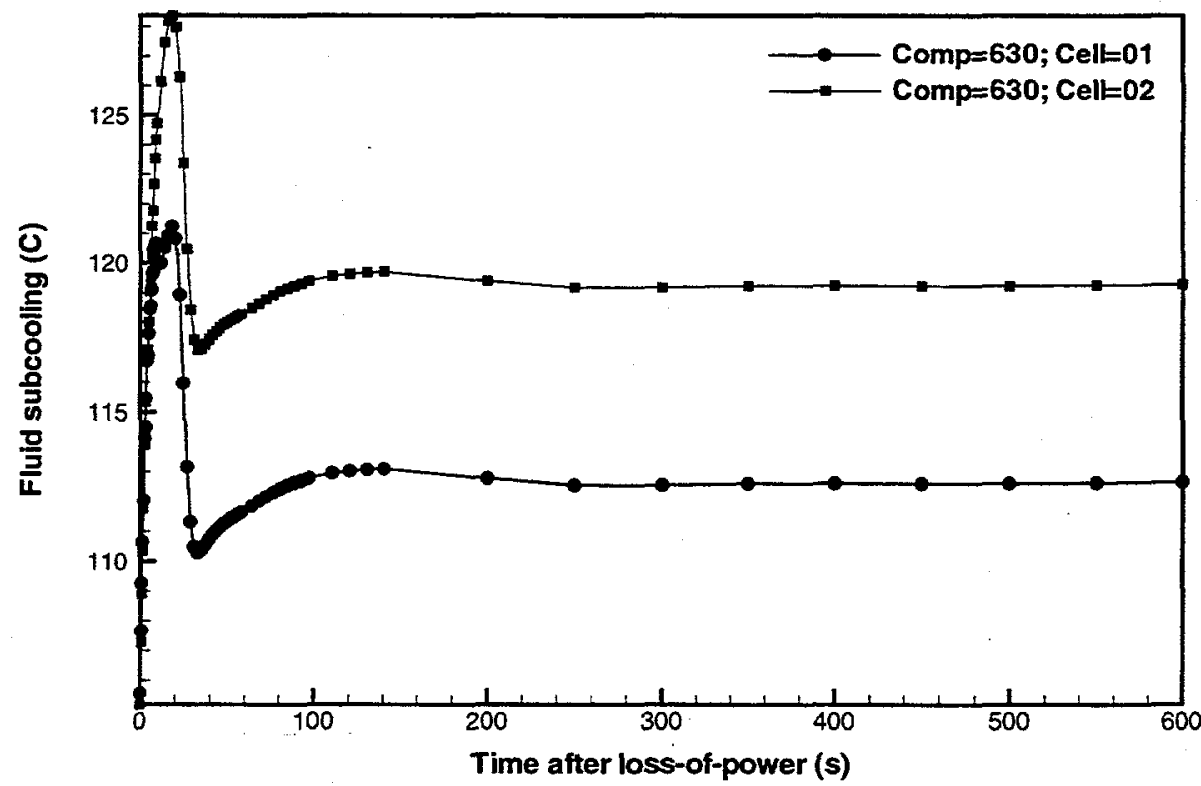

Figure B-16c Primary RHR pump fluid subcoolings for a LOFA (Case 1: with beam shutdown and active RHR). 


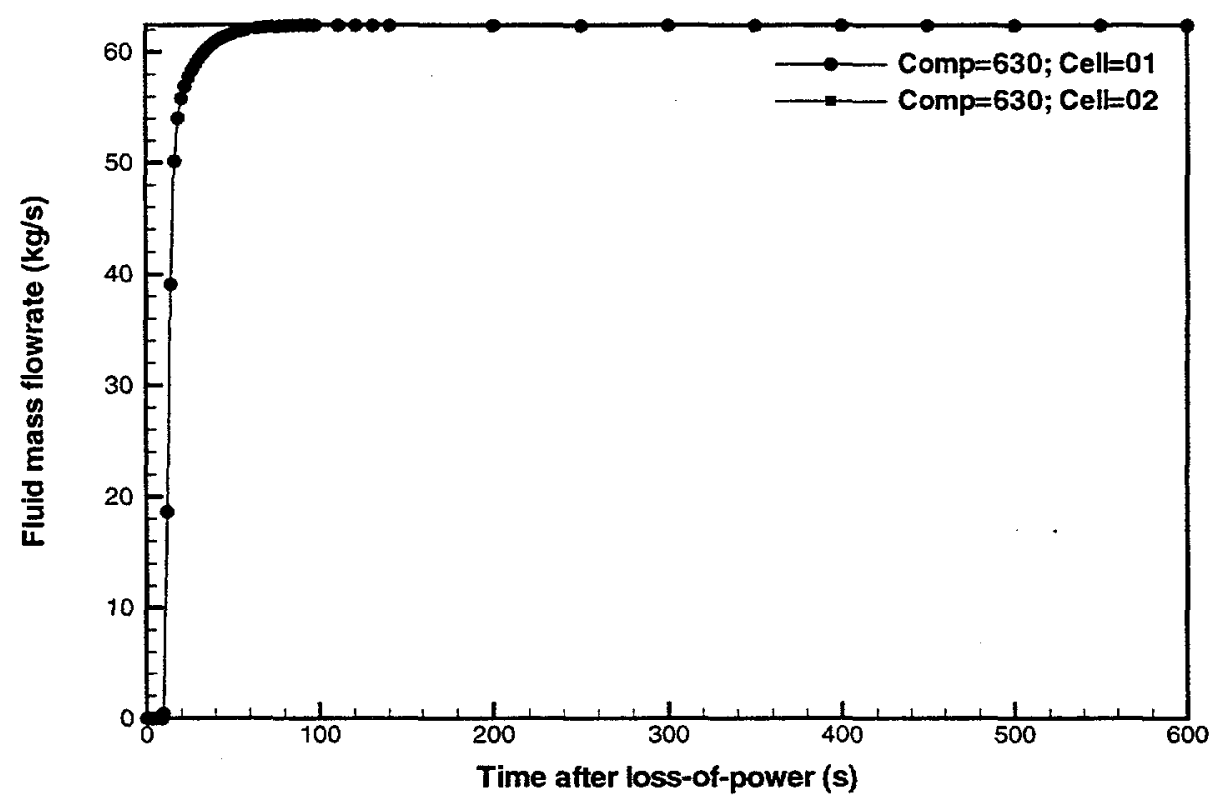

Figure B-16d Primary RHR pump liquid mass flowrates for a LOFA (Case 1: with beam shutdown and active RHR).

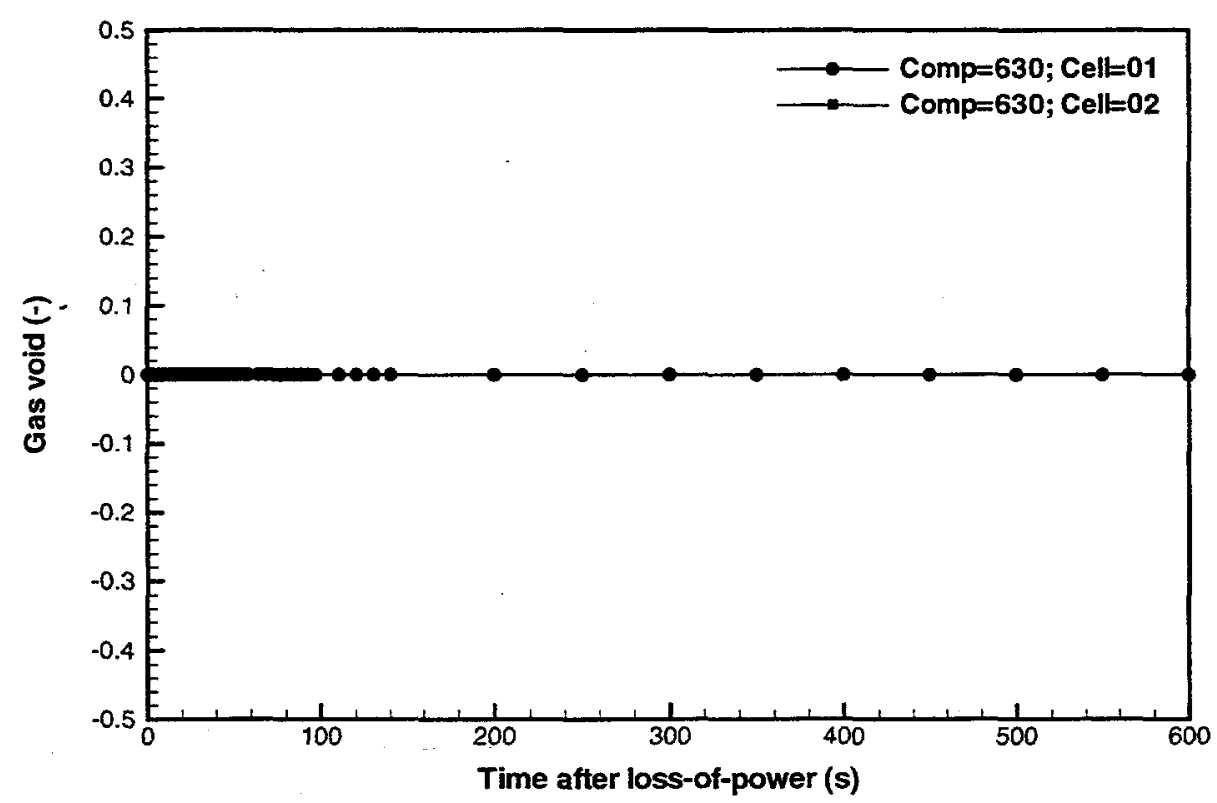

Figure B-16e Primary RHR pump void fractions for a LOFA (Case 1: with beam shutdown and active RHR). 


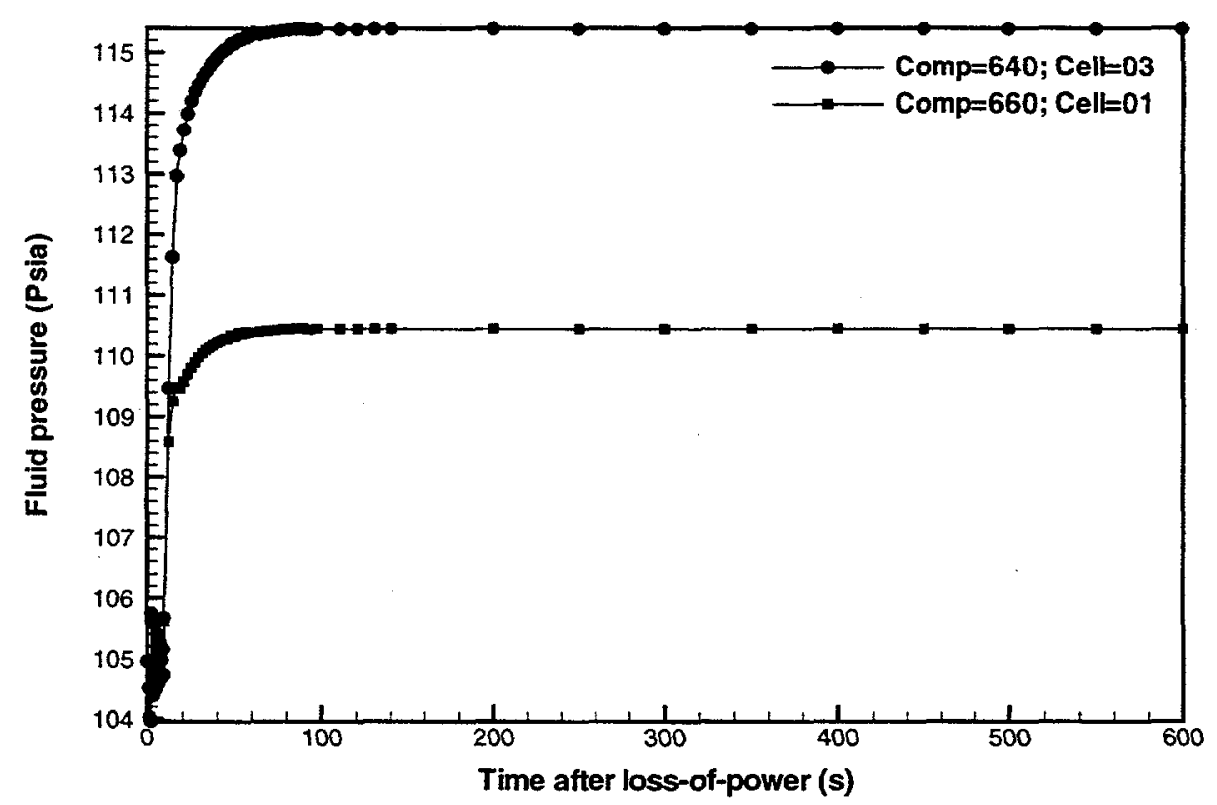

Figure B-17a Primary RHR heat exchanger fluid pressures för a LOFA (Case 1: with beam shutdown and active RHR).

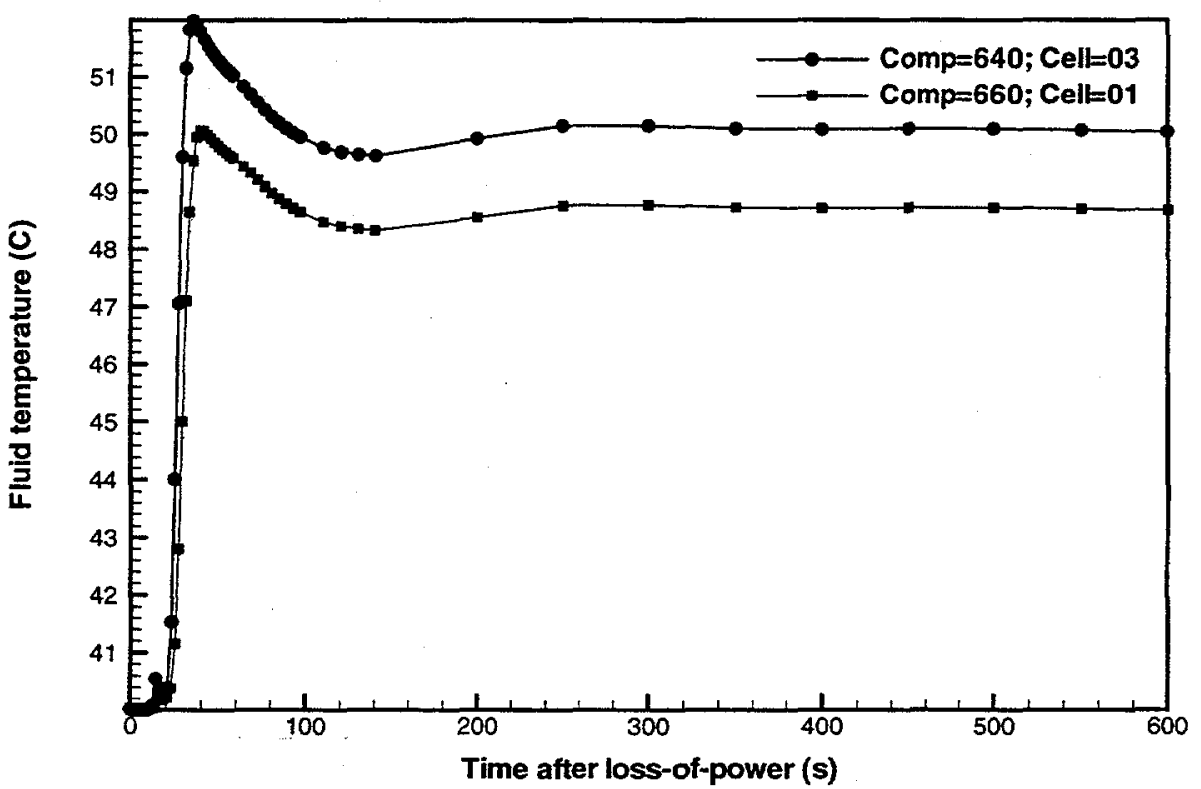

Figure B-17b Primary RHR heat exchanger fluid temperatures for a LOFA (Case 1: with beam shutdown and active RHR). 


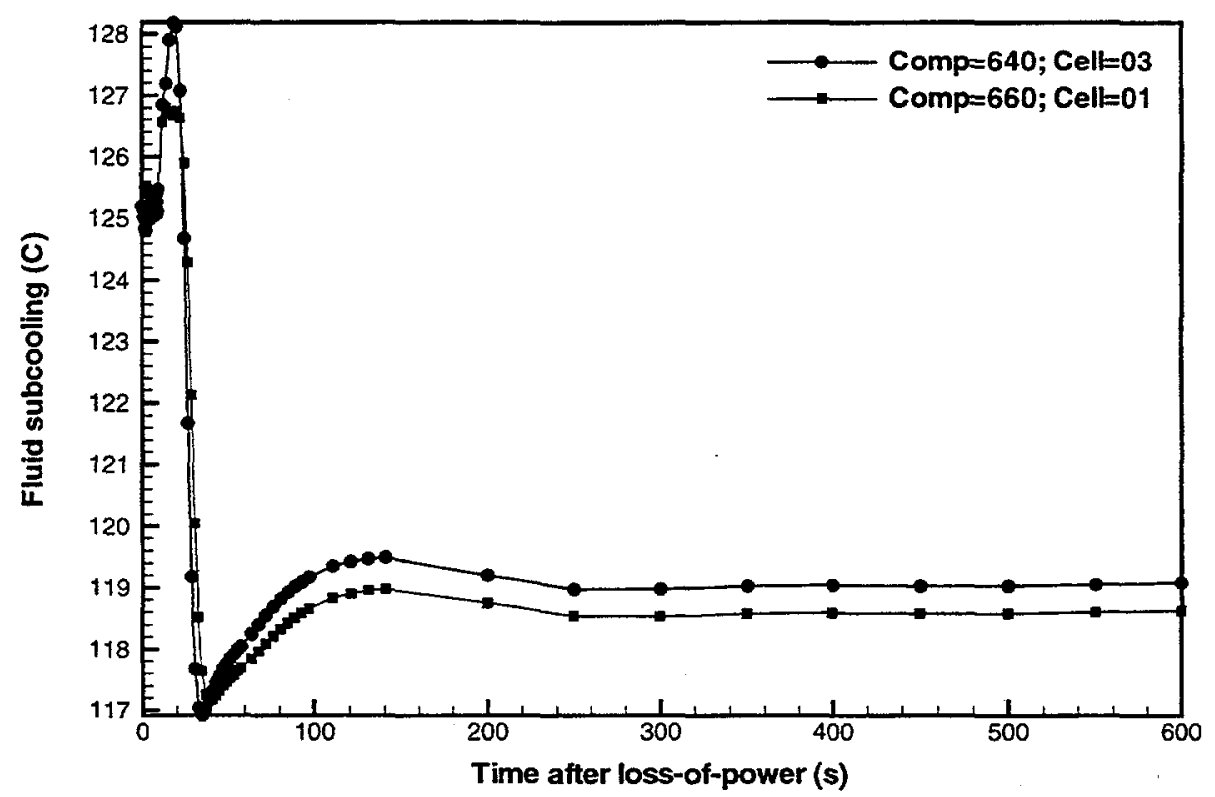

Figure B-17c Primary RHR heat exchanger fluid subcoolings for a LOFA (Case 1: with beam shutdown and active RHR).

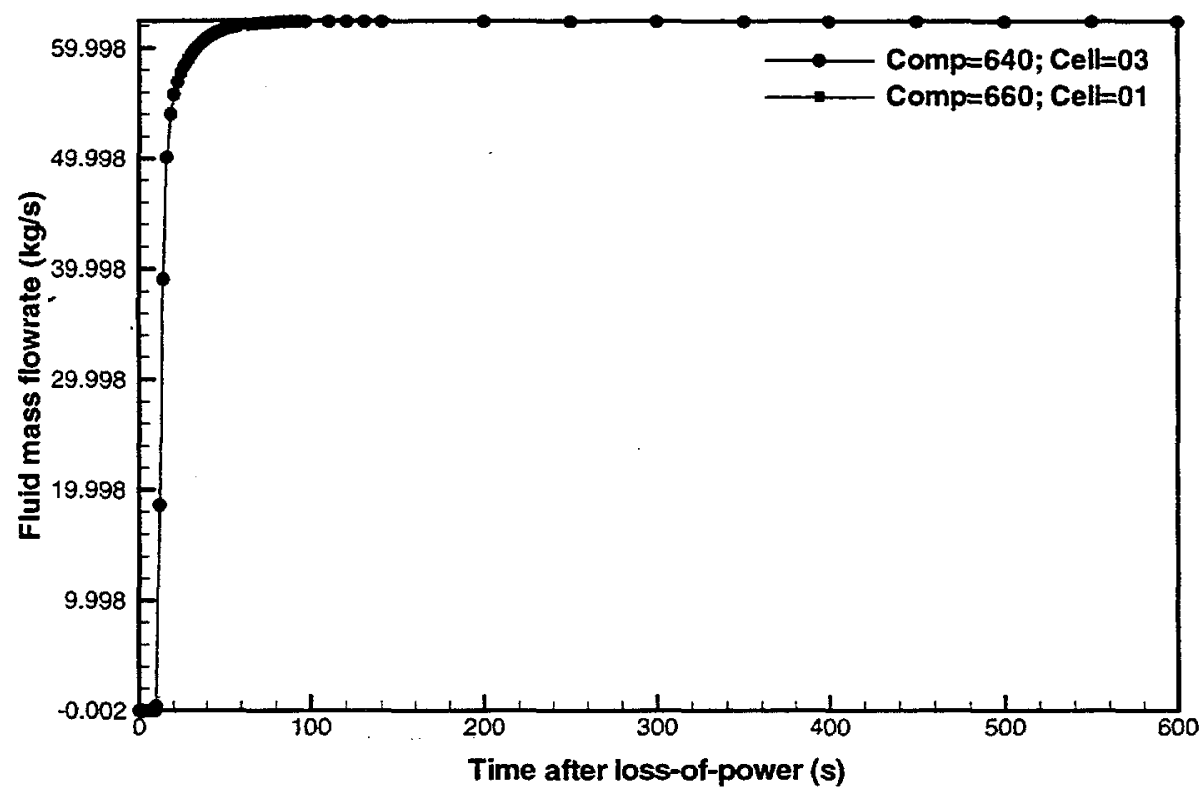

Figure B-17d Primary RHR heat exchanger liquid mass flowrates for a LOFA (Case 1: with beam shutdown and active RHR). 


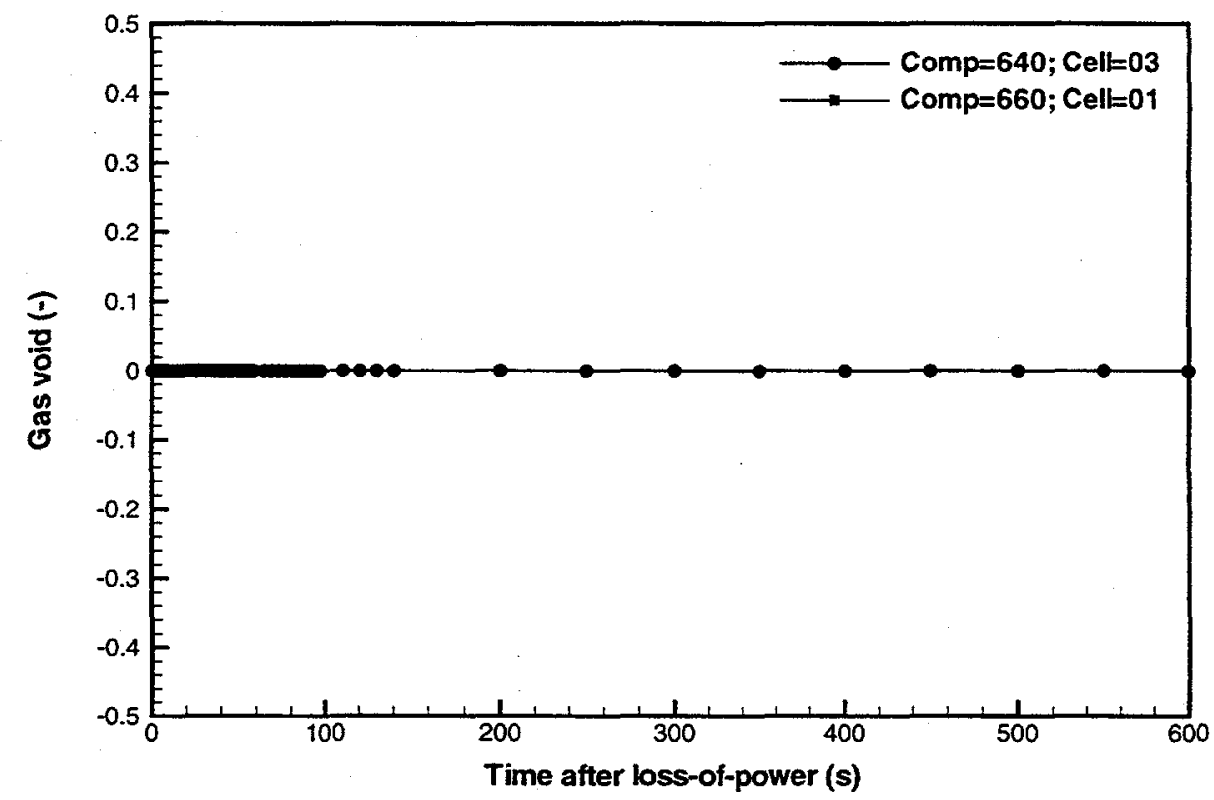

Figure B-17e Primary RHR heat exchanger void fractions för a LOFA (Case 1: with beam shutdown and active RHR).

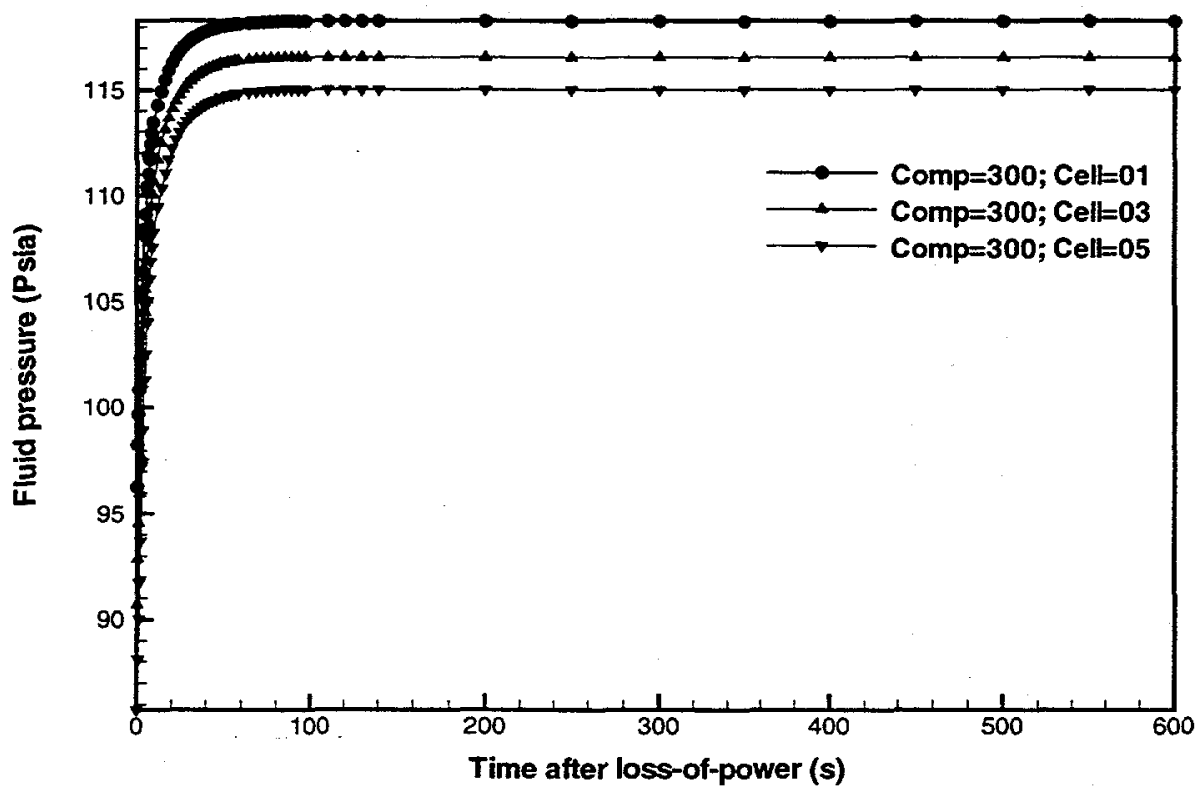

Figure B-18a Module 1 channel fluid pressures for a LOFA (Case 1: with beam shutdown and active RHR). 


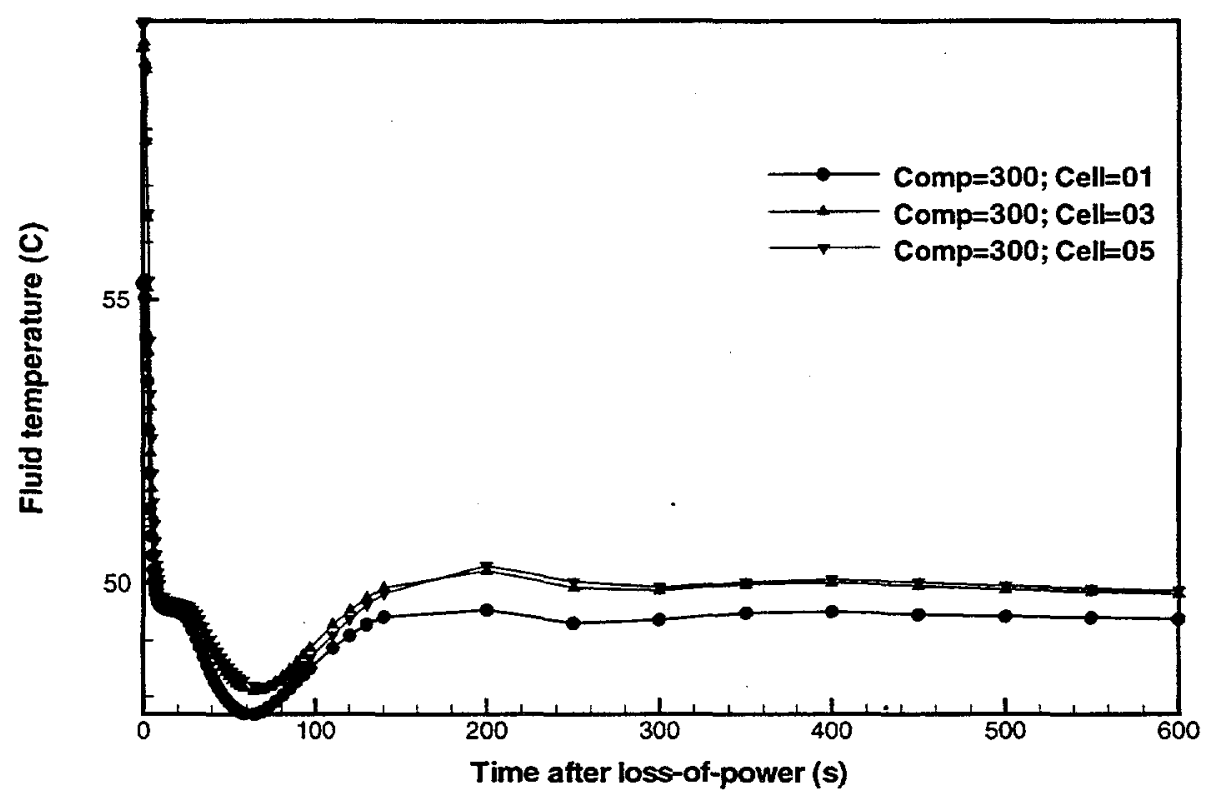

Figure B-18b Module 1 channel fluid temperatures for a LOFA (Case 1: with beam shutdown and active RHR).

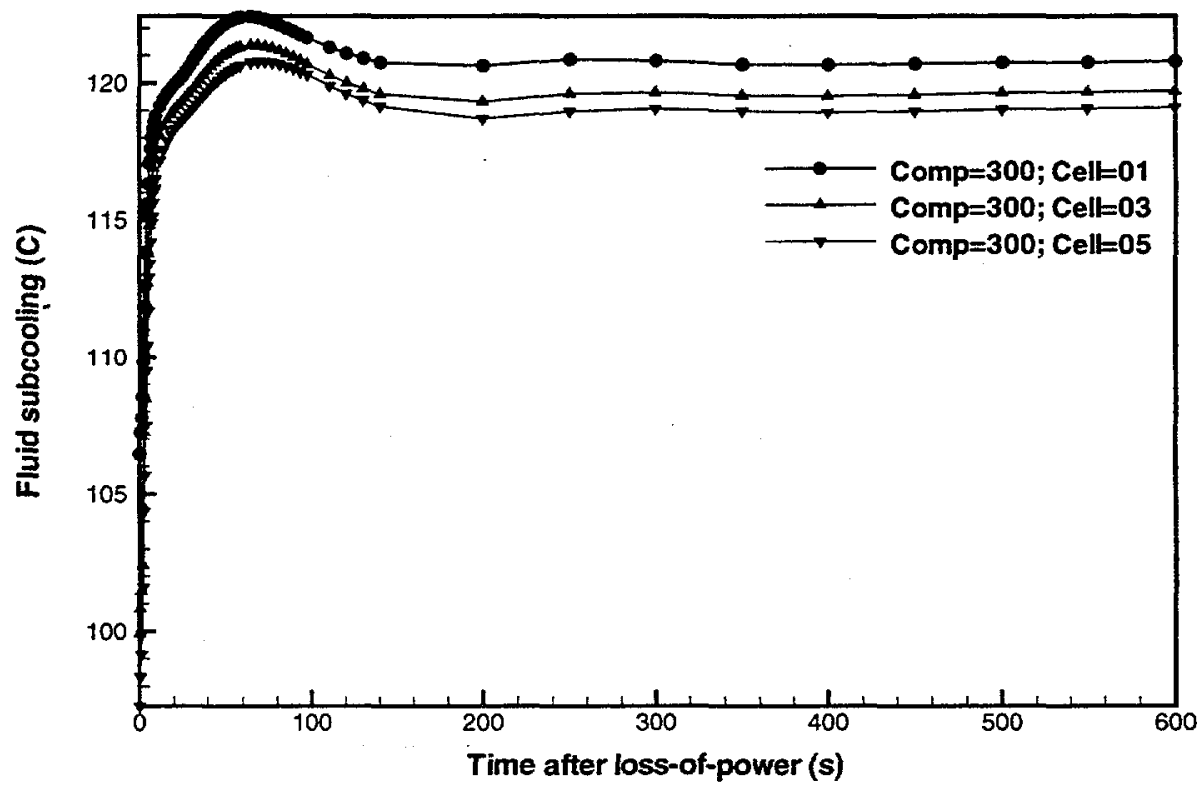

Figure B-18c Module 1 channel fluid subcoolings for a LOFA (Case 1: with beam shutdown and active RHR). 


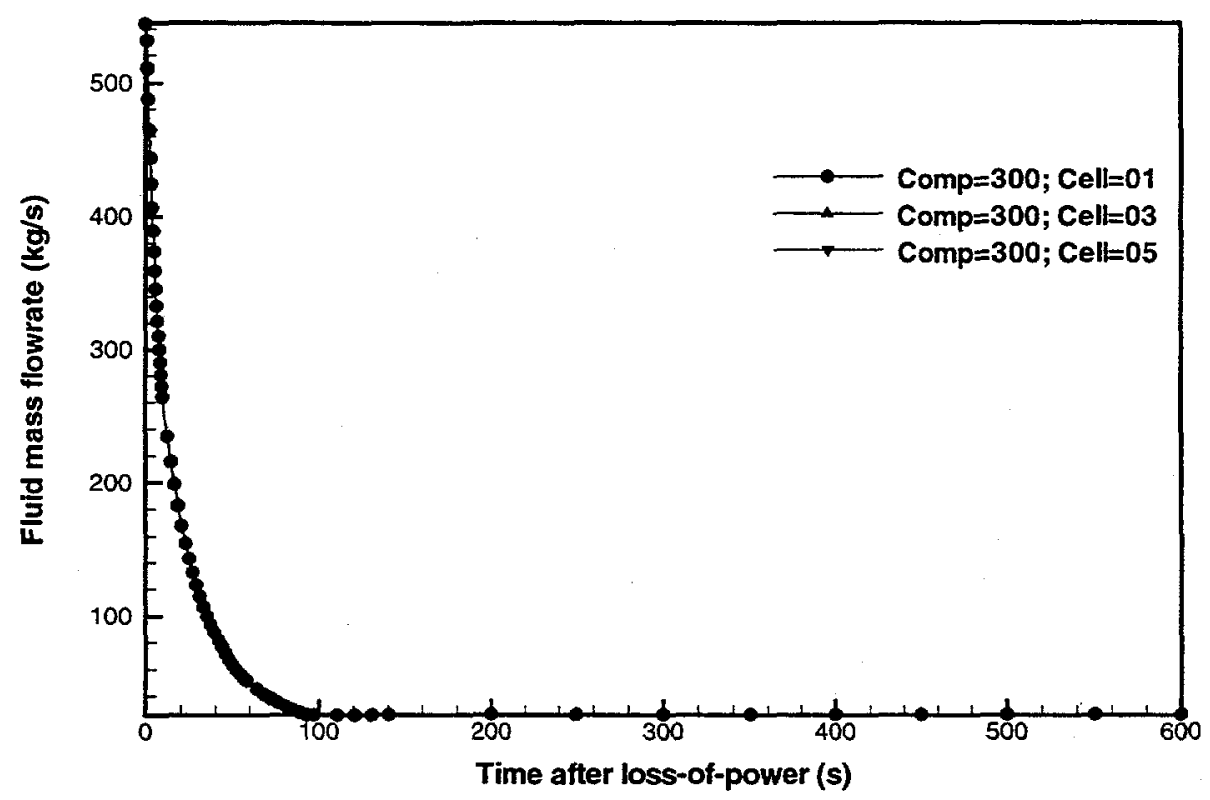

Figure B-18d Module 1 channel liquid mass flowrates for a LOFA (Case 1: with beam shutdown and active RHR).

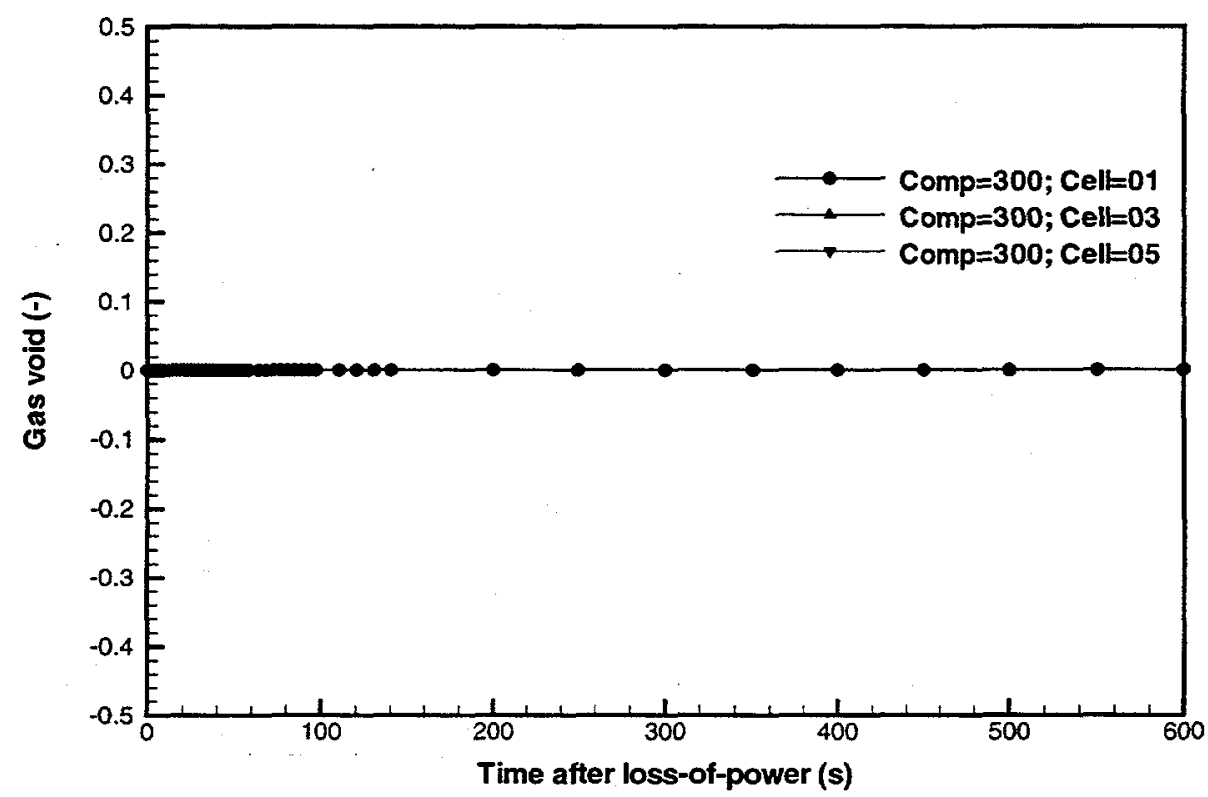

Figure B-8e Module 1 channel void fractions for a LOFA (Case 1: with beam shutdown and active RHR). 


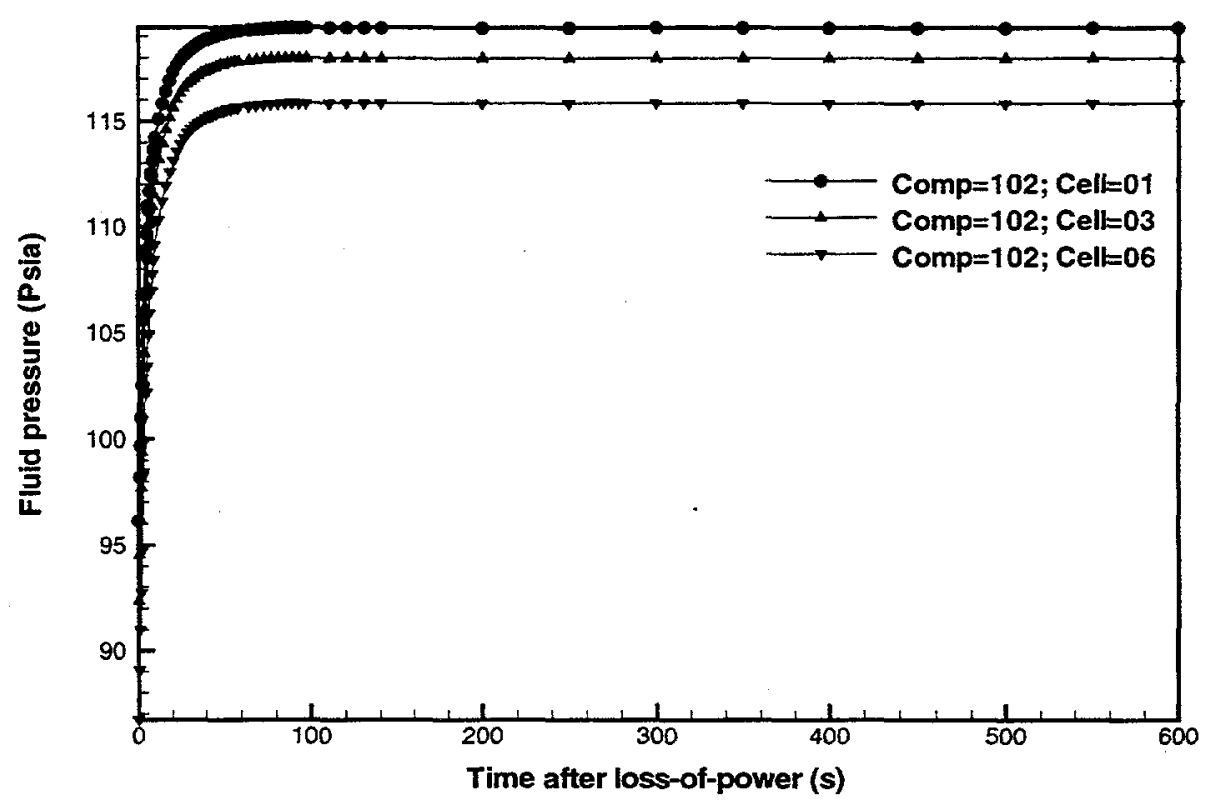

Figure B-19a Module 2 channel fluid pressures for a LOFA (Case-1: with beam shutdown and active RHR).

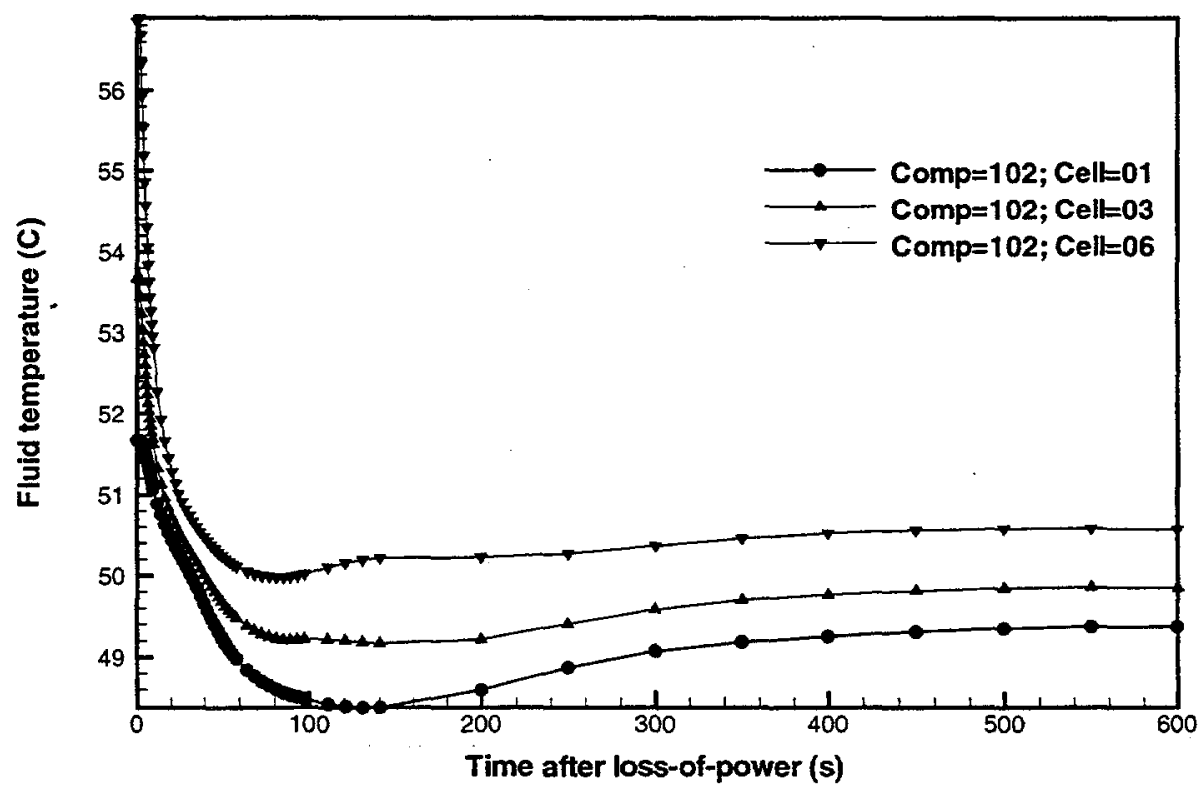

Figure B-19b Module 2 channel fluid temperatures for a LOFA (Case 1: with beam shutdown and active RHR). 


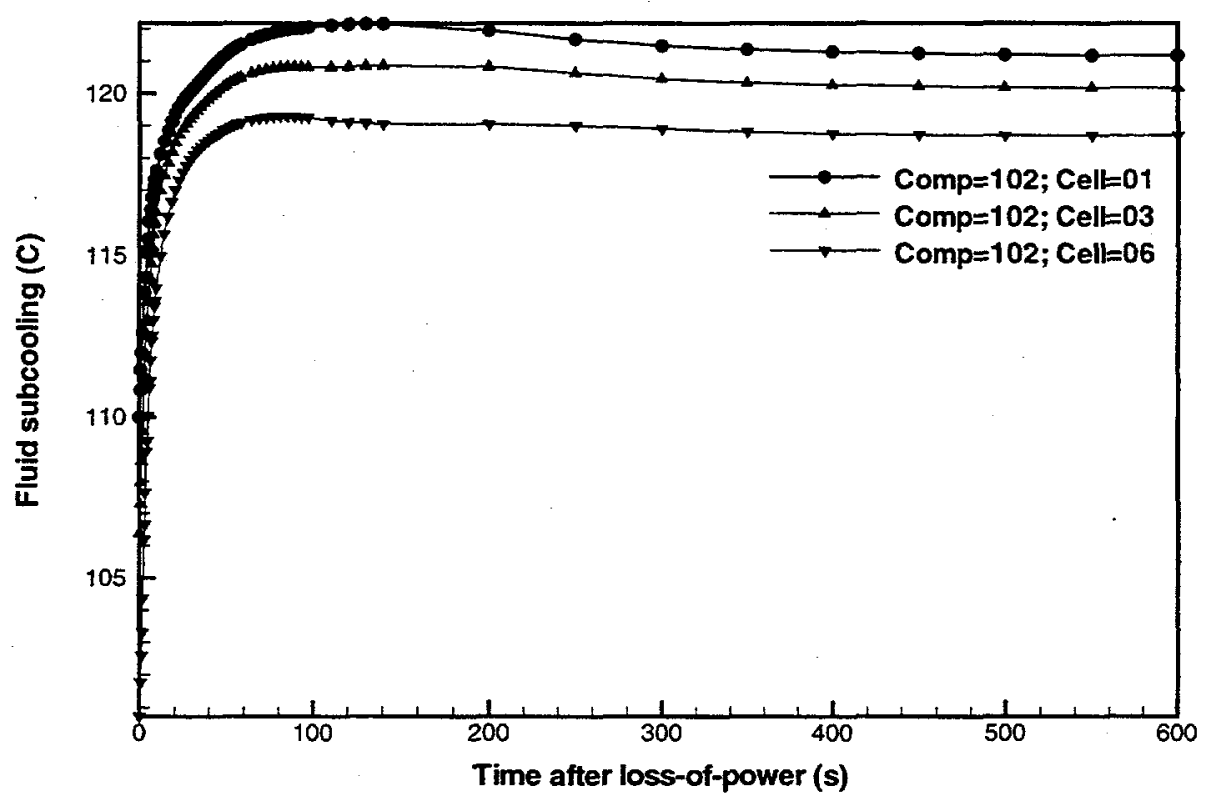

Figure B-19c Module 2 channel fluid subcoolings for a LOFA (Case 1: with beam shutdown and active RHR).

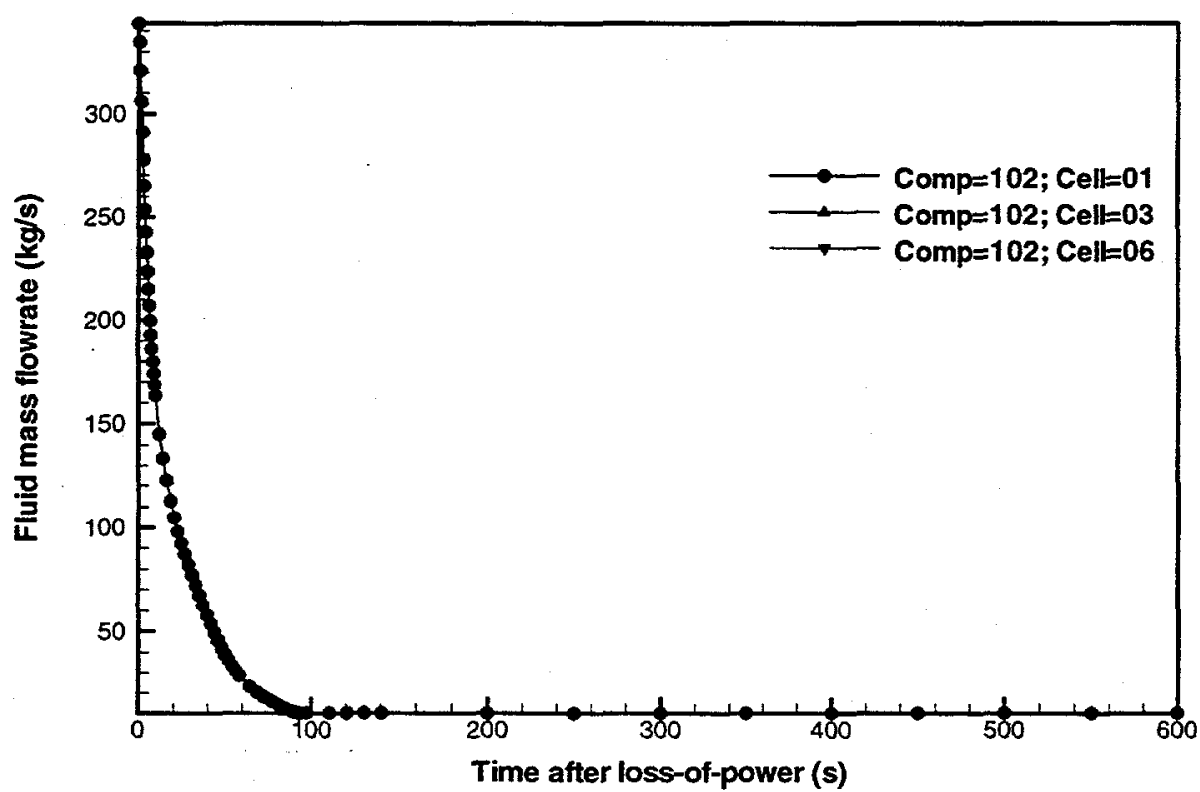

Figure B-19d Module 2 channel liquid mass flowrates for a LOFA (Case 1: with beam shutdown and active RHR). 


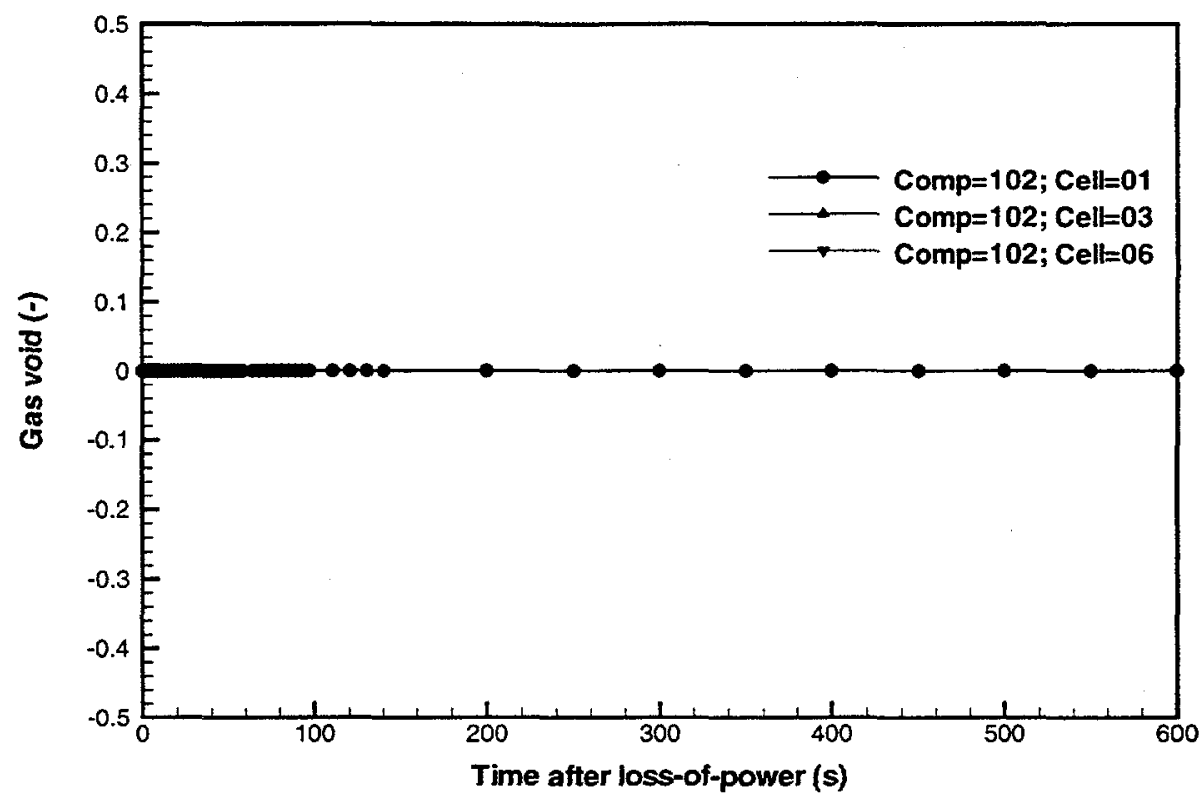

Figure B-19e Module 2 channel Module 2 channel void fractions for a LOFA (Case 1: with beam shutdown and active RHR).

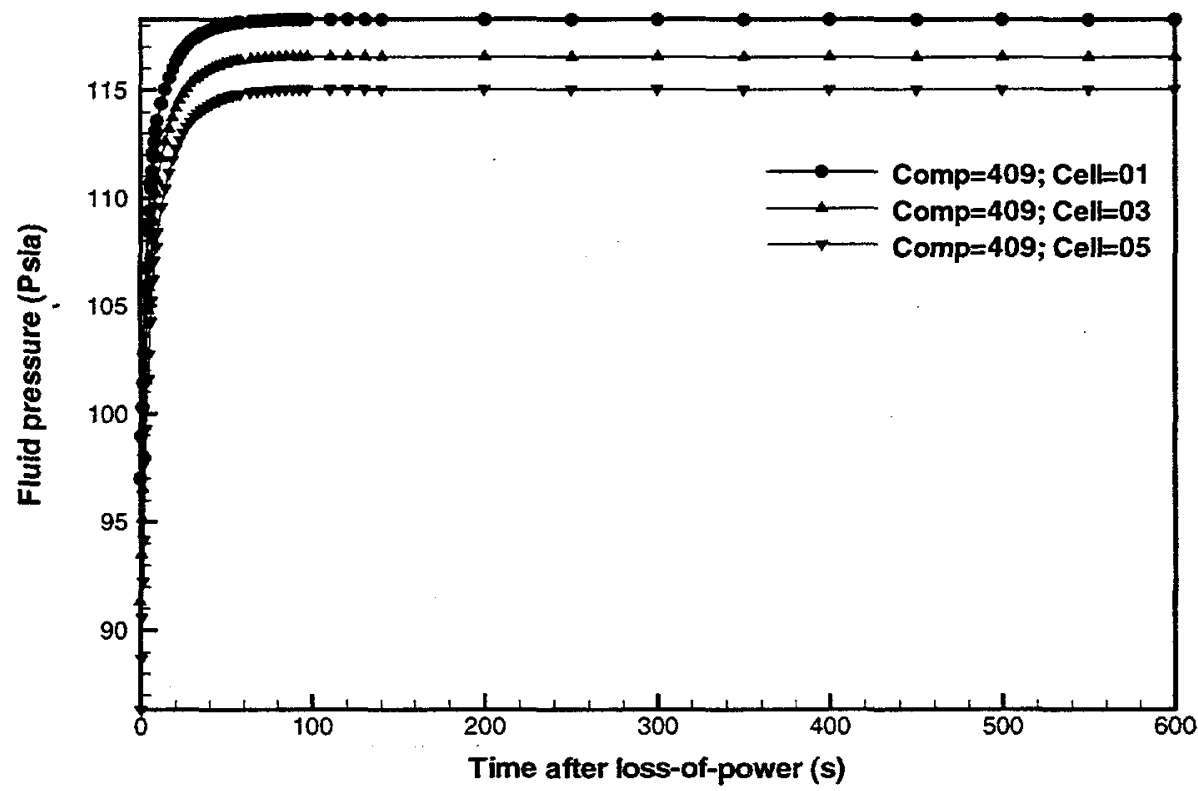

Figure B-20a Module 3 channel fluid pressures for a LOFA (Case 1: with beam shutdown and active RHR). 


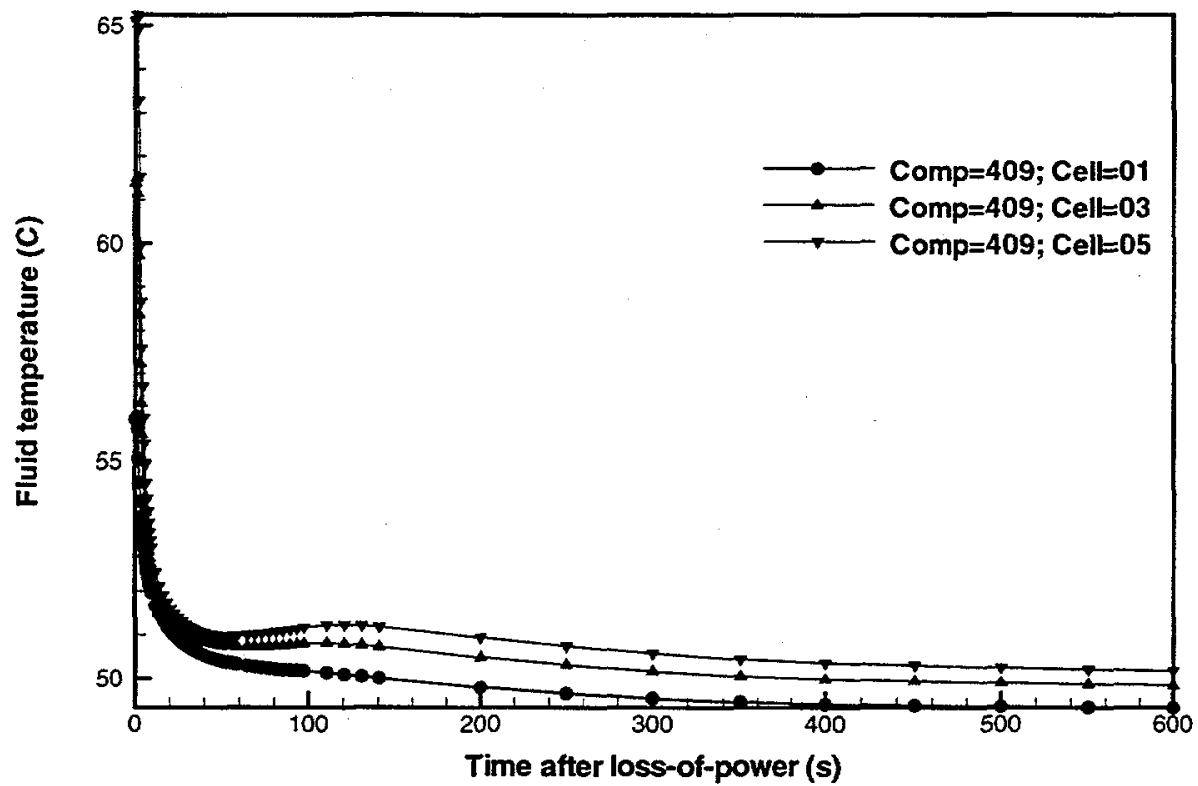

Figure B-20b Module 3 channel Module 3 channel fluid temperatures for a LOFA (Case 1: with beam shutdown and active RHR).

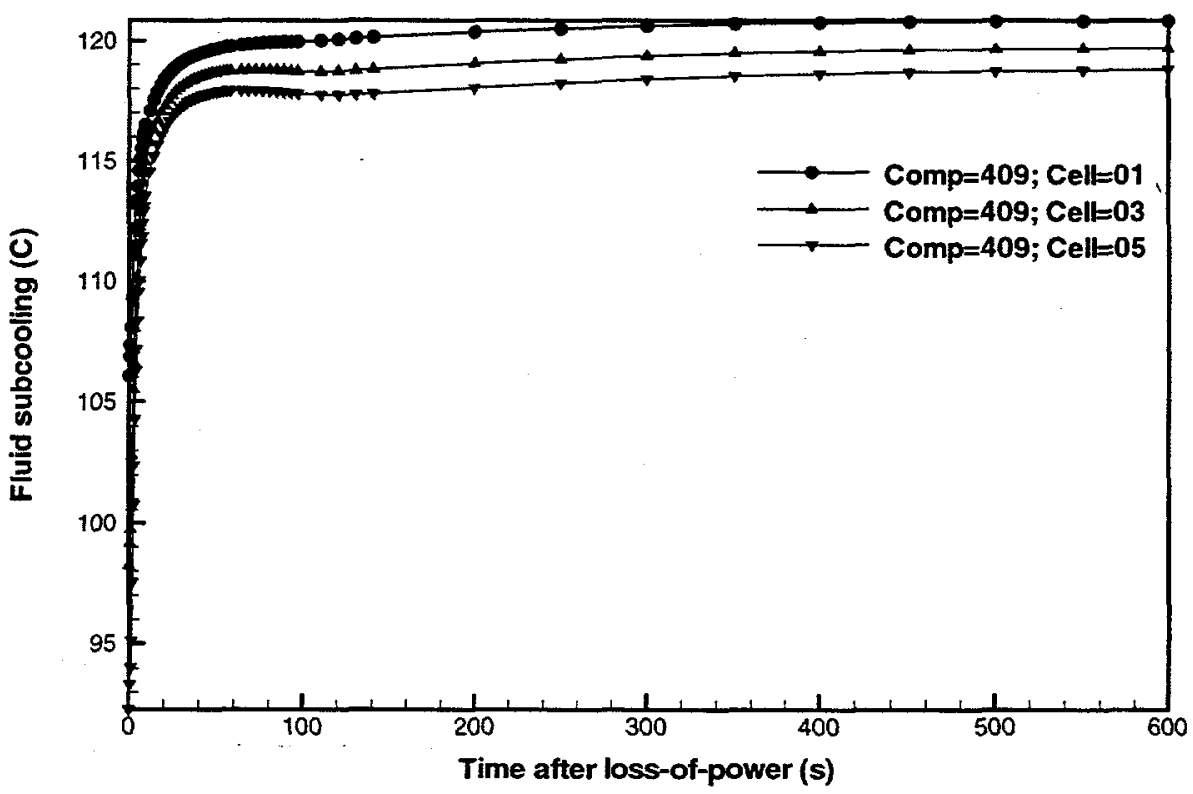

Figure B-20c Module 3 channel fluid subcoolings for a LOFA (Case 1: with beam shutdown and active RHR). 


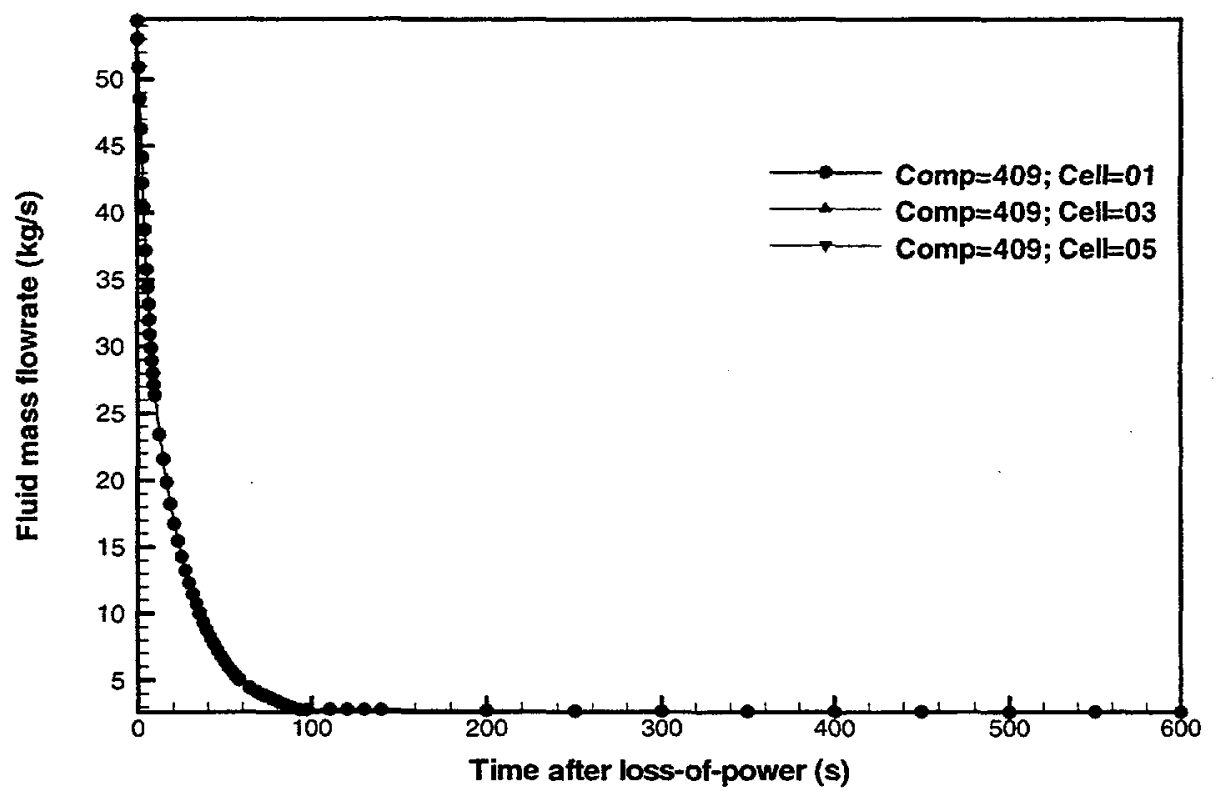

Figure B-20d Module 3 channel liquid mass flowrates for a LOFA (Case 1: with beam shutdown and active RHR).

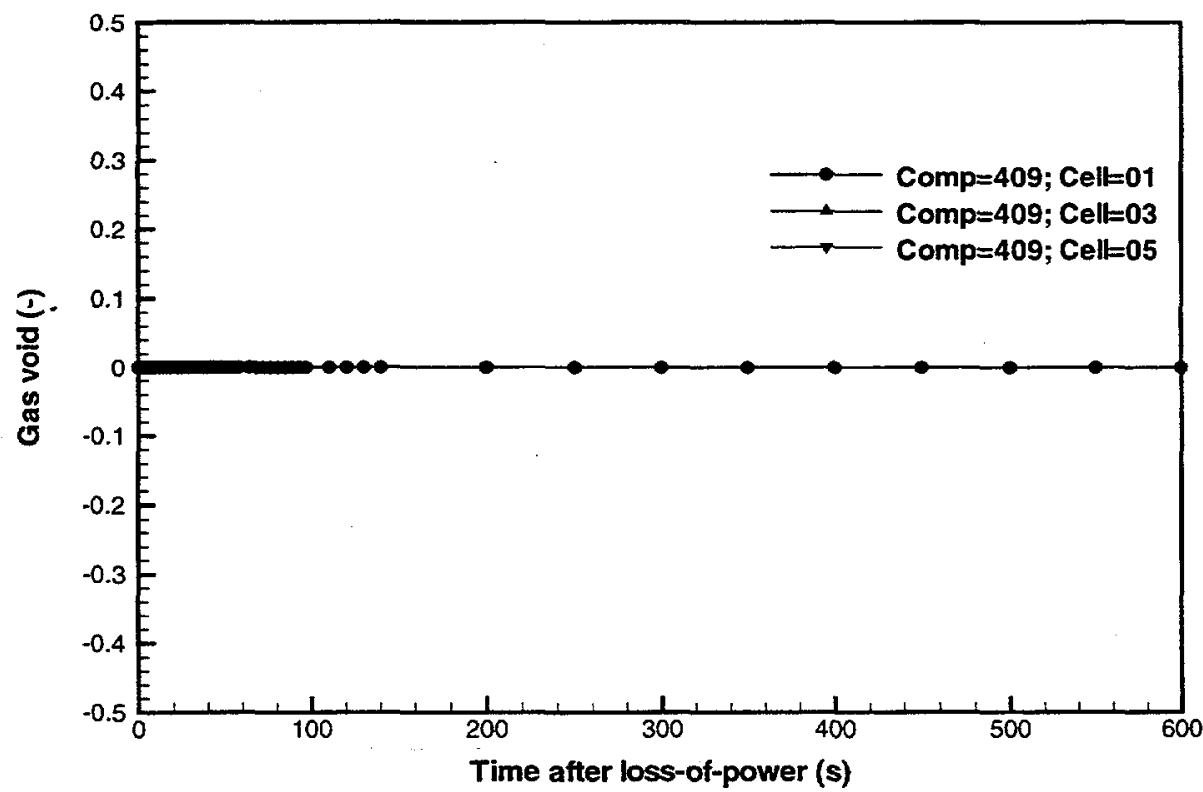

Figure B-20e Module 3 channel void fractions for a LOFA (Case 1: with beam shutdown and active RHR). 


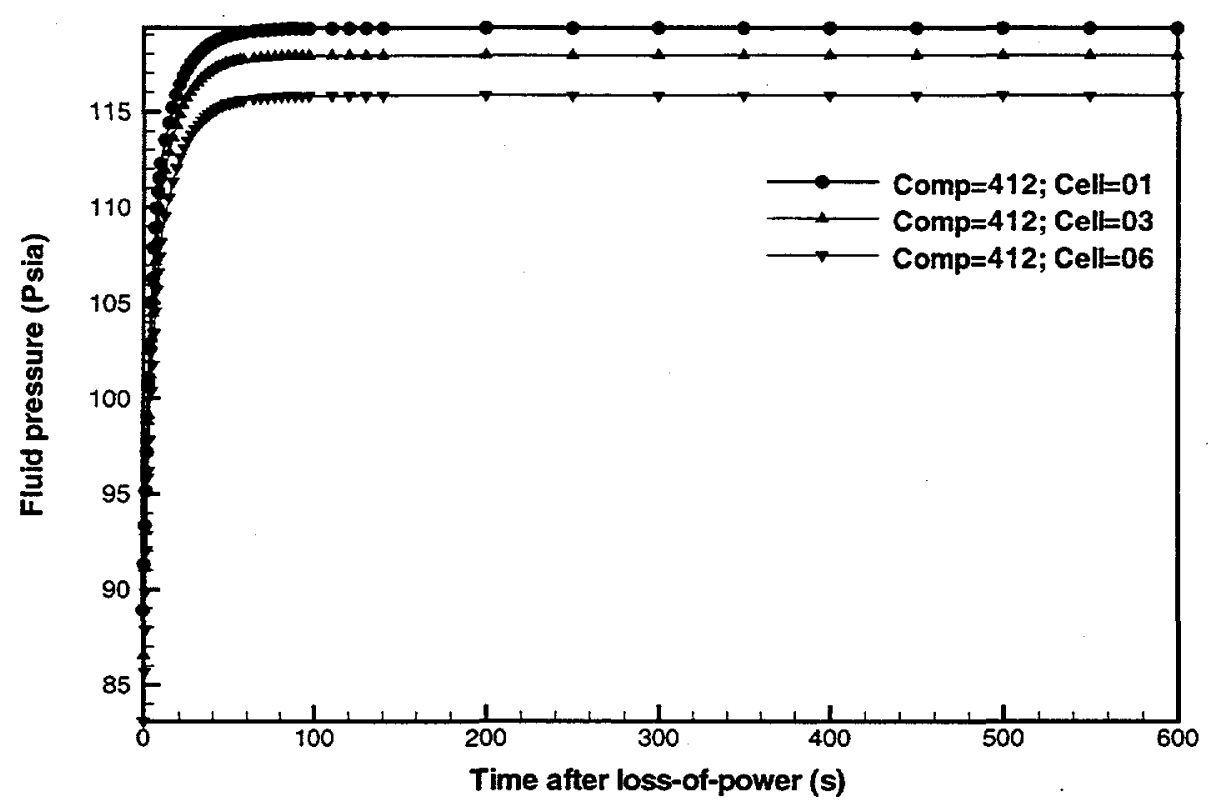

Figure B-21a Module 4 channel fluid pressures for a LOFA (Case 1: with beam shutdown and active RHR).

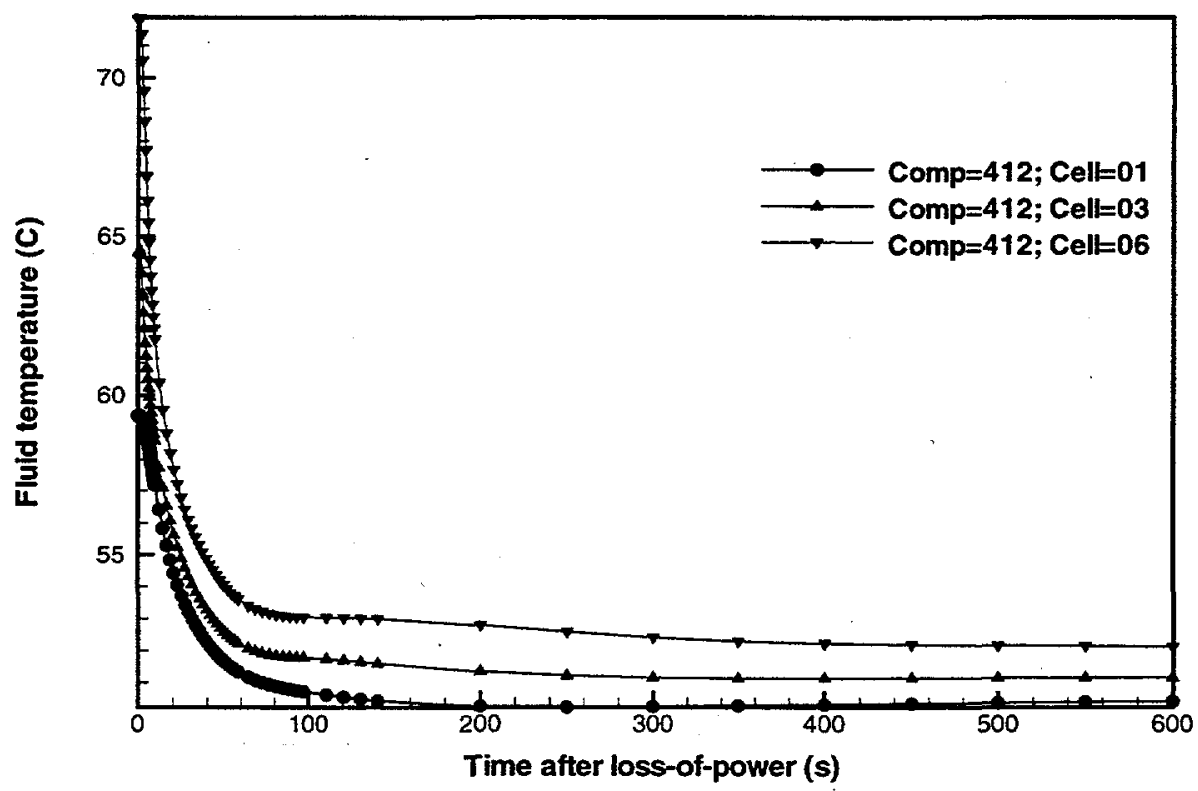

Figure B-21b Module 4 channel fluid temperatures for a LOFA (Case 1: with beam shutdown and active RHR). 


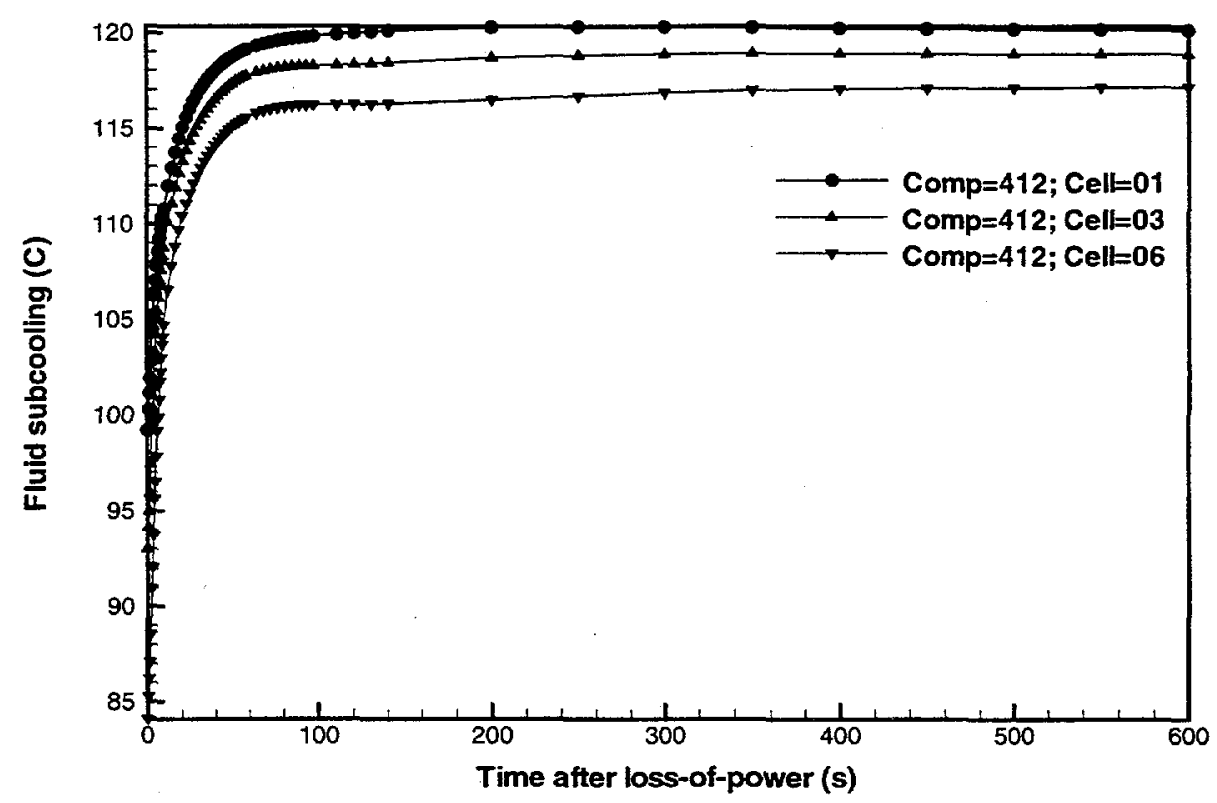

Figure B-21c Module 4 channel fluid subcoolings for a LOFA (Case 1: with beam shutdown and active RHR).

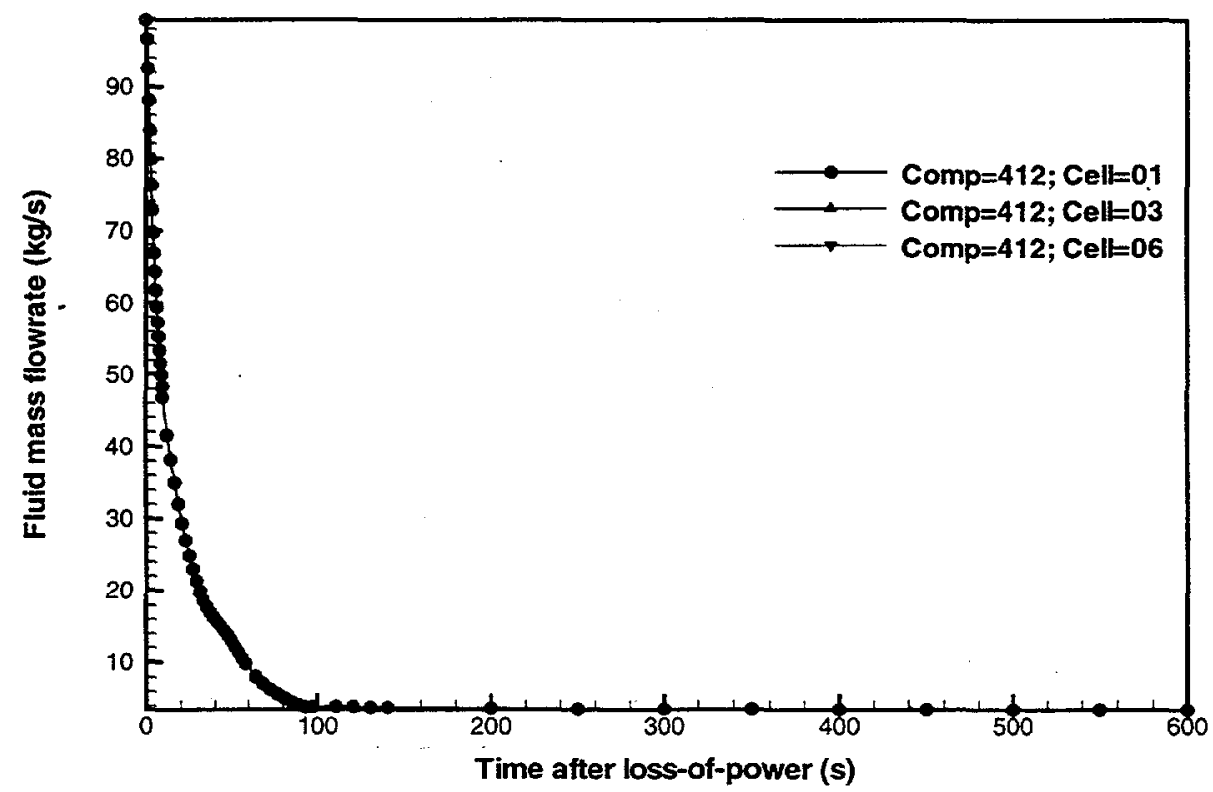

Figure B-21d Module 4 channel liquid mass flowrates for a LOFA (Case 1: with beam shutdown and active RHR). 


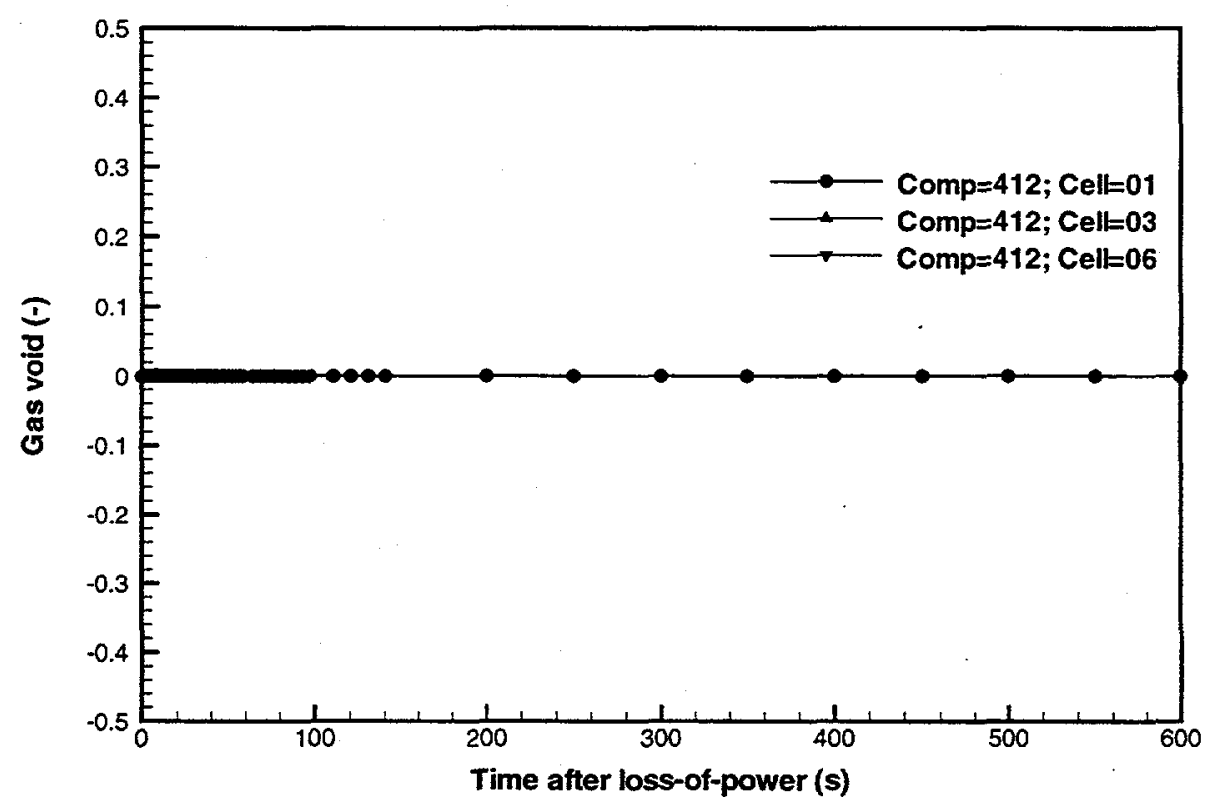

Figure B-21e Module 4 channel void fractions for a LOFA (Case 1: with beam shutdown and active RHR).

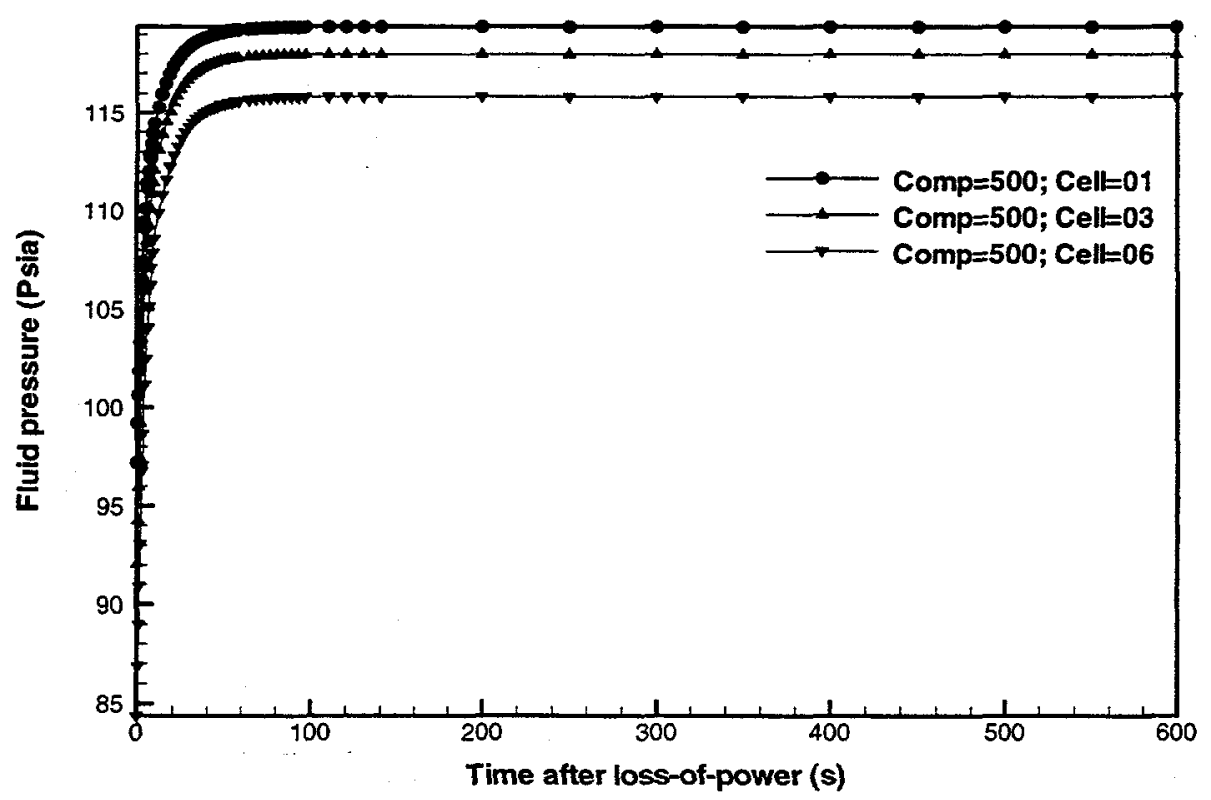

Figure B-22a Module 5 channel fluid pressures for a LOFA (Case 1: with beam shutdown and active RHR). 


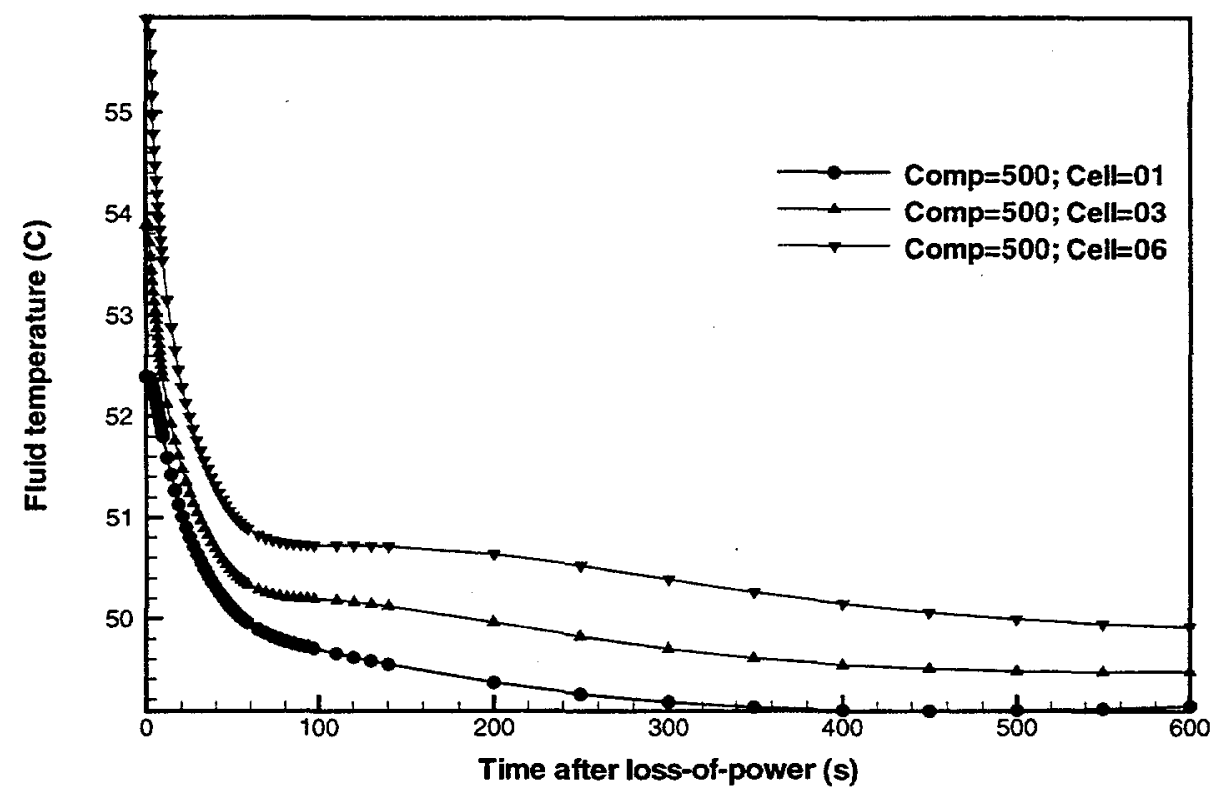

Figure B-22b Module 5 channel fluid temperatures for a LOFA (Case 1: with beam shutdown and active RHR).

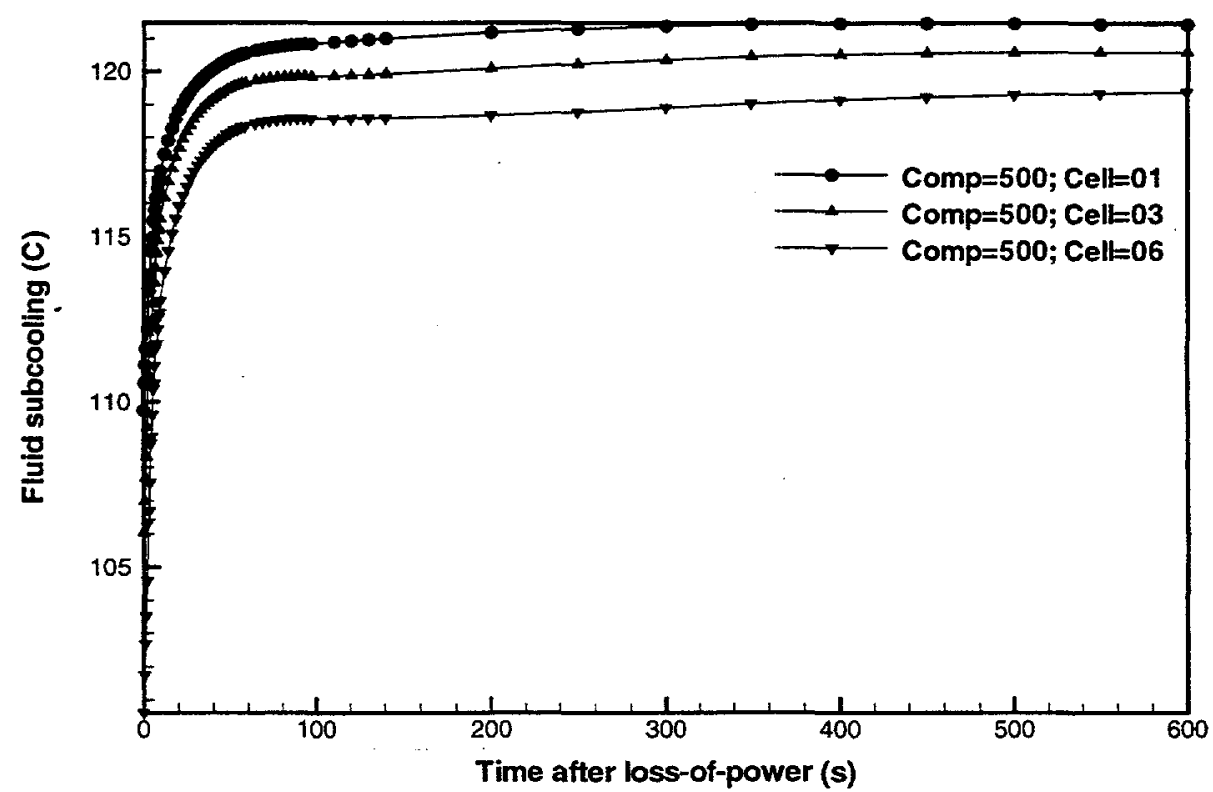

Figure B-22c Module 5 channel fluid subcoolings for a LOFA (Case 1: with beam shutdown and active RHR). 


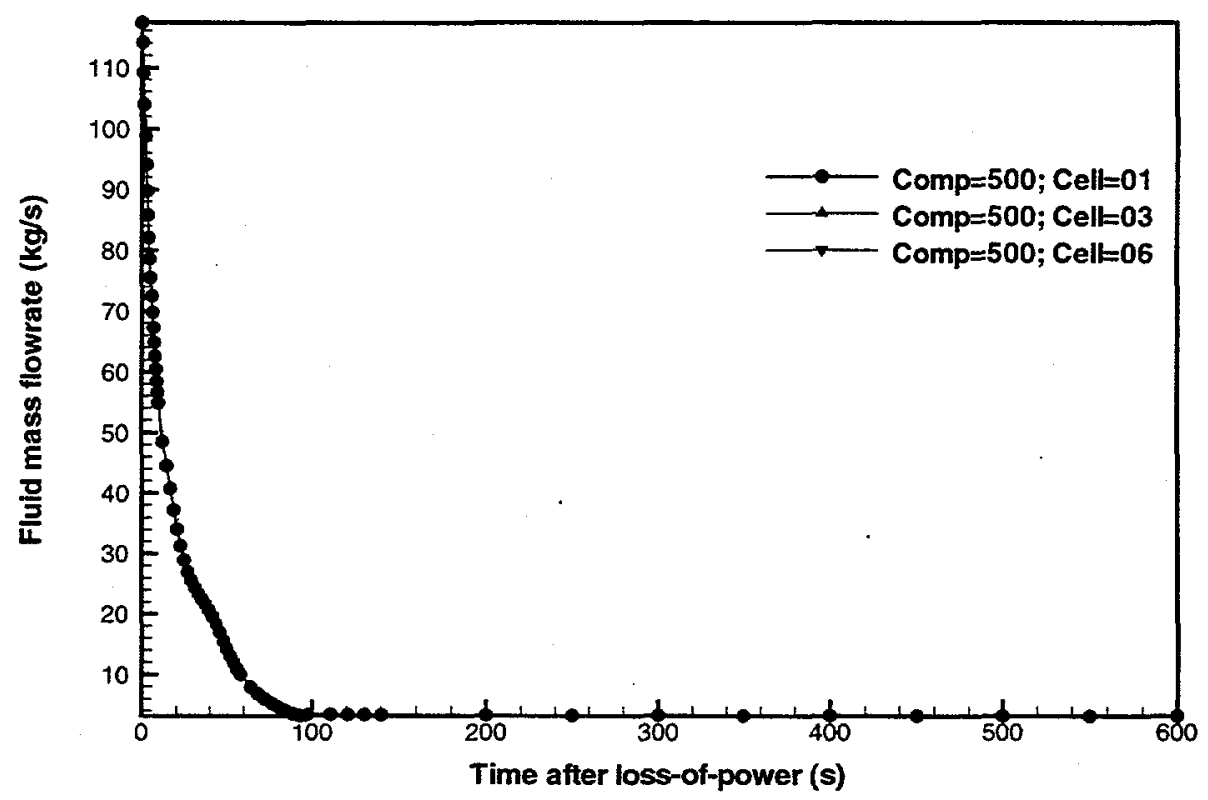

Figure B-22d Module 5 channel liquid mass flowrates for a LOFA (Case 1: with beam shutdown and active RHR).

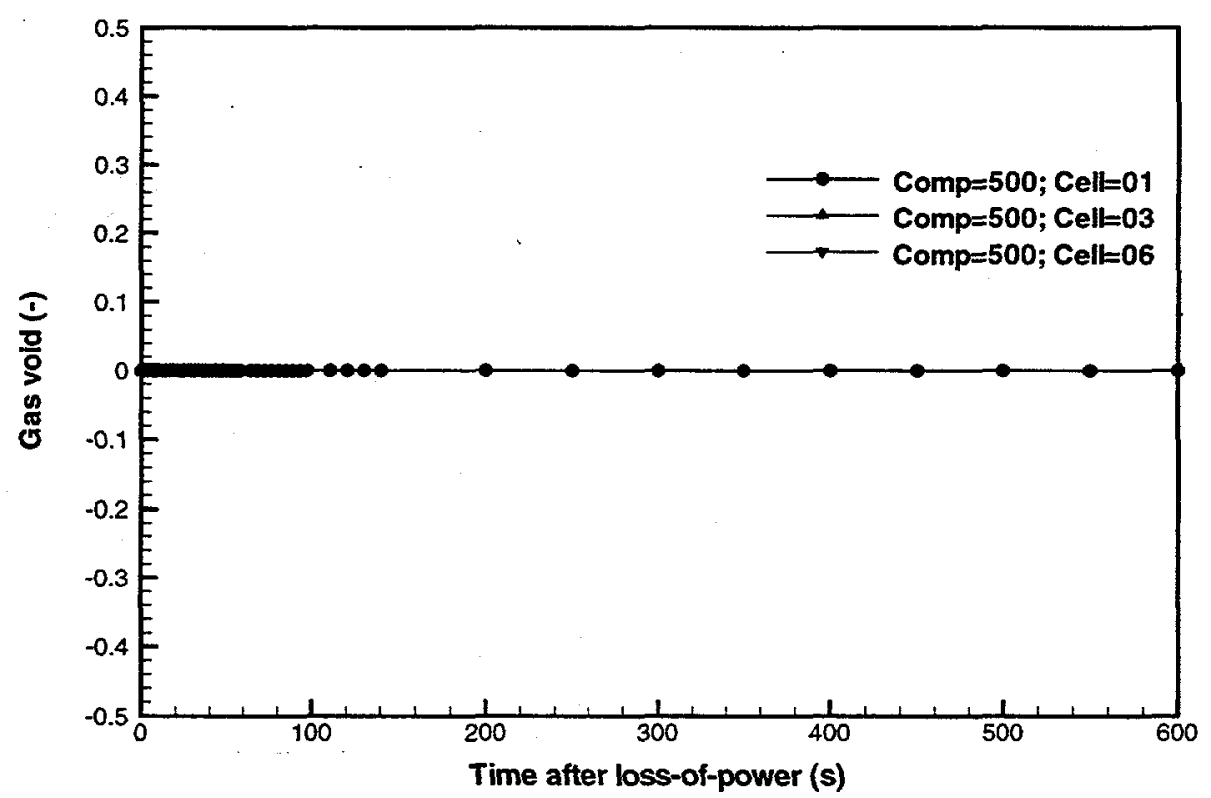

Figure B-22e Module 5 channel void fractions for a LOFA (Case 1: with beam shutdown and active RHR). 


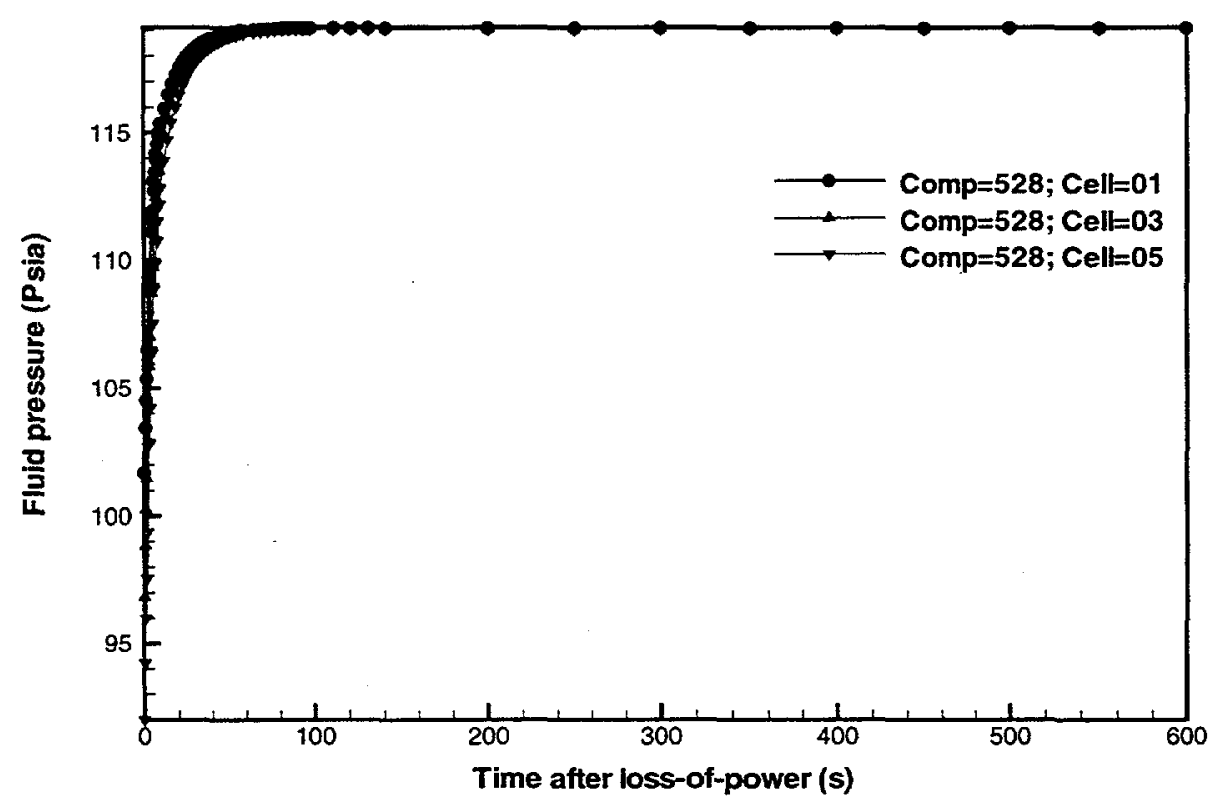

Figure B-23a Module 6 channel fluid pressures for a LOFA (Case 1: with beam shutdown and active RHR).

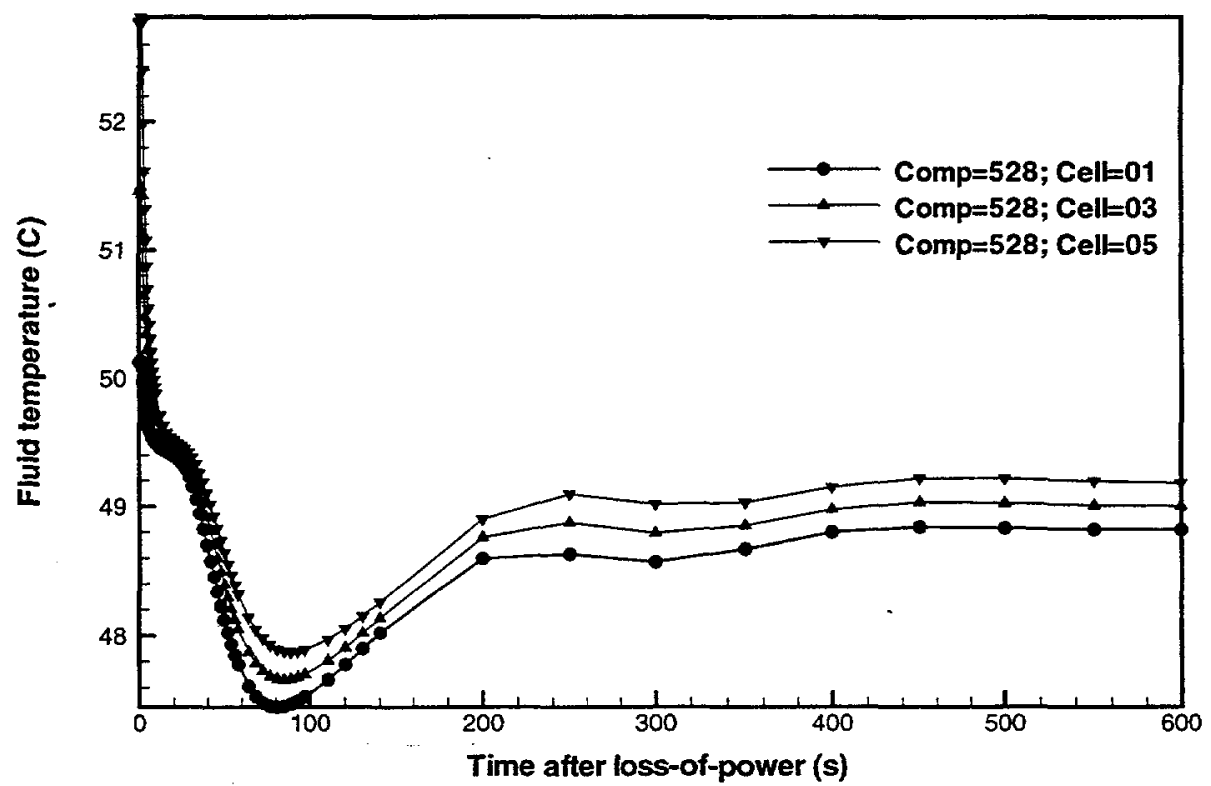

Figure B-23b Module 6 channel fluid temperatures for a LOFA (Case 1: with beam shutdown and active RHR). 


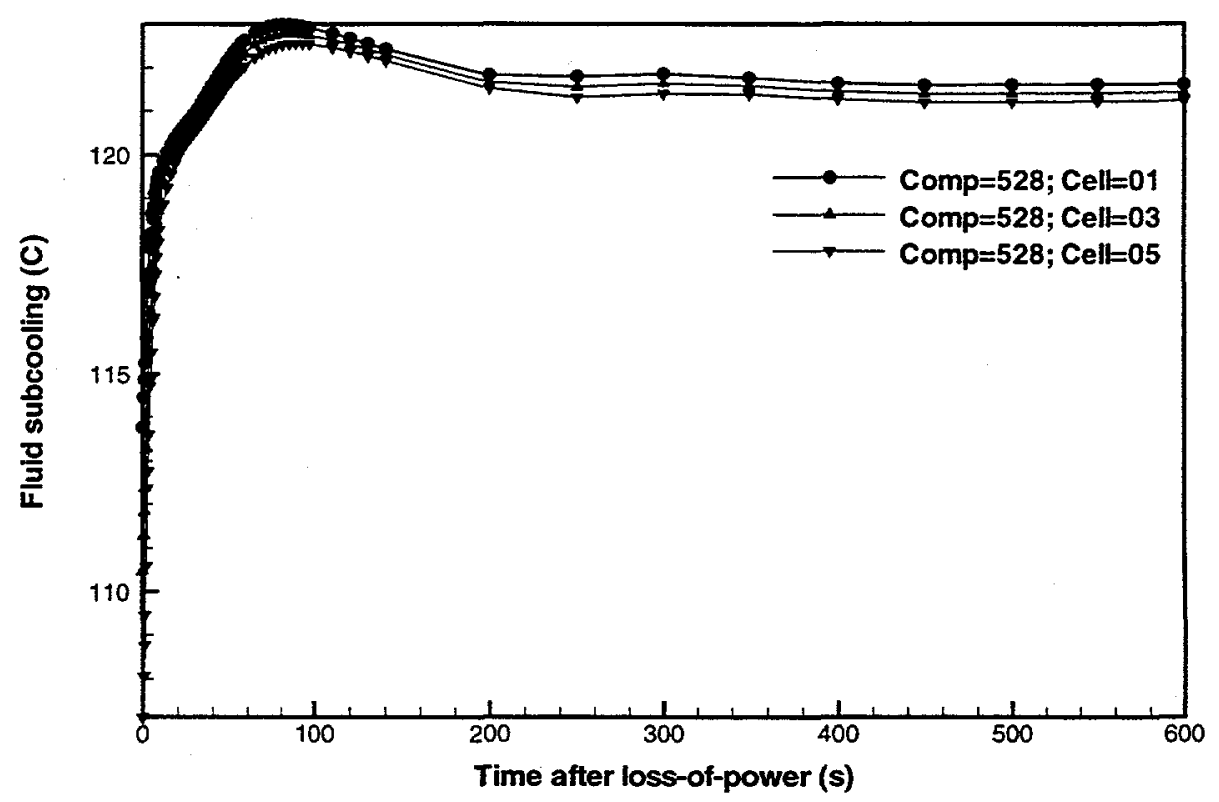

Figure B-23c Module 6 channel fluid subcoolings for a LOFA (Case 1: with beam shutdown and active RHR).

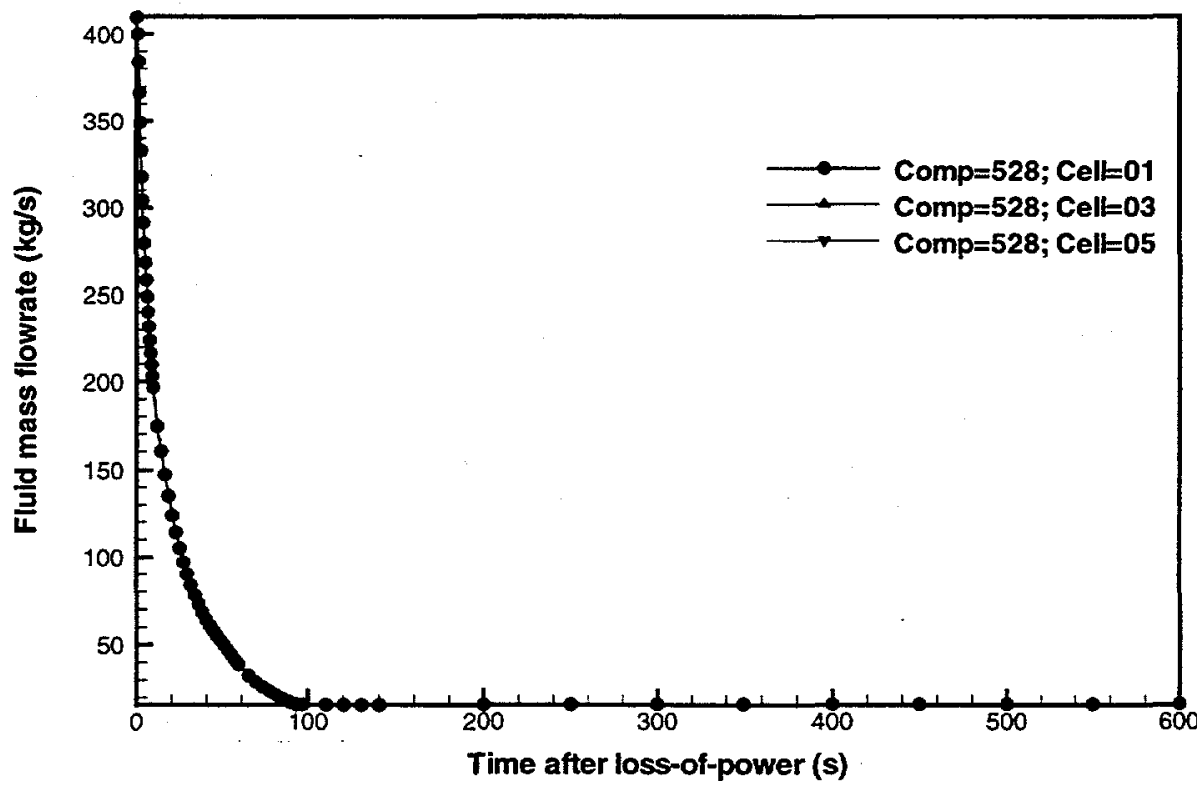

Figure B-23d Module 6 channel liquid mass flowrates for a LOFA (Case 1: with beam shutdown and active RHR). 


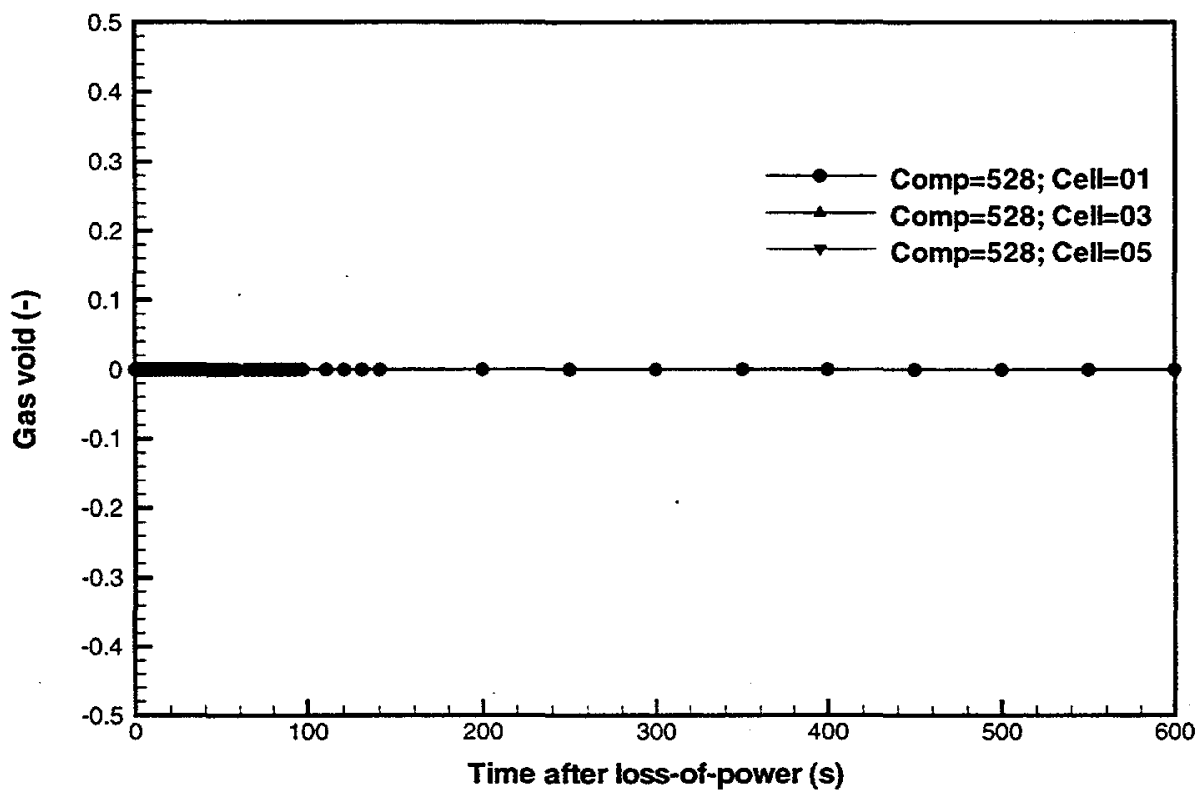

Figure B-23e Module 6 channel void fractions for a LOFA (Case 1: with beam shutdown and active RHR).

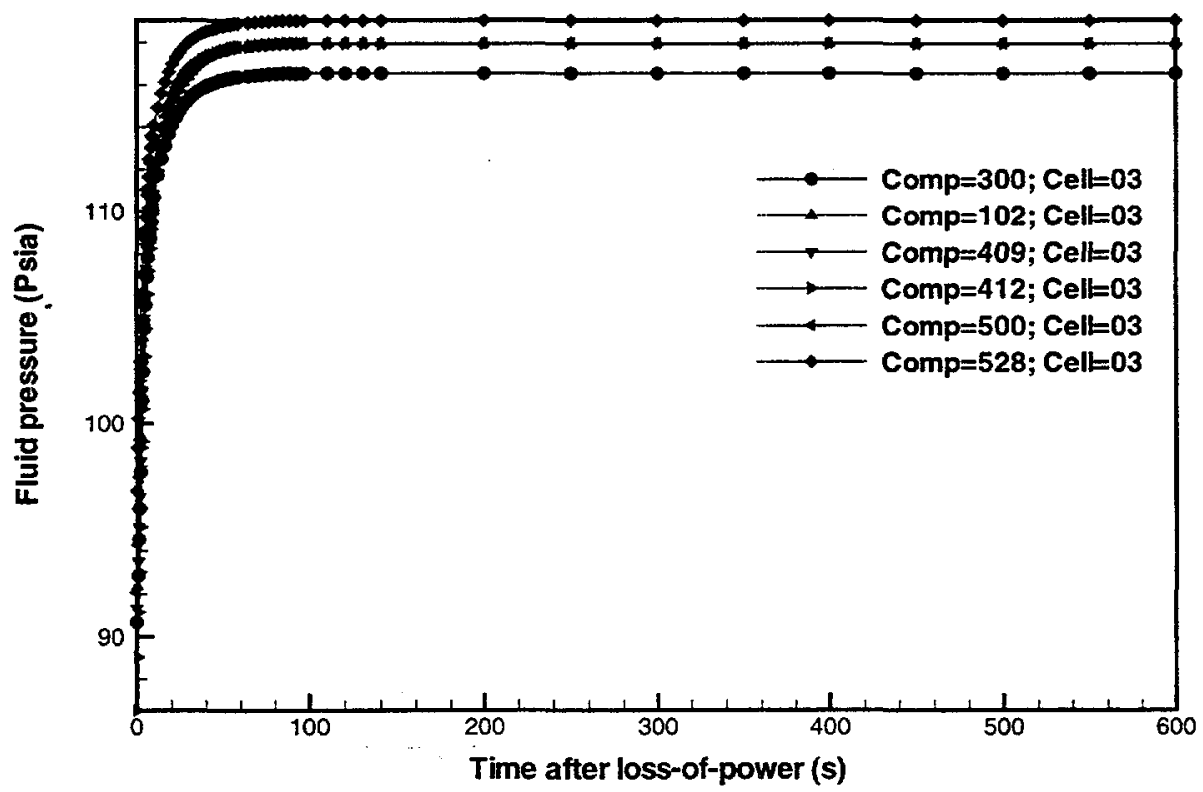

Figure B-24a Mid-plane module fluid pressures for a LOFA (Case 1: with beam shutdown and active RHR). 


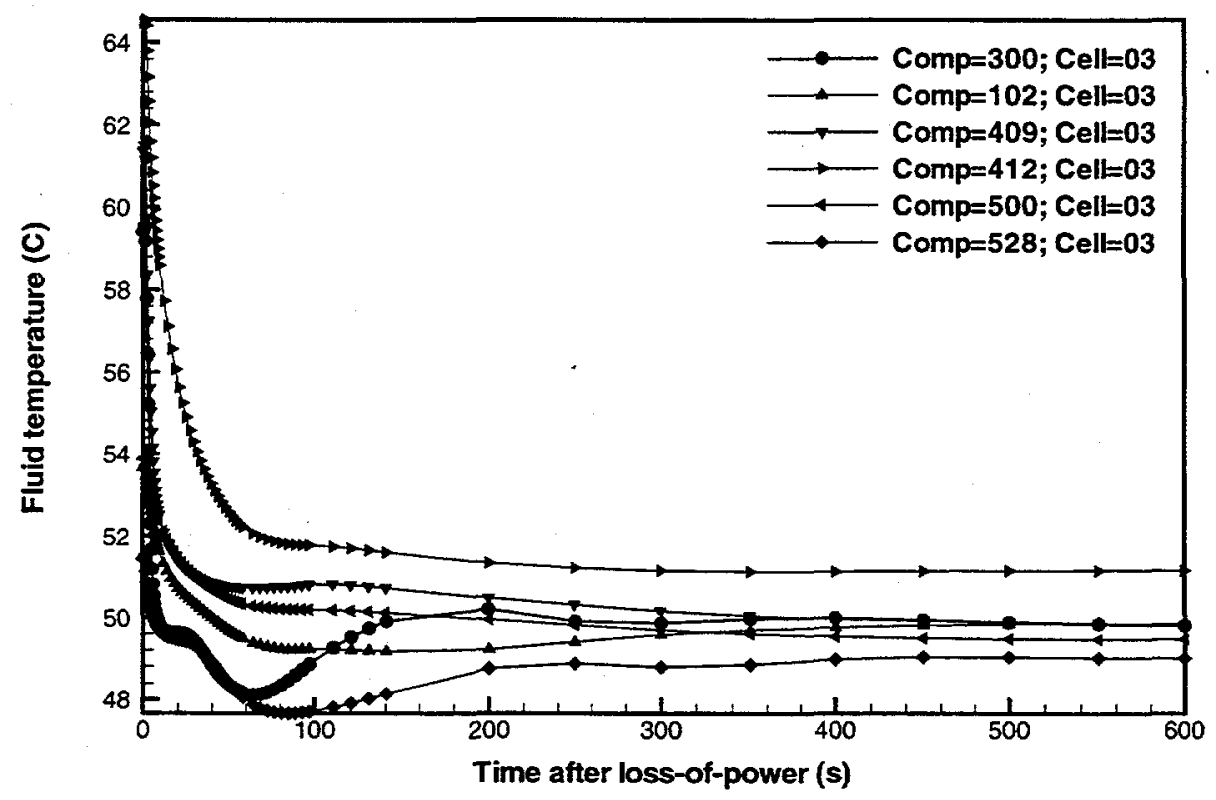

Figure B-24b Mid-plane module fluid temperatures for a LOFA (Case 1: with beam shutdown and active RHR).

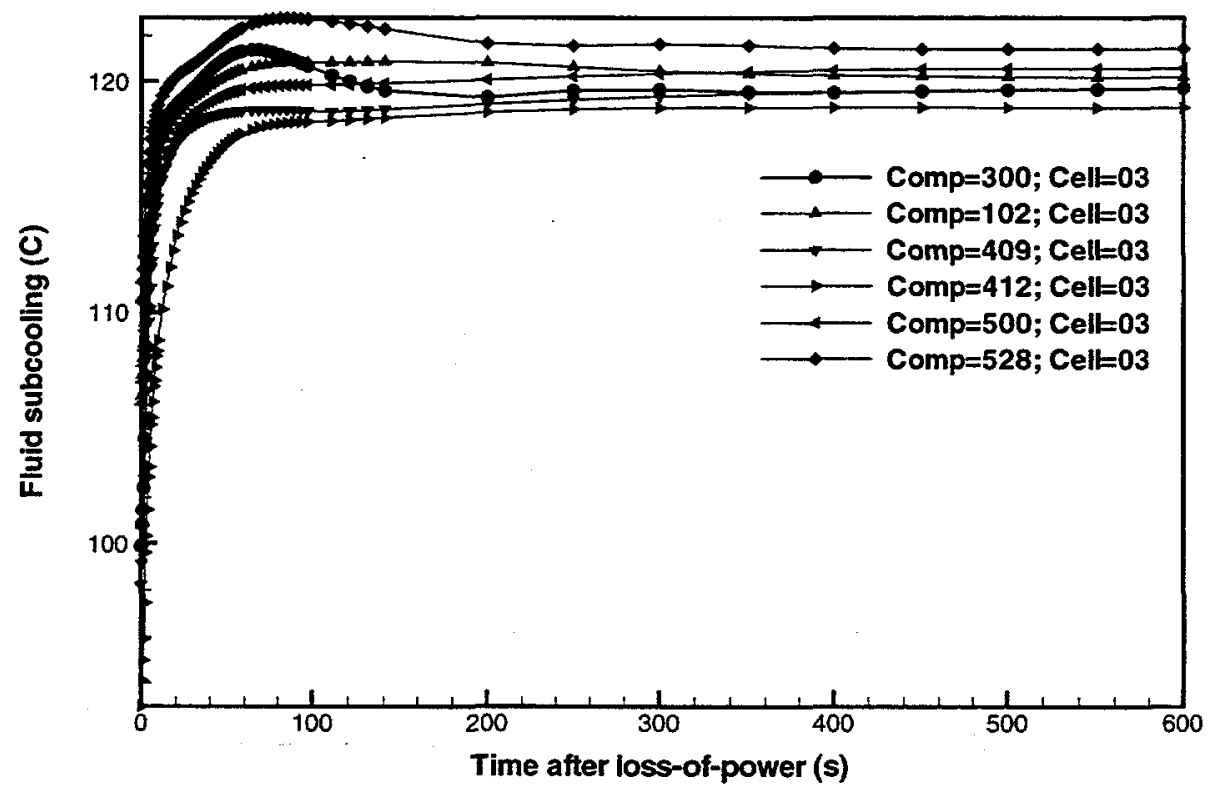

Figure B-24c Mid-plane module fluid subcoolings for a LOFA (Case 1: with beam shutdown and active RHR). 


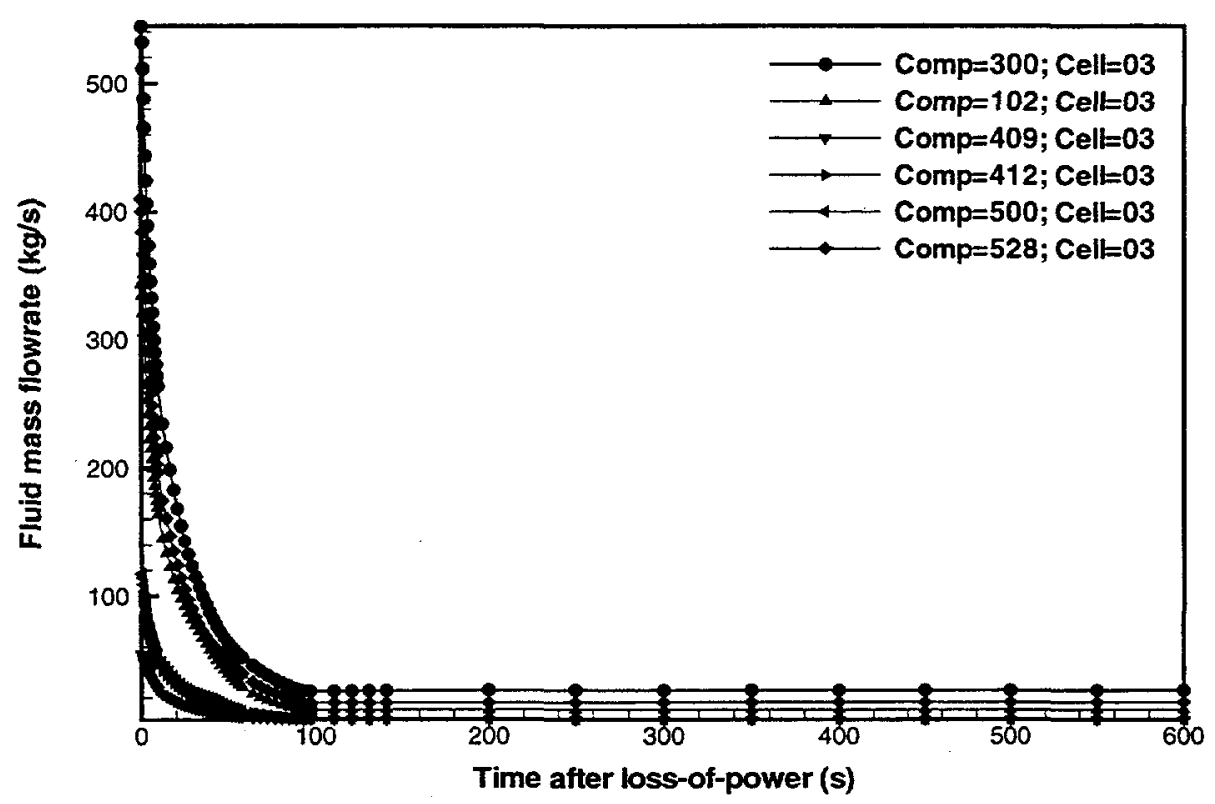

Figure B-24d Mid-plane module liquid mass flowrates for a LOFA (Case 1: with beam shutdown and active RHR).

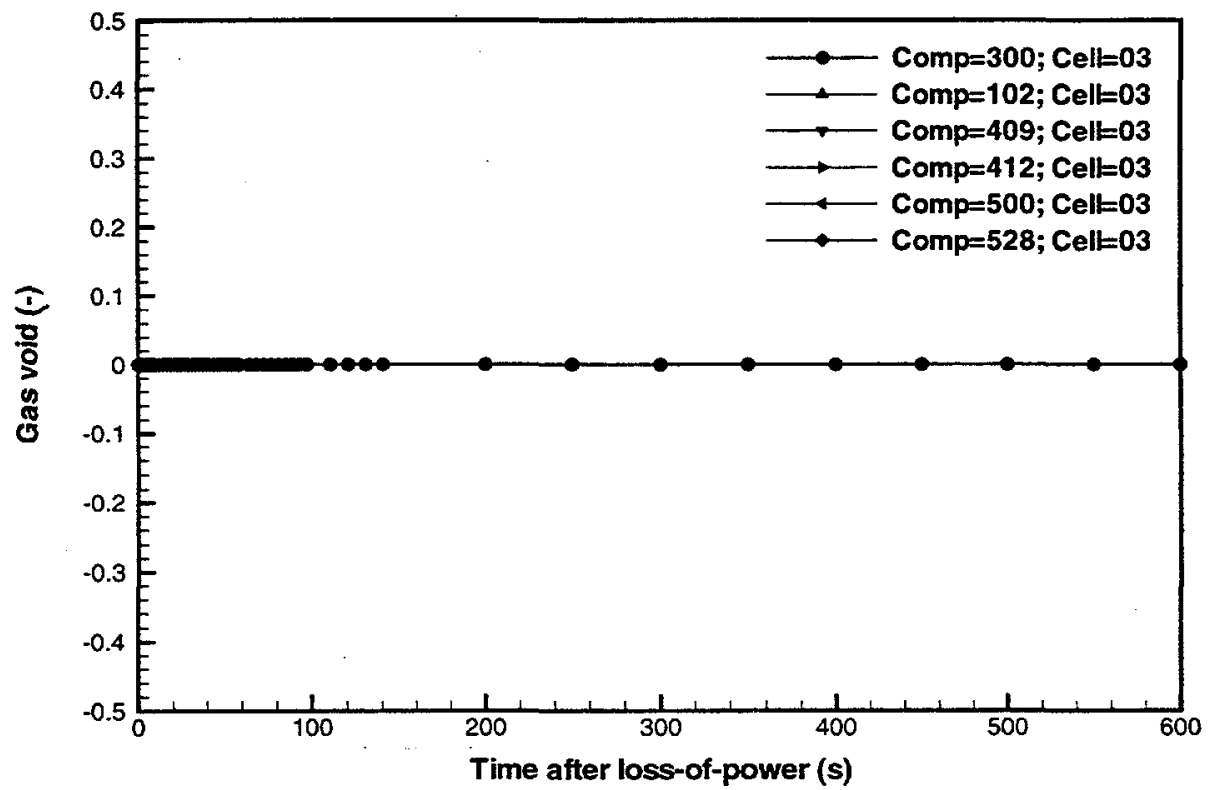

Figure B-24e Mid-plane module void fractions for a LOFA (Case 1: with beam shutdown and active RHR). 


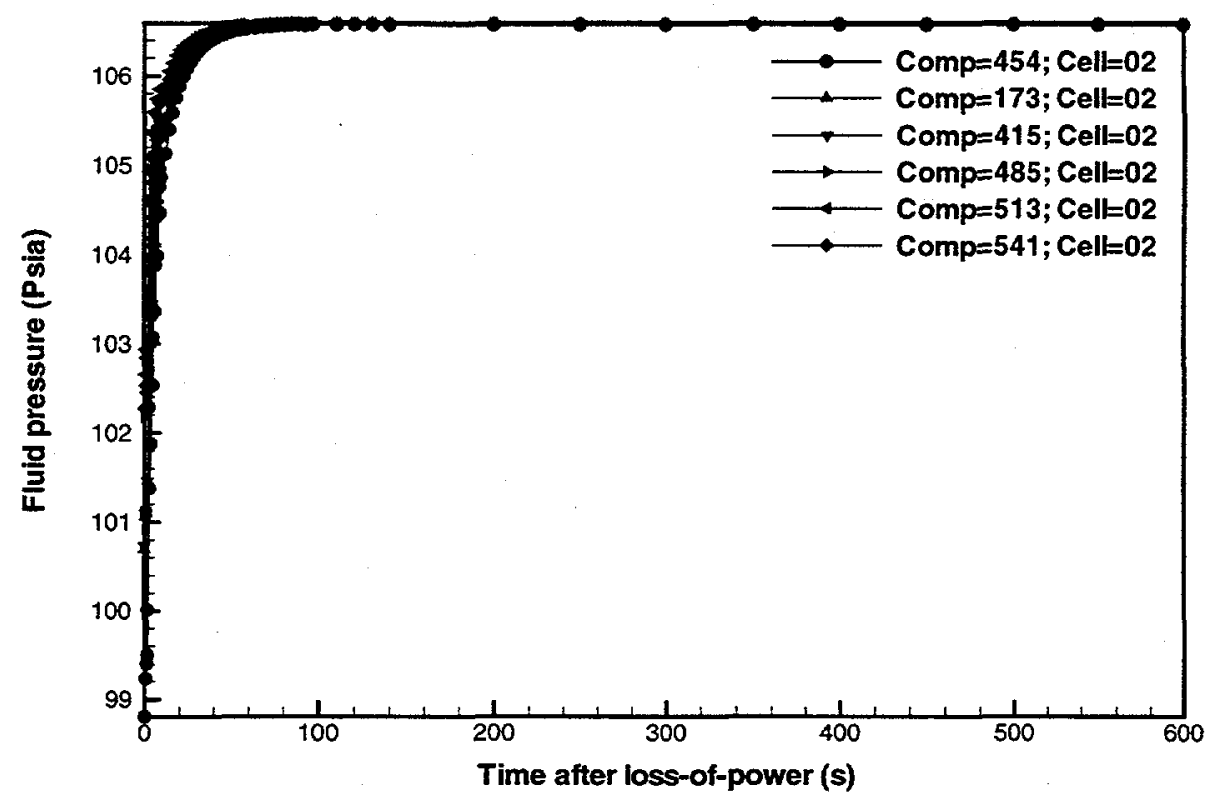

Figure B-25a Module inlet fluid pressures for a LOFA (Case-1: with beam shutdown and active RHR).

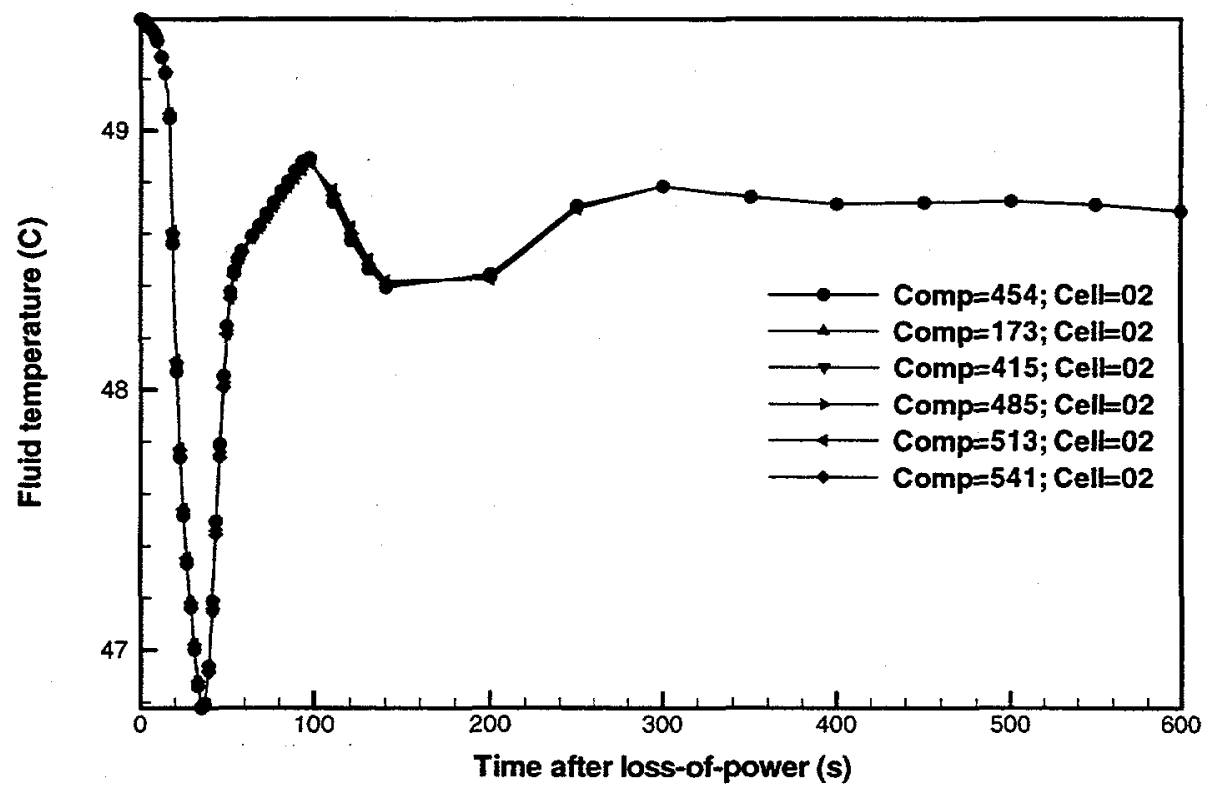

Figure B-25b Module inlet fluid temperatures for a LOFA (Case 1: with beam shutdown and active RHR). 


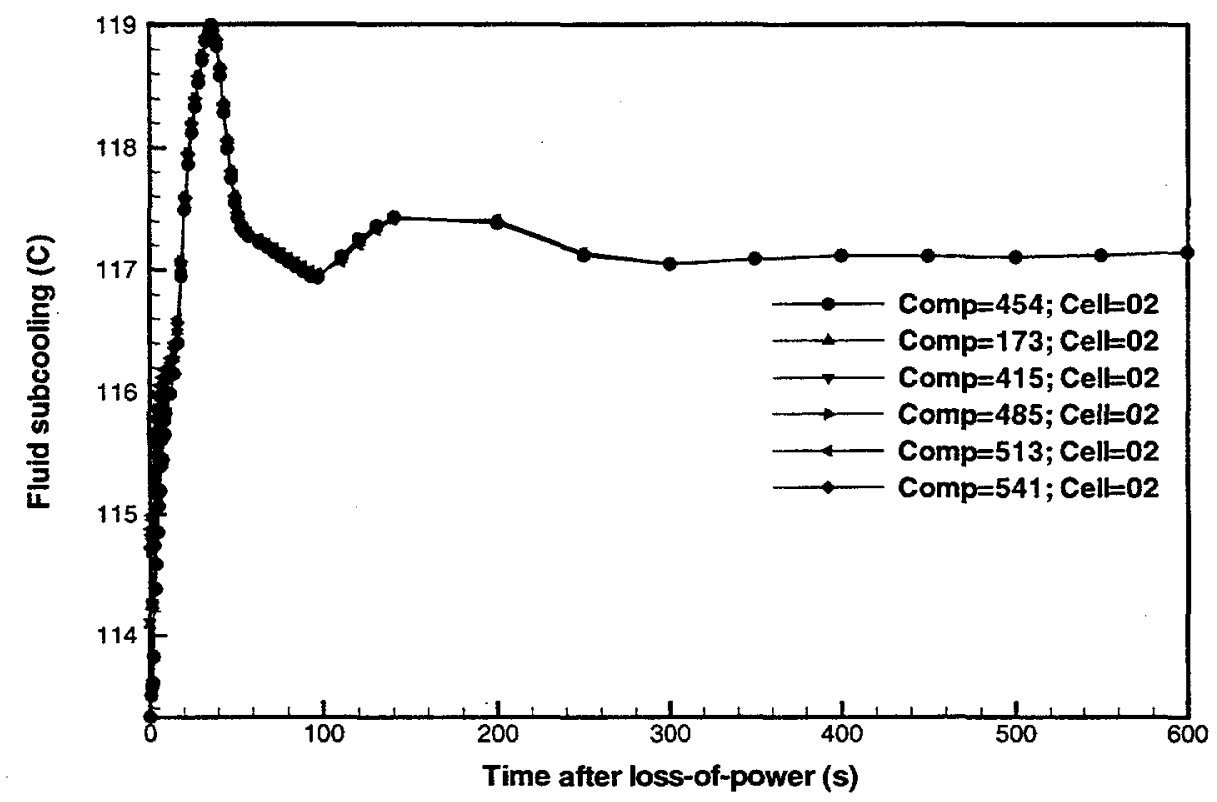

Figure B-25c Module inlet fluid subcoolings for a LOFA (Case 1: with beam shutdown and active $\mathrm{RHR}$ ).

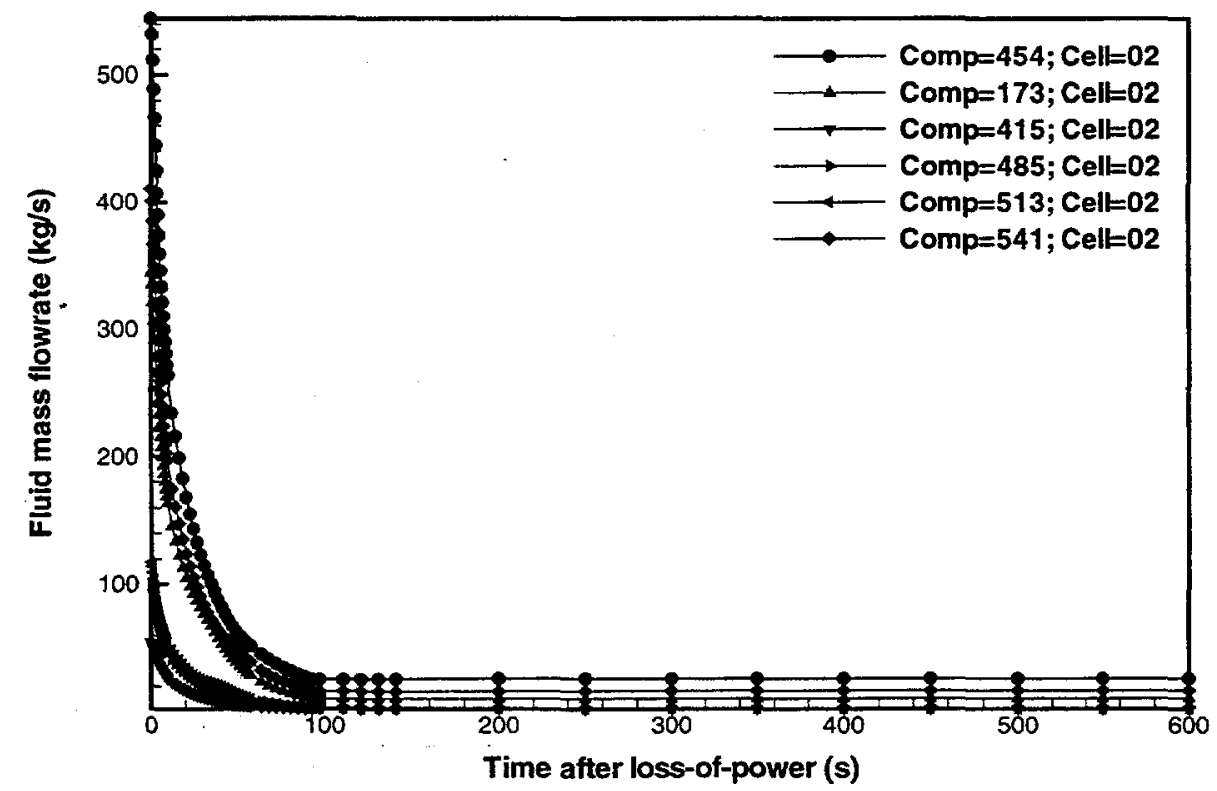

Figure B-25d Module inlet liquid mass flowrates for a LOFA (Case 1: with beam shutdown and active RHR). 


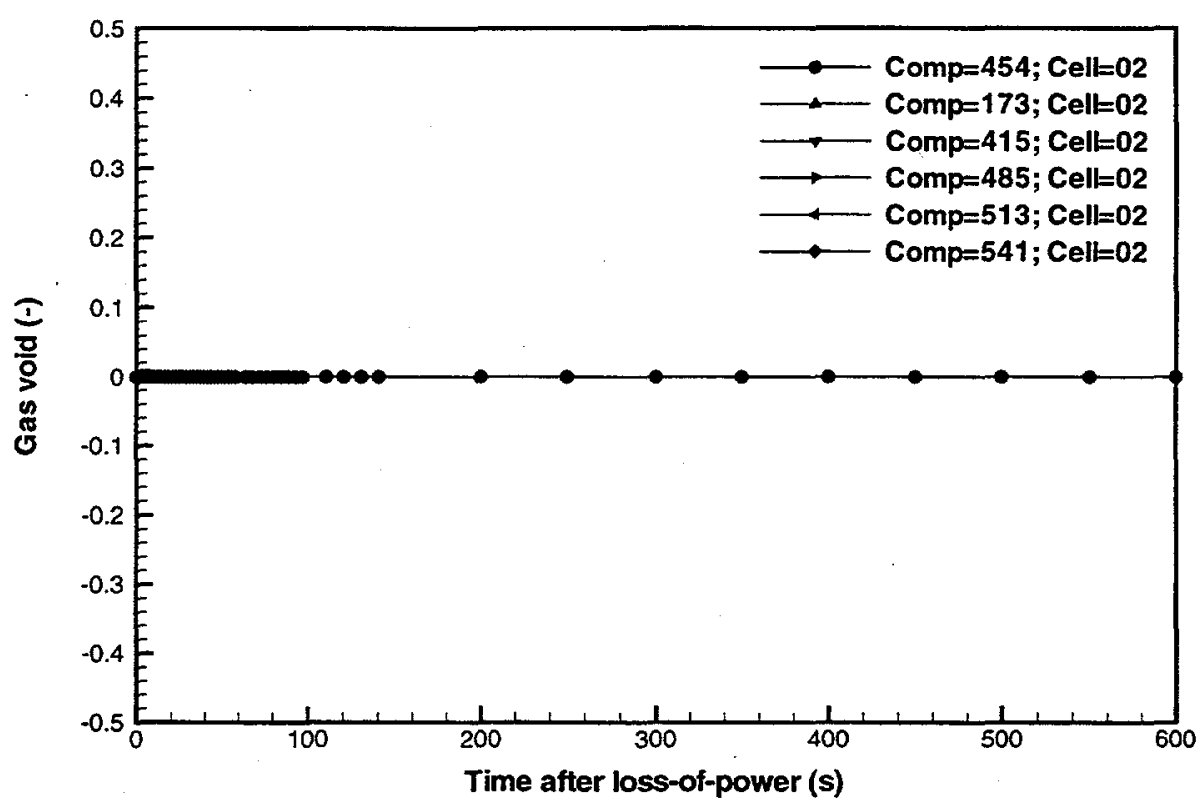

Figure B-25e Module inlet void fractions for a LOFA (Case 1:- with beam shutdown and active RHR). 


\section{Appendix B3 LOFA (Case 1) TRAC Heat Structure Component Figures}

The following figures are from a TRAC simulation for Case 1 of a LOFA (with beam shutdown and active RHR):

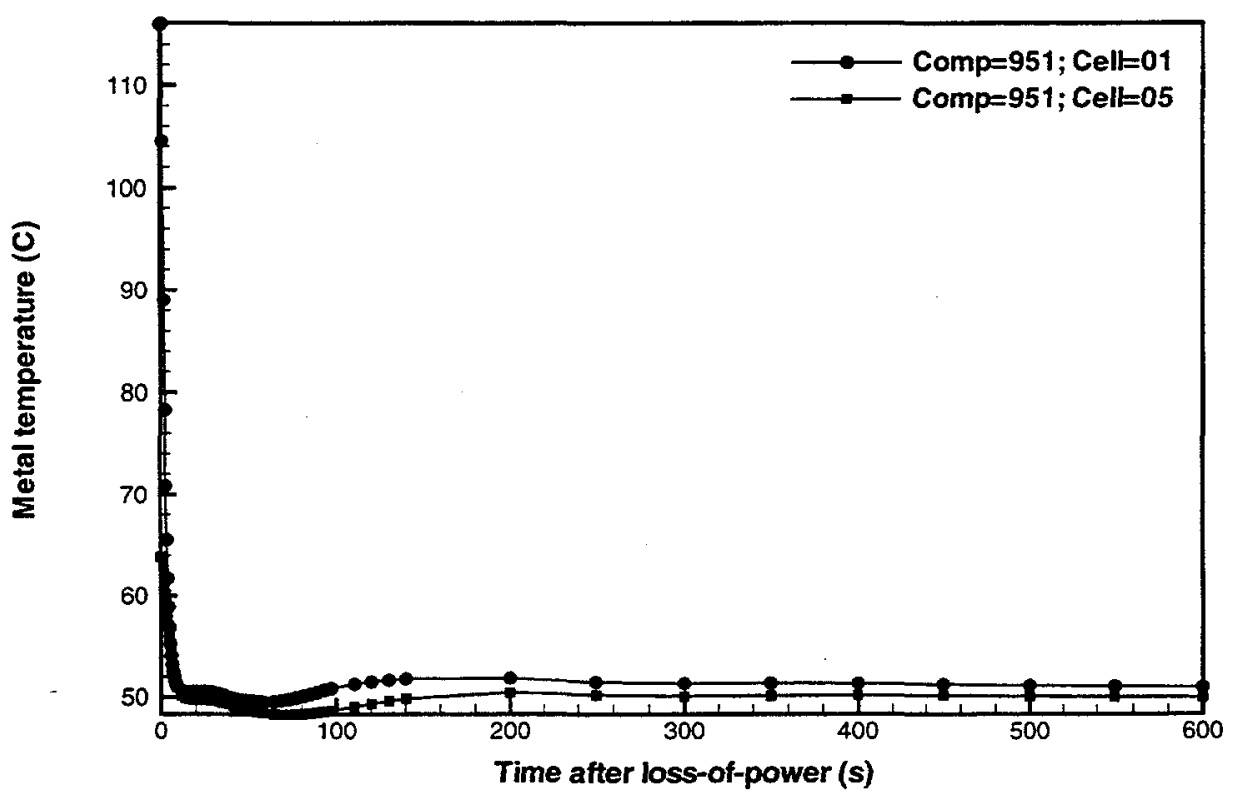

Figure B-26 Module 1 upflow section bottom and top maximum lead metal temperatures for a LOFA (Case 1: with beam shutdown and active RHR). 


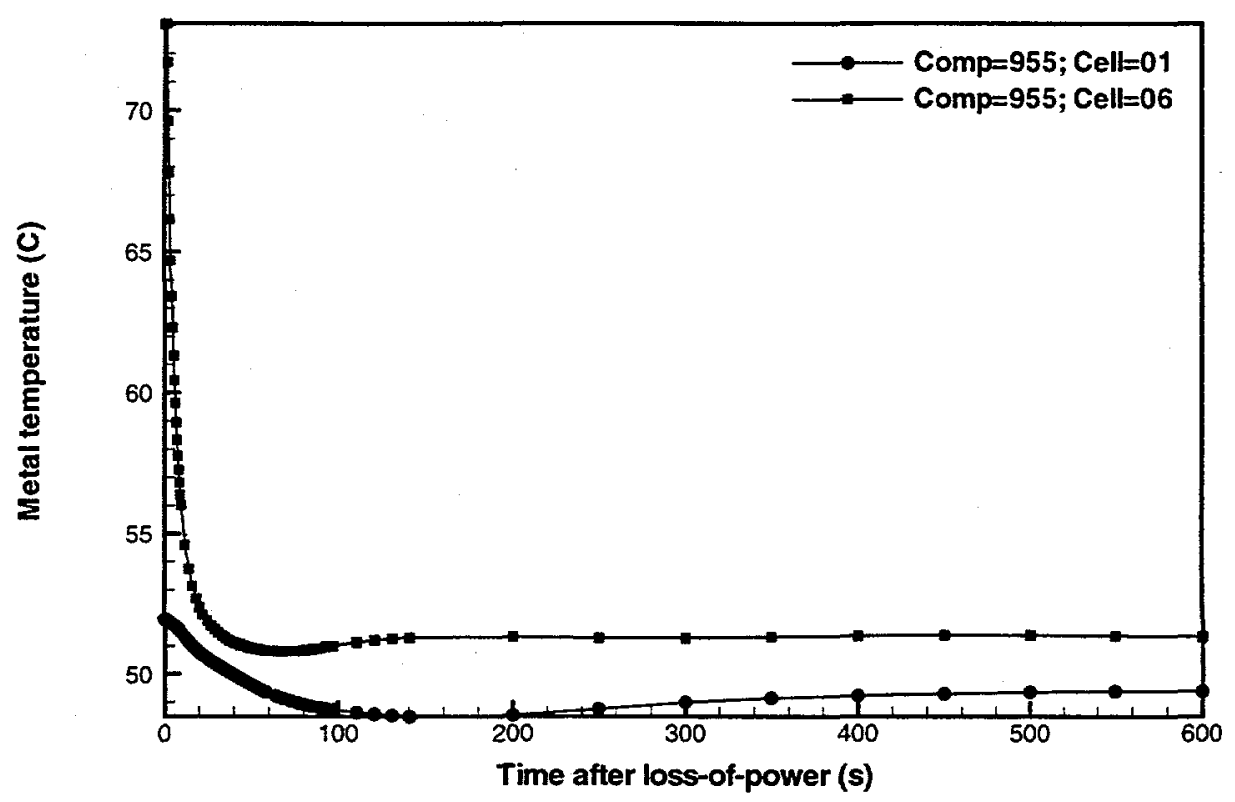

Figure B-27 Module 2 upflow section bottom and top maximum lead metal temperatures for a LOFA (Case 1: with beam shutdown and active RHR).

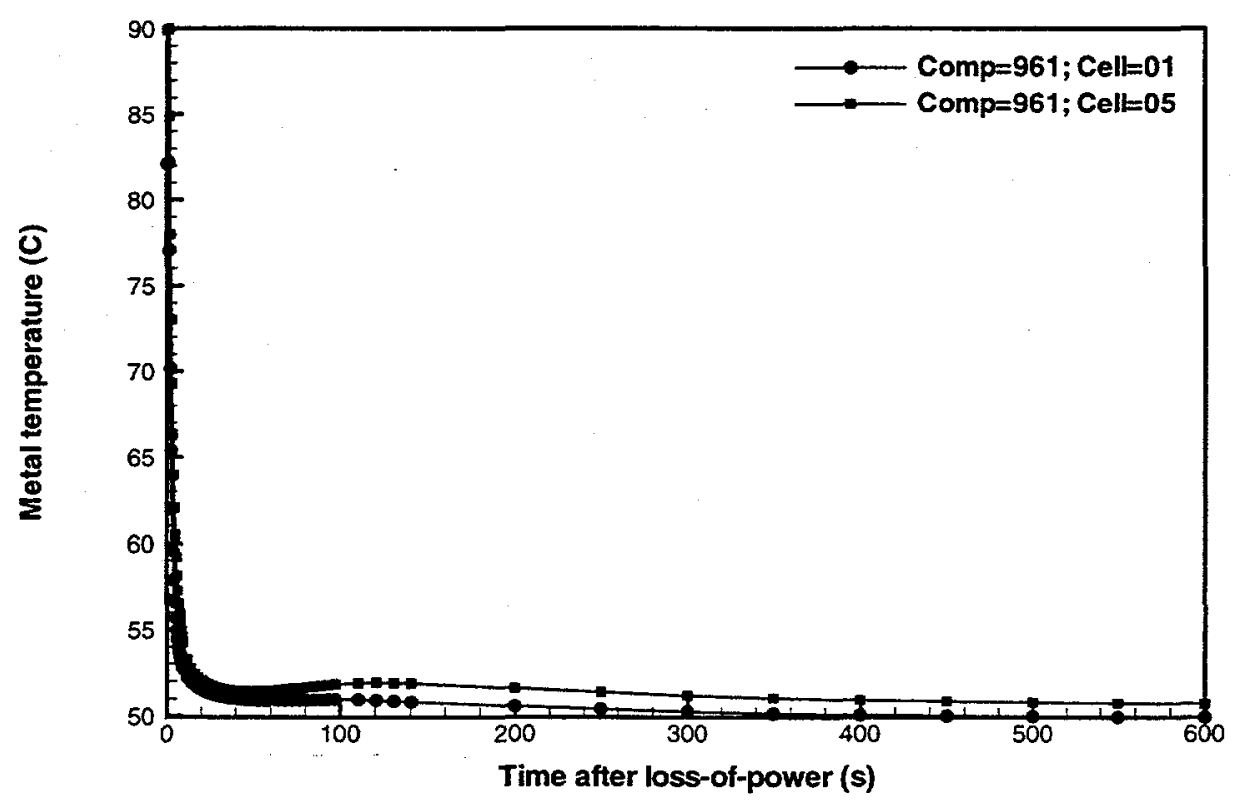

Figure B-28 Module 3 upflow section bottom and top maximum lead metal temperatures for a LOFA (Case 1: with beam shutdown and active RHR). 


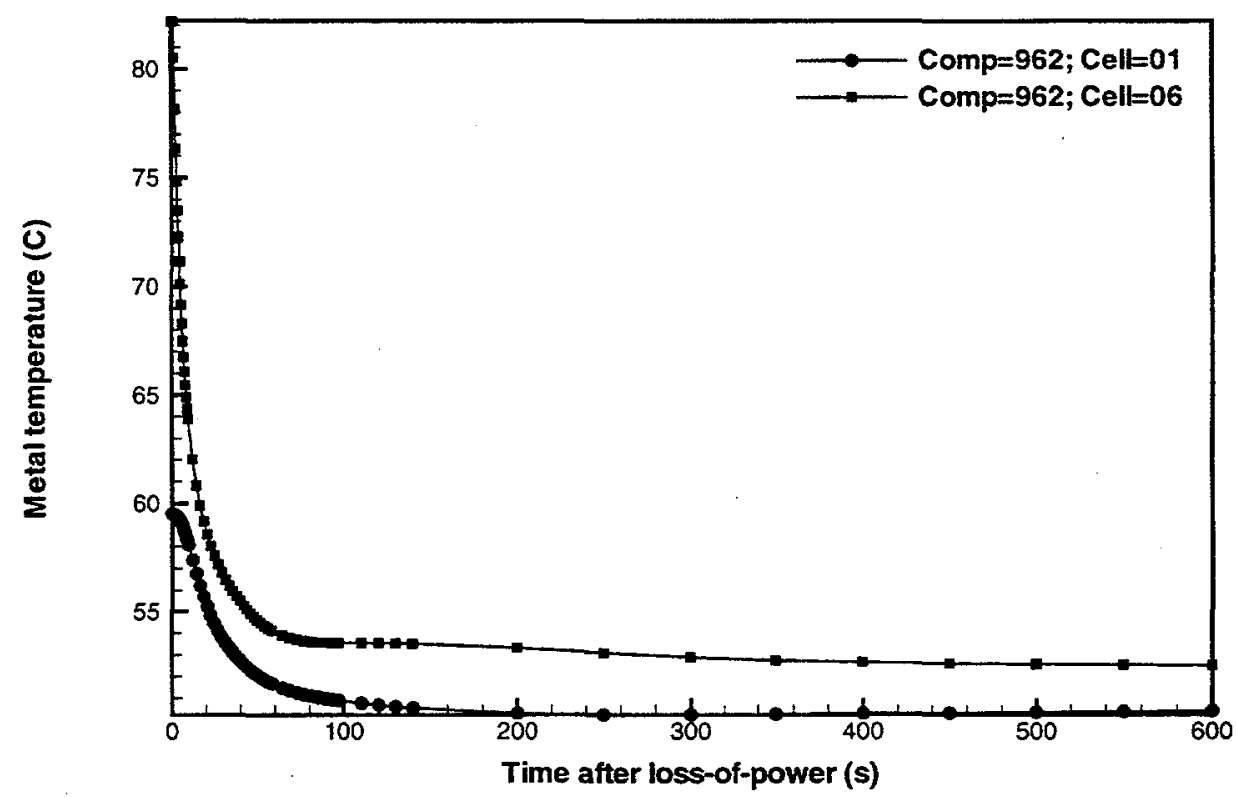

Figure B-29 Module 4 upflow section bottom and top maximum lead metal temperatures for a LOFA (Case 1: with beam shutdown and active RHR).

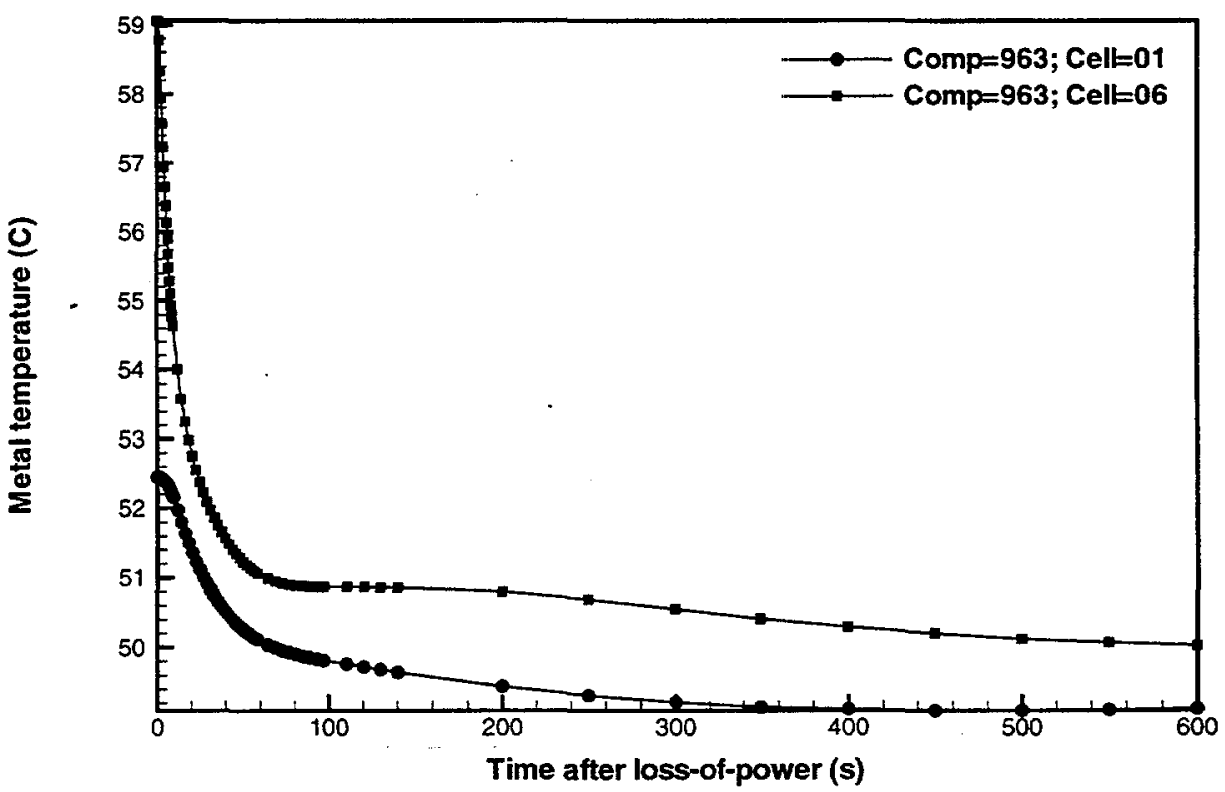

Figure B-30 Module 5 upflow section bottom and top maximum lead metal temperatures for a LOFA (Case 1: with beam shutdown and active RHR). 


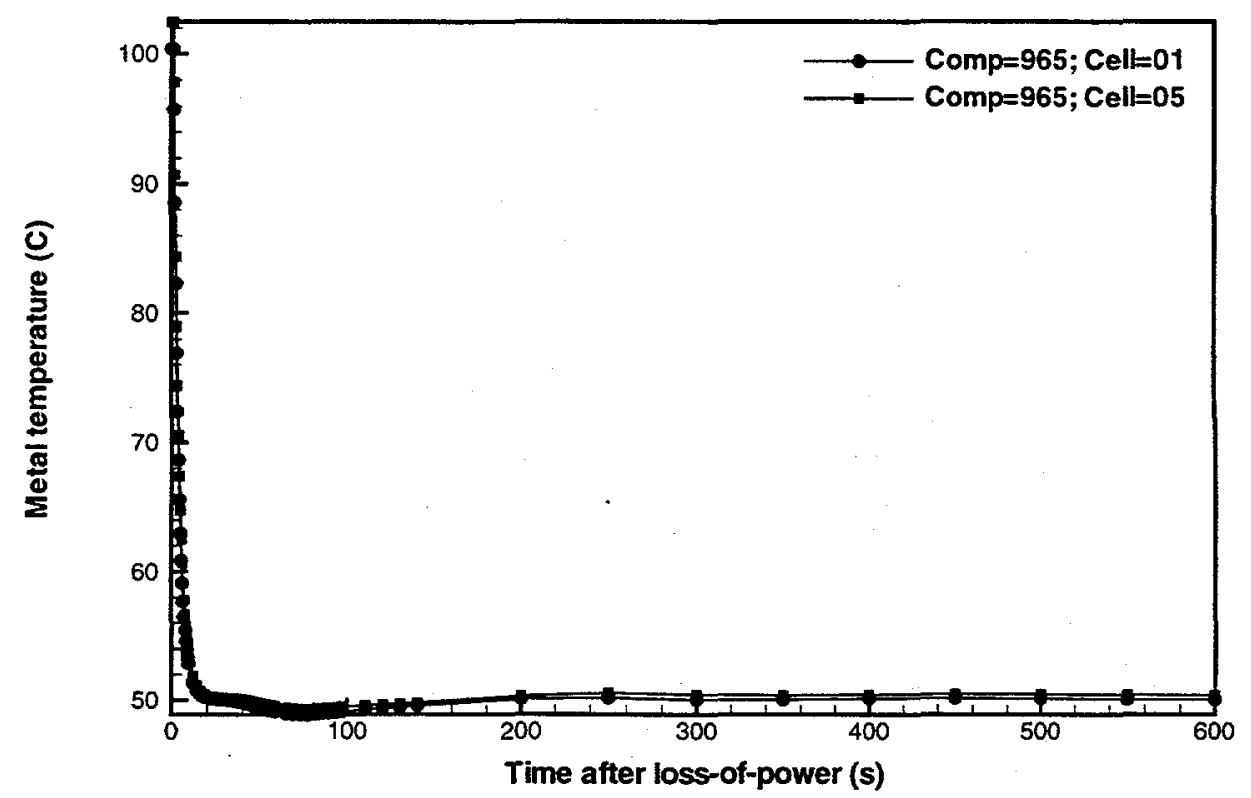

Figure B-31 Module 6 down-stream section bottom and top maximum lead metal temperatures for a LOFA (Case 1: with beam shutdown and active RHR).

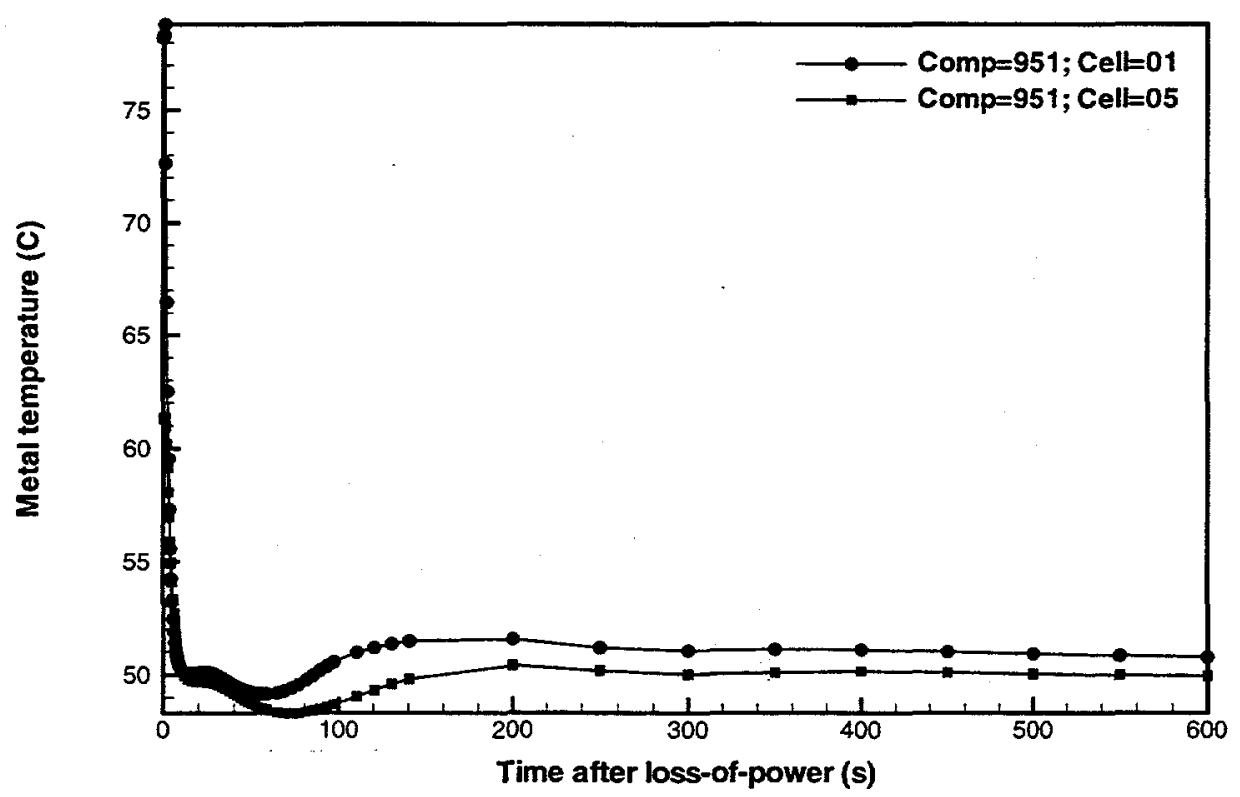

Figure B-32 Module 1 upflow section bottom and top maximum aluminum metal temperatures for a LOFA (Case 1: with beam shutdown and active RHR). 


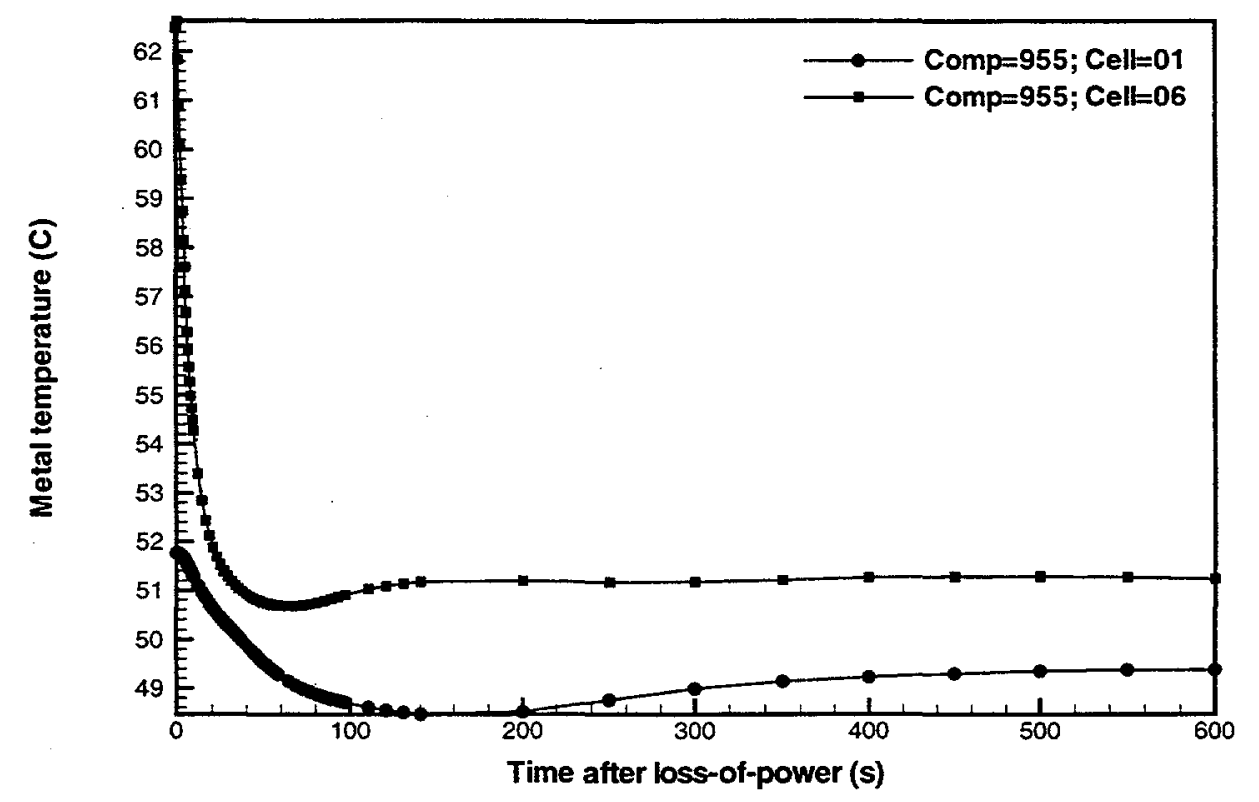

Figure B-33 Module 2 upflow section bottom and top maximum atuminum metal temperatures for a LOFA (Case 1: with beam shutdown and active RHR).

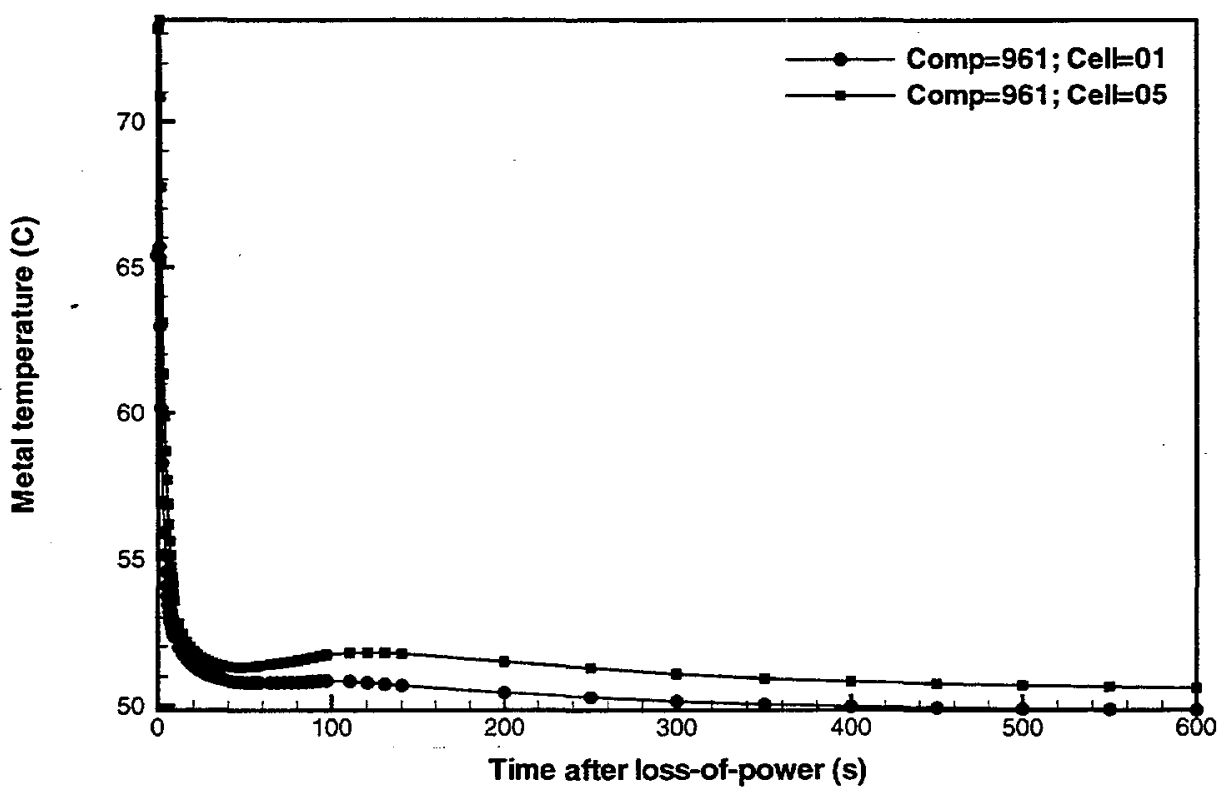

Figure B-34 Module 3 upflow section bottom and top maximum aluminum metal temperatures for a LOFA (Case 1: with beam shutdown and active RHR). 


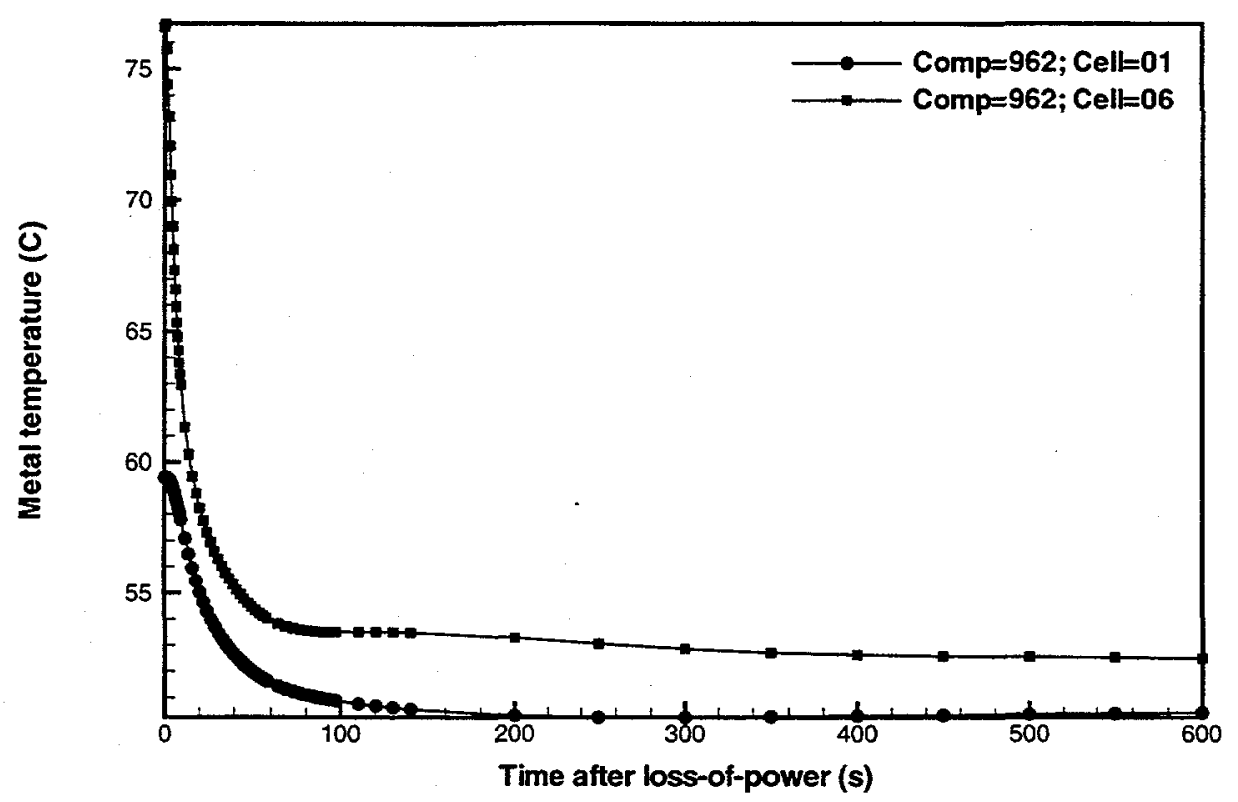

Figure B-35 Module 4 upflow section bottom and top maximum aluminum metal temperatures for a LOFA (Case 1: with beam shutdown and active RHR).

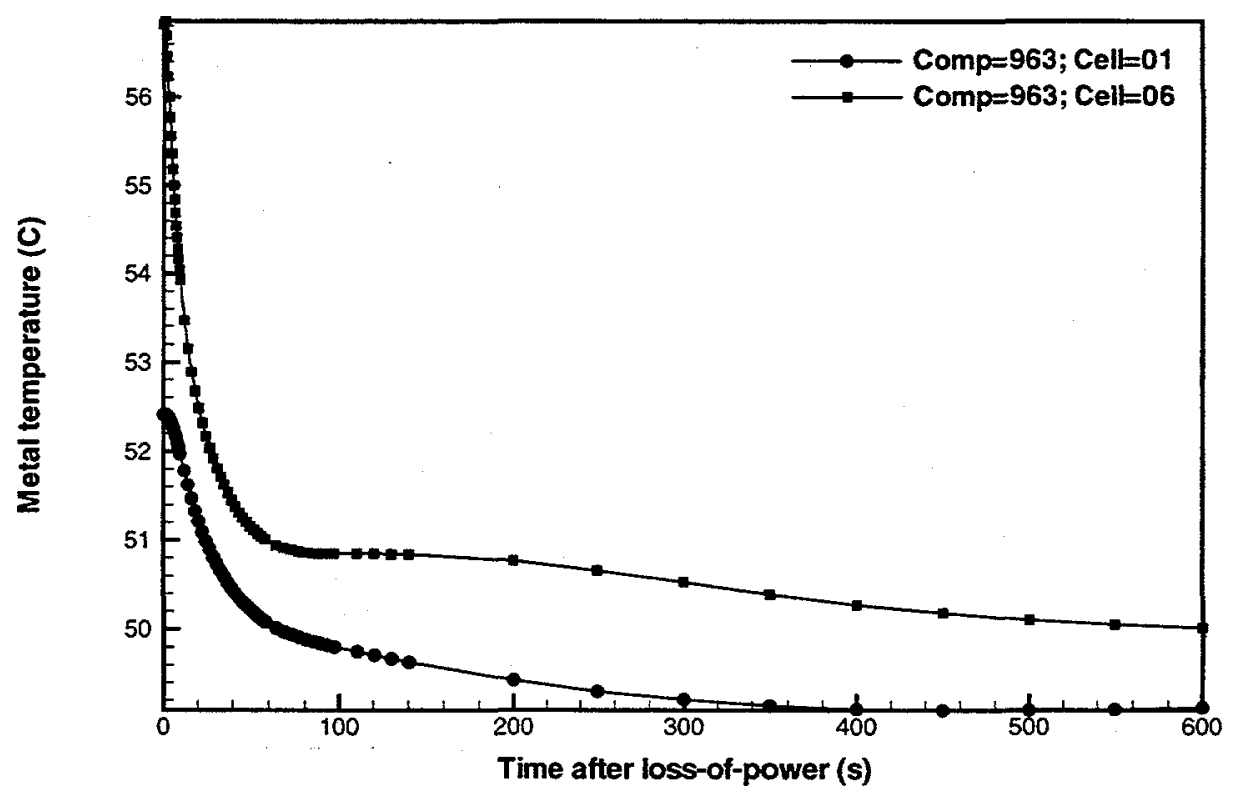

Figure B-36 Module 5 upflow section bottom and top maximum aluminum metal temperatures for a LOFA (Case 1: with beam shutdown and active RHR). 


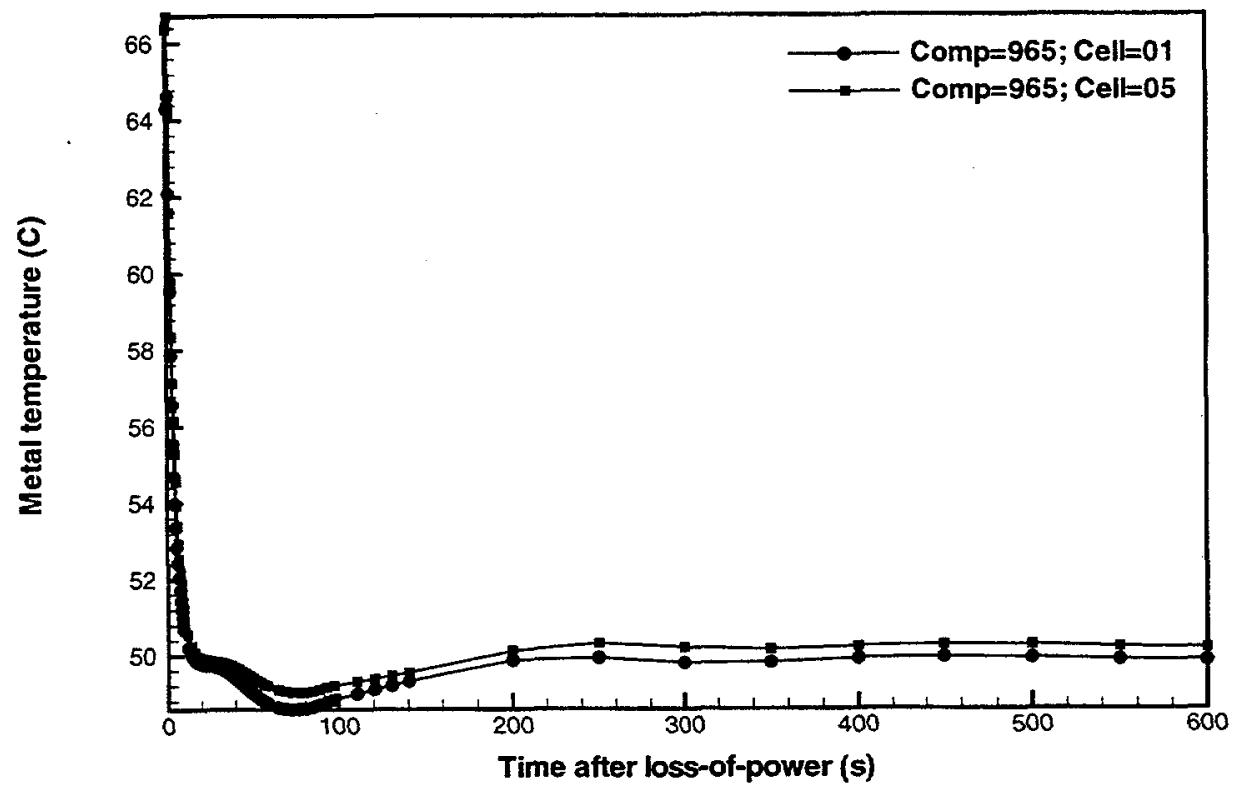

Figure B-37 Module 6 down-stream section bottom and top maximum aluminum metal temperatures for a LOFA (Case 1: with beam shutdown and active RHR).

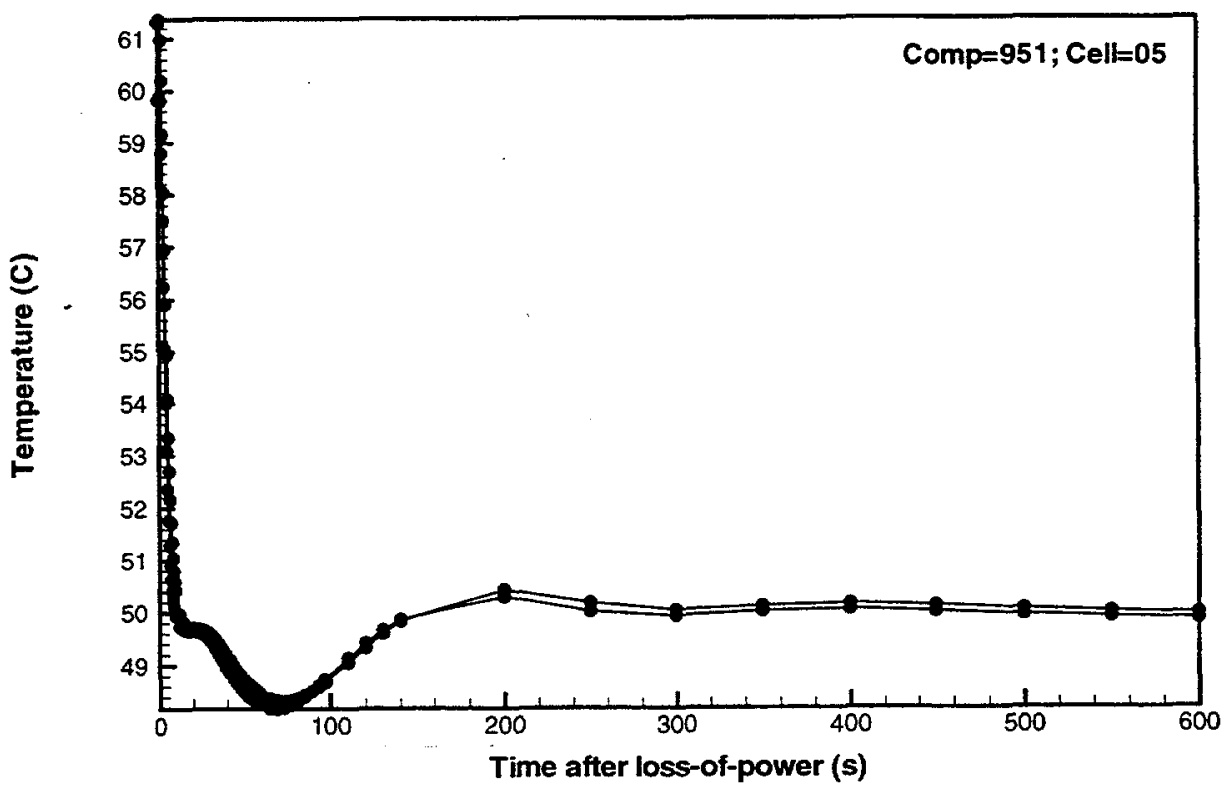

Figure B-38 Module 1 upflow section top-plane surface and fluid temperatures for a LOFA (Case 1: with beam shutdown and active RHR). 


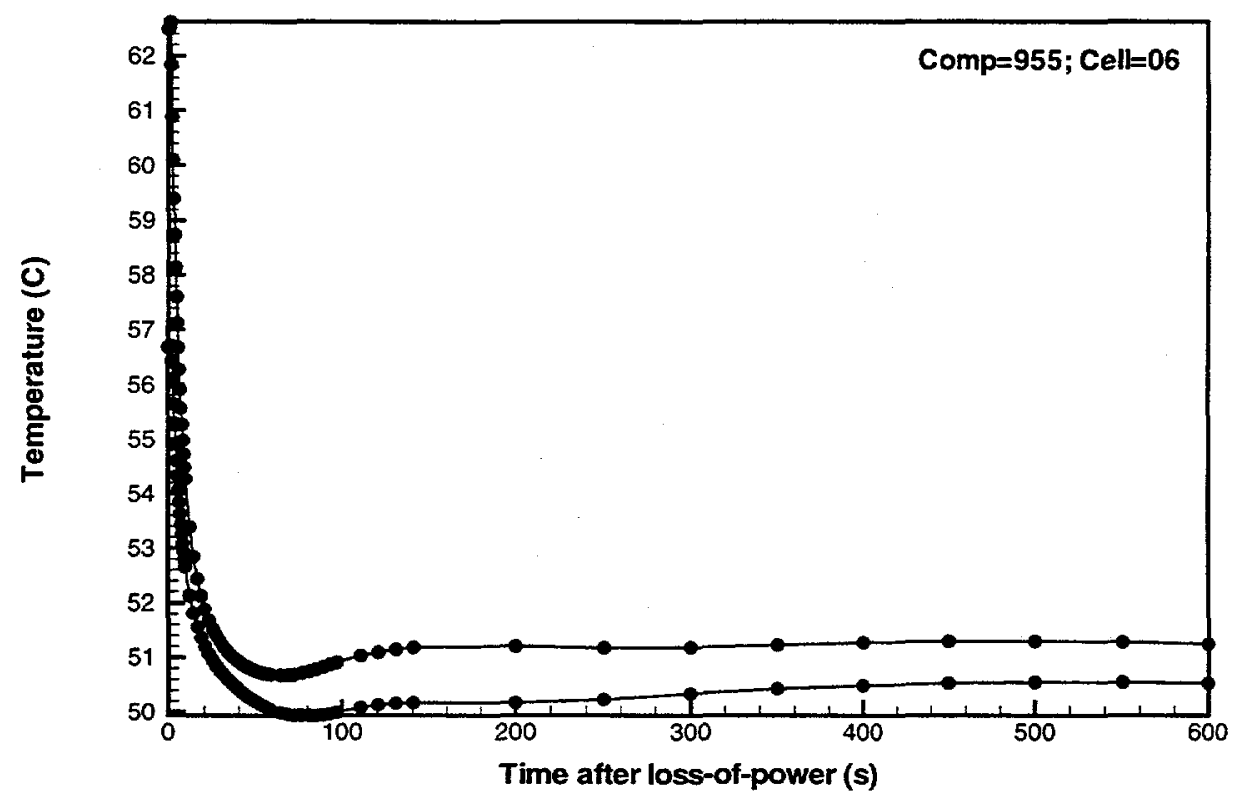

Figure B-39 Module 2 upflow section top-plane surface and fluid temperatures for a LOFA (Case 1: with beam shutdown and active RHR).

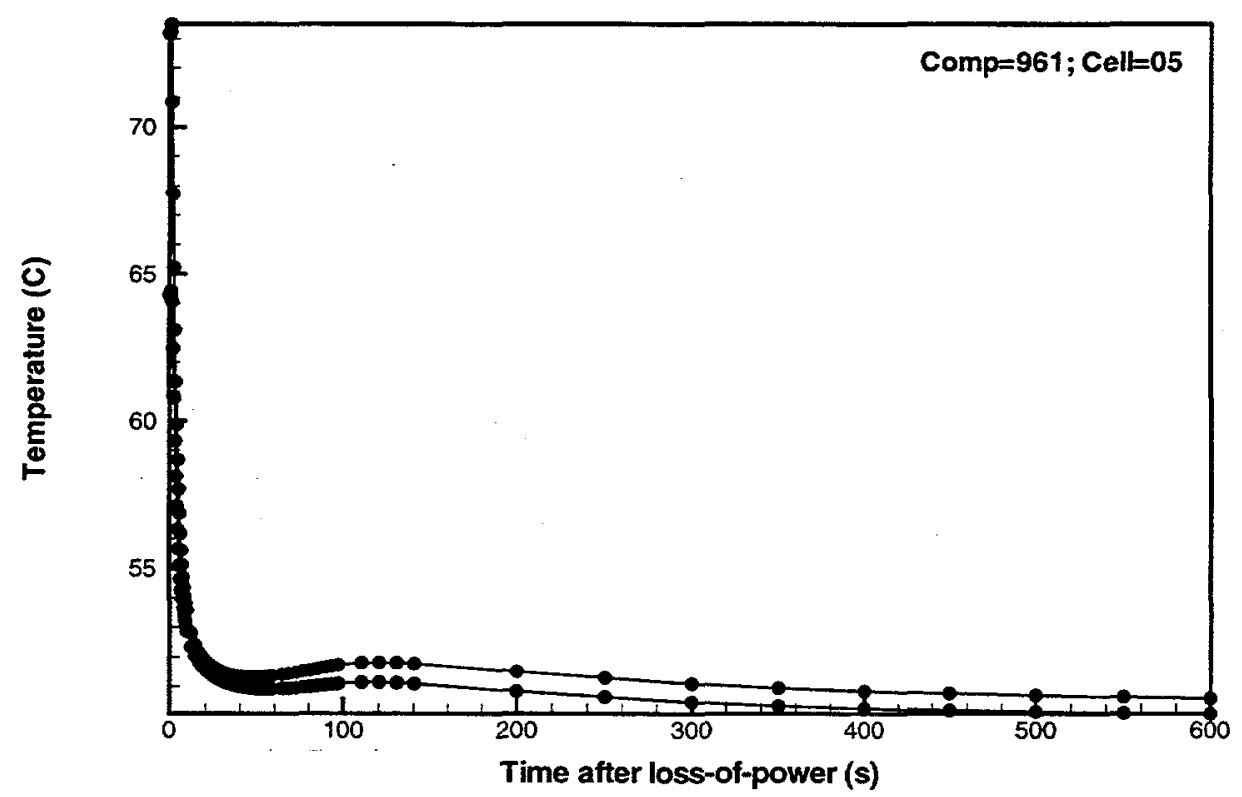

Figure B-40 Module 3 upflow section top-plane surface and fluid temperatures for a LOFA (Case 1: with beam shutdown and active RHR). 


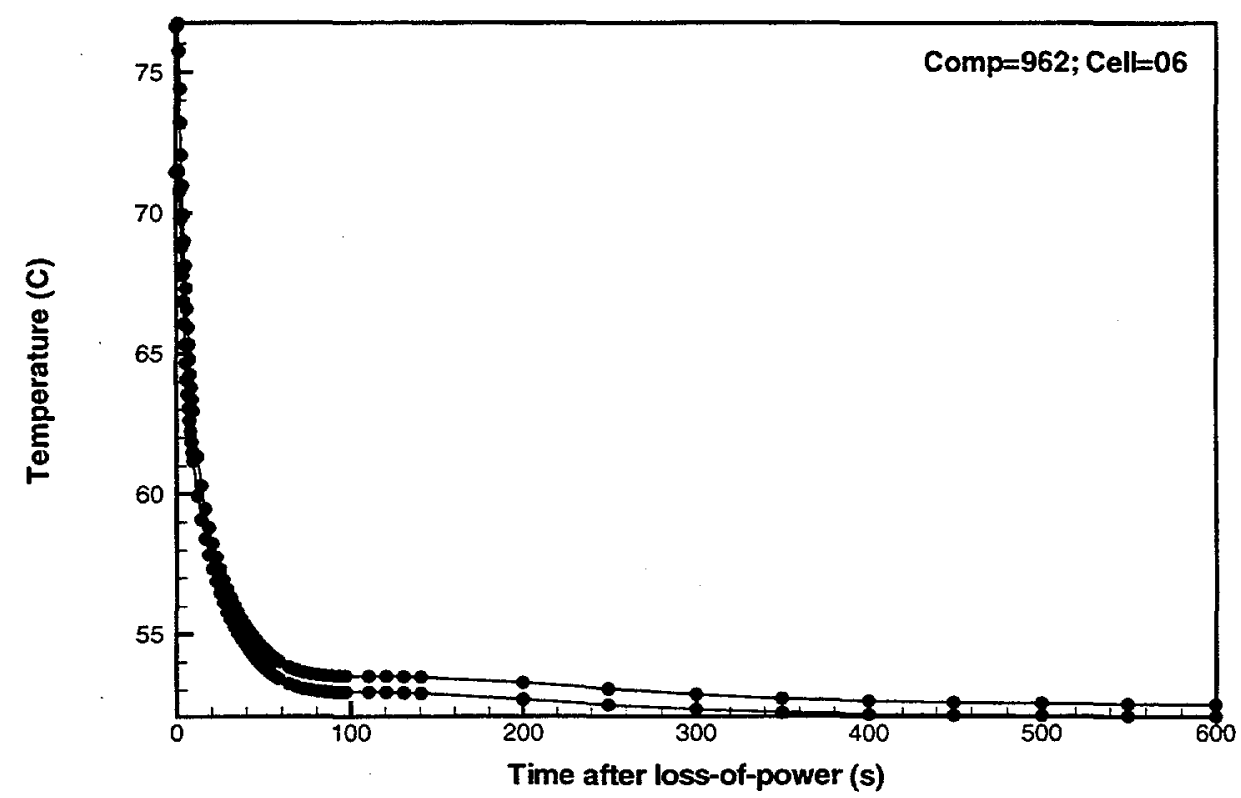

Figure B-41 Module 4 upflow section top-plane surface and fluid temperatures for a LOFA (Case 1: with beam shutdown and active RHR).

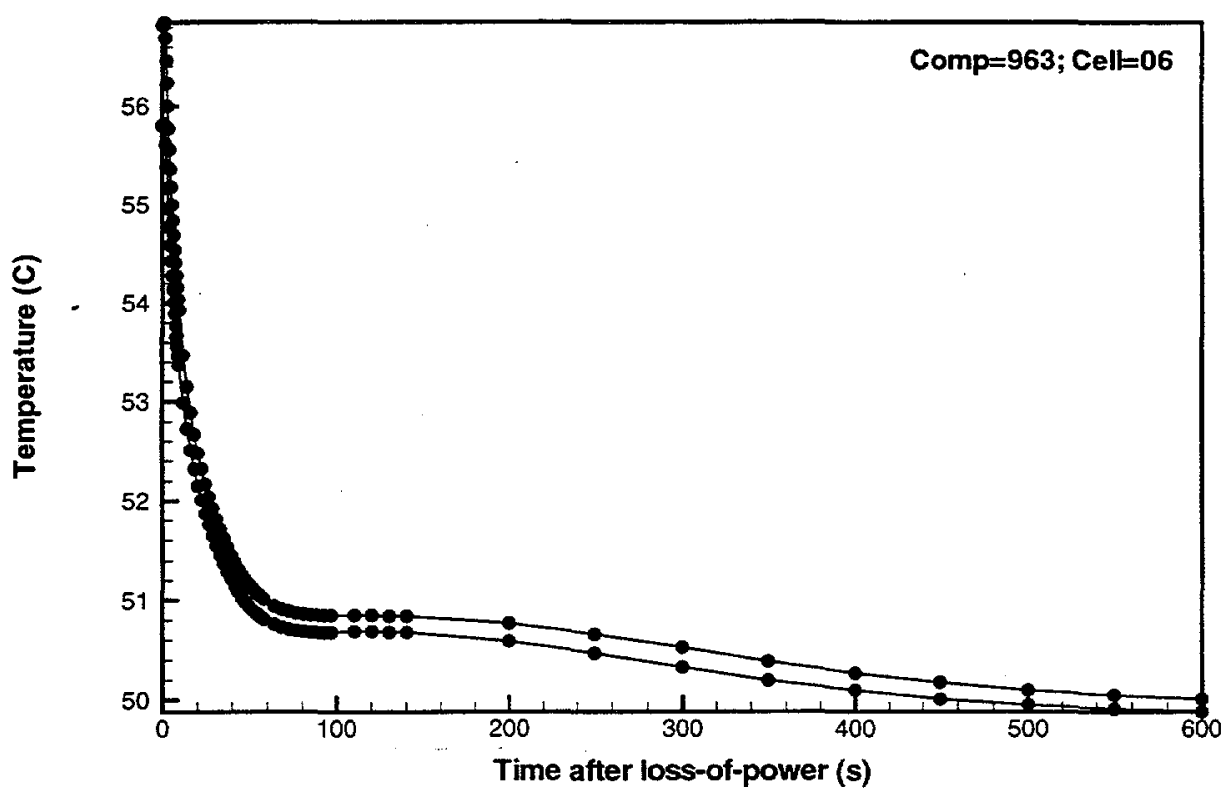

Figure B-42 Module 5 upflow section top-plane surface and fluid temperatures for a LOFA (Case 1: with beam shutdown and active RHR). 


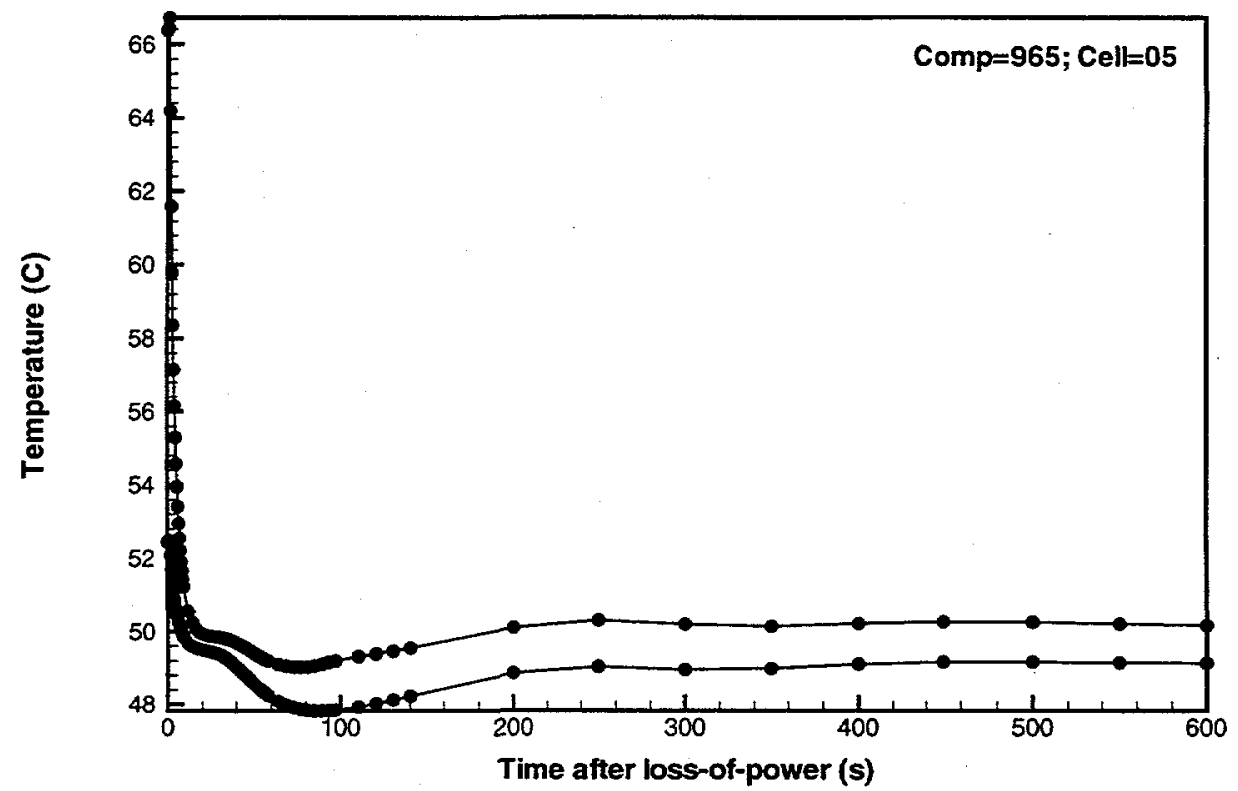

Figure B-43 Module 6 upflow section top-plane surface and-fluid temperatures for a LOFA (Case 1: with beam shutdown and active RHR). 


\section{Appendix C: TRAC Standard Input File for LOFA Case 1 (with Beam Shutdown and Active RHR)}

The file listed below represents the TRAC code "tracin" file that corresponds to the LOFA Case 1 (with beam shutdown and active RHR) for the blanket system. This input deck assumes that a TRAC restart file ("trcrst") exists based on normal operation (NO).

\section{Input file tracin:}

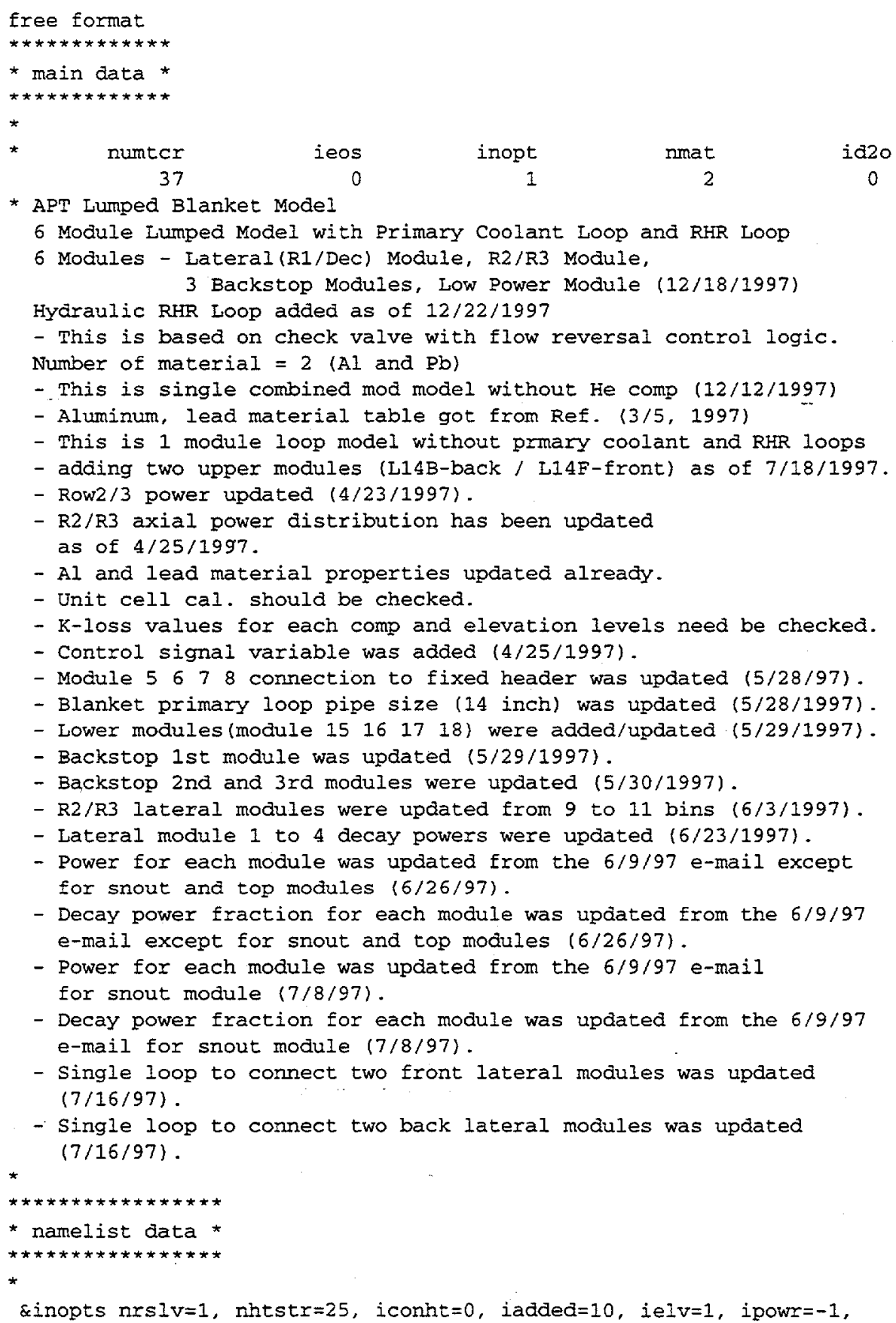


tpowr=10, igas=1, noair $=0$, nlt $=12$, ikfac $=1$, ithd $=1$, nsend $=40000 \&$

*

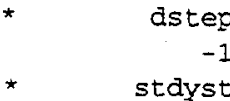

stdyst

epso

$1.0000 e-04$

oitmax

50

ntsv

7

$1.0000 e-04$
sitmax

50

ntcb

0

$\star$

* component-number data *

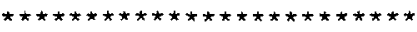

$\star$

* iorder* pressurizer surge linel pressurizer surge line2 pressurizer surge line3 pressurizex surge line4 pressurizer surge line5 pressurizer surge line6 primary pressurizer pressurizer boundary

IR pump suction pipe HR pump suction pipe (bk) HR pump suction pipe HR pump suction pipe (bk) HR pump suction pipe HR pump suction pipe (bk) FR pump suction pipe

HR pump suction plenum HR pump \#1 inlet pipe HR pump \#1 HR pump \#1 outlet pipe HR pump \$2 inlet pipe HR pump \#2 HR pump \#2 outlet pipe HR pump discharge plenum

* HR pump-to-hx piping

$$
\begin{aligned}
& 36 \text { s } \\
& 37 \text { * pipe }
\end{aligned}
$$

* hr hx's

HR pump dicharge pipe HR pump dicharge pipe (bk) HR pump dicharge pipe

HR hx inlet plenum HR hx 1 inlet pipe $\mathrm{HR} h \times 1$ tubes 1 st pass HR hx 1 mid-header $\mathrm{HR} h \times 1$ tubes $2 \mathrm{nd}$ pass $\mathrm{HR} h \mathrm{hx} 1$ outlet pipe HR $\mathrm{hx} 2$ inlet pipe HR hx 2 tubes 1st pass HR $h \times 2$ mid-header HR $h \times 2$ tubes 2 nd pass HR hx 2 outlet pipe $\mathrm{HR} h \mathrm{~h}$ outlet plenum 
* HR cola leg

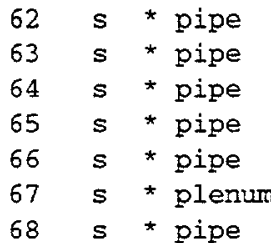

* HR hx Secondary Side 710 s * fil1

711 s * pipe

712 s * pipe

713 s * pipe

714 s * break

$730 s *$ Eill

731 s * pipe

732 s * pipe

$733 \mathrm{~s}$ * pipe

$734 \mathrm{~s}$ * break

\begin{tabular}{|c|c|c|}
\hline 621 & $\mathbf{s}$ & * pipe \\
\hline 623 & $s$ & * pipe \\
\hline 624 & $s$ & * pipe \\
\hline 625 & s & * pipe \\
\hline 630 & $s$ & * pump \\
\hline 640 & $\mathrm{~s}$ & * valve \\
\hline 652 & $s$ & * pipe \\
\hline 650 & $\mathrm{~s}$ & * pipe \\
\hline 667 & $s$ & * pipe \\
\hline 662 & $s$ & * pipe \\
\hline & $s$ & * pipe \\
\hline
\end{tabular}

* RHR hx Secondary Side

672 s * fill

671 s * pipe

$673 \mathrm{~s}$ * break

$300 s$ * pipe

$330 \mathrm{~s}$ * plenum

335 s * pipe

$340 \mathrm{~s}$ * plenum

$350 \mathrm{~s}$ * plenum

$360 \mathrm{~s}$ * pipe

$370 \mathrm{~s}$ * plenum

375 s * pipe

$380 \mathrm{~s} *$ plenum

429 s * pipe

$454 \mathrm{~s}$ * pipe

173 s * pipe

$172 \mathrm{~s} *$ plenum

$158 \mathrm{~s}$ * pipe

147 s * plenum

$102 \mathrm{~s}$ * pipe

$133 \mathrm{~s} *$ plenum

$136 \mathrm{~s}$ * pipe

541 s * pipe

538 s * plenum

$535 \mathrm{~s}$ * pipe

$531 \mathrm{~s} *$ plenum

528 s * pipe

$536 \mathrm{~s}$ * plenum
HR $h x$ discharge pipe

HR $h x$ discharge pipe (bk)

HR $h x$ discharge pipe

HR $\mathrm{hx}$ discharge pipe (bk)

HR hx discharge pipe

HR $h x$ discharge pipe (bk)

HR $h x$ discharge pipe

HR hx Secondary Side-1

HR hx Secondary Side-1

HR $h x$ Secondary Side-1

HR $h x$ Secondary Side-1

HR hx Secondary Side-1

HR hx Secondary Side-2

HR hx Secondary Side-2

HR hx Secondary Side-2

HR hx Secondary Side-2

HR hx Secondary Side-2

RHR hot leg sect 1 (bk)

RHR hot leg sect 2

RHR hot leg sect 3 (bk)

RHR hot leg sect 4

RHR primary pump

RHR pump discharge valve

RHR primary heat exchanger tubes

RHR cold leg sect 1

RHR cold leg sect 2 (bk)

RHR cold leg sect 3

RHR cold leg sect 4 (bk)

RHR hx Secondary side

RHR hx Secondary Side

RHR hx Secondary Side

L1 Blanket Row1

L1 Blanket Row1 Plenum

Il pipe conn. $330-340$

Il outlet header

L1 lower plenum

I1 decoupler

L1 decoupler upper plenum

L1 pipe conn. $370-380$

L1 inlet header

L1 connect hot header-tee

L1 connect cold header-tee

L1 Blanket Row1

L1 Blanket Row1 Plenum

L1 pipe conn. $330-340$

L1 outlet header

L1 lower plenum

L1 decoupler

L1 decoupler upper plenum

L1 Blanket Row1

L1 Blanket Rowl Plenum

L1 pipe conn. $330-340$

L1 outlet header

L1 lower plenum

I1 decoupler 


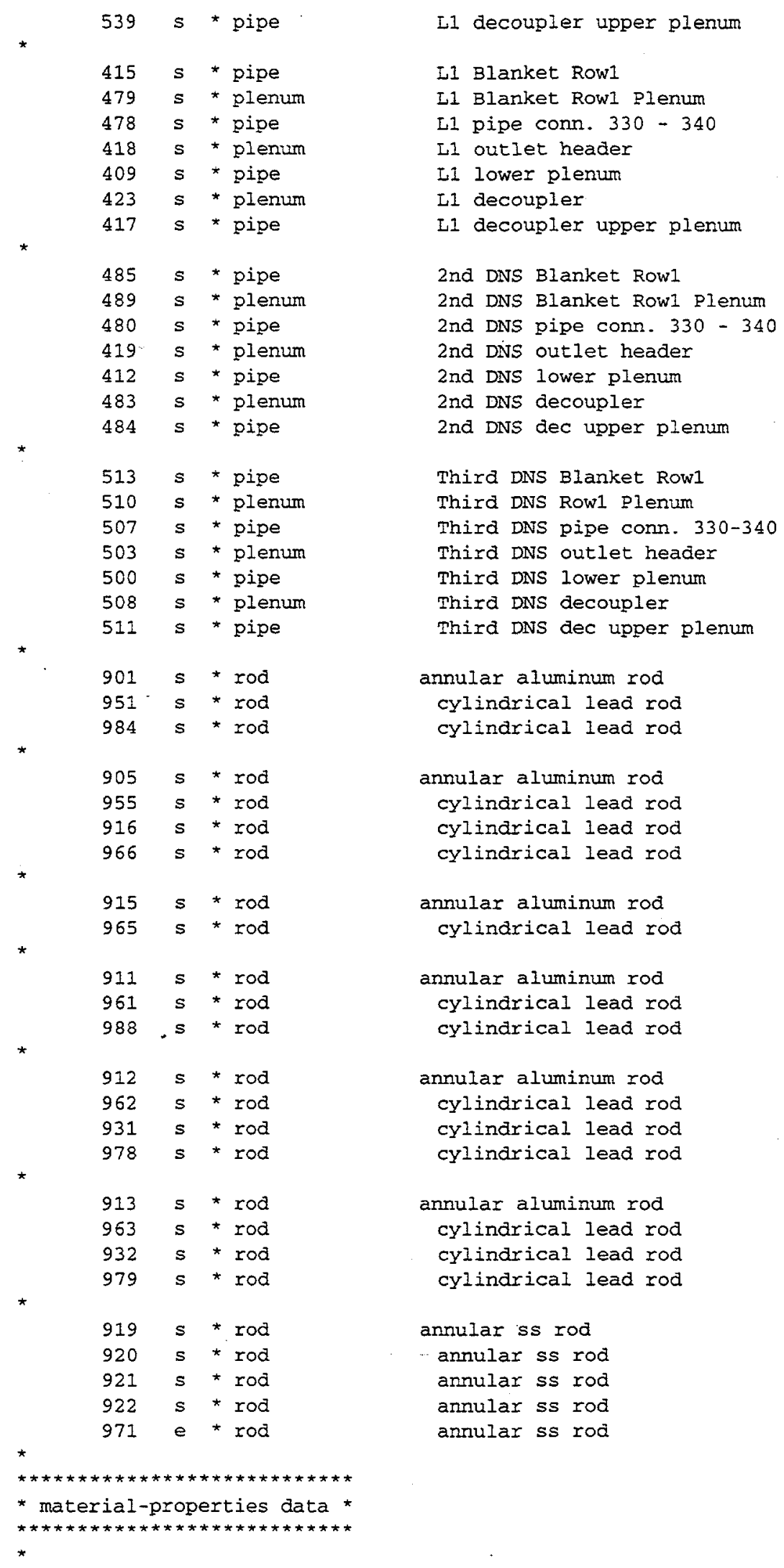


WESTINGHOUSE SAVANNAH RIVER COMPANY

BLANKET SAFETY ANALYSIS FOR LOFA

(CASE 1: WITH BEAM SHUTDOWN AND ACTIVE RHR)
Report:

Section:

Date:

Page:
WSRC-TR-98-0058

Appendix C

$07 / 13 / 98$
* matb * $51 \quad 52 e$

* ptbln *

* lead material

* $\operatorname{prptb}(1, i)$

$2.7300 e+02$

$\operatorname{prptb}(2, i)$

$1.1374 \mathrm{e}+04$

$1.1374 \mathrm{e}+04$

$1.0000 e+10$

e

*

* aluminum material$$
\star
$$

$\operatorname{prptb}(1, i)$

$2.7300 e+02$

prptb $(2, i)$

$2.6990 e+03$

$3.0000 e+02$

$3.7300 e+02$

$4.7300 e+02$

$2.6990 e+03$

$2.6990 e+03$

$6.7300 e+02$

$2.6990 e+03$

$2.6990 e+03$

$1.0000 e+10$

$2.6990 e+03$

e

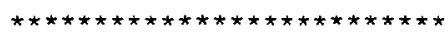

*

* css data

*

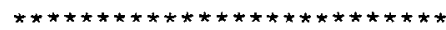

$*$

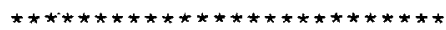

* control-parameter data *

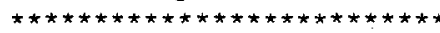

$*$

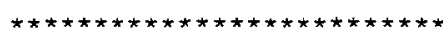

* signal variables

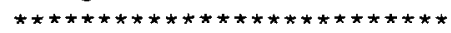

$\star$

* time

* time ias

idsv isvn

prptb (3,i)

$8.6985 e+02$

$8.9000 e+02$

9. $4140 \mathrm{e}+02$

$9.9538 e+02$

$1.0900 e+03$

$1.2000 e+03$ prptb $(4, i)$

3.4592e+01

$3.3382 e+01$ $\operatorname{prptb}(5, i)$

$2.8000 e-01$

$2.8000 e-01$ 5 of 8

* pressure difference across RHR check valve

* idsv isvn ilcn

$2 \quad-21 \quad 640$

prptb (4,i)

$2.1046 e+02$

$2.1046 e+02$

$2.1046 e+02$

$2.2175 e+02$

$2.2845 e+02$

$2.3000 e+02$

prptb $(5, i)$

5.0000e-02

$5.0000 e-02$

$5.0000 e-02$

$5.0000 e-02$

$5.0000 e-02$

$5.0000 e-02$

$\star$

* Elapse time since RHR pump activated

* idsv isvn ilcn

0

$i \operatorname{con} 1$

icn2

$i \operatorname{con} 1$

$i \operatorname{cn} 2$

1

2

icnI

icn2

* Elapse time since HR pumps activated

idsv isvn ilcn

$-21$

icn 1

icn2

1

*

* pressure difference across HR check valve

* idsv isvn ilcn

$$
-21 \quad 32
$$

$i \operatorname{con} 1$

icn2

* pressure difference across HR check valve

* idsv isvn ilcn

$6 \quad-21 \quad 33$

* pressure, cola leg at plenum, component 761

* iasv isvn . ilcn

7

21

68

icn 1

icn 2

2

icnI

icn 2

* 
* control-block data *

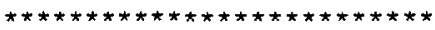

*

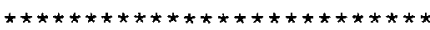

$\star$ trips

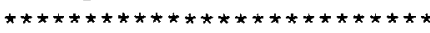

* trips from off to on at time given by setp(2), fill BC

$\begin{array}{rrrr}\text { ntse } & \text { ntct } & \text { ntsf } & \text { nta } \\ 1 & 0 & 0 & \\ \text { idtp } & \text { isrt } & \text { iset } & \text { its }\end{array}$

101

setp (1)

setp (2)

$0.0000 e+00$

$\operatorname{atsp}(1)$

$1.0000 e-06$

atsp (2)

$0.0000 e+00$

ifsp (1)

$0.0000 e+00$

ifsp (2)

* trips from on to off at time given by setp (2)

* idtp isrt iset itst idsg 102 $\operatorname{setp}(1)$

$0.0000 e+00$

$\operatorname{atsp}(1)$

$0.0000 e+00$

ifsp (1)

setp (2)

1

1

ntsd

tst

idsg

1.

* iEsp (1)

1. $0000 e+04$

atsp $\langle 2\rangle$

0.0000 et00

iEsp (2)

* trips from off to on at time given by setp(2), trips RHR check valve

* idtp isrt iset itst idsg

$$
\text { setp (1) }
$$

$0.0000 e+00$

dtsp (1)

$0.0000 \mathrm{e}+00$

ifsp (1)

$$
\text { setp (2) }
$$

1.0000e-06

atsp (2)

$0.0000 e+00$

ifsp (2)

* trips from off to on when the cold leg I press. drops below setp(1)

* trips power in bunales, heat structures

* idtp 1 isrt iset itst ids 104 setp (1)

$7.0788 e+05$ atsp (1)

$1.0000 \mathrm{e}+00$

ifsp (1)

$$
\text { setp (2) }
$$

$$
0
$$

$$
1
$$

6 of 8

$7.0788 \mathrm{e}+05$

desp (2)

1. $0000 \mathrm{e}+00$

ifsp (2)

*

* trips from ofe to on at setp(2), starts RHR pump.

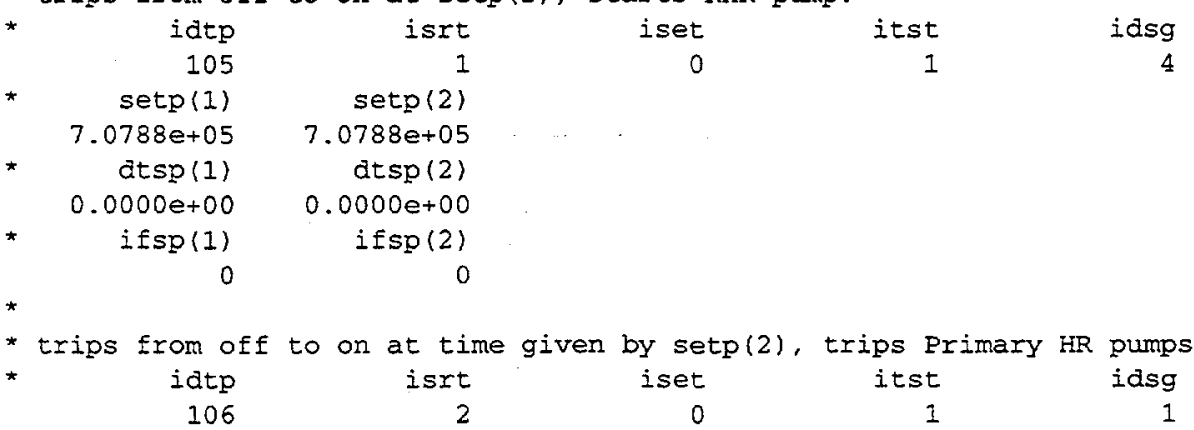




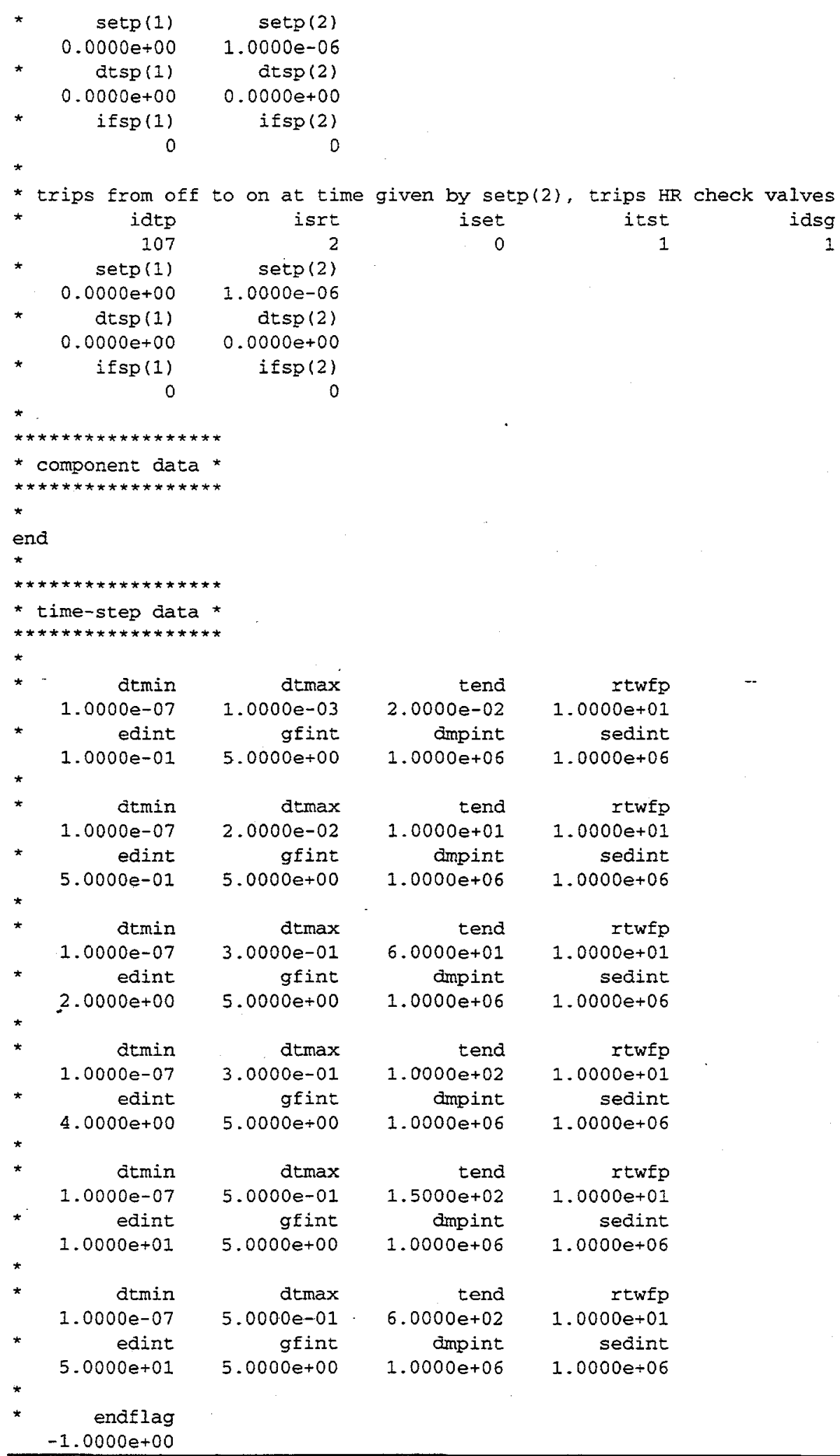$$
\text { dtmax }
$$$$
\text { 3.0000e-01 }
$$$$
\text { gfint }
$$$$
5.0000 e \div 00
$$

$$
\text { dtmax }
$$$$
5.0000 e-01
$$$$
\text { gfint }
$$$$
5.0000 e+00
$$$$
\text { dtmax }
$$$$
\text { 5.0000e-01 }
$$$$
\text { gfint }
$$$$
5.0000 e+00
$$

tena

$2.0000 e-02$

ampint

$1.0000 e+06$$$
1.0000
$$$$
\text { ampint }
$$$$
1.0000 e+06
$$$$
\text { ampint }
$$$$
1.0000 e+06
$$

ampint

$1.0000 e+06$

tend

ampint

$1.0000 e+06$

tend

$6.0000 e+02$

ampint

$1.0000 e+06$

rtwfp

1.0000 e+01

sedint

$1.0000 e+06$

1.0000

sedint

$1.0000 e+06$

$+01$

sedint

$1.0000 e+06$

rtwfp

$1.0000 e+01$

sedint

$1.0000 e+06$

rtwfp

$1.0000 e+01$

sedint

1. $0000 e+06$

rtwfp

$1.0000 e+01$

sedint

$1.0000 e \div 06$ 


\section{Appendix D: TRAC Graphics Input File for LOFA Case 1 (with Beam Shutdown and Active RHR)}

The file listed below represents the TRAC code "graphin" file that corresponds to the LOFA case 1 (with beam shutdown and active RHR) for the blanket system. This input deck contains the various graphics points selected for output to the "tecsum.grf" file.

Input file tracin:

\begin{tabular}{|c|c|c|c|c|c|}
\hline \multicolumn{6}{|l|}{$\begin{array}{c}\text { / npoints / } \\
88\end{array}$} \\
\hline / component & cel1 & ictype & itee/ & & \\
\hline 340 & 1 & 1 & 1 & Fixed outlet hea & ader \\
\hline 380 & 1 & 1 & 1 & Fixed inlet head & der \\
\hline 454 & 2 & 0 & 1 & Module 1 pipe & \\
\hline 173 & 2 & 0 & 1 & Module 2 pipe & \\
\hline 415 & 2 & 0 & 1 & Module 3 pipe & \\
\hline 485 & 2 & 0 & 1 & Module 4 pipe & \\
\hline 513 & 2 & 0 & 1 & Module 5 pipe & \\
\hline 541 & 2 & 0 & 1 & Module 6 pipe & \\
\hline 300 & 1 & 0 & 1 & Module 1 Row 1 & \\
\hline 102 & 1 & 0 & 1 & Module 2 Row2 & \\
\hline 409 & 1 & 0 & 1 & Module 3 Row1 & \\
\hline 412 & 1 & 0 & 1 & Module 4 Row1 & \\
\hline 500 & 1 & 0 & 1 & Module 5 Row2 & \\
\hline 528 & 1 & 0 & 1 & Module 6 Low Pow & wer \\
\hline 300 & 3 & 0 & 1 & Module 1 Row 1 & \\
\hline 102 & 3 & 0 & 1 & Module 2 Row2 & \\
\hline 409 & 3 & 0 & 1 & Module 3 Row1 & \\
\hline 412 & 3 & 0 & 1 & Module 4 Row 1 & \\
\hline 500 & 3 & 0 & 1 & Module 5 Row2 & \\
\hline 528 & 3 & 0 & 1 & Module 6 Low Pow & wer \\
\hline 300 & 5 & 0 & 1 & Module 1 Row 1 & \\
\hline 102 & 6 & 0 & 1 & Module 2 Row2 & \\
\hline 409 & 5 & 0 & 1 & Module 3 Row 1 & \\
\hline 412 & 6 & 0 & 1 & Module 4 Row1 & \\
\hline 500 & 6 & 0 & 1 & Module 5 Row2 & \\
\hline 528 & 5 & 0 & 1 & Module 6 Low Pow & wer \\
\hline 370 & 1 & 1 & 1 & Mocule I Inlet & Plenum \\
\hline 350 & 1 & 1 & 1 & Module I Middle & Plenum \\
\hline 330 & 1 & 1 & 1 & Module 1 outlet & Plenum \\
\hline 172 & 1 & 1 & 1 & Module 2 Inlet & Plenum \\
\hline 147 & 1 & 1 & 1 & Module 2 middle & Plenum \\
\hline 133 & 1 & 1 & 1 & Module 2 Outlet & Plenum \\
\hline 479 & 1 & 1 & 1 & Module 3 Inlet & Plenum \\
\hline 418 & 1 & 1 & 1 & Module 3 Middle & Plenum \\
\hline 423 & 1 & 1 & 1 & Module 3 outlet & Plenum \\
\hline 489 & 1 & 1 & 1 & Module 4 Inlet & Plenum \\
\hline 419 & 1 & 1 & 1 & Module 4 Middle & Plenum \\
\hline 483 & 1 & 1 & 1 & Module 4 Outlet & Plenum \\
\hline 510 & 1 & 1 & 1 & Module 5 Inlet & Plenum \\
\hline 503 & 1 & 1 & 1 & Module 5 Midale & Plenum \\
\hline 508 & 1 & 1 & 1 & Module 5 outlet & Plenum \\
\hline 538 & 1 & 1 & 1 & Module 6 Inlet & Plenum \\
\hline 531 & 1 & 1 & 1 & Module 6 Middle & Plenum \\
\hline
\end{tabular}


536

26

30

30

31

31

32

33

37

48

56
49

57

62

66

630

630

640

660

761

766

951

951

951

951

955

955

955

955

961

961

961

961

962

962

962

962

963

963

963

963

965

965

965

965

1

1

2

2

1

2

2

2

2

1

1

1

2

3

1

1

1

1
5

$$
5
$$

1

5

$$
1
$$$$
6
$$$$
\begin{aligned}
& 1 \\
& 6
\end{aligned}
$$$$
6
$$$$
1
$$$$
\begin{aligned}
& 5 \\
& 1
\end{aligned}
$$$$
\begin{aligned}
& 1 \\
& 5
\end{aligned}
$$$$
\begin{aligned}
& 5 \\
& 1
\end{aligned}
$$$$
\begin{aligned}
& 1 \\
& 6
\end{aligned}
$$$$
\begin{aligned}
& 6 \\
& 1 \\
& 6 \\
& 1
\end{aligned}
$$$$
\begin{aligned}
& 6 \\
& 1
\end{aligned}
$$$$
6
$$$$
\begin{aligned}
& 1 \\
& 6
\end{aligned}
$$$$
6
$$$$
\begin{aligned}
& 1 \\
& 5
\end{aligned}
$$$$
1
$$

1

1 Module 6 outlet Plenum

1 Hot leg pump suction line

1 PCL Pump 1 suction

1 PCL Pump 1 Discharge

1 PCL Pump 2 suction

1 PCL Pump 2 Discharge

1 PCL Pump I check valve

1 PCL Pump 2 check valve

1 PCL Pump to $\mathrm{HX}$

1 PCL $\mathrm{Hx} 1$ inlet

1 PCL $\mathrm{Hx} I$ outlet

1 PCL Hx 2 inlet

1 PCL Hx 2 outlet

I Cold leg $\mathrm{Hx}$ discharge line

1 Cold leg $\mathrm{Hx}$ discharge line

1 RHR Pump Suction

1 RHR Pump Discharge

1 RHR $\mathrm{Hx}$ inlet

1 RHR Hx outlet

I Pzr Pressure Signal

1 Pzr Bottom Pressure

1 Hot Module (1) upflow inside

1 Hot Module (1) upflow inside

2 Hot Module (1) upflow outside

2 Hot Module (1) upflow outside

1 Hot Module (2) upflow inside

1 Hot Module (2) upflow inside

2 Hot Module (2) upflow outside

2 Hot Module (2) upflow outside

1 Hot Module (3) upflow inside

1 Hot Module (3) upflow inside

2 Hot Module (3) upflow outside

2 Hot Module (3) upflow outside

1 Hot Module (4) upflow inside

1 Hot Module (4) upflow inside

2 Hot Module (4) upflow outside

2 Hot Module (4) upflow outside

1 Hot Module (5) upflow inside

1 Hot Module (5) upflow inside

2 Hot Module (5) upflow outside

2 Hot Module (5) upflow outside

1 Hot Module (6) upflow inside

1 Hot Mocule (6) upflow inside

2 Hot Module (6) upflow outside

2 Hot Module (6) upflow outside

INPUT NOTES:

npoints - number of locations (points) within TRAC model graphics requested component - component id number containing specified graph point

cell - cell number with in component where graphics requested

ictype - type of component:

10 for fill, pipe, pressurizer, pump, tee, turb, value) 
(1) for plenum)

OUTPUT NOTES:

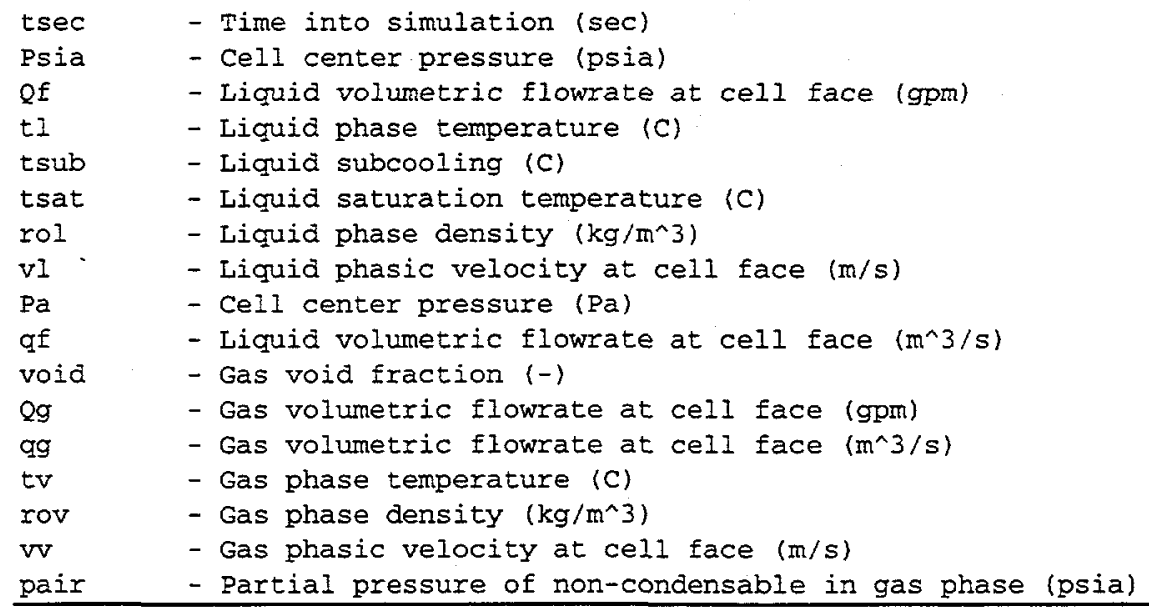




\section{Appendix E: FLOWTRAN-TF Input File for LOFA Case 1 (with Beam Shutdown and Active RHR)}

Below is an abridged listing of the FLOWTRAN-TF input deck for LOFA Case 1. The finite element input of the solid geometric parameters used in the heat conduction calculations and the fluid geometry input are identical to the values given in Ref. [1] and have been edited from this listing to save space.

\section{Input file apt.in:}

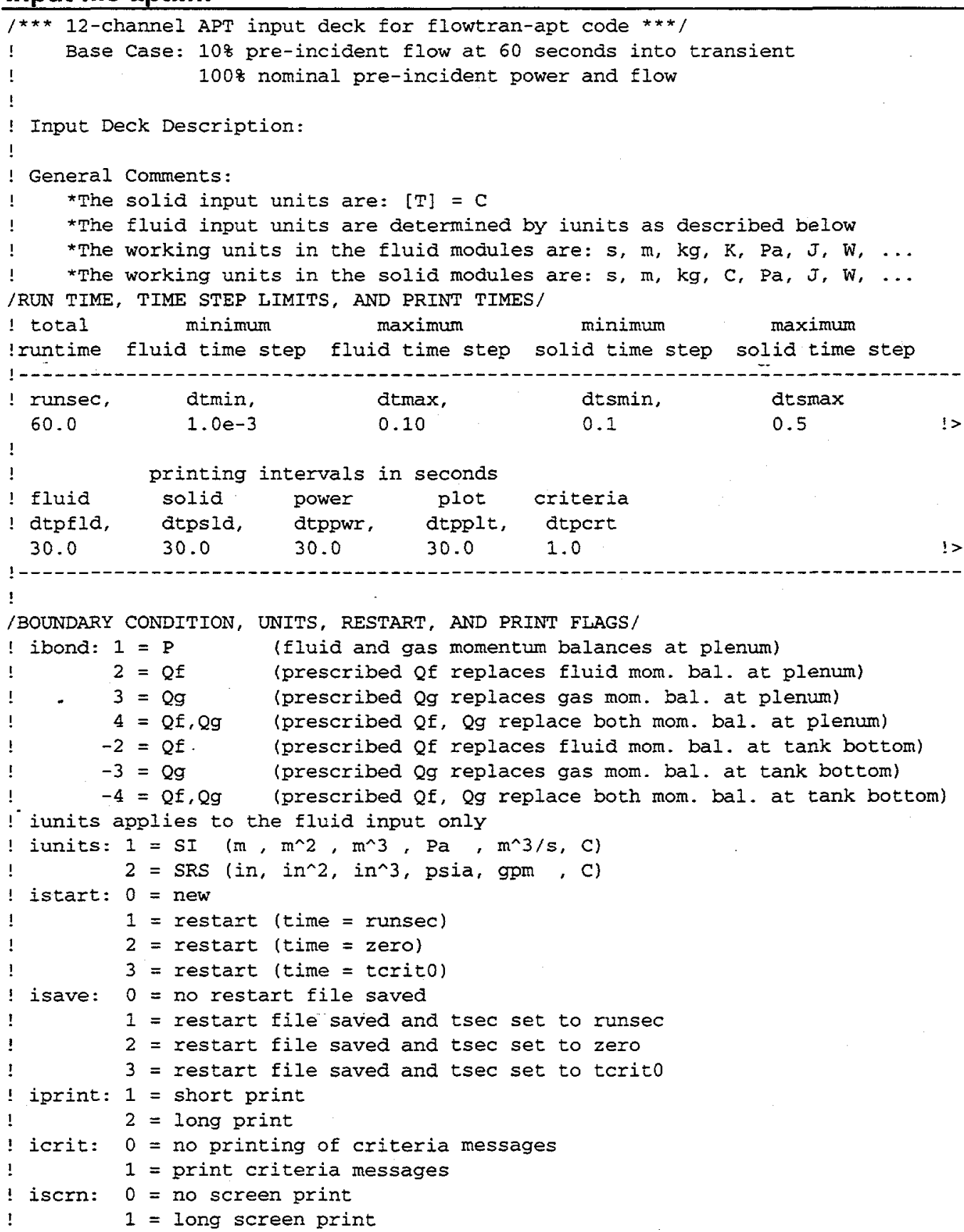




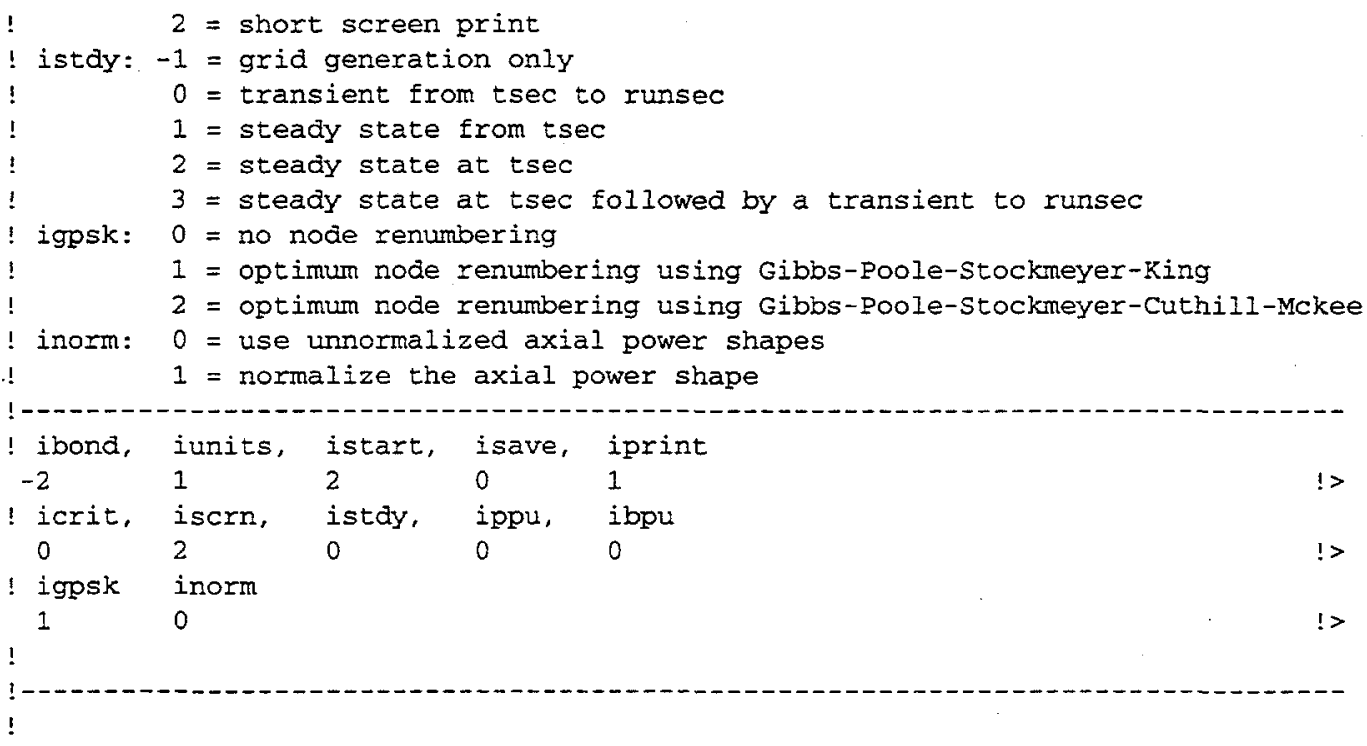




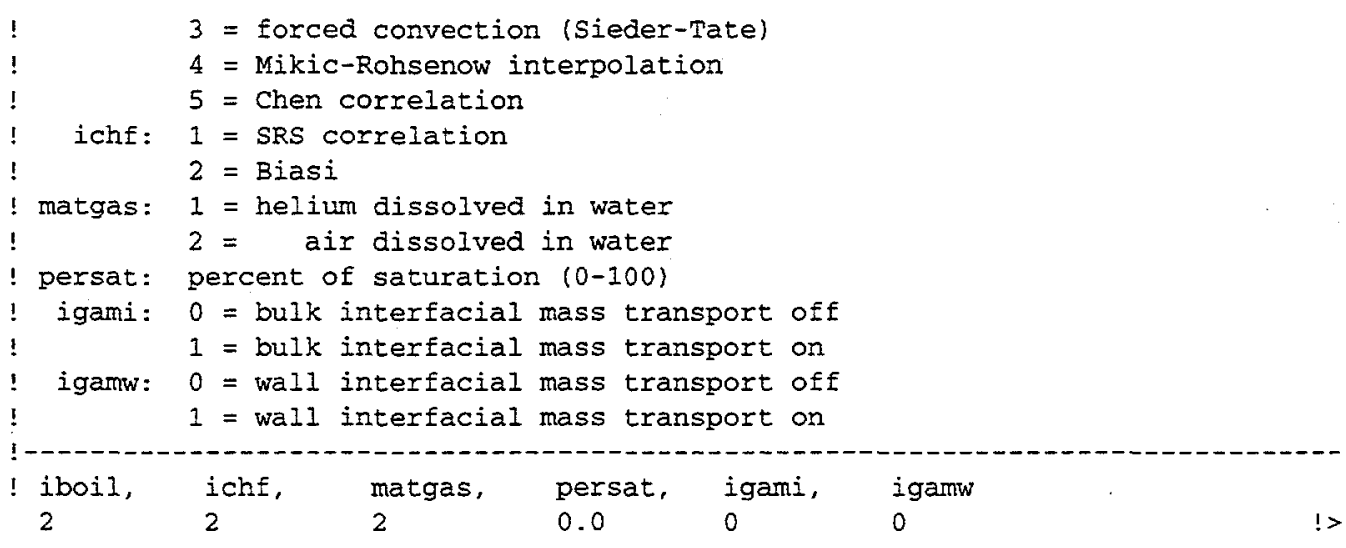

/SOLID PARAMETERS/

! isolid: $0=$ no solid calculations

! 1 = solid calculations with matrix decomposition every time step

! $\quad 2$ = solid calculations with matrix decomposition first time step

tsolid: initial solid temperature

beta: implicitness parameter in solid calculations

iheat: 0 = no wall heat transfer calculation

1 = wall heat transfer calculations

qsurf: specified surface heat flux (used when iheat $=0$ )

hfix: specified heat transfer coefficient (used when iboil $=0$ )

! iaxcon: $0=$ no axial concuction

$! \quad I=$ explicit axial conduction calculation

! isolid, tsolid, beta, iheat, gsurf, hfix, iaxcon

$\begin{array}{llllllll}2 & 53.04 & 1.0 & 1 & 0.0 & 1.0 \mathrm{e} 4 & 1 & \text { l }\end{array}$

!

!

/INNER ITERATION OPTIONS \& NEWTON ITERATION PARAMETERS/

! irebal: $0=$ no coarse mesh rebalance

1 = coarse mesh rebalance on first pass

2 = coarse mesh rebalance on each pass

ncmr: number of coarse mesh rebalances when irebal = 1 or 2

epsin: inner iteration convergence criterion for relative dp error

initmx: max. number of inner iterations allowed

epsp: newton iteration convergence criterion for absolute p error in $\mathrm{Pa}$

epsalp: newton iteration convergence criterion for absolute alp error

epstg: newton iteration convergence criterion for absolute tg error in $k$

epstf: newton iteration convergence criterion for absolute tf exror in $K$

epsxa: newton iteration convergence criterion for absolute xa exxor

nitmax: $\mid$ nitmax $\mid$ = max. number of newton iterations allowed

If nitmax is positive and |nitmax| iterations are reached, then

then computations continue using the mth iterate values from the

|nitmax| iteration.

If nitmax is negative and $\mid$ nitmax| iterations are reached, then

a new time step with a time step reduction is requested.

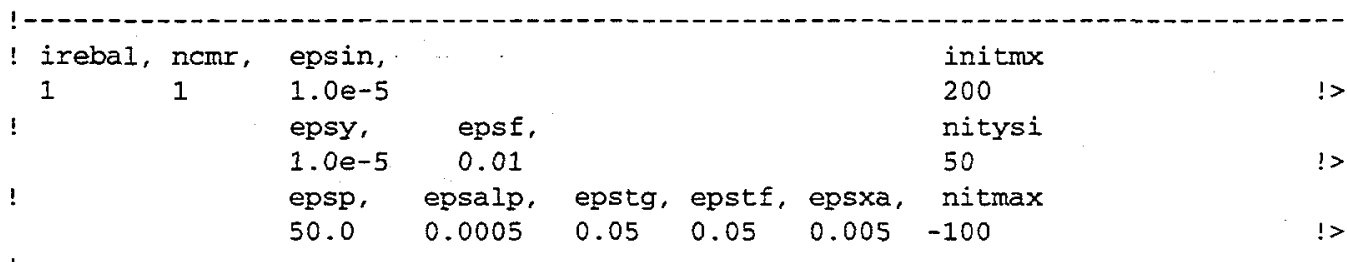

!

/NUMBER OF SPLINE PROFILES AND DATA POINTS/ 
! ndata: number of data groups

! itime: number of time snapshots for axial power profiles

! ndata, itime

8

! npdat: number of data points per data set

1 nset: number of data sets in data group

I npdat nset

31

41

$29 \quad 1$

131

151

151

$15 \quad 1$

15

! -

/GEOMETRIC DIMENSIONS: /

! nchn: number of flow channels

nzt: number of top section axial cells (>=2)

$n z$ : number of middle section axial cell layers ( $>=3$ )

nzb: number of bottom section axial cells ( $>=2$ )

! - - -

! nchn, nzt, nz, nzb

$122^{-} \quad 20 \quad 2$

/POWER ITERATION INPUT/

! power: initial power in $\mathrm{kw}$

! maxpi: maximum number of power iterations

! tolpow: tolerance on power limit

! norit: number of criteria used to check for power limit

!-----

! power, maxpi, tolpow, ncrit

$\begin{array}{llllll}61.5 & 1 & 0.005 & 8 & \text { ! nominal operating power }\end{array}$

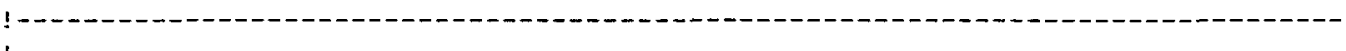

! SENSITIVITY VARIABLES INPUT SECTION

/SENSITIVITY PARAMETERS/

! cizfac: axial interfacial arag multiplying factor

! xcoth, xreh, xcofl, xrel, xkmet, xcrmet

$\begin{array}{llllll}1.0 & 1.0 & 1.0 & 1.0 & 1.0 & 1.0\end{array}$ !>

! xhfi, xhgi, xkgi, xphi

$\begin{array}{llll}1.0 & 1.0 & 1.0 & 1.0\end{array}$

1

cizfac xfric, pluht, cipln, formhs, alphs

$\begin{array}{llll}1.0 & 1.0 & 8.75 & 1.0\end{array}$

alb2, als2, ala2, expbs, expsa

$\begin{array}{lllll}0.25 & 0.52 & 0.75 & 4.0 & 4.0\end{array}$ 


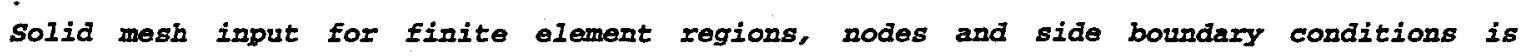




$\begin{array}{cl}\text { tgtbo, } & \text { itgtb } \\ 53.04 & 6\end{array}$

!

/INLET FLOW DATA/

! The following inlet flow data is always used to initialize

! axial velocities and will also be used to define the

! appropriate prescribed flowrate for $t>0$ if ibond $=2,3$, or 4 .

! qfino: multiplier to Qf transient profile

! iqfin: Qf transient identifiex

! qgino: multiplier to $Q g$ transient profile

! iqgin: Qg transient identifier

! qfino = Nominal APT total flow 12 half channels, transient

! -

! gfino, iqfin $-1.508 e-35$ is

! qgino, iqgin
0.0
1
!>

! -

/INITIAL CONDITION INPUT SECTION/

! If iseto $>0$ then initial conditions are

! input for fluid parameters at each axial level

! iseto

/CRITERIA CHECKING FLAGS AND PEAKING FACTORS/

$\begin{array}{lrrrrrrrrr}\text { ! checking flags for criteria } & \# 1 & \# 2 & \# 3 & \# 4 & \# 5 & \# 6 & \# 7 & \# 8 & \text { !> } \\ \text { ! peaking factors for criteria } & 0 & 0 & 0 & 0 & 0 & 0 & 0 & 0 & \text { ! } \\ & 1.0 & 1.0 & 1.0 & 1.0 & 1.0 & 1.0 & 1.0 & 1.0 & \text { !> }\end{array}$

/CRITERIA CHECKING TIME/

! time to begin criteria checking, sec

torito

0.0

!>

!

! POWER INPUTT

/POWER PROFILE SPLINE POINTERS/

$!$ DECAY HEAT TRANSIENT

4

!

/AXIAI SPLINE POINTERS AND TIMES/

$$
\begin{array}{llll}
3 & 0.0 & 3 & 300.00
\end{array}
$$

/TRANSIENT DATA SET INPUT SECTION/

/DATA SET NUMBER 1/

! enter data set label below

data set 1 - UNIFORM

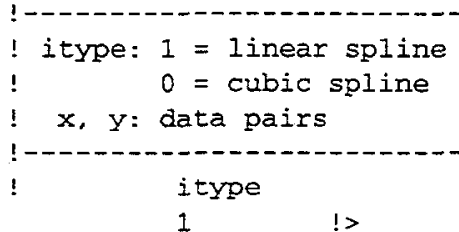




\begin{tabular}{|c|c|c|}
\hline ! $x(i p t)$ & $y(i p t)$ & ipt $=1$, npts \\
\hline 0.0 & 1.0 & $!>$ \\
\hline 5.0 & 1.0 & !> \\
\hline 100.0 & 1.0 & $!>$ \\
\hline ! - & 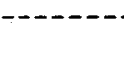 & 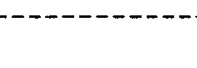 \\
\hline /DATA SET & NUMBER & \\
\hline data set & $2-\mathrm{DEC}$ & POWER SHAPE \\
\hline$!$ & itype & \\
\hline & 1 & !> \\
\hline$! x(i p t)$, & $y$ (ipt) & ipt $=1$, npts \\
\hline 0.0 & 1.0 & $1>$ \\
\hline 1.0 & 1.0 & $!>$ \\
\hline 10.0 & 1.0 & $!>$ \\
\hline 1000.0 & 1.0 & $!>$ \\
\hline
\end{tabular}

\section{data set 3 - NON-UNIFORM AXIAL POWER PROFILE}

$\begin{array}{lll} & \text { itype } & \\ 1 & 1 & !> \\ 0.00 & \text { ipt }), \text { ipt }) & \text { ipt=1, npts } \\ 0.10 & 0.043 & !> \\ 0.20 & 0.049 & !> \\ 0.30 & 0.074 & !> \\ 0.40 & 0.093 & !> \\ 0.50 & 0.124 & !> \\ 0.60 & 0.165 & !> \\ 0.70 & 0.217 & !> \\ 0.80 & 0.317 & !> \\ 0.90 & 0.508 & !> \\ 1.00 & 0.943 & !> \\ 1.10 & 1.446 & !> \\ 1.20 & 1.658 & !> \\ 1.30 & 1.754 & !> \\ 1.40 & 1.783 & !> \\ 1.50 & 1.827 & !> \\ 1.60 & 1.870 & !> \\ 1.70 & 1.881 & !> \\ 1.80 & 1.915 & !> \\ 1.90 & 1.915 & !> \\ 2.00 & 1.887 & !> \\ 2.10 & 1.864 & !> \\ 2.20 & 1.790 & !> \\ 2.30 & 1.660 & !> \\ 2.40 & 1.423 & !> \\ 2.50 & 0.932 & !> \\ 2.60 & 0.506 & !> \\ 2.70 & 0.313 & !> \\ 2.80 & 0.229 & !> \\ & 0 \\ 1.90\end{array}$




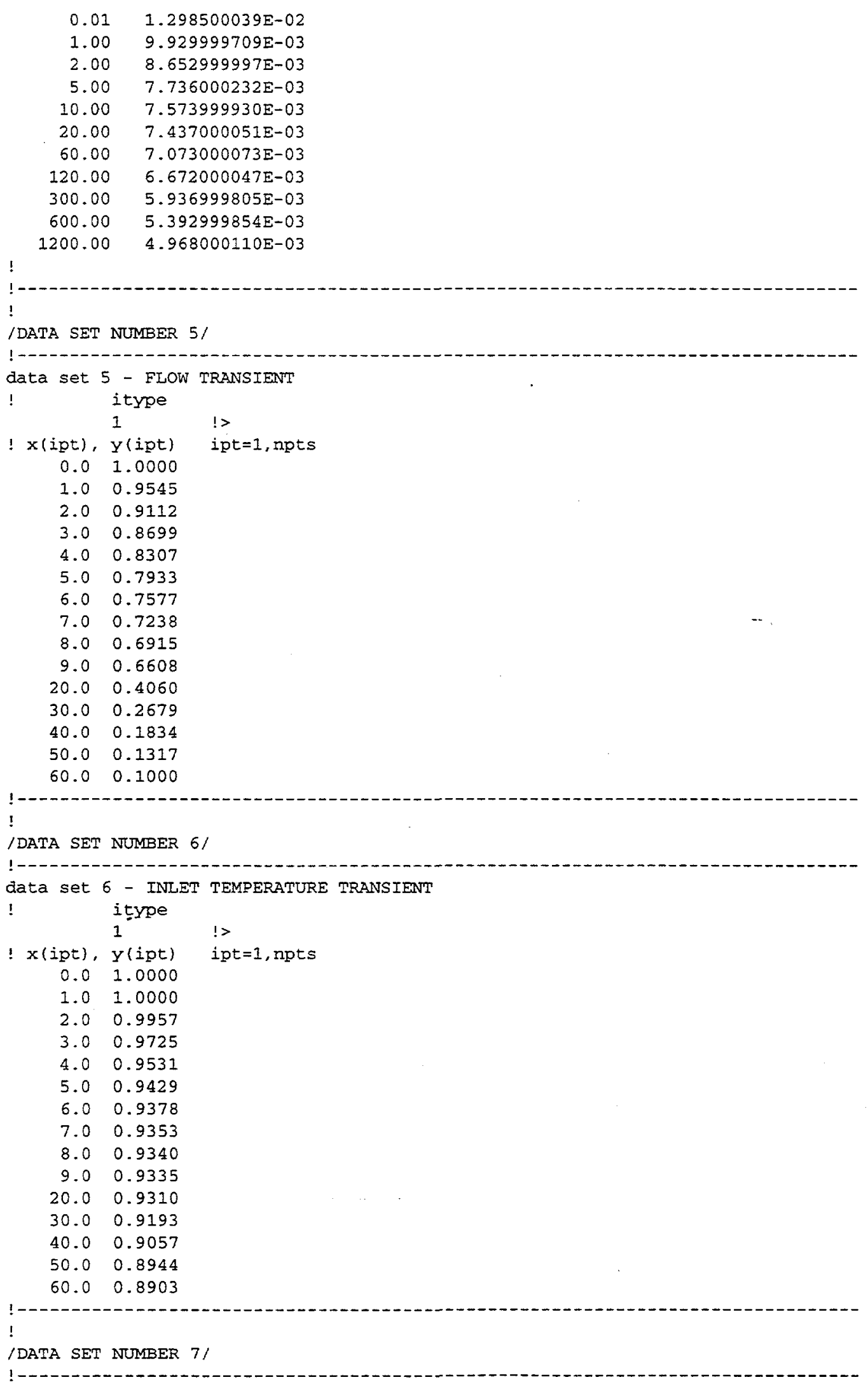


data set 7 - INLET PRESSURE TRANSIENT

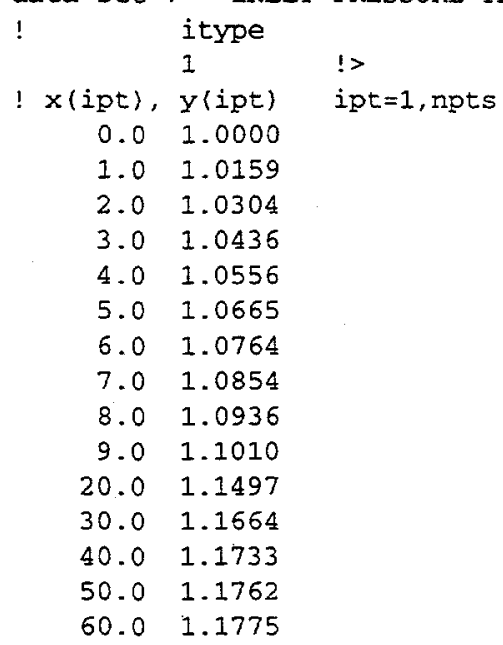

ipt $=1$, npts

\section{1 -}

data set 8 - OUTLET PRESSURE TRANSIENT

! itype

$x(i p t), y(i p t)$

!)

0.01 .0000

1.01 .0326

$2.0 \quad 1.0622$

$3.0 \quad 1.0892$

$4.0 \quad 1.1136$

$5.0 \quad 1.1359$

$6.0 \quad 1.1561$

$7.0 \quad 1.1746$

$8.0 \quad 1.1913$

$9.0 \quad 1.2065$

$20.0 \quad 1.3062$

$30.0 \quad 1.3403$

$40.0 \quad 1.3543$

$50.0 \quad 1.3603$

60.01 .3630

ipt $=1$, npts

(1)

Page:

9 of 10 
